\title{
MEASURING \\ HIV INCIDENCE, \\ MORTALITY, \\ AND \\ THE CASCADE \\ OF HIV CARE \\ IN KENYA
}

Peter Wesley Young 


\section{Measuring HIV incidence, mortality, and the cascade of HIV care in Kenya}

Peter Wesley Young 
(C) 2021, Peter Wesley Young

Measuring HIV incidence, mortality, and the cascade of HIV care in Kenya Ph.D. Thesis Utrecht University

ISBN/EAN: 978-94-93184-82-4

Lay-out: Guus Gijben | Proefschrift-aio.nl

Printing: Proefschrift-aio.nl

Cover design: Catherine Crawford (http://catecrawfordstudio.com)

Chapters 2, 5 \& 6 were reprinted with permission by the publishers (Elsevier, Wolter Kluwer). 


\title{
Measuring HIV incidence, mortality, and the cascade of HIV care in Kenya
}

\author{
Het meten van hiv-incidentie, mortaliteit en \\ de cascade van hiv-zorg in Kenia \\ (met een samenvatting in het Nederlands)
}

\author{
Proefschrift
}
ter verkrijging van de graad van doctor aan de
Universiteit Utrecht
op gezag van de
rector magnificus, prof.dr. H.R.B.M. Kummeling, ingevolge het besluit van het college voor promoties
in het openbaar te verdedigen op

woensdag 7 april 2021 des middags te 12.45 uur

door

Peter Wesley Young

geboren op 20 juli 1973

te Rochester, New York, Verenigde Staten van Amerika 


\section{Promotor:}

Prof. dr. M.E.E. Kretzschmar

\section{Copromotor:}

Dr. K.M. De Cock 


\section{Table of Contents}

\section{Chapter 1}

General introduction and outline of the thesis

\section{Chapter 2}

HIV incidence in western Kenya during scale up of antiretroviral therapy and voluntary medical male circumcision: a population-based cohort analysis

\section{Chapter 3}

Evolution of sub-national HIV estimates for a high-HIV-burden region in Kenya

\section{Chapter 4}

Equity of antiretroviral treatment use in high HIV burden countries: Analyses of data from nationally-representative surveys in Kenya and South Africa

\section{Chapter 5}

Use of viral load to improve survey estimates of known HIV-positive status and antiretroviral treatment coverage

\section{Chapter 6}

HIV-related deaths in Nairobi, Kenya: Results from a HIV mortuary surveillance study, 2015

\section{Chapter 7}

HIV-associated mortality in the era of antiretroviral therapy scale-up - Nairobi, Kenya, 2015

\section{Chapter 8}

Leading causes of death and high mortality rates in a HIV-endemic setting,

Kisumu County, Kenya, 2019

\section{Chapter 9}

General discussion

\section{Appendices}

Summary

Dutch summary

Acknowledgments 


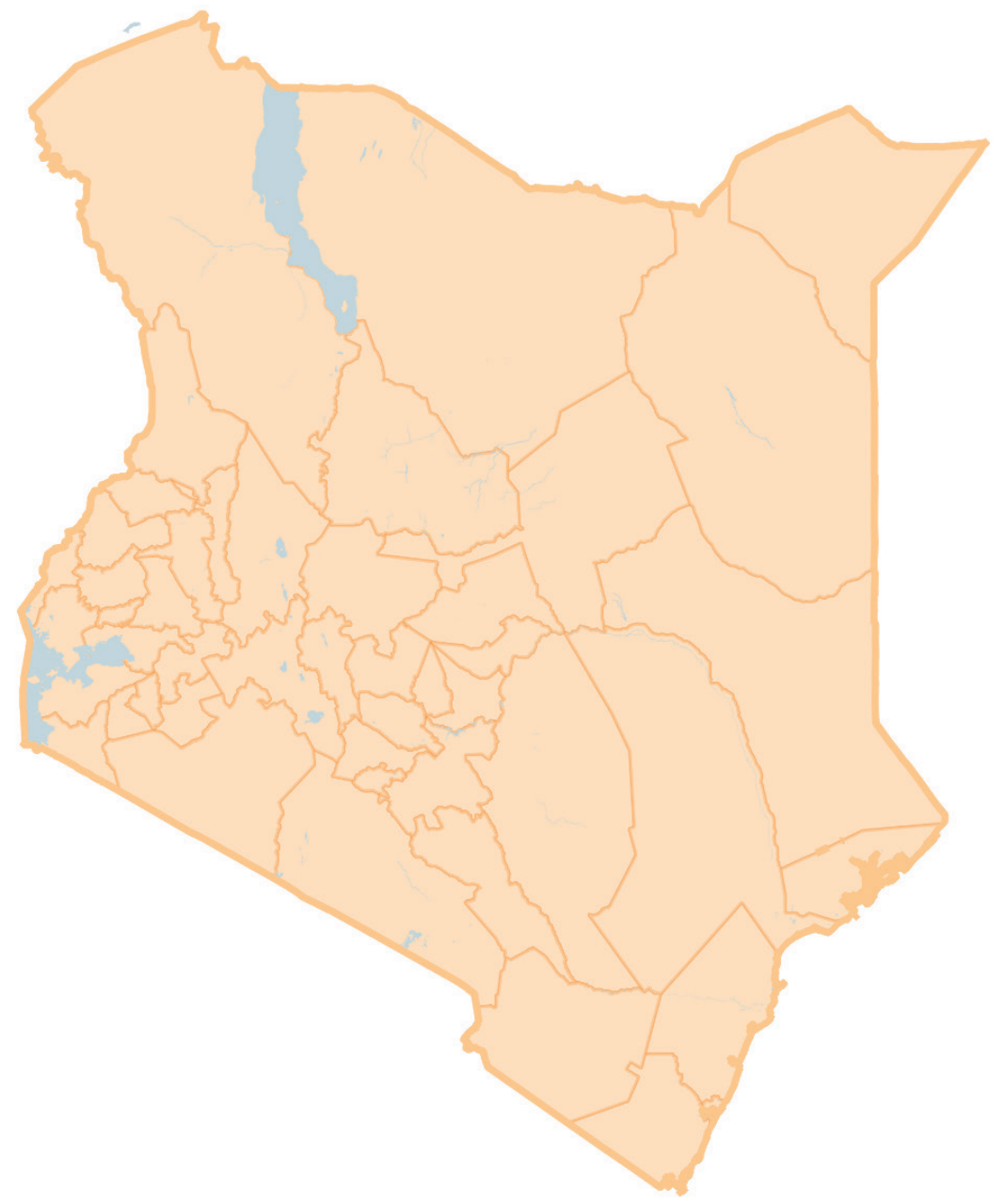


Chapter 1

General introduction and
outline of the thesis 


\section{General introduction and outline of the thesis}

The syndrome that would later be called acquired immunodeficiency syndrome (AIDS) was first described in 1981 among gay males (1). Thirty-nine years after AIDS was first identified, infection with human immunodeficiency virus (HIV) is found in every country on Earth, though the highest burden is found in eastern and southern Africa, which according to the Joint United Nations Programme on HIV/ AIDS (UNAIDS) is where 54\% of people living with HIV (PLHIV) resided in 2019 (2). According to UNAIDS estimates, new HIV infections peaked globally in 1998 at 2.8 million per year. UNAIDS estimates that 38 million people were living with HIV and 690 thousand died due to HIV in 2019 (2). In Kenya, an estimated 1.5 million people were living with HIV in 2019, of whom $74 \%$ were on antiretroviral treatment (ART). To date, no effective vaccines or cures for HIV infection have been identified, though research continues on new therapeutic options, vaccines, and functional cures. This introduction begins with a brief history of the identification of HIV and AIDS, followed by a summary of global efforts to control the HIV pandemic, then provides an overview of HIV epidemiology, biology and clinical presentation. It follows with a description of measurement issues related to the incidence of infection, disease progression, treatment, and death. Finally, it summarizes disease surveillance methods commonly applied to the HIV epidemic.

\section{Early developments in the diagnosis and treatment of HIV}

In 1983, a research group led by Françoise Barré-Sinoussi and Luc Montagnier in France identified the human immunodeficiency virus (3). The first commerciallyavailable diagnostic test for HIV infection was based on the enzyme-linked immunosorbent assay (ELISA), which detects antibodies to HIV and was commercialized in 1985 (4). Given the silent nature of early HIV infection, low cost and accessible diagnostic tests meant blood donations could be screened and infections due to tainted blood products reduced or eliminated (5). Further, it allowed for the design of prevention campaigns based on getting tested and knowing one's HIV status (6).

In 1985, the nucleoside analog zidovudine (azidothymidine) was first tested in patients with AIDS and found to be effective at slowing the progression of HIV (7). However, used in isolation, it did not result in improved long-term outcomes for infected patients due to the rapid development of drug resistant virus leading to viral rebound and treatment failure (8). The introduction of combination therapy and the approval of the first protease inhibitors in 1996 drastically reduced HIVassociated morbidity and mortality (9-11), transforming HIV infection from a nearly universally fatal diagnosis to a chronic condition for those with access to 
treatment (12). It would take years of concerted efforts by advocacy groups before antiretrovirals were readily accessible in developing countries, where most deaths due to HIV were occurring (13).

\section{The global response to AIDS}

In the midst of growing international recognition of the scope of the HIV epidemic, a dedicated AIDS program was first created within the World Health Organization (WHO) in 1986 (14). The Joint United Nations (UN) Programme on HIV and AIDS was created in 1994 to coordinate global action on HIV/AIDS (15). Launched by the UN in 2000, the Millennium Development Goals (MDG) included a commitment to universal access to antiretroviral treatment for all who needed it by 2010 (goal 6.B) and to halt and begin to reverse the spread of HIV by 2015 (goal 6.A). The Global Fund to fight HIV/AIDS, Tuberculosis and Malaria was launched in 2002. The following year, the US government announced the creation of the President's Emergency Plan for AIDS Relief (PEPFAR) and WHO launched the " 3 by 5" initiative to put three million people, or half those in need under contemporary guidelines, on antiretroviral treatment by 2005 (16). The MDG HIV goals were not achieved: an estimated $25 \%$ of all people living with HIV were on treatment in 2010, and new infections still outstripped deaths among people living with HIV in 2019 (2), four years after the MDG deadline. Against this backdrop, world leaders endorsed the Sustainable Development Goals (SDG) in 2015, which included ending AIDS as a public health threat by 2030 (target 3.3) and ensuring access to universal health coverage (target 3.8). To operationalize these broad health imperatives, UNAIDS launched the Fast-Track approach in late 2014, which included the 90 90-90 targets to ensure $90 \%$ of people living with HIV are aware of their status, $90 \%$ of which are on HIV treatment, of which $90 \%$ were to be virally suppressed by 2020 (17), increasing to $95-95-95$ by 2030 . By meeting these goals, UNAIDS hoped to achieve an almost 90\% reduction in new HIV infections in 2030 from 2010 to $<280,000$ per year, a nearly $80 \%$ reduction in deaths due to HIV and the elimination of HIV-related discrimination by 2030 (18). Although they garner less attention or funding, the 90-90-90 targets were accompanied by ambitious (non-treatment) prevention goals, and the impact modeling commissioned by UNAIDS assumed both the prevention and treatment targets would be met. Though performance is not as far off as for the 2015 universal treatment goal, the world does not appear to be on track to reach the 2020 diagnosis and treatment targets (19).

\section{The Human Immunodeficiency Virus}

The human immunodeficiency virus is a lentivirus of the retroviridiae family. Lentiviruses are implicated in chronic conditions of the immune and central nervous systems (20). HIV has two types, HIV-1 and HIV-2; both are believed to 
have resulted from separate crossover events to humans by different strains of the simian immunodeficiency virus (SIV). Based on genetic analyses, HIV-1 group M, the HIV sub-type responsible for the HIV pandemic, crossed over from SIVcpz in chimpanzees early in the $20^{\text {th }}$ century, though the earliest blood specimen from which HIV has been retrospectively identified was taken in 1959 from a man living in present-day Kinshasa (21). The HIV-2 virus crossed over from SIVsmm, which infects the sooty mangabey (22). First described in 1986 (23), HIV-2 is most common in West Africa and Lusophone countries, is declining in prevalence, and is being replaced by HIV-1 (24). The HIV-1 virus is more virulent than HIV-2 and is responsible for most HIV infections around the world (25).

HIV targets the immune system by binding the CD4+ receptor of T-lymphocytes and macrophages (Figure 1) (26). After a series of subsequent steps, including coreceptor binding and membrane fusion, HIV infects the host cell by introducing viral genetic material and proteins, including reverse transcriptase, into the cytoplasm. The reverse transcriptase then transcribes the viral RNA into DNA, which after transport into the nucleus is incorporated by viral integrase into the host cell genome. The normal cell replication machinery then generates more viral RNA and protein components, which are released as mature infectious virus, allowing the cycle to repeat (27).

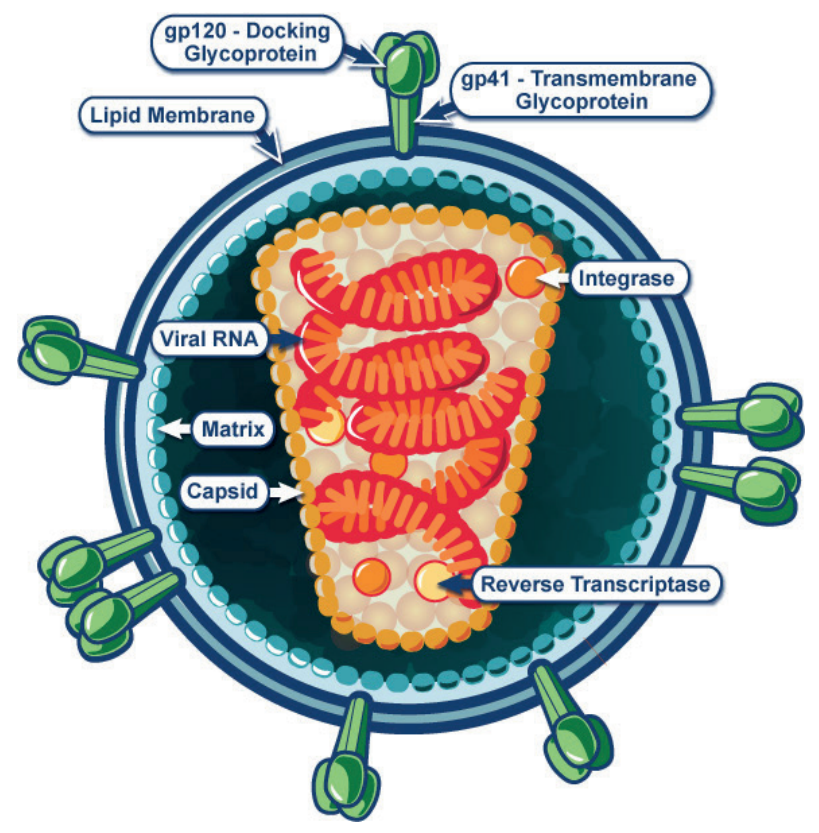

Figure 1. Model of the Human immunodeficiency Virus. Source: National Institute of Allergy and Infectious Diseases, National Institutes of Health, 2009. 
During acute infection, viral copies can double more than once per day, reaching $10^{5}-10^{6}$ copies per milliliter of blood within a couple of weeks (28). The intrinsic mutation rate of RNA viruses is 1-2 orders of magnitude higher than DNA viruses due to differences in transcriptional machinery (29), resulting in an error rate in HIV of about 1 in 10,000 nucleotides per copy (30), giving rise to a "quasispecies" of different viruses in each infected individual. This genetic diversity facilitates the rapid emergence of drug-resistant mutants when selective pressure is applied, such as continuous exposure to a single antiretroviral agent (31). When suppressed effectively through continuous combination antiretroviral treatment, HIV remains present in a latent state in viral reservoirs in different tissues, from which the virus can re-activate if treatment is suspended (32).

\section{Clinical presentation Acute HIV infection}

Acute HIV infection is often sub-clinical or causes only mild symptoms that are non-specific and self-resolve. Among a cohort of HIV-negative female sex workers followed prospectively in Mombasa, Kenya, $24 \%$ presented no symptoms associated with primary HIV infection. Among those with symptoms, most were non-specific, such as fever, headache, fatigue, arthralgia, and vomiting (33). In a predominantly male European cohort, symptoms were also non-specific, with fever, fatigue, myalgia, skin rash, headache and pharyngitis all commonly reported (34). Both studies also showed that increasing severity of primary infection is associated with more rapid disease progression and mortality (33-35). HIV generally replicates silently for many years after the acute phase, slowly depleting the immune system until other opportunistic infections attack the body (36).

\section{Advanced HIV disease}

The WHO defines advanced HIV disease as having a CD4+ cell count of $<200$ cells/ $\mathrm{mm}^{3}$ or a stage 3 or 4 event at presentation (37). A quarter to half of all patients present with a CD4+ count below this threshold, depending on region (38). Events such as cryptococcosis, Pneumocystis jiroveci pneumonia and toxoplasmosis are more frequent with decreasing CD4+ cell count (39). People living with HIV are also at increased risk of tuberculosis, even on long-term antiretroviral treatment or with high CD4+ cell counts $(39,40)$, though the risk of tuberculosis (TB) infection increases exponentially with decreasing CD4+ cell count among those not on ART (41). Although many present with advanced disease due to missed opportunities for early diagnosis, up to $60 \%$ are ART-experienced in eastern and southern Africa $(42,43)$. The occurrence of these and other conditions associated with HIV 
infection is also used to stage HIV illness in the absence of or in conjunction with immunological markers, such as counts of CD4+ cells, the primary immune target of HIV infection (44).

Immune reconstitution disease, whereby the rapid restoration of immune function combined with the presence of antigen from opportunistic infection results in illness, commonly results in morbidity (16.1\%) and more rarely in mortality $(4.5 \%)$. It is most common in those starting treatment with low CD4+ cell counts (45).

\section{An aging epidemic}

As people living with HIV live longer due to increased access to effective treatment resulting in demographic shifts in the HIV-infected population, non-AIDS conditions associated with traditional risk factors are emerging as common causes of morbidity and mortality in this group (46). Treatment-associated toxicity along with increased immune activation and chronic inflammation due to HIV infection, even when infection is controlled by ART, increase disease and mortality risk (45).

\section{Monitoring disease progression and treatment failure}

Given HIV primarily targets CD4+ T-lymphocytes, measures of total CD4+ cells, and $\mathrm{CD} 4+$ percentage relative to other $\mathrm{T}$ cells are strong indicators for disease progression (47). Analyses of large population cohorts have shown the prognostic value of CD4+ cell counts, along with age and sex (48). Initially, CD4+ cell counts were used to determine when to initiate antiretroviral treatment as well as to assess treatment failure. Although the first WHO HIV treatment guidelines, targeted at resource-limited settings, did not mandate CD4 testing due to the complexity and limited availability, they did advocate for its expansion (49). Eventually, in 1996, the first viral load test based on the polymerase chain reaction was licensed for treatment monitoring. The monitoring of viral load is now recommended over CD4 testing alone for detecting treatment failure (50). Several platforms have been developed for measuring HIV viral load from whole blood, plasma and dried blood spots (DBS) (51). Many countries have adopted these platforms for routine monitoring of HIV treatment. World Health Organization guidelines were updated in 2013 to recommend viral load for monitoring patient response to treatment at 6 months and then every 12 months thereafter (52). Kenya adopted these guidelines in 2014 , with additional testing for those with unsuppressed viremia ( $\geq 1000$ copies per milliliter) to diagnose treatment failure (53). As of 2018, Kenya was estimated to have achieved $71 \%$ coverage of routine viral load among patients on treatment (54). Given its superiority for monitoring of treatment failure and that WHO 
guidelines now recommend immediate initiation of treatment among all people diagnosed with HIV regardless of immune status (55), viral load testing has gained in importance relative to CD4 monitoring (56).

\section{The cascade of HIV care}

In the 1960s, tuberculosis and sexually-transmitted infection control programs usefully formulated the disease control process at the population level as a linear series, or cascade, of contingent events $(57,58)$. Despite its clinical complexity and chronicity, HIV infection can also be reduced to a linear sequence of critical transitions, including infection, diagnosis, enrolment in care, initiation of antiretroviral treatment, and achievement of viral load suppression. Once a patient has been diagnosed and entered the health system, these transitions can be monitored to ensure a patient progresses from diagnosis to viral suppression as quickly as possible to minimize the risk of HIV-related morbidity and mortality and onward transmission of infection. Cohort analysis is an effective approach to monitoring how many patients are retained at each stage of the cascade, allowing for objective assessments of program quality and measurement of program outcomes (see first column in table 1).

Table 1. formulation of alternative versions of selected HIV testing and treatment indicators

Program Cascade

\begin{tabular}{|c|c|c|c|c|}
\hline Transition & $\begin{array}{c}\text { Cohort } \\
\text { measures }\end{array}$ & $\begin{array}{c}\text { Transition } \\
\text { measures }\end{array}$ & $\begin{array}{c}\text { Cross-sectional } \\
\text { measures }\end{array}$ & $\begin{array}{c}\begin{array}{c}\text { Cross-sectional } \\
\text { measures }\end{array} \\
\end{array}$ \\
\hline Diagnosis (Dx) & N/A & $\begin{array}{l}\text { Number of new } \\
\text { Dx per unit time }\end{array}$ & $\begin{array}{l}\text { Total number } \\
\text { currently } \mathrm{Dx}^{*} \text { at } \\
\text { end of period }\end{array}$ & $\begin{array}{c}\text { Proportion of } \\
\text { PLHIV ever Dx }\end{array}$ \\
\hline Treatment $(\mathrm{Tx})$ & $\begin{array}{l}\text { Proportion Dx } \\
\text { that initiate Tx } \\
\text { within time X, } \\
\text { time from Dx to } \\
\text { Tx initiation }\end{array}$ & $\begin{array}{l}\text { Number of Tx } \\
\text { initiations per } \\
\text { unit time }\end{array}$ & $\begin{array}{l}\text { Total number } \\
\text { currently on Tx } \\
\text { at end of period }\end{array}$ & $\begin{array}{l}\text { Proportion of } \\
\text { PLHIV that are } \\
\text { on } \mathrm{Tx}\end{array}$ \\
\hline $\begin{array}{l}\text { Viral load } \\
\text { suppression } \\
\text { (VLS) }\end{array}$ & $\begin{array}{l}\text { Proportion of } \\
\text { patients initiating } \\
\text { Tx that achieve } \\
\text { VLS within time } \\
\text { X, time from Tx } \\
\text { initiation to VLS }\end{array}$ & $\begin{array}{c}\text { Number of } \\
\text { patients newly } \\
\text { VLS }\end{array}$ & $\begin{array}{l}\text { Proportion of } \\
\text { patients on Tx } \\
\text { that are VLS }\end{array}$ & $\begin{array}{c}\text { Proportion of } \\
\text { PLHIV that are } \\
\text { VLS }\end{array}$ \\
\hline
\end{tabular}

Notes: ${ }^{*}$ difficult or impossible to measure in many settings due to lack of a comprehensive registry of ever-diagnosed patients. ' often referred to as 'proportion of people living with HIV (PLHIV) that know their HIV-positive status.' 
At an aggregate level, programs can track how many patients successfully enter, or are currently in, each of these states (depicted in the 'transition' and 'cross-sectional' measures under 'program' in table 1). In the absence of cohort analysis, various proxy measures can be defined, such as the number initiating treatment in a threemonth period / the number diagnosed in the same period (a proxy for 'linkage to care' among those newly diagnosed). The proxy measures can be confounded by population mobility or delayed transition from one state to the next. They are not true proportions, as those starting treatment in this period may have been diagnosed in a previous period, and they can exceed $100 \%$ in some circumstances.

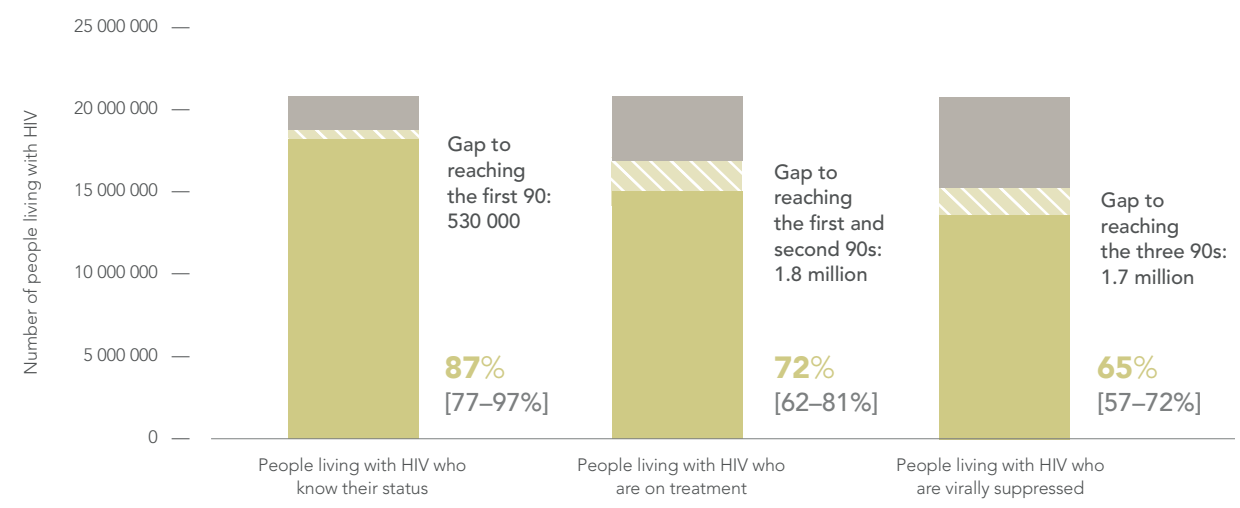

Figure 2. HIV testing and treatment cascade, eastern and southern Africa, 2019. Figures shown are coverage relative to the total population of people living with HIV. Figure source: UNAIDS, used with permission (59).

Cross-sectional measures benefit from not requiring an extended follow-up period, allowing for rapid action in response to poor performance. However, such crosssectional measures of cascade indicators are an imperfect substitute for monitoring individual progression, since disengagement from (and re-engagement in) care can also happen anywhere along the cascade, potentially inflating the number of transitions to diagnosis, treatment, or viral load suppression. Even without reengagement in care, patient choices about where to seek different services can skew cascade estimates at the facility or district level. In the absence of robust unique identifiers and centralized patient tracking, this results in inaccurate measures of program success.

The cross-sectional UNAIDS Fast-Track targets are appealing due to their simplicity: they reduce the complex series of events required to achieve successful HIV outcomes into just three indicators. However, they also present challenges 
for estimation. The first 90 is not possible to measure entirely within a program as the denominator requires an estimate of the size of the catchment population of people living with HIV, which is rarely known with any precision at a local level. The numerator of the first 90 (and the denominator of the second 90) also requires a robust estimate of the number of people living with HIV ever diagnosed and still living, which is only available in jurisdictions with functioning case surveillance. The numerator of the second 90 (which is the denominator of the third 90) can be estimated from standardized, centrally-procured commodities, facilitating estimation. The numerator of the third 90 depends on an adequate coverage of routine viral load testing for estimation. When all three 90 s are expressed as proportions of all people living with HIV, they form an HIV testing and treatment cascade (Figure 2)(60).

Given the limitations of routine data for estimating the HIV testing and treatment cascade, population-based surveys are also important tools for validating estimates in higher-prevalence populations. Each sentinel event in the cascade of care can present specific survey measurement challenges. Even HIV diagnosis or coverage of antiretroviral treatment can be challenging to measure with accuracy. A significant number of survey respondents who report not being aware of their HIV infection have antiretroviral drugs detected in their blood, indicating that they have been diagnosed and are on treatment (61). Though significant progress has been made, the world is not on track to meet the 2020 targets (Figure 2). The challenge of accurately modeling progress towards targets is explored in Chapter 3, while survey measurement issues are explored in depth in Chapters $4 \& 5$. As countries approach the 90-90-90 and then the 95-95-95 targets, measurement issues are likely to gain more attention, as small absolute differences in estimates can mean the difference between (apparent) success and failure.

\section{Measures of HIV in the context of epidemic control}

The SDGs strive to end AIDS as a public health threat by 2030. In order to better define what the 'end of AIDS' might look like, UNAIDS held consultations which led to four measures of epidemic control: relative reductions in incidence and mortality since 2010, crossing below absolute thresholds in incidence, achieving a ratio of new HIV infections to deaths among people living with HIV less than 1, and achieving an incidence to prevalence ratio less than a context-specific threshold $(62,63)$. The UNAIDS Fast-Track targets are designed to measure successful rollout and uptake of HIV programs to diagnose patients and get them on treatment, rather than to assess progress towards epidemic control specifically. Although achieving the goals will be beneficial to those living with HIV, it appears that achievement will not be sufficient to control the HIV epidemic (64). The four large community trials 
conducted in sub-Saharan African countries that aimed to measure the impact of universal test and treat (65-68) on HIV incidence exceeded targets for knowledge of status; three of the four also exceeded community ART coverage and viral load suppression targets. Nonetheless, the resulting HIV incidence reductions were only statistically significant in two out of four trials. They did not meet epidemic control targets of $<1$ new infection per 10,000 population per year, indicating that universal treatment is necessary but insufficient to eliminate HIV (69).

\section{Measures of incidence}

The impact of HIV prevention is measured through the incidence of new HIV infection. Infectious disease incidence is traditionally estimated through prospectively following an uninfected cohort of persons at risk. Given the relative infrequency of HIV transmission in most populations, large cohorts or long followup periods are needed to observe sufficient seroconversions to measure HIV incidence reliably. Trends in the prevalence of HIV infection in 15-19 year olds (male and female, or pregnant women) have been used as a proxy for monitoring incidence in a generalized epidemic, as this age group is likely to have been recently infected and not yet subject to significant HIV-related mortality. However, with expanded ART coverage among children leading to increased survival of HIVinfected children into adolescence, this assumption may no longer be valid (70). Alternative methods that can be applied in cross-sectional surveys or programmatic settings have also been developed, including biomarkers for recent infection, which estimate what proportion of infections are recent, i.e., within some window period that is assay- and population-dependent (71). These tests' specificity can be improved by screening out persons with evidence of antiretroviral treatment or viral suppression (72). Together with the number of uninfected in the sample and other assumptions, they can be used in a recent infection testing algorithm (RITA) to estimate incidence (73). Detection of recent infection before seroconversion using nucleic acid amplification testing (NAAT) to detect viral RNA in those who are antibody-negative is another approach (74); however, given the short window period between initial infection and seroconversion (approximately 14-28 days), use of this marker is most appropriate in large samples from high-incidence populations (75). A series of assays have been developed that use the differing concentrations of IgG and IgM antibodies over time to create tests for recent $(<3-$ 6 months) infection $(76,77)$. The longer window period makes it possible to use these assays in moderate incidence populations, but still with large sample sizes (often $>25,000$ subjects). These assays do not provide accurate results in patients on treatment since treatment modifies the antibody response; hence questions on ART 
status or additional biomarkers such as antiretroviral detection in blood and viral load suppression must be included in the RITA to rule out false-recent infections due to treatment exposure.

Other approaches to estimating incidence include mathematical models that use a combination of information about prevalence, treatment coverage, self-reported history of HIV testing, population structure, and expected mortality on and off treatment to estimate historical incidence $(78,79)$. The Spectrum model developed by Avenir Health is one such model and has been adopted by UNAIDS as a standard approach recommended for estimating incidence and other HIV indicators for UN member states (80). According to the most recent estimates based on this model, $\mathrm{HIV}$ incidence peaked at 3,000,000 new infections per year among those aged 15 years and older in 1995 worldwide, falling to 1,600,000 new infections per year by 2017 (UNAIDS, 2018). In Kenya, in 2017, the official estimates were 45,000 new infections per year (corresponding to an incidence rate of 1.8 / 1000 susceptible in adults aged 15 years and older).

\section{HIV mortality}

The overall impact of HIV treatment (and indirectly, prevention) can be assessed by monitoring mortality due to HIV infection. Despite conceptual simplicity, measuring mortality at the population level, and attributing it to a specific cause, can be difficult in resource-constrained settings. Only 15\% of the world's population is covered by vital statistics systems that produce high-quality data on the cause of death (81). Both deaths due to HIV and all deaths among those living with HIV are essential metrics. All-cause mortality among the HIV-infected is critical because, ultimately, the epidemic's course is determined by the relationship between new infections and deaths among those infected, as HIV is currently a lifelong infection. As illness and death due to HIV infection are almost entirely avoidable through effective antiretroviral treatment, HIV-associated mortality is an indicator of the quality of care and impact of treatment on quality and duration of life among those infected with HIV.

Ascertaining HIV as an underlying cause of death presents challenges due to the complexity of the disease. The International Statistical Classification of Diseases and Related Health Problems: $10^{\text {th }}$ revision (ICD-10) provides rules for establishing the underlying cause from among a series of events leading to death (82), including for HIV (81). Many HIV-associated conditions are rare in immunocompetent individuals, hence their presence is highly indicative of underlying HIV infection. However, others such as tuberculosis are common causes of death in both HIVinfected and uninfected persons in many regions of the world, hence reliable 
attribution of cause depends on knowing the HIV status of the individual. At the time of death HIV status may be unknown or unavailable to those certifying the cause of death, or there may be a reluctance to document HIV as a cause of death due to stigma. Deaths that occur in the community rather than in a health facility often do not have a reliable clinical history from which medical causes of death can be reliably deduced (83). While standardized methods for classifying causes for community deaths exist, their sensitivity and specificity for HIV are limited, particularly in children (84).

Mortality among people living with HIV can also be ascertained by monitoring patients enrolled in HIV care. As access to care and treatment expands, this group increasingly represents the entire HIV-infected population. However, many large HIV treatment programs manage thousands of patients and experience significant loss to follow-up among their patient population, making it difficult to determine if patients that are lost have disengaged from care, enrolled in care elsewhere without a formal transfer from their previous treatment site, or have died (85). Special studies in East Africa have shown that actual adult all-cause mortality among patients on ART can be threefold higher than that observed based on program data alone (86).

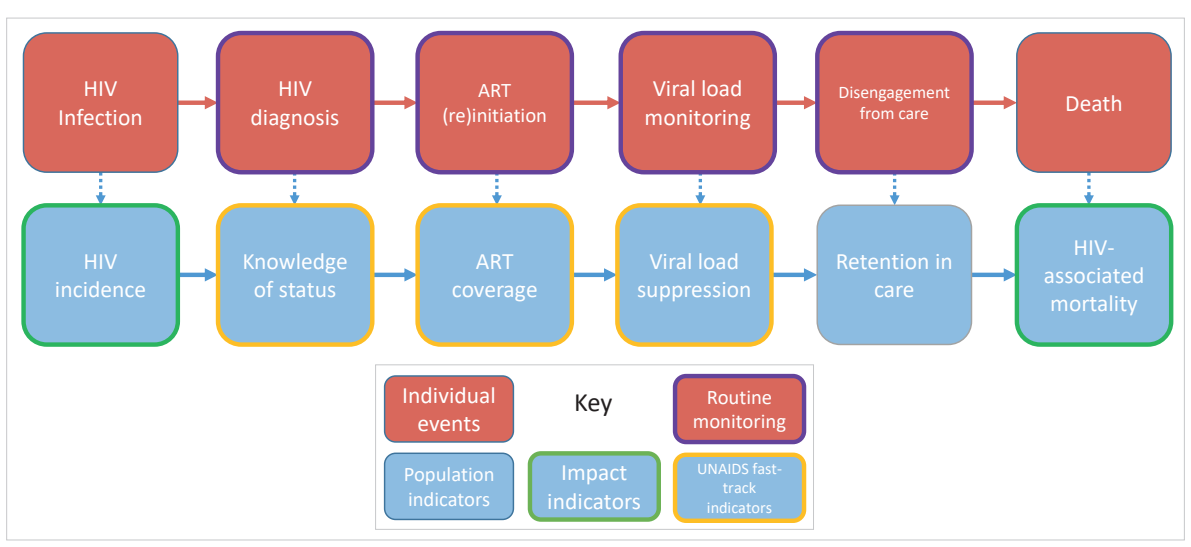

Figure 3. HIV disease monitoring and surveillance

\section{HIV disease surveillance}

Harold Jaffe and colleagues described the epidemiology of the first 1,000 cases of AIDS in the US reported to the CDC between June 1981 and February 1983 through a combination of active and passive surveillance measures (87); by 1989, 28 of 50 US states had implemented HIV case reporting in addition to AIDS case reporting (88). In the same year, the WHO Global Programme on AIDS first 
advocated for countries to develop national HIV surveillance systems. Initial surveillance systems in sub-Saharan Africa were based on a combination of AIDS case reporting and cross-sectional, anonymous seroprevalence surveys in antenatal care services, as the uptake of facility-based antenatal care was high in many countries. Though limited to pregnant women, these surveys provided a snapshot of HIV prevalence in the general population and estimated trends in prevalence over time (89). In 2000, WHO issued guidelines for second-generation HIV surveillance, which recommended adapting surveillance to changing needs as epidemics matured and treatment availability increased, including through capture of risk behavior information to help monitor the effects of prevention efforts, and including key populations at greater risk for infection, such as men who have sex with men, sex workers, or injection drug users (90). National serosurveys were implemented in many countries either as add-ons to national health surveys such as the Demographic and Health Survey (DHS) program or as standalone surveys focused on HIV risk behaviors and infection prevalence in key populations or the general population. Over time, these surveys have evolved to focus more on the cascade of care and the impact of treatment programs, by requesting self-reported knowledge of HIV status and ART use and by testing for HIV, ART, viral load, and recent infection (91). In 2017, WHO introduced HIV case surveillance guidelines to bridge the gap between periodic national surveys, monitor outcomes including death, and provide more locally-actionable information about the HIV epidemic (Figure 3) (92).

In parallel with these efforts, large population cohorts have been used to monitor the impact of HIV and increasing treatment coverage on mortality in sub-Saharan Africa. Such population-based studies can attempt to ascertain HIV status, and its role in the cause of death, retrospectively once the death has occurred. Crosssectional approaches are also possible; Mozambique conducted a nationallyrepresentative post-census mortality survey in 2008/2009 based on verbal autopsy (93), and other countries have developed national sampling frames for longitudinal follow-up of mortality (94). Another approach is to ascertain HIV status post mortem as a public health intervention, which has been done sporadically, in Abidjan, Cote D'Ivoire in the 1990s (95), in the Democratic Republic of Congo in 2001 (96), in New York City from 2008-2012 (97), and Kenya in 2015 (98) and 2019. In an attempt to increase the availability and comparability of HIV-related mortality data, the WHO issued guidance on mortality measurement for HIV surveillance purposes in 2014 (81). 


\section{Thesis outline}

This Ph.D. thesis aims to enhance our understanding of the epidemiology of HIV in Kenya, with a focus on measurement and estimation along the entire cascade of HIV care. Specifically, the thesis sets out to answer the following questions:

- What are the incidence and prevalence of HIV in Kenya?

- Has access to HIV treatment increased over time in Kenya, and have increases been equitably distributed?

- Has HIV incidence declined during the rapid scale-up of HIV prevention and treatment programs in the regions of Kenya most heavily impacted by the epidemic?

- Is excess mortality due to HIV still a significant public health problem in Kenya?

- Can measurement of the cascade of HIV care be further improved?

In chapter 2, data from a community-based HIV testing program nested in a health demographic surveillance site are used to assess recent changes in HIV incidence in western Kenya, a region that historically has had the highest HIV prevalence in Kenya. Testing results and demographic data from the surveillance site are used to construct an open cohort to measure trends in HIV incidence. This study's results are used to assess whether HIV incidence declined significantly from 2010 to 2016, concomitant with scale-up of voluntary medical male circumcision and antiretroviral treatment access.

Chapter 3 provides estimates of HIV prevalence and incidence in Kenya. It describes how the standard UNAIDS methodology for estimating HIV incidence, prevalence, mortality and other indicators are applied to Kenya and its 47 counties, as well as how these estimates have evolved from 2015-17 in response to changes in the methods endorsed by UNAIDS, and changing availability of data over time.

To determine whether the use of antiretroviral treatment has significantly increased, chapter 4 describes a two-country analysis looking at the equity of treatment coverage at the population level in Kenya and South Africa in 2007 and 2012. This chapter also describes using a biomarker to estimate quantities that traditionally had been self-reported by survey respondents.

Chapter 5 presents an analysis of an alternative biomarker-based adjustment approach to estimating knowledge of HIV-infected status, ART treatment coverage, and viral load suppression (the three indicators along the cascade of HIV care 
included in the UNAIDS fast-track targets). The chapter presents a potentially improved method for estimating these indicators using a low-cost, widely available marker, namely HIV viral load.

Chapters 6 through 8 explore HIV-related mortality, using a relatively underutilized approach of mortuary-based HIV surveillance to measure rates of HIV-associated mortality and causes of death among those who were HIV-infected at the time of death in the capital city of Kenya. Chapter 6 presents the findings of a mortuarybased study undertaken in Nairobi in early 2015 at the two largest mortuaries in the city, which measured the prevalence of HIV among deaths as well as care-related indicators such as HIV diagnosis prior to death or hospitalization, treatment history, and viral load at the time of death. Chapter 7 applies the findings of this study, together with the mathematical model described in chapter 3, to estimate population indicators such as the fraction of deaths among adults in Nairobi attributable to HIV. Chapter 8 shares the results of a similar study conducted in a higher-HIV-prevalence region in western Kenya in 2019. Finally, the thesis is summarized in chapter 9 with a general discussion, a summary of findings and recommendations. 


\section{References}

1. Gottlieb M, Schanker H, Fan P, Saxon A, Weisman J, Pozalski I. Pneumocystis Pneumonia - Los Angeles. MMWR Morb Mortal Wkly Rep. 1981;30(250).

2. AIDSinfo team. UNAIDS estimates. AIDSinfo. 2020 [cited 2020 0ct 24]. Available from: https://aisinfo. unaids.org

3. Barré-Sinoussi $F$, Chermann JC, Rey F, Nugeyre MT, Chamaret $S$, Gruest J, et al. Isolation of a T-lymphotropic retrovirus from a patient at risk for acquired immune deficiency syndrome (AIDS). Science. 1983;220(4599):868-71. doi: 10.1126/science.6189183

4. Simonetti FR, Dewar $R$, Maldarelli F. Specific laboratory methods for detection of HIV infection. In: Bennett J, Dolin R, Dolin R, editors. Mandell, Douglas, and Bennett's principles and practice of infectious diseases: 2-volume set. 8th ed. Elsevier Health Sciences; 2015. Available from: https:// www.r2library.com/Resource/Title/1455748013

5. De Cock KM, Jaffe HW, Curran JW. The evolving epidemiology of HIV/AIDS. Aids. 2012;26(10):120513. doi: 10.1097/QAD.0b013e328354622a

6. Centers for Disease Control. Current trends human T-lymphotropic virus type III/ lymphadenopathyassociated virus antibody testing at alternate sites. MMWR Morb Mortal Wkly Rep. 1986;35(17):2847. Available from: https://www.cdc.gov/mmwr/preview/mmwrhtml/00000728.htm

7. Fischl MA, Richman DD, Grieco MH, Gottlieb MS, Volberding PA, Laskin OL, et al. The efficacy of azidothymidine (AZT) in the treatment of patients with AIDS and AIDS-related complex. N Engl J Med. 1987 Jul 23;317(4):185-91. doi: 10.1056/NEJM198707233170401

8. Concorde: MRC/ANRS randomised double-blind controlled trial of immediate and deferred zidovudine in symptom-free HIV infection. Lancet. 1994 Apr;343(8902):871-81. doi: 10.1016/S01406736(94)90006-X

9. Palella FJ, Delaney KM, Moorman AC, Loveless MO, Fuhrer J, Satten GA, et al. Declining morbidity and mortality among patients with advanced human immunodeficiency virus infection. HIV Outpatient Study Investigators. N Engl J Med. 1998;338(13):853-60. doi: 10.1056/NEJM199803263381301

10. Darbyshire J. Delta: a randomised double-blind controlled trial comparing combinations of zidovudine plus didanosine or zalcitabine with zidovudine alone in HIV-infected individuals. Lancet. 1996 Aug;348(9023):283-91. doi: 10.1016/S0140-6736(96)05387-1

11. Cohen OJ, Fauci AS. HIV/AIDS in 1998-Gaining the upper hand? JAMA. 1998 Jul 1;280(1):87. doi: 10.1001/jama.280.1.87

12. Montagnier L. A history of HIV discovery. Science. 2002 Nov;298(5599):1727-8. doi: 10.1126/ science.1079027

13. Achmat Z. Commentary: Most South Africans cannot afford anti-HIV drugs. BMJ. 2002;324:217-8. doi: 10.1136/bmj.324.7331.214

14. Mann JM. The World Health Organization's global strategy for the prevention and control of AIDS. West J Med. 1987;147:732-4.

15. UNAIDS: mission and roles. Glob AIDS news. 1995;(3-4):2-3.

16. The Lancet. WHO 2003-08: a programme of quiet thunder takes shape. Lancet. 2003 Jul;362(9379):179. doi: 10.1016/S0140-6736(03)13947-5 
17. 90-90-90: an ambitious treatment target to help end the AIDS epidemic. Geneva: UNAIDS; 2014. Available from: http://www.unaids.org/sites/default/files/media_asset/90-90-90_en_0.pdf

18. Stover J, Bollinger L, Antonio Izazola J, Loures L, DeLay P, Ghys PD, et al. What is required to end the AIDS epidemic as a public health threat by 2030 ? The cost and impact of the fast-track approach. PLoS One. 2016;11(5):1-14. doi: 10.1371/journal.pone.0154893

19. Marsh K, Eaton JW, Mahy M, Sabin K, Autenrieth C, Wanyeki I, et al. Global, regional and countrylevel 90-90-90 estimates for 2018. AIDS. 2019 Dec 15; 33(Supp 3):S213-26. doi: 10.1097I qad.0000000000002355

20. Tang H, Kuhen KL, Wong-Staal F. Lentivirus replication and regulation. Annu Rev Genet. 1999;33:13370. doi: 10.1146/annurev.genet.33.1.133

21. Nahmias AJ, Weiss J, Yao $X_{1}$ Lee $F$, Kodsi R, Schanfield $M$, et al. Evidence for human infection with an HTLV II/LAV-like virus in Central Africa, 1959. Lancet. 1986 May;327(8492):1279-80. doi: 10.1016/ S0140-6736(86)91422-4

22. Visseaux B, Damond F, Matheron S, Descamps D, Charpentier C. Hiv-2 molecular epidemiology. Infect Genet Evol. 2016;46:233-40. doi: 10.1016/j.meegid.2016.08.010

23. Clavel F, Guétard D, Brun-Vézinet F, Chamaret $S$, Rey MA, Santos-Ferreira MO, et al. Isolation of a new human retrovirus from West African patients with AIDS. Science. 1986;233(4761):343-6. doi: $10.1126 /$ science. 2425430

24. Sharp PM, Hahn BH. Origins of HIV and the AIDS pandemic. Cold Spring Harb Perspect Med. 2011;1(1):a006841. doi: 10.1101/cshperspect.a006841

25. Pereira JMA, Costa QS. HIV interaction with human host : HIV-2 as a model of a less virulent infection. AIDS Rev. 2016;18:44-53.

26. Wilen CB, Tilton JC, Doms RW. HIV: Cell binding and entry. Cold Spring Harb Perspect Med. 2012;2(8):1-5. doi: 10.1101/cshperspect.a006866

27. Coffin JM, Hughes SH, Varmus HE, editors. Retroviruses. Cold Spring Harbor (NY, USA): Cold Spring Harbor Laboratory Press; 1997. Available from: https://www.ncbi.nlm.nih.gov/books/NBK19376/

28. Ribeiro RM, Qin L, Chavez LL, Li D, Self SG, Perelson AS. Estimation of the initial viral growth rate and basic reproductive number during acute HIV-1 infection. J Virol. 2010 Jun 15;84(12):6096-102. doi: 10.1128/JVI.00127-10

29. Holmes EC. Evolutionary history and phylogeography of human viruses. Annu Rev Microbiol. 2008 Oct;62(1):307-28. doi: 10.1146/annurev.micro.62.081307.162912

30. Menéndez-Arias L, Sebastián-Martín A, Álvarez M. Viral reverse transcriptases. Virus Res. 2017;234:153-76. doi: 10.1016/j.virusres.2016.12.019

31. Richman DD, Nathanson N. Antiviral therapy. In: Katze M, Korth M, Law G, Nathanson N, editors. Viral pathogenesis: from basics to systems biology: Third edition. 3rd ed. Elsevier Health Sciences; 2016. doi: 10.1016/B978-0-12-800964-2.00020-3

32. Margolis D, Bushman F. Persistence by proliferation? Science. 2014;345(6193):143-4. doi: 10.1126/ science. 1257426

33. Lavreys L, Baeten JM, Chohan V, McClelland RS, Hassan WM, Richardson BA, et al. Higher set point plasma viral load and more-severe acute HIV type 1 (HIV-1) illness predict mortality among high-risk HIV-1-infected African women. Clin Infect Dis. 2006 May 1;42(9):1333-9. doi: 10.1086/503258 
34. Vanhems $P$, Routy J-P, Hirschel B, Baratin D, Vora $S$, Maenza J, et al. Clinical features of acute retroviral syndrome differ by route of infection but not by gender and age. J Acquir Immune Defic Syndr. 2002;31(3). Available from: https://journals.lww.com/jaids/Fulltext/2002/11010/Clinical_ Features_of_Acute_Retroviral_Syndrome.7.aspx

35. Daar ES, Pilcher CD, Hecht FM. Clinical presentation and diagnosis of primary HIV-1 infection. Curr Opin HIV AIDS. 2008 Jan;3(1):10-5. doi: 10.1097/COH.0b013e3282f2e295

36. Moir S, Chun T-W, Fauci AS. Pathogenic mechanisms of HIV disease. Annu Rev Pathol Mech Dis. 2011 Feb 28;6(1):223-48. doi: 10.1146/annurev-pathol-011110-130254

37. Waldrop G, Doherty M, Vitoria M, Ford N. Stable patients and patients with advanced disease: consensus definitions to support sustained scale up of antiretroviral therapy. Trop Med Int Heal. 2016;21(9):1124-30. doi: 10.1111/tmi.12746

38. Anderegg N, Panayidou K, Abo Y, Alejos B, Althoff KN, Anastos K, et al. Global trends in CD4 cell count at the start of antiretroviral therapy: collaborative study of treatment programs. Clin Infect Dis. 2018;66(6):893-903. doi: 10.1093/cid/cix915

39. Summers NA, Armstrong WS. Management of advanced HIV disease. Infect Dis Clin North Am. 2019;33(3):743-67. doi: 10.1016/j.idc.2019.05.005

40. Gupta RK, Rice B, Brown AE, Thomas HL, Zenner D, Anderson L, et al. Does antiretroviral therapy reduce HIV-associated tuberculosis incidence to background rates? A national observational cohort study from England, Wales, and Northern Ireland. Lancet HIV. 2015 Jun;2(6):e243-51. doi: 10.1016/ S2352-3018(15)00063-6

41. Ellis PK, Martin WJ, Dodd PJ. CD 4 count and tuberculosis risk in HIV-positive adults not on ART: a systematic review and meta-analysis. PeerJ. 2017 Dec 14;5(12):e4165. doi: 10.7717/peerj.4165

42. Ndlovu Z, Burton R, Stewart R, Bygrave H, Roberts T, Fajardo E, et al. Framework for the implementation of advanced HIV disease diagnostics in sub-Saharan Africa: programmatic perspectives. Lancet HIV. 2020;7(7):e514-20. doi: 10.1016/S2352-3018(20)30101-6

43. Ousley J, Niyibizi AA, Wanjala S, Vandenbulcke A, Kirubi B, Omwoyo W, et al. High proportions of patients with advanced HIV are antiretroviral therapy experienced: Hospitalization outcomes from 2 sub-Saharan African sites. Clin Infect Dis. 2018 Mar 4;66(suppl_2):S126-31. doi: 10.1093/cid/ ciy103

44. Gebo KA, Gallant JE, Keruly JC, Moore RD. Absolute CD4 vs. CD4 percentage for predicting the risk of opportunistic illness in HIV infection. JAIDS J Acquir Immune Defic Syndr. 2004 Aug;36(5):1028-33. doi: 10.1097/00126334-200408150-00005

45. Maartens G, Celum C, Lewin SR. HIV infection: Epidemiology, pathogenesis, treatment, and prevention. Lancet. 2014;384(9939):258-71. doi: 10.1016/S0140-6736(14)60164-1

46. Ghosn J, Taiwo B, Seedat S, Autran B, Katlama C. HIV. Lancet. 2018 Aug;392(10148):685-97. doi: 10.1016/S0140-6736(18)31311-4

47. Phillips AN, Elford J, Sabin C, Janossy G, Lee CA. Pattern of CD4+ T cell loss in HIV infection. J Acquir Immune Defic Syndr. 1992;5(9):950-1.

48. Stover J, Andreev K, Slaymaker E, Gopalappa C, Sabin K, Velasquez C, et al. Updates to the Spectrum model to estimate key HIV indicators for adults and children. AIDS. 2014;28(4):S427-34. doi: 10.1097/QAD.0000000000000483 
49. World Health Organization. Scaling up antiretroviral therapy in resource-limited settings: Guidelines for a public health approach. Geneva, Switzerland: World Health Organization; 2002. Available from: https://www.who.int/hiv/pub/prev_care/en/ScalingUp_E.pdf?ua=1

50. World Health Organization. What's new in treatment monitoring: viral load and CD4 testing. Geneva, Switzerland; 2017. Available from: https://apps.who.int/iris/bitstream/handle/10665/255891/WHOHIV-2017.22-eng.pdf?sequence=1

51. Smit PW, Sollis KA, Fiscus S, Ford N, Vitoria M, Essajee $S$, et al. Systematic review of the use of dried blood spots for monitoring HIV viral load and for early infant diagnosis. PLoS One. 2014; doi: 10.1371/ journal.pone.0086461

52. World Health Organization. Consolidated guidelines on the use of antiretroviral drugs for treating and preventing HIV infection. Recommendations for a public health approach. Geneva, Switzerland; 2013 Jun. Available from: https://www.who.int/hiv/pub/guidelines/arv2013/en/

53. Ministry of Health, National AIDS Control Council (NACC), National AIDS and STI Control Programme (NASCOP). Guidelines on use of antiretroviral drugs for treating and preventing HIV infection: A rapid advice, 2014. Nairobi, Kenya: NASCOP; 2014 [cited 2016 Dec 23]. Available from: http:// healthservices.uonbi.ac.ke/sites/default/files/centraladmin/healthservices/Rapid Advice Booklet 201424 June 12 noon_0.pdf

54. National AIDS and STI Control Programme. KENPHIA 2018 preliminary report. Nairobi, Kenya; 2019. Available from: https://phia.icap.columbia.edu/wp-content/uploads/2020/02/KENPHIA-2018_ Preliminary-Report_final-web.pdf

55. World Health Organization. Guideline on when to start antiretroviral therapy and on pre-exposure prophylaxis for HIV. 2015. Available from: https://www.who.int/hiv/pub/guidelines/earlyrelease-arv/ enl

56. World Health Organization. Consolidated guidelines on the use of antiretroviral drugs for treating and preventing HIV infection, 2nd edition. 2016. Available from: https://www.who.int/hiv/pub/arv/arv2016/en/

57. Piot M. A simulation model of case finding and treatment in tuberculosis control programmes. 1967. Report No.: WHO/TB/Techn.Information/67.53. Available from: https://apps.who.int/iris/ handle/10665/69827

58. De Cock KM. Plus ça change ... antiretroviral therapy, HIV prevention, and the HIV treatment cascade. Clin Infect Dis. 2014;58(7):1012-4. doi: 10.1093/cid/ciu026

59. UNAIDS. UNAIDS Data 2020. Geneva, Switzerland; 2020. Available from: https://www.unaids.org/ sites/default/files/media_asset/2020_aids-data-book_en.pdf

60. UNAIDS. Global AIDS update 2019 - Communities at the centre - Defending rights, breaking barriers, reaching people with HIV services. Geneva, Switzerland; 2019. Available from: https://www.unaids. org/sites/default/files/media_asset/2019-global-AIDS-update_en.pdf

61. Kim AA, Mukui I, Young PW, Mirjahangir J, Mwanyumba S, Wamicwe J, et al. Undisclosed HIV infection and antiretroviral therapy use in the Kenya AIDS indicator survey 2012. AIDS. 2016 Nov;30(17):268595. doi: 10.1097/QAD.0000000000001227

62. UNAIDS. Making the end of AIDS real: Consensus building around what we mean by "Epidemic Control." UNAIDS. Glion, Switzerland; 2017.

63. Galvani AP, Pandey A, Fitzpatrick MC, Medlock J, Gray GE. Defining control of HIV epidemics. Lancet HIV. 2018;5(11):e667-70. doi: 10.1016/S2352-3018(18)30178-4 
64. Bekker LG, Alleyne G, Baral S, Cepeda J, Daskalakis D, Dowdy D, et al. Advancing global health and strengthening the HIV response in the era of the Sustainable Development Goals: the International AIDS Society-Lancet Commission. Lancet. 2018;392(10144):312-58. doi: 10.1016/S0140$6736(18) 31070-5$

65. Iwuji CC, Orne-Gliemann J, Larmarange J, Balestre E, Thiebaut $\mathrm{R}_{\text {, Tanser }} \mathrm{F}_{\text {, et al. Universal test and }}$ treat and the HIV epidemic in rural South Africa: a phase 4, open-label, community cluster randomised trial. Lancet HIV. 2018;5(3):e116-25. doi: 10.1016/S2352-3018(17)30205-9

66. Hayes RJ, Donnell D, Floyd S, Mandla N, Bwalya J, Sabapathy K, et al. Effect of universal testing and treatment on HIV incidence - HPTN 071 (PopART). N Engl J Med. 2019;381(3):207-18. doi: 10.1056/ NEJMoa1814556

67. Makhema J, Wirth KE, Holme MP, Gaolathe T, Mmalane M, Kadima E, et al. Universal testing, expanded treatment, and incidence of HIV infection in Botswana. N Engl J Med. 2019;381(3):230-42. doi: 10.1056/NEJMoa1812281

68. Havlir D V., Balzer LB, Charlebois ED, Clark TD, Kwarisiima D, Ayieko J, et al. HIV testing and treatment with the use of a community health approach in rural Africa. N Engl J Med. 2019;381(3):219-29. doi: 10.1056/nejmoa1809866

69. Havlir D, Lockman S, Ayles H, Larmarange J, Chamie G, Gaolathe $T$, et al. What do the universal test and treat trials tell us about the path to HIV epidemic control? J Int AIDS Soc. 2020 Feb 24;23(2). doi: 10.1002/jia2.25455

70. Eaton JW, Garnett GP, Takavarasha FR, Mason PR, Robertson L, Schumacher CM, et al. Increasing adolescent HIV prevalence in eastern Zimbabwe - Evidence of long-term survivors of mother-tochild transmission? Sandstrom P, editor. PLoS One. 2013 Aug 7;8(8):e70447. doi: 10.1371/journal. pone.0070447

71. Mastro TD, Kim AA, Hallett $T$, Rehle $T$, Welte $A$, Laeyendecker 0 , et al. Estimating HIV incidence in populations using tests for recent infection: Issues, challenges and the way forward. J HIV AIDS Surveill Epidemiol. 2010 Jan 1;2(1):1-14. Available from: http://www.ncbi.nlm.nih.gov/ pubmed/21743821

72. Kim AA, Rehle T. Assessing estimates of HIV incidence with a recent infection testing algorithm that includes viral load testing and exposure to antiretroviral therapy. AIDS Res Hum Retroviruses. 2018;34(10):aid.2017.0316. doi: 10.1089/aid.2017.0316

73. Simmons R, Lutsar I, Malyuta R, Rosińska M, Porter K. Using incidence assays within the context of the recent infections testing algorithm: AIDS., 2014;28(14):2167. doi: 10.1097/QAD.0000000000000367

74. Quinn TC, Brookmeyer R, Kline R, Shepherd M, Paranjape R, Mehendale S, et al. Feasibility of pooling sera for HIV-1 viral RNA to diagnose acute primary HIV-1 infection and estimate HIV incidence. AIDS. 2000; doi: 10.1097/00002030-200012010-00015

75. Blaizot S, Kim AA, Zeh C, Riche B, Maman D, De Cock KM, et al. Estimating HIV incidence using a crosssectional survey: Comparison of three approaches in a hyperendemic setting, Ndhiwa subcounty, Kenya, 2012. AIDS Res Hum Retroviruses. 2017 May;33(5):472-81. doi: 10.1089/aid.2016.0123

76. Parekh BS, Kennedy MS, Dobbs T, Pau C-P, Byers R, Green $T$, et al. Quantitative detection of increasing HIV type 1 antibodies after seroconversion: A simple assay for detecting recent HIV infection and estimating incidence. AIDS Res Hum Retroviruses. 2002 Mar;18(4):295-307. doi: $10.1089 / 088922202753472874$ 
77. Duong YT, Qiu M, De AK, Jackson K, Dobbs T, Kim AA, et al. Detection of recent HIV-1 infection using a new limiting-antigen avidity assay: Potential for HIV-1 incidence estimates and avidity maturation studies. PLoS One. 2012; doi: 10.1371/journal.pone.0033328

78. Fellows IE, Shiraishi RW, Cherutich P, Achia T, Young PW, Kim AA. A new method for estimating HIV incidence from a single cross-sectional survey. Ferrand RA, editor. PLoS One. 2020 Aug 12;15(8):e0237221. doi: 10.1371/journal.pone.0237221

79. Hallett TB, Zaba B, Todd J, Lopman B, Mwita W, Biraro S, et al. Estimating incidence from prevalence in generalised HIV epidemics: Methods and validation. PLoS Med. 2008;5(4):0611-22. doi: 10.1371/ journal.pmed.0050080

80. Stover J, Glaubius R, Mofenson L, Dugdale CM, Davies M-A, Patten G, et al. Updates to the Spectrum/ AIM model for estimating key HIV indicators at national and subnational levels. AIDS. 2019 Dec;33:S227-34. doi: 10.1097/QAD.0000000000002357

81. World Health Organization. Guidelines for HIV mortality measurement. Geneva, Switzerland; 2014.

82. World Health Organization. International statistical classification of diseases and related health problems, tenth revision, volume 2. 2004;

83. de Savigny D, Riley I, Chandramohan D, Odhiambo F, Nichols E, Notzon S, et al. Integrating communitybased verbal autopsy into civil registration and vital statistics (CRVS): System-level considerations. Glob Health Action. 2017;10(1). doi: 10.1080/16549716.2017.1272882

84. Setel PW, Whiting DR, Hemed Y, Chandramohan D, Wolfson LJ, Alberti KGMM, et al. Validity of verbal autopsy procedures for determining cause of death in Tanzania. Trop Med Int Heal. 2006;11(5):681696. doi: 10.1111/j.1365-3156.2006.01603.x

85. Rachlis $B$, Ochieng $D$, Geng $E$, Rotich $E_{1}$ Ochieng $V$, Maritim $B$, et al. Implementation and operational research: evaluating outcomes of patients lost to follow-up in a large comprehensive care treatment program in western Kenya. JAIDS J Acquir Immune Defic Syndr. 2015 Apr;68(4):e46-55. doi: 10.1097/ QAl.0000000000000492

86. Geng EH, Odeny TA, Lyamuya RE, Nakiwogga-muwanga A, Diero L, Bwana $M$, et al. Estimation of mortality among HIV-infected people on antiretroviral treatment in east Africa: a sampling based approach in an observational, multisite, cohort study. Lancet HIV. 2015;2:e107-16. doi: 10.1016/ S2352-3018(15)00002-8

87. Jaffe HW, Bregman DJ, Selik RM. Acquired immune deficiency syndrome in the United States: The first 1,000 cases. J Infect Dis. 1983;148(2):339-45. doi: 10.1093/infdis/148.2.339

88. Centers for Disease Control. HIV infection reporting -- United States. MMWR Morb Mortal Wkly Rep. 1989;38(28):496-9. Available from: https://www.cdc.gov/mmwr/preview/mmwrhtml/00001425. htm

89. Dee J, Garcia Calleja JM, Marsh K, Zaidi I, Murrill C, Swaminathan M. HIV surveillance among pregnant women attending antenatal clinics: evolution and current direction. JMIR Public Heal Surveill. 2017; doi: $10.2196 /$ publichealth. 8000

90. World Health Organization. Second generation surveillance for HIVIAIDS. Geneva, Switzerland; 2000. Available from: https://www.who.int/hiv/topics/surveillance/2ndgen/en/

91. Waruiru W, Kim AA, Kimanga DO, Ng'ang'a J, Schwarcz S, Kimondo L, et al. The Kenya AIDS Indicator Survey 2012: rationale, methods, description of participants, and response rates. J Acquir Immune Defic Syndr. 2014;66 Suppl 1:S3-12. doi: 10.1097/QAl.0000000000000114 
92. World Health Organization. Consolidated guidelines on person-centred HIV patient monitoring and case surveillance. Geneva, Switzerland; 2017.

93. Mortality in Mozambique. Results from a 2007-2008 post-census mortality survey. Chapel Hill, USA: Mozambique National Institute of Statistics, U.S. Census Bureau, MEASURE Evaluation, U.S. Centers for Disease Control and Prevention; 2012.

94. Office of the Registrar General. Sample registration system statistical report 2018. new Delhi; 2018. Available from: https://censusindia.gov.in/Vital_Statistics/SRS_Report_2018/SRS_Statistical_ Report_2018.pdf

95. De Cock KM, Barrere B, Diaby L, Lafontaine MF, Gnaore E, Porter A, et al. AlDS--the leading cause of adult death in the West African City of Abidjan, Ivory Coast. Science. 1990;249(4970):793-6. doi: 10.1126/ science. 2167515

96. Le Coeur $S$, Halembokaka $G$, Khlat M, Brouard N, Purhuence F, M'Pelé $P$, et al. Impact of AIDS on adult mortality: a morgue-based study in Pointe-Noire, Republic of Congo. AIDS. 2005;19(15):1683-7. doi: 10.1097/01.aids.0000184926.98497.0e

97. Ramaswamy C, Ellman TM, Myers J, Madsen A, Sepkowitz K, Shepard C. Human immunodeficiency virus infection newly diagnosed at autopsy in New York City, 2008-2012. Open Forum Infect Dis. 2015 Dec;2(4):ofv146. doi: 10.1093/ofid/ofv146

98. Nyagah LM, Young PW, Kim AA, Wamicwe J, Kimani M, Waruiru W, et al. HIV-related deaths in Nairobi, Kenya: Results from a HIV mortuary surveillance study, 2015.. J Acquir Immune Defic Syndr. 2019 May:81(1):18-23. doi: 10.1097/QAl.0000000000001975 


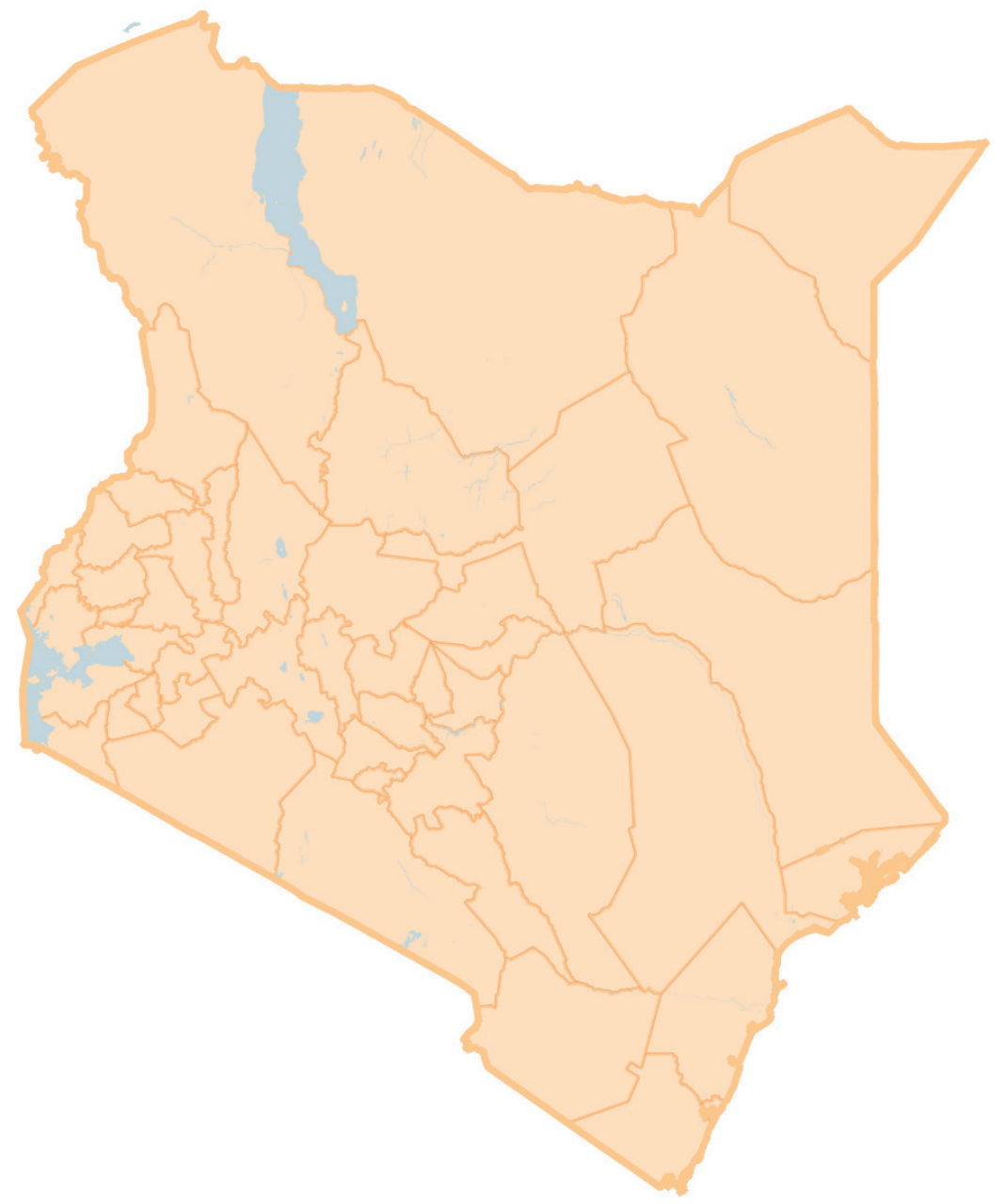




\section{Chapter 2}

\section{HIV incidence in western Kenya during scale up of antiretroviral therapy and voluntary medical male circumcision: a population- based cohort analysis}

Martien W. Borgdorff

Daniel Kwaro

David Obor

George Otieno

Viviane Kamire

Frederick Odongo

Patrick Owuor
Jacques Muthusi

Lisa A. Mills

Rachael Joseph

Mary E. Schmitz

Peter Young

Emily Zielinski-Gutierrez

Kevin M. De Cock 


\section{Abstract}

Background: In Kenya, coverage of antiretroviral therapy (ART) among people with HIV infection has increased from $7 \%$ in 2006, to $57 \%$ in 2016; and, in western Kenya, coverage of voluntary medical male circumcision (VMMC) increased from $45 \%$ in 2008 , to $72 \%$ in 2014 . We investigated trends in HIV prevalence and incidence in a high burden area in western Kenya in 2011-16.

Methods: In 2011, 2012, and 2016, population-based surveys were done via a health and demographic surveillance system and home-based counselling and testing in Gem, Siaya County, Kenya, including 28,688, 17,021, and 16,772 individuals aged 15-64 years. Data on demographic variables, self-reported HIV status, and risk factors were collected. Rapid HIV testing was offered to survey participants. Participants were tracked between surveys by use of health and demographic surveillance system identification numbers. HIV prevalence was calculated as a proportion, and HIV incidence was expressed as number of new infections per 1000 person-years of follow-up.

Results: HIV prevalence was stable in participants aged 15-64 years: 15\% $(4300 / 28,532)$ in $2011,12 \%(2051 / 16,875)$ in 2012 , and $15 \%(2312 / 15,626)$ in 2016. Crude prevalences in participants aged $15-34$ years were $11 \%(1893 / 17,197)$ in $2011,10 \%(1015 / 10,118)$ in 2012 , and $9 \%(848 / 9125)$ in 2016; adjusted for age and sex these prevalences were $11 \%, 9 \%$, and $8 \% .12,606$ (41\%) of the 30,520 non-HIVinfected individuals enrolled were seen again in at least one more survey round, and were included in the analysis of HIV incidence. HIV incidence was 11.1 (95\% CI 9.1-13.1) per 1000 person-years from 2011 to 2012, and 5.7 (4.6-6.9) per 1000 person-years from 2012 to 2016.

Interpretation: With increasing coverage of ART and VMMC, HIV incidence declined substantially in Siaya County between 2011 and 2016. VMMC, but not ART, was suggested to have a direct protective effect, presumably because ART tended to be given to individuals with advanced HIV infection. HIV incidence is still high and not close to the elimination target of one per 1000 person-years. The effect of further scale-up of ART and VMMC needs to be monitored. 


\section{Research in context}

\section{Evidence before the study}

Scale-up of antiretroviral therapy (ART) and voluntary medical male circumcision (VMMC) is expected to lead to a reduction in HIV incidence in Siaya County, western Kenya, on the basis of their protective efficacy in clinical trials, supported by mathematical models and observational studies. Little information on the effect of ART and VMMC under programmatic conditions exists, and the coverage required to achieve HIV elimination is unknown. We searched PubMed with the terms "incidence", "HIV”, "Kenya", "sub-Saharan Africa”, "prevalence”, "risk factors", "antiretroviral therapy", and "voluntary medical male circumcision", and searched publication lists from other sub-Saharan African institutions researching HIV. We restricted our search to English language articles published between 2006 and 2015.

\section{Added value of this study}

After programmatic real world scale-up of ART and VMMC in western Kenya, HIV incidence among individuals aged 15-64 years substantially decreased, as did HIV prevalence among those aged 15-34 years. However, HIV incidence remained well above the elimination target of 1 per 1000 person-years.

\section{Implications of all the available evidence}

Although scale-up of ART and VMMC under programmatic conditions had a substantial effect on HIV incidence, coverage probably has to be very high to achieve HIV elimination. Determination of the coverage required, through realworld experience, is a public health priority, essential for resource allocation and service delivery.

\section{Introduction}

UNAIDS estimated that HIV infection affected 36.7 million people globally in 2016, with 2.1 million new infections and 1.1 million AIDS-related deaths (1). The number of $\mathrm{HIV}$-infected individuals receiving antiretroviral treatment increased from 7.5 million in 2010, to 17.0 million in 2015. Eastern and southern Africa account for more than half of the global HIV burden,1 and, in this area, HIV/ AIDS is among the leading causes of death (2). In Kenya, HIV prevalence in people aged 15-64 years was estimated at 5.6\% in a national survey in 2012, compared with $7.2 \%$ in 2007 (3). The present study was done in western Kenya, where HIV prevalence was the highest nationally at $15.1 \%$ in 2012 , and has shown no decline since 2007 (3). 
Scale-up of antiretroviral therapy (ART) and voluntary medical male circumcision (VMMC) is expected to reduce HIV incidence. Use of ART by the HIV-infected partner of discordant couples reduced linked HIV transmission to the uninfected partner by $93 \%$ (4). VMMC reduced HIV transmission in clinical trials by more than $60 \%(5,6,7)$. which was sustained over time $(8,9)$. Modelling studies suggest ART has a substantial effect on HIV incidence $(10,11)$. Scale-up of ART in South Africa, and ART and VMMC in Uganda, were associated with a reduction of HIV incidence $(12,13)$.

In Kenya, ART coverage increased from $7 \%$ in 2006 to $57 \%$ in $2016(14,15)$. In Siaya County, the number of individuals on ART increased from 2096 in 2006, to 32,125 in 2011 , to 70,261 in $2016(14,15)$. Before 2011 , ART was prescribed to $\mathrm{HIV}$-infected individuals with CD4 counts less than 200 cells per $\mu \mathrm{L}$ if the infection was classified as WHO stage 1 or 2, and to those with CD4 counts less than 350 cells per $\mu \mathrm{L}$ if the infection was classified as WHO stage 3 or 4 . From 2011, eligibility for ART included people with CD4 counts less than 350 cells per $\mu \mathrm{L}$ and WHO stage 1 or 2 infection, and anyone with WHO stage 3 or 4 infection; from 2014, all HIVinfected people with CD4 counts less than 500 cells per $\mu \mathrm{L}$ were eligible for ART $(16,17)$; and from 2016, all HIV-infected people were eligible for ART regardless of CD4 cell counts (18).

A national VMMC programme was initiated in Kenya in 2008, and expanded to include male infants and boys aged 10-14 years in 2014 (19, 20). Kenya Demographic Health Surveys showed a substantial increase in the prevalence of circumcision among boys and men aged 15-49 years in western Kenya from 45\% in 2008 to $72 \%$ in 2014 (21). Similar findings were reported by the Kenya AIDS Indicator Survey of 2012 (22).

In Siaya County, the Kenya Medical Research Institute (KEMRI) has operated a health and demographic surveillance system (HDSS) since 2001, covering close to 250,000 people (23). Gem is one of the three subareas of the HDSS in which home-based counselling and testing (HBCT) surveys have been done since 2011, to increase the coverage of HIV control interventions. This study is a secondary analysis of HBCT and HDSS data, aiming to determine the trends in HIV prevalence and incidence in Siaya County in 2011-16.

\section{Study design and population}

All households in the HDSS were visited two or three times per year to document births, deaths, and migration. The HDSS methods are described in detail elsewhere (23). Data collected in three HBCT surveys were available for analysis. Surveys 
took place from October, 2010, to July, 2011 (referred to as HBCT 2011), January to May, 2012, and May to September, 2016. HBCT is a service delivery strategy to increase knowledge of HIV status and accelerate access to services for HIVinfected people. HBCT teams intended to cover as many households within Gem as possible, given time, funding, and test kit availability. The teams offered enrolment to all individuals aged 13 years or older. Individuals eligible to participate in the surveys were asked for written informed consent in Dholuo, English, or Kiswahili. For those aged 13-17 years, parental consent was sought as well as assent from the minor. HIV testing, HBCT data collection, and HDSS linkage were reviewed and approved by the KEMRI Scientific Ethics Review Unit (number 1801) and US Centers for Disease Control and Prevention (number 3308).

\section{Procedures}

Rapid HIV testing was done according to the national testing algorithm of the Kenyan Ministry of Health. In HBCT 2011, parallel testing was done with two HIV tests, followed by a third test in case of discrepant results between the first and second test. In the other surveys, the first test was used for screening, the second was for confirmation if the first test was positive, and the third as a referee test if the second test was negative. The first test was Determine (Alere, Orlando, FL, USA), the second was SD Bioline HIV-1/2 3.0 (Standard Diagnostics, Giheunggu, Gyonggi-do, South Korea) in 2011 and 2012, and First Response (Premier Medical Corporation, Nadi Daman, India) in 2016, and the third was Uni-gold (Trinity Biotech, Bray, Wicklow, Ireland). All participants received risk reduction counselling. HIV-positive individuals were given a referral to services at the health facility of their choice. The HDSS resident identification number was recorded and used for linkage of the individual's HIV test results and data from questionnaires.

\section{Statistical analysis}

Survey responses to structured questionnaires and HIV test results were logged directly into portable netbook computers in the field. Data were transferred to a central server at the KEMRI Center for Global Health Research each day. Initial data management was done with STATA (version 14).

The HDSS identification numbers were replaced by anonymous study identification numbers, with the link table kept by the data managers of HDSS (DO) and HBCT (DK). The three datasets of the surveys in 2011, 2012, and 2016, were explored with frequency distributions, and then merged and further range and consistency checks done. Inconsistencies of age and sex between rounds were resolved by referring to the HDSS database. The HDSS database was also used to identify spouses of participants. 
A previous study (24) in an adjacent area in Siaya County had reported HIV prevalence in the 15-34 years age group in 2003-04. We estimated HIV prevalence in the same age group in the three consecutive HBCT surveys to establish the trend in HIV prevalence among young adults over time. We also established the trend of HIV prevalence among all those aged 15-64 years. We compared HIV prevalence of repeat participants with that of single round participants to estimate the degree of self-selection bias in the serial prevalence estimates.

Participants aged 15-64 years who had enrolled in 2011 or 2012, were not HIV infected at enrolment and had participated in at least one further HBCT survey were eligible for the cohort analysis of HIV incidence. We defined HIV infection status on the basis of the HIV test results, and among people not tested we accepted self-reported HIV infection as evidence of infection. We did a sensitivity analysis to determine to what extent the inclusion of self-reported HIV-positive status and the exclusion of self-reported HIV-negative status influenced our main conclusions. We identified 51 individuals with apparent HIV seroreversion from HIV-positive to HIV-negative test results. This result was interpreted as a data entry problem of a key variable, and these individuals were excluded from all analyses.

HIV prevalence was calculated as a proportion and incidence was expressed as number of new infections per 1000 person-years of follow-up. Person-time in the denominator of the HIV incidence estimates started at their first participation in 2011 or 2012, and ended at their last survey participation if still HIV negative or after seroconversion. Seroconversions were assumed to have taken place at the midpoint between the last HIV-negative test result and first HIV-positive test result. Serial prevalence estimates and HIV incidence estimates were standardised for age and sex with the HDSS population as the standard population. The strength of association of risk factors for prevalent and incident HIV infection were calculated as odds ratios, derived from logistic regression in univariate and multivariate analysis. From the multivariate analysis, variables were excluded if their addition to the final multivariate model showed a $\mathrm{p}$ value of more than 0.1 . For the analysis of risk factors for incident HIV, we ran an additional model with imputation of missing values. Imputed datasets were created in SPSS (version 24), followed by logistic regression.

Risk factors explored for incident HIV included age, sex, marital status, having had sex in the past 3 months, condom use with these partners, HIV status and ART use of the spouse, and self-reported circumcision status of men and of the main male 
partner of women $(4,5,6,7,8,9,10,11,12,13,24)$. Since many values for risk factor information were missing in 2011, we used information from 2012; if the individual had not participated in 2012, we used data from 2016.

\section{Role of funding source}

Data collection was funded by the Presidential Emergency Program for AIDS Relief (PEPFAR) and the Centers for Disease Control and Prevention. PEPFAR support is acknowledged. PEPFAR did not have a role in writing of the manuscript or the decision to submit for publication. The corresponding author had full access to all the data in the study and had final responsibility to submit for publication.

\section{Results}

Gem had a population of 82,798 in 2012 , according to the HDSS database, and the HBCT surveys included 28,688 individuals aged 15-64 years in 2011, 17,021 in 2012, and 16,772 in 2016. 464 (9\%) of 4884 participants who reported being HIV positive had HIV tests. Of 464 adults who reported being HIV infected and were tested, six (1\%) had a negative test result and were classified as non-HIV infected. Of 37,973 adults who reported not being HIV infected, 37,361 (98\%) were tested and $1802(5 \%)$ had a positive test result.

Among individuals aged 15-64 years, 4300 of 28,532 had HIV in 2011 (prevalence $15 \%), 2051$ of 16,875 in 2012 (12\%), and 2312 of 15,626 in 2016 (15\%). 17,197, 10,118, and 9125 participants aged 15-34 years had known HIV status in 2011, 2012, and 2016. Crude prevalences were $11 \%(1893 / 17,197)$ in $2011,10 \%(1015 / 10,118)$ in 2012, and $9 \%(848 / 9125)$ in 2016; adjusted for age and sex these prevalences were $11 \%, 9 \%$, and $8 \%$, compared with $20 \%$ in an earlier study in $2003-04$, in an adjacent area (figure 1).

The registered population of the Gem HDSS area aged 15-64 years in 2012 was 43,256; combined enrolment for the incidence cohort in 2011 and 2012 was 35,733 individuals with known HIV status (table 1; figure 2). Enrolment rates were higher for those aged younger than 25 years, than for older individuals (table 1). At enrolment, HIV prevalence was 5213 (15\%) among 35,733. 4070 (15\%) of 27,664 individuals who dropped out of the study were HIV infected (figure 1), suggesting that overall dropout was not associated with HIV status. 12,606 (41\%) of the 30,520 non-HIV-infected individuals enrolled were seen again in at least one more survey 
round and included in the analysis of HIV incidence (table 1). Participation in the HIV incidence analysis was lower for men and boys (35\%) than women and girls $(46 \%)$, and increased with age for both sexes (table 1 ).
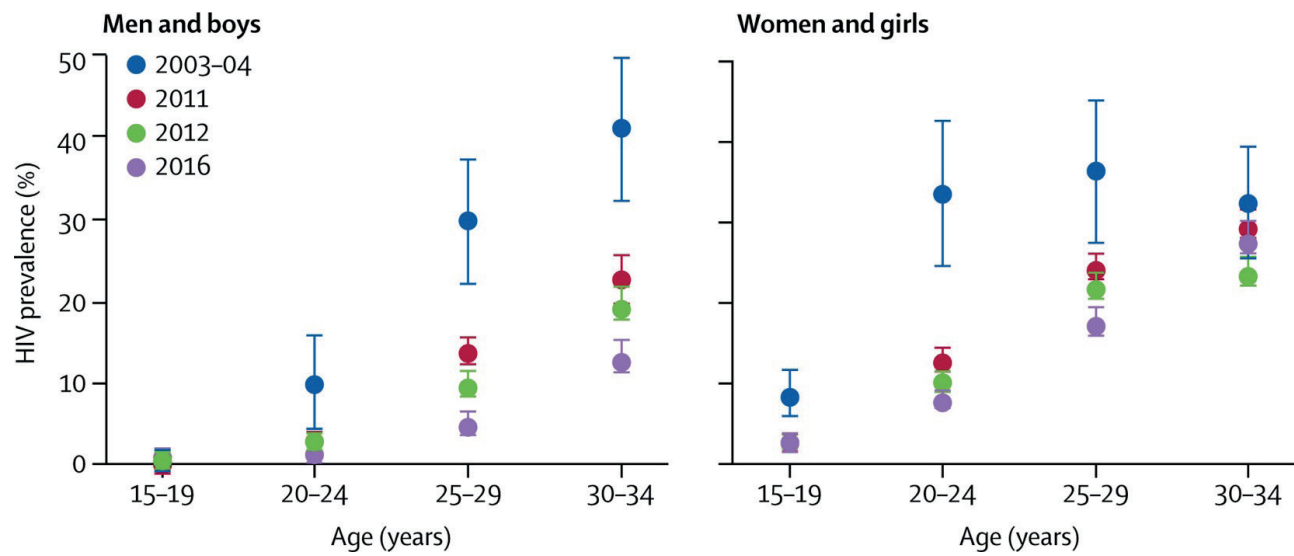

Figure 1. HIV prevalence in men and boys, and women and girls aged 15-34 years in Siaya County, Kenya

Table 1. Age and sex distribution of HDSS population, participants enrolled in rounds 1 and 2, and those included in HIV incidence analysis

\begin{tabular}{|c|c|c|c|c|c|c|}
\hline & \multirow{2}{*}{$\begin{array}{c}\text { HDSS } \\
\text { general } \\
\text { population } \\
\text { number }\end{array}$} & \multicolumn{2}{|c|}{$\begin{array}{l}\text { Enrolled in HBCT surveys } \\
2011 \text { or } 2012\end{array}$} & \multirow[t]{2}{*}{$\begin{array}{l}\text { HIV negative } \\
\text { at enrolment }\end{array}$} & \multicolumn{2}{|c|}{$\begin{array}{c}\text { HIV negative at } \\
\text { enrolment and present } \\
\text { at }>1 \text { survey }\end{array}$} \\
\hline & & number & $\%$ of population & & number & $\%$ of enrolled \\
\hline \multicolumn{7}{|l|}{ Male } \\
\hline $15-24$ & 8572 & 6998 & $82 \%$ & 6884 & 1852 & $27 \%$ \\
\hline $25-34$ & 4499 & 3030 & $67 \%$ & 2520 & 807 & $32 \%$ \\
\hline $35-44$ & 2845 & 1923 & $68 \%$ & 1427 & 650 & $46 \%$ \\
\hline $45-54$ & 2038 & 1491 & $73 \%$ & 1144 & 576 & $50 \%$ \\
\hline $55-64$ & 1836 & 1398 & $76 \%$ & 1206 & 701 & $58 \%$ \\
\hline subtotal & 19790 & 14840 & $75 \%$ & 13181 & 4586 & $35 \%$ \\
\hline \multicolumn{7}{|l|}{ Female } \\
\hline $15-24$ & 8266 & 7876 & $95 \%$ & 7320 & 1934 & $26 \%$ \\
\hline $25-34$ & 5507 & 4758 & $86 \%$ & 3475 & 1686 & $49 \%$ \\
\hline $35-44$ & 3758 & 3214 & $86 \%$ & 2335 & 1524 & $65 \%$ \\
\hline $45-54$ & 3327 & 2823 & $85 \%$ & 2273 & 1580 & $70 \%$ \\
\hline $55-64$ & 2608 & 2222 & $85 \%$ & 1936 & 1296 & $67 \%$ \\
\hline Subtotal & 23466 & 20893 & $89 \%$ & 17339 & 8020 & $46 \%$ \\
\hline Total & 43256 & 35733 & $83 \%$ & 30520 & 12606 & $41 \%$ \\
\hline
\end{tabular}

Data are $\mathrm{n}$ or $\mathrm{n}(\%)$. HDSS=health and demographic surveillance system. HBCT=home-based counselling and testing. 


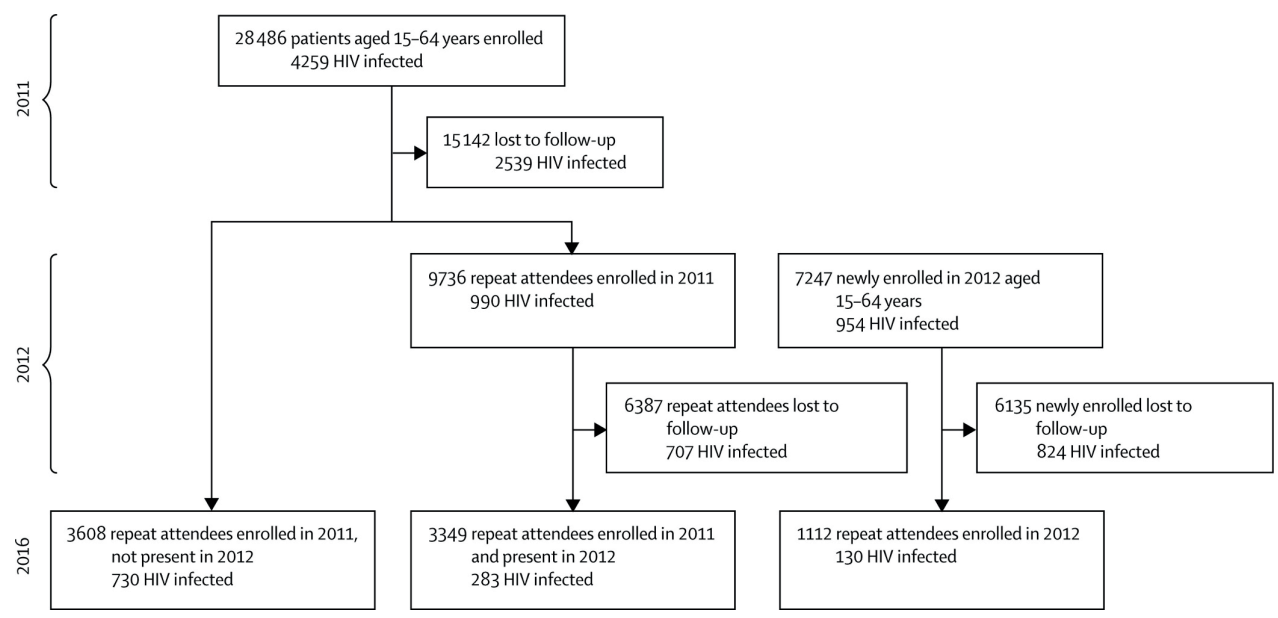

Figure 2. Study profile of home-based counselling and test surveys in 2011, 2012, and 2016, in Gem, Siaya County, Kenya

The proportion of HIV-infected individuals who were aware of their status increased over time, from 44\% (1875/4300) in 2011, to 85\% (1956/2312) in 2016. HIV prevalence at enrolment increased with age in both sexes up to age 3544 years, after which it declined (table 2). Prevalence was lowest in people who were single (adjusted odds ratio 0.3 , 95\% CI 0.2-0.3), and increased in widowed (4.2, 3.7-4.7), widowed and remarried (5.0, 4.1-6.1), and separated (1.7, 1.5-2.0) individuals, compared with married individuals. Compared with individuals whose spouses were not HIV infected, those with an HIV-infected spouse not on ART had a much higher HIV prevalence (14.9, 12.7-17.5); prevalence was even higher if the spouse was on ART $(26.8,22.4-32.2)$. Circumcised men and boys had lower HIV prevalence $(0.6,0.5-0.8$; table 2$)$ than uncircumcised men and boys.

HIV incidence was 11.1 (95\% CI 9.1-13.1) per 1000 person-years in 2011-12, and 5.7 (4.6-6.9) per 1000 person-years in 2012-16 (table 3). The age-standardised HIV incidence was slightly higher in women and girls (8.2 per 1000 person-years) than in men and boys (6.4 per 1000 person-years; table 3 ). 


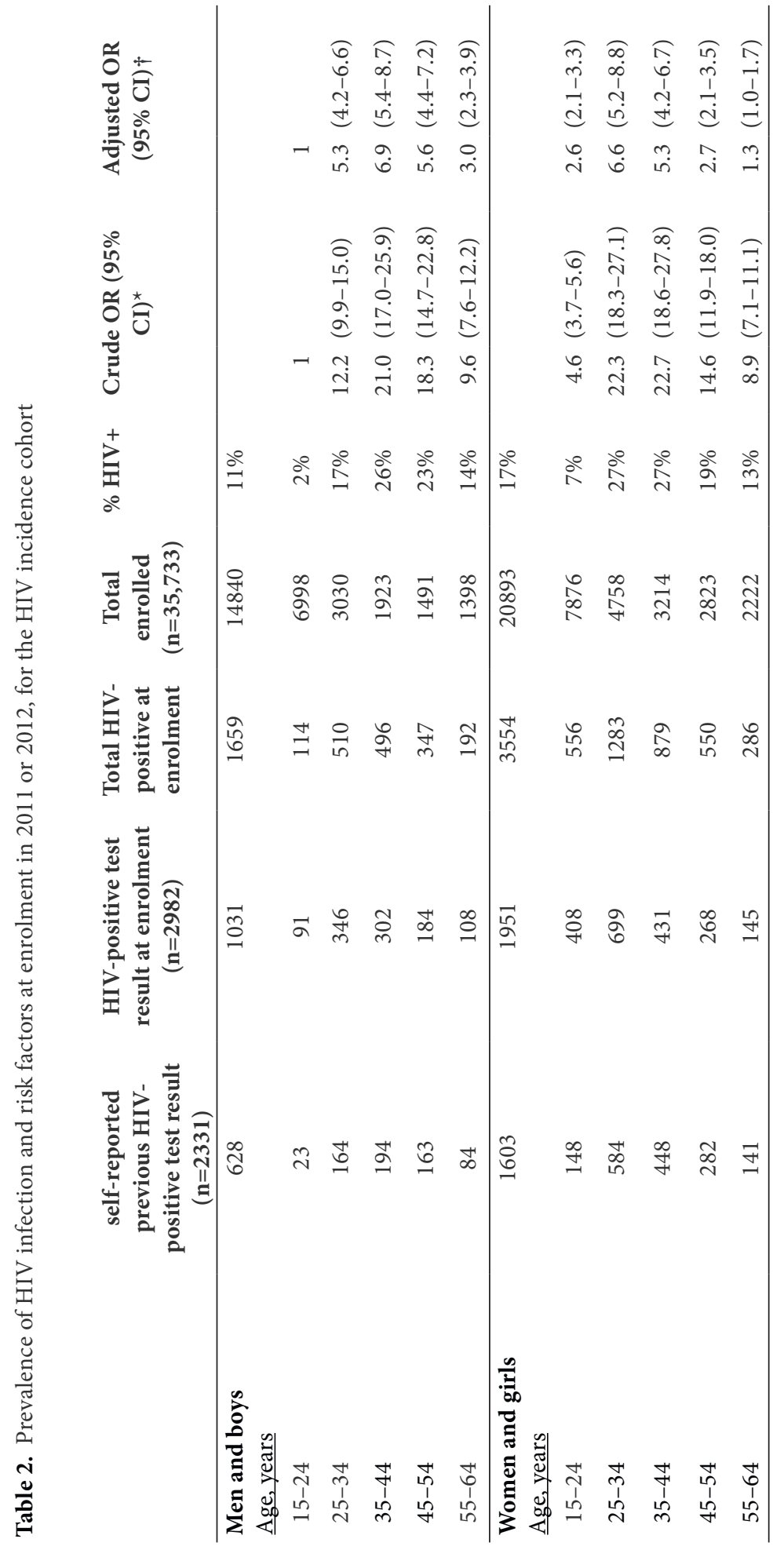




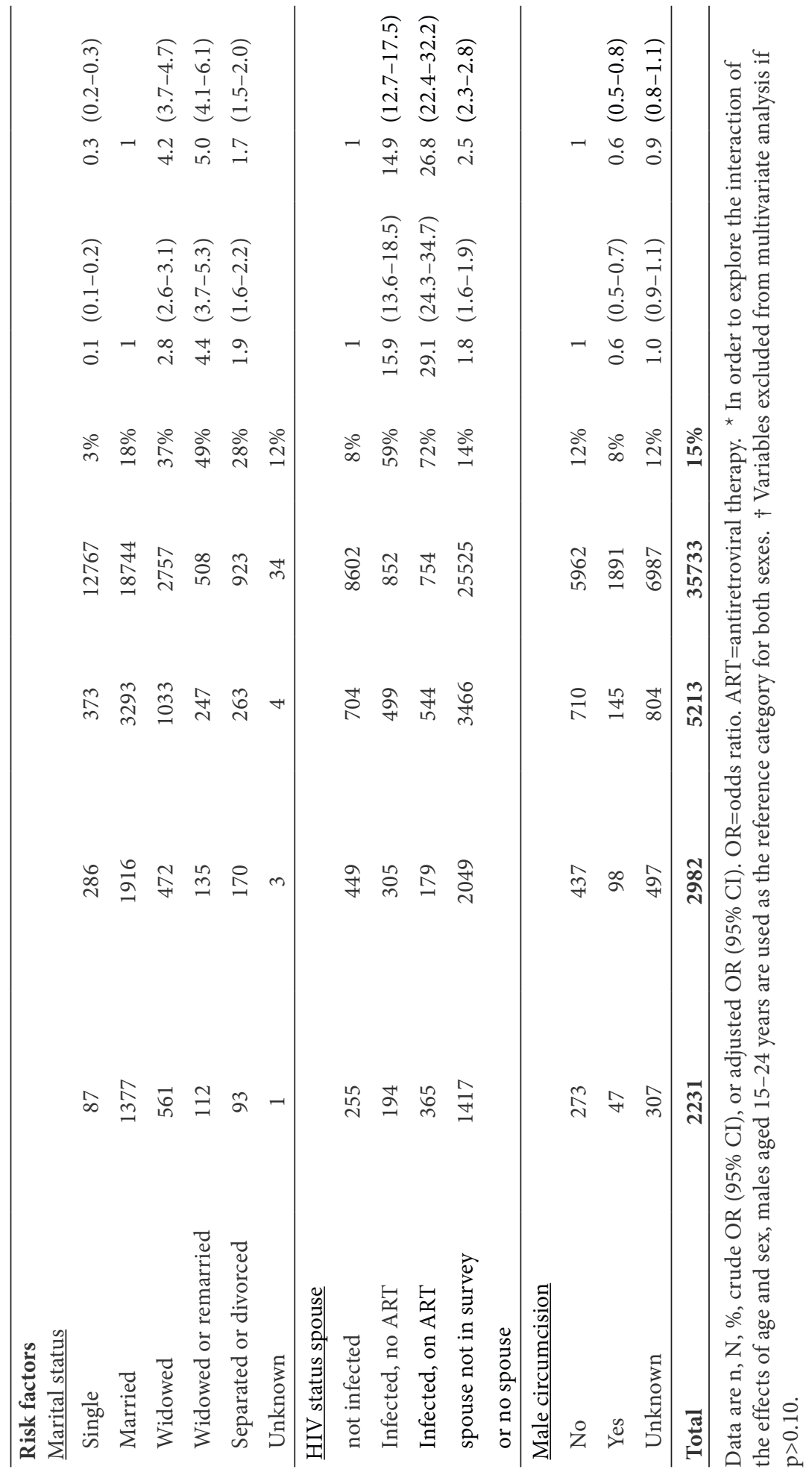


Table 3. HIV incidence by age and sex and between rounds

\begin{tabular}{|c|c|c|c|c|c|}
\hline & $\begin{array}{c}\text { Incident } \\
\text { HIV }\end{array}$ & $\begin{array}{c}\text { Person-years } \\
\text { of observation } \\
\text { x } 1000\end{array}$ & $\begin{array}{c}\text { crude rate } \\
\text { per } 1000 \\
\text { person-years }\end{array}$ & $\begin{array}{c}\text { age and sex } \\
\text { adjusted rate } \\
\text { per } 1000 \\
\text { person-years }\end{array}$ & $95 \% \mathrm{CI}^{*}$ \\
\hline \multicolumn{6}{|c|}{ Men and boys } \\
\hline \multicolumn{6}{|c|}{ Age, years } \\
\hline $15-24$ & 17 & 5.3 & 3.2 & & \\
\hline $25-34$ & 27 & 2.5 & 10.7 & & \\
\hline $35-44$ & 21 & 2.3 & 9.3 & & \\
\hline $45-54$ & 13 & 2.1 & 6.3 & & \\
\hline $55-64$ & 16 & 2.5 & 6.5 & & \\
\hline All & 94 & 14.6 & 6.5 & 6.4 & $(5.1-7.8)$ \\
\hline \multicolumn{6}{|c|}{ Women and girls } \\
\hline $15-24$ & 51 & 5.7 & 8.9 & & \\
\hline $25-34$ & 56 & 5.8 & 9.6 & & \\
\hline $35-44$ & 59 & 5.7 & 10.4 & & \\
\hline $45-54$ & 40 & 5.9 & 6.8 & & \\
\hline $55-64$ & 7 & 4.7 & 1.5 & & \\
\hline All & 213 & 27.7 & 7.7 & 8.2 & $(6.7-8.7)$ \\
\hline \multicolumn{6}{|c|}{ Survey rounds } \\
\hline 2011-2012 & 118 & 10.7 & 11.1 & 11.4 & $(9.1-13.1)$ \\
\hline $2012-2016$ & 95 & 16.6 & 5.7 & 5.5 & $(4.6-6.9)$ \\
\hline 2011-2016 & 94 & 15.1 & 6.2 & 6.6 & $(5.0-7.5)$ \\
\hline All & 307 & 42.3 & 7.3 & 7.4 & $(6.4-8.1)$ \\
\hline
\end{tabular}

* Using direct standardization, with the health and demographic surveillance system population as the standard population.

Age was a risk factor for incident HIV, with the highest incidence in those aged 25-44 years, for both sexes (table 4). Other risk factors included being widowed or divorced, reporting regular condom use with all partners, and having an HIV-infected spouse. Reported use of ART by the HIV-infected spouse was not associated with incident HIV infection, with CIs overlapping with those of HIVinfected spouses not on ART. Having a circumcised male partner was protective for women and girls, although the protective effect of circumcision was not significant among men and boys (table 4). 341 (6\%) of the 5334 spouses surveyed had HIV infection; 16 (57\%) of the 28 individuals reporting consistent condom use had a spouse who was HIV infected. The aforementioned risk factors for incident HIV 
infection were all identified in univariate analysis, and, if significant in univariate analysis, remained significant in multivariate analysis and after unit imputation (table 4).

In a sensitivity analysis, if we accepted a self-reported status of not being HIV infected in the absence of test results for the individual concerned, HIV prevalence and incidence remained unchanged compared with the main analysis: at enrolment the estimated HIV prevalence changed from $14.6 \%(5213 / 35,733)$ to $14.4 \%$ $(5151 / 35,824)$, and age-adjusted overall incidence remained at 7.4 per 1000 personyears. If we excluded self-reported HIV status, the results changed: HIV prevalence at enrolment was 9\% $(3204 / 33,723)$ instead of $14.6 \%(5213 / 35,733)$. Age-adjusted HIV incidence came down from 7.4 to 4.2 per 1000 person-years overall, from 11.1 to 9.6 per 1000 person-years for 2011-12, and from 5.5 to 2.4 per 1000 person-years for 2012-16. Ignoring self-reported HIV infection thus had the largest influence later in the study period, when a larger proportion of HIV-infected individuals reported their HIV status and thus would lead to a greater observed decline in HIV incidence.

\section{Discussion}

In the period in which ART and VMMC coverage increased most notably, we observed a decline of HIV incidence-by half-in those aged 15-64 years. Between 2011 and 2016, HIV prevalence declined by a third in participants aged 15-34 years, but not among those aged 15-64 years. In participants aged 15-34 years, HIV prevalence is probably primarily determined by HIV incidence in the past 5 to 10 years; whereas in participants aged 35-64 years, HIV prevalence is more likely to reflect HIV incidence over a longer period and the effect of declining excess mortality among HIV-infected individuals. In combination, we conclude that the data are consistent with a declining HIV incidence in 2011-16, in this area, possibly in combination with declining HIV-associated mortality resulting from the scaleup of ART. We plan to do further work to establish mortality trends. Given the decline of HIV incidence to 5.7 per 1000 person-years between 2012 and 2016, the incidence is not close to the elimination target of one per 1000 person-years (25).

The decline of HIV prevalence and incidence cannot be directly attributed to increasing ART and VMMC coverage. Other explanatory factors might include the natural history of the HIV epidemic in eastern Africa, which showed declines of HIV incidence even before the onset of large-scale ART use and expanding VMMC coverage (26). However, increased ART and VMMC coverage have probably been 


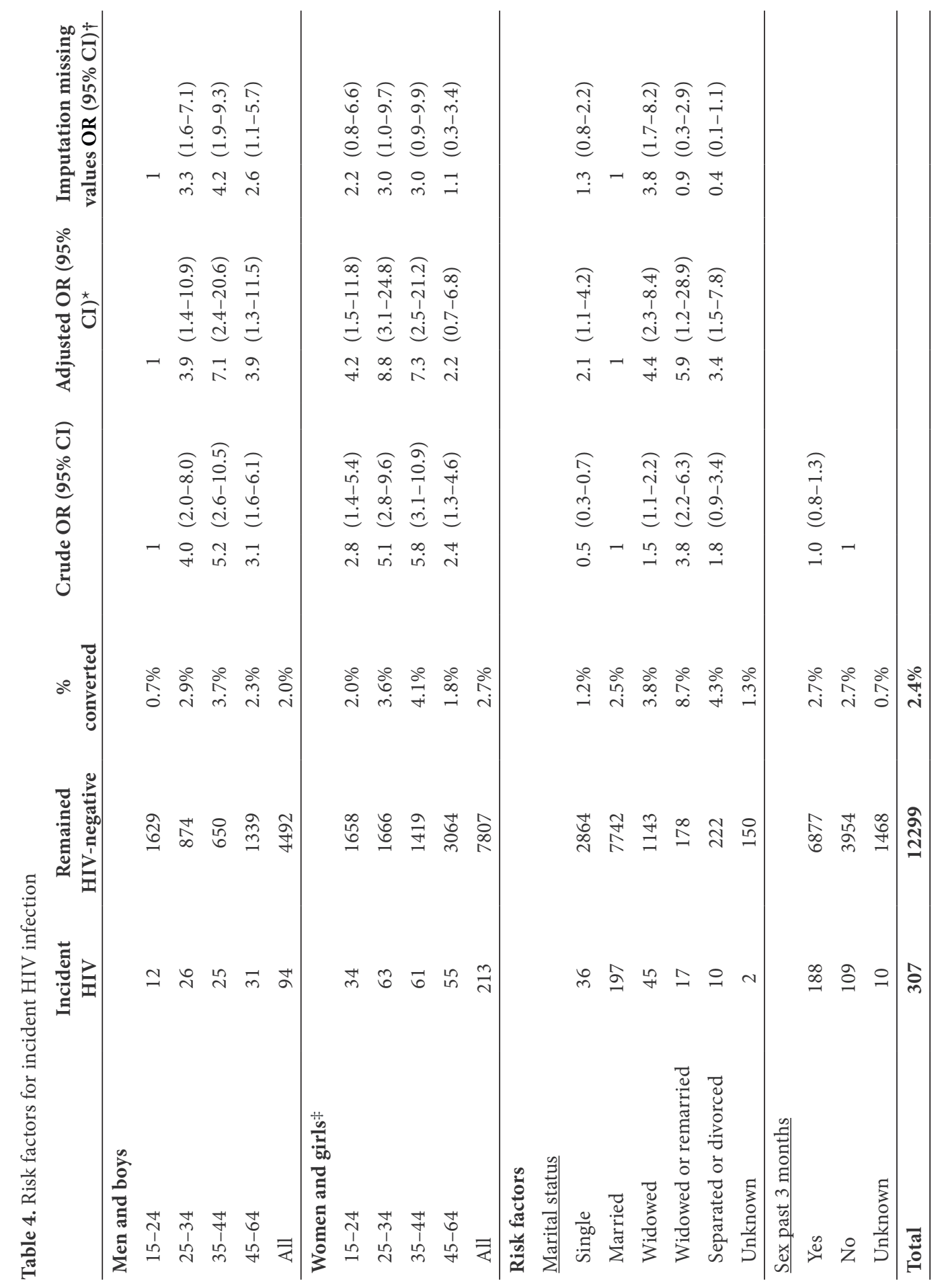


important determinants of declining HIV incidence, given their rapid scale-up in 2011-16 $(14,15,21,22)$ and known efficacy in the reduction of HIV transmission $(4,5,6,7,8,9)$.

The highest HIV prevalence and risk of incident HIV was found in participants of both sexes aged 25-44 years. The younger age at which women and girls acquire HIV infection was seen in the HIV prevalence results. This result was expected, and is attributed, at least in part, to common age differences in sexual partnerships (27). The risk according to marital status was also expected, with the particularly high prevalence among those widowed probably largely explained by death of the previous spouse because of HIV infection. Known HIV infection of a spouse remains a strong risk factor for incident HIV infection, suggesting room for improvement in the reduction of HIV transmission in discordant couples. ART use of the spouse was a risk factor for prevalent HIV, probably because ART was more likely to be prescribed to individuals with long-standing, advanced HIV infection $(16,17)$ and many of these individuals might have transmitted HIV before the onset of ART. In the present study, we suspect ART of the HIV-infected spouse was not associated with reduced risk of HIV infection for the same reasons: ART was more likely to be given to individuals with advanced HIV who were likely to have increased infectiousness. Moreover, the time between the surveys was long, and the onset of ART and degree of immunodeficiency was not well known, limiting our ability to show the protective efficacy of ART in discordant couples.

The protective effect of male circumcision was shown both for prevalent HIV infection in men and boys; however, it was not significant as a protective factor for incident HIV. Women and girls who reported having a circumcised male partner were less likely to acquire HIV infection, presumably because of the reduced HIV prevalence in their partners. This study adds to the evidence regarding the protective effect against HIV infection for female partners of circumcised men described in the meta-analysis (28) by Lei and colleagues. Condom use was not shown to be protective, presumably because condoms were more likely to be used in high-risk situations, such as with HIV-infected partners.

Although HIV incidence failed to reach elimination levels between 2012 and 2016, in this area, HIV incidence might have declined with the rollout of the test-andstart strategy since 2016. Further work is planned to assess progress towards the UNAIDS 90-90-90 targets. A study (29) published in 2017, suggests that linkage to care might be a challenge for the test and start strategy and would be important to monitor. 
Chapter 2. HIV incidence in western Kenya during scale up of antiretroviral therapy 
UNAIDS produces HIV prevalence and incidence estimates at a regional level in Kenya on the basis of the Spectrum model (30). These estimates are further broken down to county level through the use of additional county-specific data (eg, HIV prevalence among antenatal clinic attendees). The estimates are used to inform HIV testing and treatment targets. In 2016, HIV prevalence in the general population aged 15-49 years in Siaya County was estimated at 25\% on the basis of the Spectrum model and at $17 \%$ among antenatal clinic attendees according to routine service delivery data. HIV prevalence in the HBCT survey 2016 in Gem among those aged 15-49 years was $14 \%(1796 / 12,772)$. These discrepancies suggest the need to review the HIV estimates at county level because they might be too high.

This study has various limitations. First, the surveys were done as service provision to identify HIV-infected individuals and link them to care, and were not intended primarily for cohort analysis. Survey participants were not randomly selected. However, given that the HBCT participants represented a large proportion of the eligible population, the prevalence estimates are probably robust. No specific measures were in place to reduce loss to follow-up. The loss to follow-up was high, though not associated with HIV prevalence. The differential participation by age and sex was resolved in the analysis by standardising for age and sex, which had little influence on the incidence estimates. Second, we excluded 51 apparent HIV seroreverters who changed from HIV-positive status to HIV-negative status, because reversion was attributed to data problems of a key variable. Because there were some misclassified reversions, some conversions might have been misclassified and HIV incidence might therefore have been somewhat overestimated. Third, we accepted self-reported HIV infection as evidence of infection in the absence of HIV test results. Excluding self-reported HIV infection would have led to substantially lower HIV prevalence and incidence estimates, in particular later in the study period. Given the positive predictive value of $98 \%$ of self-reported HIV infection, we believe including these people is likely to provide the best estimates of prevalence and incidence. The main finding, with respect to declining HIV incidence, did not depend on the HIV case definition. Fourth, we did not have data available on viral suppression in those receiving ART. Finally, risk factor variables had many missing values, in particular during the first survey, thus limiting our ability to determine their association with prevalent and incident HIV infection.

In conclusion, HIV prevalence in participants aged 15-34 years and the HIV incidence in all adults in this population has declined strongly during the scaleup of ART and VMMC. However, incidence is well above elimination level, and further scale-up of interventions is needed. 


\section{Contributors}

MWB, DK, GO, LAM, EZ-G, and KMDC designed the study. DK, DO, GO, VK, FO, PO, LAM, MES, and EZ-G collected the data. MWB, DK, DO, GO, PO, JM, and RJ managed the data. MWB, DK, DO, GO, RJ, EZ-G, KMDC, and PWY analysed the data. MWB, DO, GO, RJ, MES, EZ-G, and KMDC drafted the Article. All authors were involved in critical revision of the Article and final approval for submission.

\section{Declaration of interests}

We declare no competing interests.

\section{Acknowledgements and disclaimer}

The findings and conclusions in this manuscript are those of the authors and do not necessarily represent the official position of the Centers for Disease Control and Prevention or the US Department of Health and Human Services. This work has been supported, in part, by the President's Emergency Plan for AIDS Relief through the Centers for Disease Control and Prevention. We thank the Director of KEMRI for permission to publish this manuscript. People interested in accessing the data used for this analysis are encouraged to contact the corresponding author. 


\section{References}

1. UNAIDS. Global AIDS update. Geneva: UNAIDS, 2016.

2. GBD 2015 Disease and Injury Incidence and Prevalence Collaborators. Global, regional, and national incidence, prevalence, and years lived with disabilities for 310 diseases and injuries, 1990-2015: a systematic analysis for the Global Burden of Disease Study 2015. Lancet 2016;388:1545-1602.

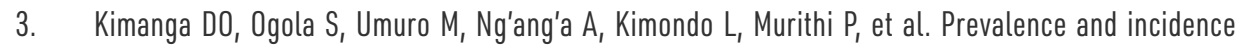
of HIV infection, trends, and risk factors among persons aged 15-64 years in Kenya: results from a nationally representative study. J Acquir Immune Defic Syndr 2014;66(Suppl 1):S13-S26.

4. Cohen MS, Chen YQ, McCauley M, Gamble T, Hosseinipour MC, Kumarasamy N, et al. Anttiretroviral therapy for the prevention of HIV-1 transmission. N Engl J Med 2016;375:830-9.

5. Auvert B, Taljaard D, Lagarde E, Sobngwi-Tambekou J, Sitta R, Puren A. Randomized, controlled intervention trial of male circumcision for reduction of HIV infection risk: the ANRS 1265 Trial. PLoS Med. 2005;2(11):e298.

6. Bailey RC, Moses S, Parker CB, Agot K, Maclean I, Krieger JN, et al. Male circumcision for HIV prevention in young men in Kisumu, Kenya: a randomised controlled trial. Lancet. 2007;369:643-56.

7. Gray RH1, Kigozi G, Serwadda D, Makumbi F, Watya S, Nalugoda F, et al. Male circumcision for HIV prevention in men in Rakai, Uganda: a randomised trial. Lancet. 2007;369:657-66.

8. Gray R, Kigozi G, Kong X, Ssempiija V, Makumbi F, Wattya S, Serwadda D, Nalugoda F, Sewenkambo NK, Wawer MJ. The effectiveness of male circumcision for HIV prevention and effects on risk behaviors in a posttrial follow-up study. AIDS. 2012;26:609-15.

9. Mehta SD, Moses S, Parker CB, Agot K, Maclean I, Bailey RC. Circumcision status and incident herpes simplex virus type 2 infection, genital ulcer disease, and HIV infection. AIDS 2012;26:1141-9.

10. Granich RM, Gilks CF, Dye C, De Cock KM, Williams BG. Universal voluntary HIV testing with immediate antiretroviral therapy as a strategy for elimination of HIV transmission: a mathematical model. Lancet. 2009;373:48-57.

11. Blaizot S, Maman D, Riche B, Mukui I, Kirubi B, Ecochard R, Etard JF. Potential impact of multiple interventions on HIV incidence in a hyperendemic region in Western Kenya: a modelling study. BMC Infect Dis. 2016;16:189.

12. Tanser F, Bärnighausen T, Grapsa E, Zaidi J, Newell ML. High coverage of ART associated with decline in risk of HIV acquisition in rural KwaZulu-Natal, South Africa. Science 2013;339:966-71.

13. Kong X, Kigozi G2, Ssekasanvu J3, Nalugoda F2, Nakigozi G2, Ndyanabo A2, et al. Association of Medical Male Circumcision and Antiretroviral Therapy Scale-up With Community HIV Incidence in Rakai, Uganda. JAMA. 2016;316:182-90.

14. President's Emergency Plan for AIDS Relief (PEPFAR) Kenya. United States Government Agencies and implementing partners. Annual report for the period October 1, 2009 to September 30, 2010. Nairobi: PEPFAR, 2010.

15. PEPFAR Panorama Data System. https://pepfar-panorama.org/. Accessed 8 May 2017.

16. National AIDS and STI Control Programme (NASCOP). Guidelines for Antiretroviral Therapy in Kenya 4th Edition. Vol 2011. Nairobi, Kenya; 2011. 
17. National AIDS and STI Control Programme (NASCOP). Guidelines on Use of Antiretroviral Drugs for treating and Preventing HIV Infection: A Rapid Advice, 2014. Nairobi, Kenya; 2014.

18. National AIDS and STI Control Programme (NASCOP). Guidelines on Use of Antiretroviral Drugs for Treating and Preventing HIV Infection in Kenya 2016. Nairobi, Kenya; 2016.

19. Government of Kenya, Ministry of Health, National AIDS and STI Control Program. National voluntary medical male circumcision strategy, 2009. Nairobi, Ministry of Health, 2009.

20. Government of Kenya, Ministry of Health, National AIDS and STI Control Program. National Voluntary Medical Male Circumcision Strategy, 2014/15 - 2018/19. Nairobi, Kenya 2015.

21. Kenya National Bureau of Statistics, Ministry of Health Kenya, National AIDS Control Council Kenya, Kenya Medical Research Institute, National Council for Population and Development Kenya, the DHS Program, ICF International. Kenya Demographic and Health Survey 2014. Nairobi: Kenya National Bureau of Statistics, 2015. Available at http://dhsprogram.com/pubs/pdf/FR308/FR308.pdf.

22. Galbraith JS, Ochieng A, Mwalili S, Emusu D, Mwandi Z, Kim AA, et al. Status of voluntary medical male circumcision in Kenya: findings from 2 nationally representative surveys in Kenya, 2007 and 2012. J Acquir Immune Defic Syndr 2014;66 Suppl 1:S37-45.

23. Odhiambo FO, Laserson KF, Sewe M, Hamel MJ, Feikin DR, Adazu K, et al. Profile: the KEMRI/CDC Health and Demographic Surveillance System-Western Kenya. Int J Epidemiol 2012;41:977-87.

24. Amornkul PN, Vandenhoudt $H$, Nasokho P, Odhiambo F, Mwaengo D, Hightower $A$, et al. HIV prevalence and associated risk factors among individuals aged 13-34 years in rural western Kenya. PLoS ONE 2009; 4:e6470.

25. Okano JT, Robbins D, Palk L, Gerstoft J, Obel N, Blower S. Testing the hypothesis that treatment can eliminate HIV: a nationwide, population-based study of the Danish HIV epidemic in men who have sex with men. Lancet Infect Dis. 2016;16:789-96.

26. World Bank. Evaluating the evidence for historical interventions having reduced HIV incidence: a retrospective programmatic mapping modelling analysis. Washington DC, World Bank, 2016.

27. Schaefer R, Gregson S, Eaton JW, Mugurungi 0, Rhead R, Takaruza A, Maswera R, Nyamukapa C. Agedisparate relationships and HIV incidence in adolescent girls and young women: evidence from a general-population cohort in Zimbabwe. AIDS. 2017 Apr 19. [Epub ahead of print]

28. Lei JH, Liu LR, Wei Q, Yan SB, Yang L, Song TR, Yuan HC, Lv X, Han P. Circumcision Status and Risk of HIV Acquisition during Heterosexual Intercourse for Both Males and Females: A Meta-Analysis. PLoS ONE. 2015 May 5;10(5):e0125436.

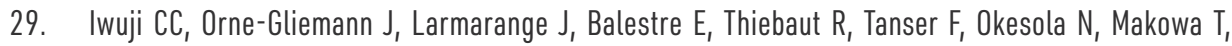
Dreyer J, Herbst K, McGrath N, Bärnighausen T, Boyer S, De Oliveira T, Rekacewicz C, Bazin B, Newell ML, Pillay D, Dabis F; ANRS 12249 TasP Study Group. Universal test and treat and the HIV epidemic in rural South Africa: a phase 4, open-label, community cluster randomised trial. Lancet HIV. 2017 Nov 30. pii: S2352-3018(17)30205-9. [Epub ahead of print]

30. Stover J, Andreev K, Slaymaker E, Gopalappa C, Sabin K, Velasquez $C_{1}$ et al. Updates to the spectrum model to estimate indicators for adults and children. AIDS 2014; Suppl 4:S427-34. 


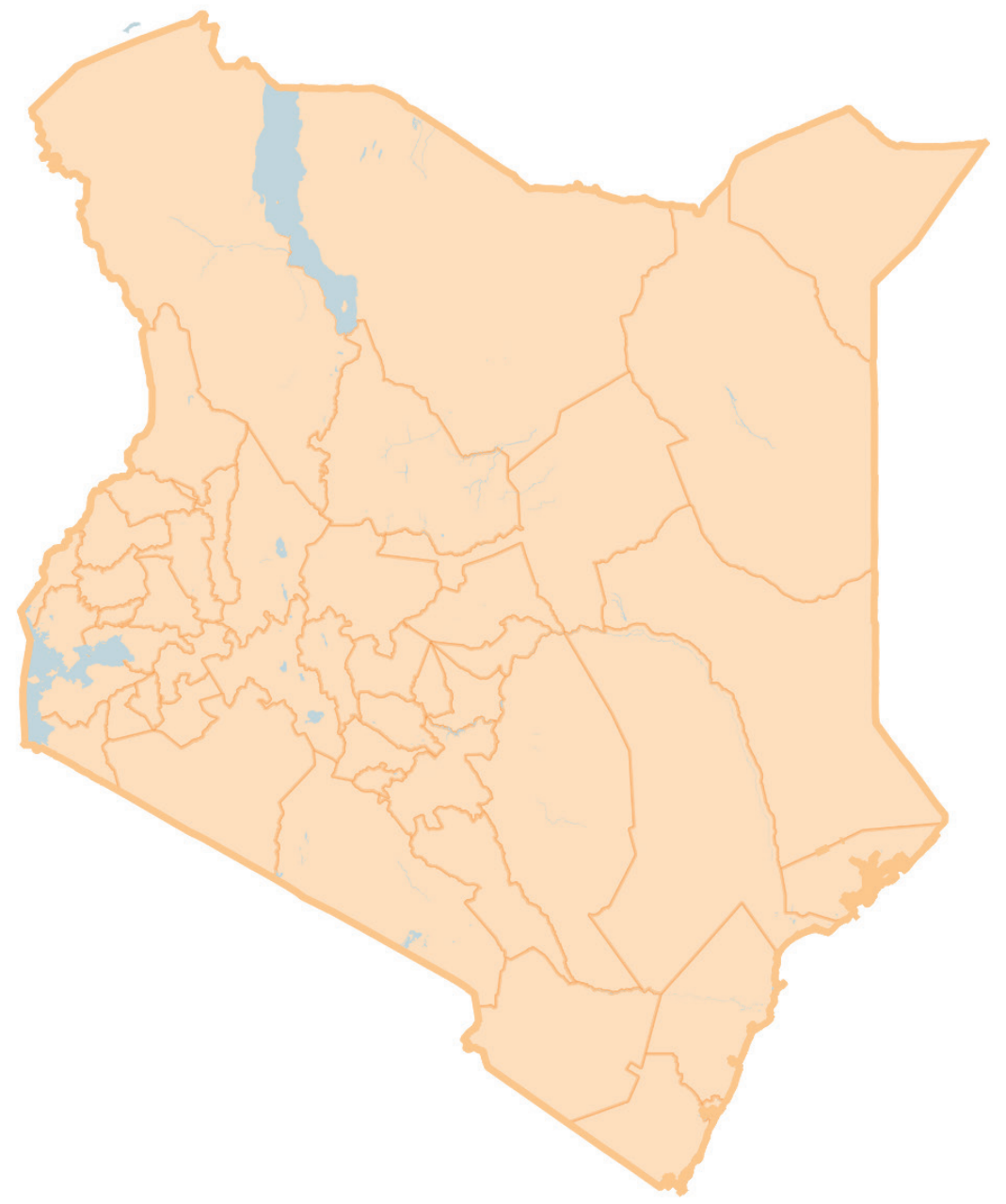




\section{Chapter 3}

\section{Evolution of sub-national HIV estimates for a high-HIV-burden region in Kenya}

Peter W. Young

Emily Zielinski-Gutierrez

Daniel Kwaro

Kennedy Mutai

Samuel Mwalili
Joyce Wamicwe

Joshua Gitonga

Martien W. Borgdorff

Kevin M. De Cock

on behalf of the Kenya HIV Estimates Task Team 


\section{Abstract}

Introduction: According to official estimates, the Nyanza region of western Kenya comprising six high-HIV-burden counties accounted for $38 \%$ of prevalent HIV infections in Kenya in 2015. We iteratively revised epidemic models to obtain realistic HIV estimates for these counties, which is essential for program planning.

Methods: We revised annual estimates using the Spectrum model in 2016 and 2017 , incorporating population-based survey estimates, routine antenatal (RANC) HIV prevalence from monthly facility reports from 2013-17 in the national health information system, and comparing with results from a longitudinal communitybased HIV sero-surveillance activity in Gem sub-county, Siaya County. Countylevel official estimates were disaggregated from Spectrum using a workbook method and small-area estimation.

Results: Adult HIV prevalence estimates for the Nyanza region evolved from $16.1 \%$ (95\% uncertainty interval [UI] 14.5-18.5) in 2015 to $13.3 \%$ (95\% UI, 11.2-15.7) in 2017. Routine antenatal HIV prevalence was found to show similar trends to previous antenatal surveillance data and was incorporated in 2016, along with a new fitting algorithm in Spectrum. In Gem, community-based prevalence estimates were lower than RANC (ratio 0.82); both were significantly lower than the 2016 official estimate of $24.8 \%$ (95\% uncertainty interval 20.0-29.5) for Siaya County. Population projections for Nyanza were adjusted to match official projections in 2017. The updates resulted in a 9\% reduction in estimated adult PLHIV from 537,000 in 2015 to 486,000 in 2017. Revisions to the demographic model and inclusion of RANC accounted for $12 \%$ and $9 \%$ of the reduction in estimated PLHIV in Nyanza, respectively. After revisions, prior treatment targets for all six counties were above 2030 UNAIDS fast-track targets.

Conclusions: The revised official estimates for 2017 for Nyanza show that targets for knowledge of HIV status and antiretroviral treatment coverage based on the 2015 estimates may have been unreachable. Assessing models against high-quality epidemiological data is essential to ensure robust estimates. The inclusion of RANC in models may improve quality of HIV estimates and enable setting of more achievable program targets. 


\section{Introduction}

Kenya is the fifth-highest HIV-burden country in the world, with an estimated 1.5 million people living with HIV (PLHIV) in $2017(1,2)$. The Nyanza region of western Kenya, bordering Lake Victoria and comprising the six high-HIV-burden counties of Kisumu, Homabay, Siaya, Migori, Kisii and Nyamira, was the epicenter of the HIV epidemic with sustained HIV prevalence among adults aged 15-49 years of $14-16 \%$ from 2003-12 according to population-based surveys (3). Nyanza accounted for $38 \%$ of PLHIV, 37\% of all patients on antiretroviral treatment (ART) and $39 \%$ of the estimated unmet need for ART in Kenya in 2015 (4).

Models are increasingly used to estimate the number of PLHIV to set national and sub-national testing, prevention and treatment targets focused on reaching a critical level of treatment coverage and viral suppression. Globally, national HIV estimates are developed through a country-led process coordinated by the United Nations Joint Programme on HIV/AIDS (UNAIDS) that relies on the Spectrum model (Avenir Health, Glastonbury, US) (5) to generate key HIV indicators, which are compiled and published by UNAIDS annually (6). A workbook method has been used in Kenya to generate official estimates for all 47 counties based on Spectrum files representing eight regions corresponding to former provinces, including Nyanza. As programs approach the UNAIDS Fast-Track targets of getting 90\% of PLHIV diagnosed and 90\% of diagnosed PLHIV on treatment by 2020 (7), consistent challenges in achieving these estimates-driven targets have led to questions about the accuracy of the official HIV estimates for these counties.

HIV prevalence in pregnant women from sentinel surveys in antenatal care (ANC) settings has long been used as a proxy for the prevalence of HIV in the adult population in the absence of population-based estimates; direct use of ANC sentinel surveillance (ANCSS) prevalence has been found to over-estimate true population HIV prevalence on average (8). In population-based surveys conducted in sub-Saharan Africa, the prevalence in pregnant women tends to be lower than in other women, though the prevalence was equal or greater in pregnant women than non-pregnant women in Kenyan surveys. These differences are not significant, though precision for estimating prevalence among pregnant women in population-based surveys is limited (9). Antenatal care sentinel surveillance and, starting in 2017, routine antenatal care (RANC) HIV prevalence are key inputs to Spectrum, and RANC data are readily available at high resolution and relatively high completeness for counties in Kenya, especially in the Nyanza region. Despite data quality concerns with RANC data $(10,11)$ we evaluated whether recommended World Health Organization standards were fulfilled by conducting data and 
administrative reviews of antenatal clinics that offered both routine testing and sentinel surveillance in 2010. Results The proportion of tests that were HIV-positive among women aged 15-49 years was $6.2 \%$ (95\% confidence interval [CI] 4.6-7.7 \%] in sentinel surveillance and 6.5\% (95\% CI 5.1-8.0\%, and as of yet limited direct evidence of the relationship between HIV prevalence in RANC and the general population, the use of RANC data as a proxy in Kenya is attractive because fertility (total fertility rate of 3.9), coverage of antenatal care (96\% of pregnancies) and coverage of HIV testing in ANC (92\% of women attending ANC) are high (12). Estimating HIV prevalence from a census of all women receiving RANC avoids some of the limitations of using ANCSS as a proxy for the general population, such as a bias towards larger facilities from predominantly urban areas, though other important biases remain, such as exclusion of men and non-sexually-active women.

Health and Demographic Surveillance Systems (HDSS) exist throughout Africa and provide robust data on relatively small yet well-characterized populations by enumerating their catchment population regularly and conducting active surveillance for demographic events such as births, deaths and in/out-migration. The Kenya Medical Research Institute (KEMRI), in collaboration with the U.S. Centers for Disease Control and Prevention (CDC) has operated an HDSS in Siaya County for nearly 20 years (13); KEMRI has conducted several HIV serosurveillance activities since 2001 in the section of the HDSS located in Gem subcounty; a previous analysis showed declining HIV incidence in this population between 2001-6 (14). Comparing HIV prevalence from community-based surveillance activities within the HDSS with RANC prevalence for the same area could inform the representativeness of RANC prevalence in the region where the HDSS is located.

Given the key programmatic role played by HIV estimates, it is important to assess them thoroughly and compare them with all available data sources. To this end, we reviewed available epidemiological data for the Nyanza region, including RANC data, to update the estimates as part of the annual process led by the Kenya National AIDS Control Council (NACC) and National AIDS and STI Control Programme (NASCOP). As there is presently no "gold standard" external estimate for HIV prevalence for these counties, we first assessed consistency between RANC and ANCSS data, then representativeness of RANC in the region using the HDSS, which in turn required assessing the representativeness of the HDSS HIV prevalence data. After addressing these questions, we compared RANC HIV prevalence to official HIV prevalence estimates for the Nyanza region. We then developed revised estimates for the region, incorporating RANC and using RANC to distribute the regional estimates to the counties within the Nyanza region. 


\section{Methods}

\section{Study design}

In this manuscript we describe the process used by the National HIV Estimates Task Team, convened by NACC and NASCOP, to revise national estimates annually. We have also conducted complementary retrospective analyses of existing data. In order to investigate what RANC HIV prevalence data can tell us about the estimates in the highest-burden counties, we assembled the following estimates and data: i) monthly RANC from facility reports from 2013-17 submitted to Kenya's national health information system (district health information system [dhis2] (15)) for all health facilities reporting in the six counties in the Nyanza region and ii) HIV prevalence from a community-based HIV sero-surveillance activity that screened persons aged 15-64 years in Gem sub-country of the KEMRI HDSS sub-county, Siaya County in four survey rounds between 2011 and 2016; iii) annual county-level HIV prevalence estimates for 2014-17 indirectly estimated from a mathematical model by the national HIV estimates task team. NACC publishes national estimates annually via the UNAIDS global reporting process, and county estimates every two years, most recently in 2018, through a national County Estimates report (4).

Given the community-based sero-surveillance activity in Gem HDSS provides a recent estimate of general adult HIV prevalence for a well-defined, if limited, geographic area, we first looked at its similarity with respect to the sub-county of Gem and Siaya County as a whole. We used data on current pregnancy among female DSS participants to assess the relationship between HIV prevalence and pregnancy status in this population. Then we used RANC data to compare HIV prevalence in pregnant women accessing ANC between the Gem HDSS, Gem sub-county and Siaya County. We then compared the RANC estimates to official county and regional estimates for Nyanza. We also compared the RANC to official Spectrum estimates for Nairobi County.

\section{Data sources}

\section{Health and Demographic Surveillance System sero-surveillance activity:}

The HDSS has operated continuously by KEMRI since 2002 (Figure 1), encompassing three areas within Siaya County (13). A population census is conducted twice annually, including births, deaths and migrations. We worked with data from Gem, one of the three HDSS areas, which in 2014, included 89,225 persons. To increase treatment coverage, KEMRI has conducted repeated rounds of door-to-door HIV sero-surveillance in 2011, 2012, 2014 and 2016 within the Gem catchment area. Each round attempted to cover as many households as possible, given available test 
kits, time and funding. The activities targeted all residents aged 13 years and older, collected knowledge of status, and offered rapid HIV testing as per the national diagnostic algorithm. In 2011 and 2012, the national algorithm allowed for the use of two distinct parallel tests (Determine ${ }^{\mathrm{m}}$ [Alere, Orlando, Florida, USA], and SD Bioline HIV-1/2 3.0 [Standard Diagnostics, Giheung-gu, Gyonggi-do, Republic of Korea]) followed by a third tie-breaker in case of discrepant results (Uni-gold ${ }^{\text {tw }} H I V$ [Trinity Biotech, Bray, Co Wicklow, Ireland]). During the 2013-14 round, a serial three-test procedure was used, including a screening test (Colloidal Gold [KHB Shanghai Kehua Bio-engineering, Ltd, Shanghai, China], replaced by Determine ${ }^{\mathrm{mm}}$ in 2015), a confirmatory test (First Response ${ }^{\mathrm{mw}}$ [Premier Medical Corporation, Nadi Daman, India]), and a tie-breaker for discrepant results (Uni-gold $\left.{ }^{\text {mit }} H I V\right)$ (16). In 2015, the national diagnostic algorithm was updated to a serial two-test procedure consisting of Determine $^{\mathrm{mw}}$ followed by First Response ${ }^{\mathrm{m}}$ as a confirmatory test, with repeat testing by a separate tester in the case of inconclusive (discrepant) results, and for confirming all positives before treatment initiation, and DNA PCR at a central lab to resolve repeatedly inconclusive results (17). Results were recorded and linked back to the resident's HDSS identifier. HIV status (either self-reported known-positive or HIV test result) was tabulated for participants aged 15-49 years independently for each round for this analysis. For female participants, we included current pregnancy status if they had participated in a biobehavioral survey within +/- 30 days of their HIV test in the 2016 round. Borgdorff et al. have previously described this dataset in more detail, including analyses conducted to establish the cohort's representativeness (14).

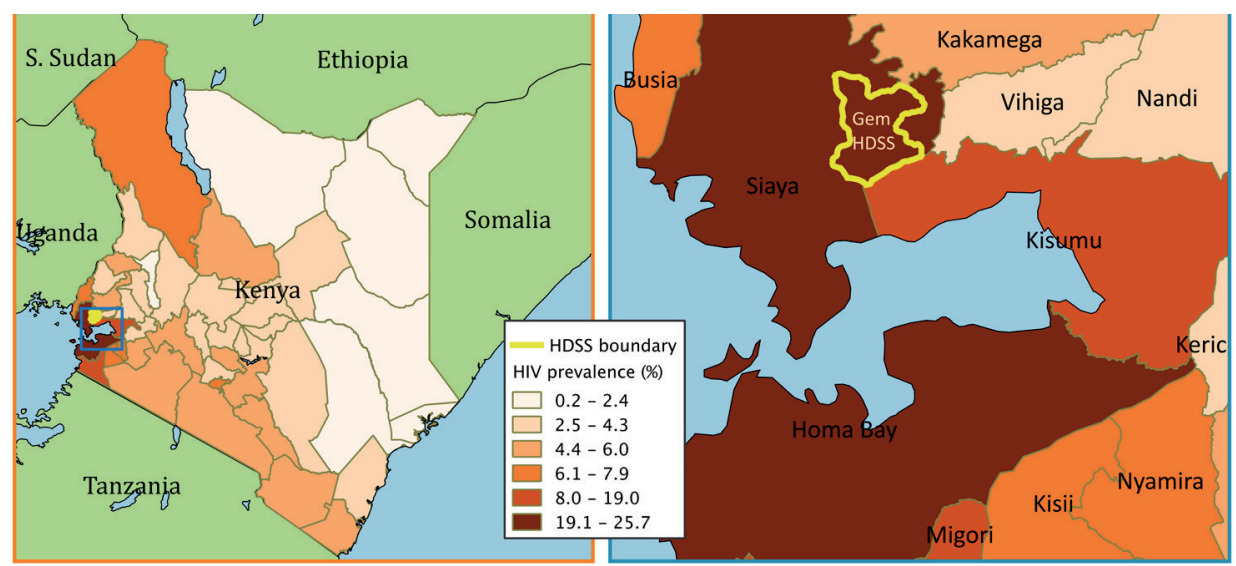

Figure 1. Location of the KEMRI health and demographic surveillance site (HDSS), Gem area in Gem sub-county, Siaya County, Kenya

Notes: HIV prevalence from official 2015 county estimates; shape files courtesy of http:// naturalearthdata.com and KEMRI. 


\section{Routine ANC HIV prevalence:}

Women attending antenatal care at public health facilities in Kenya are routinely offered free rapid HIV testing following the national HIV diagnostic rapid test algorithm, as described above. All public facilities and many larger private facilities report aggregate monthly indicators to dhis2, including the number of women seen at first ANC visit, the number of women tested in ANC, number of positive tests in ANC, and number of women with known HIV-positive status at first ANC. Routine ANC HIV indicators were cleaned by reviewing monthly reports from dhis 2 for consistency and excluding monthly reports that showed clear signs of artifacts that would bias prevalence estimates (See Text S1, which provides a summary of the cleaning steps, their rationale, and the number of reports excluded during cleaning). After cleaning, we aggregated the RANC data by year and county, then for Nyanza as a whole, producing pooled estimates self-weighted by the number of pregnant women tested at each site. As routine ANC HIV testing is not reported by age bands, we did not restrict the analysis to women in a specific age group, though generally few women below age 15 or over age 49 years are seen in ANC settings in Kenya. We included results for 2014-17 in this analysis. We multiplied RANC HIV prevalence by the county-specific population projections used for the official Kenya HIV estimates to obtain hypothetical estimates of the population size of PLHIV aged 15 years and above. As this approach likely over-estimates HIV prevalence in older age groups by assuming the prevalence among those aged 50 years and older is the same as those aged 15-49 years, it produces a slight over-estimate of PLHIV, which is conservative for purposes of this analysis.

\section{Official estimates:}

Spectrum's Estimates and Projections Package (EPP) models the force of infection over time as a function of population, numbers of adults on ART based on reports from dhis2, HIV prevalence among pregnant women at sentinel sites, populationbased sero-surveys, and more recently, HIV prevalence from routine testing in antenatal settings at either sentinel sites or all sites in a geographic area. The methods are described in detail elsewhere $(5,18,19)$. The version of Spectrum used to generate the 2015 County estimates (5.441) did not yet allow the inclusion of RANC in the model, while the version used for 2016 (5.563) and 2017 estimates (5.63) does. Spectrum projections were developed annually for regions (former provinces of Kenya) such as Nyanza or Nairobi; we then used a bespoke structured Excel $^{\triangleright}$ workbook to assign weights to each county and disaggregate indicators such as HIV prevalence, PLHIV and need for prevention of mother-to-child transmission (PMTCT) to the county level. In the case of Nyanza starting in 2016, the weights were set using a small-area estimates model designed to predict HIV prevalence from the 2012 Kenya AIDS indicator survey (KAIS 2012) based on a multivariate 
regression model incorporating RANC and percent of county population residing in rural areas. In prior years weights were distributed based on manual selection of a method based on an arithmetic average, linear regression, or other method based on recent Demographic and Health Surveys, AIDS Indicator Surveys, ANCSS or RANC data. These weights were then used to distribute PLHIV to the counties, ensuring the total PLHIV estimate (age 15+) equals the Spectrum estimate for the region. Spectrum also provides estimates of HIV infection among pregnant women generated from age-specific fertility rates, reductions in the same due to HIV infection, and age-specific HIV prevalence among women aged $15-49$ years $(5,20)$. County estimates for alternate years $(2013,2015,2017)$ were validated through national and county-level consultations and published in an annual County HIV Estimates report $(2,4,21)$.

To convey uncertainty in the model-based estimates, we used the Spectrum 95\% uncertainty interval for Nyanza, which is generated by Monte Carlo simulation and reflects uncertainty in estimated HIV prevalence and other model parameters (18). Uncertainty intervals were calculated for official county estimates by computing a regional sample size and distributing it among the counties. The county estimates that result from this process are point estimates that are not meant to be interpreted as trends at the county level. We used the resulting annual county estimates of HIV prevalence for 15-49 year olds as well as PLHIV aged 15 years and above from the workbook from 2014-17, the most recent years for which county estimates were published, along with the Spectrum estimates for the entire region of Nyanza for the same years.

\section{Program targets:}

Regional program targets for the U.S. President's Emergency Plan for AIDS Relief (PEPFAR) were extracted from publicly-available PEPFAR dashboards (www.pepfar.net) for fiscal year 2018 for total adults aged 15+ years currently on treatment by the end of period (i.e. September 30 ).

\section{Population projections:}

We analyzed the base demographic population used in Spectrum and compared with official population projections obtained from the Kenya National Bureau of Statistics to identify differences that could impact estimates. 


\section{Data analysis:}

Official estimates, dhis 2 data, and Spectrum uncertainty analyses were extracted, processed and visualized in the R program $(22,23)$. To assess the impact of changes to the model and inputs on estimates, we incrementally backed-out updates to Spectrum and source data, tabulated resulting estimates and calculated incremental increases or decreases in estimates for each change.

\section{Ethical considerations}

The data used in this analysis were all collected for other purposes. The KEMRI HDSS HIV home-based counseling and testing program and longitudinal biobehavioral surveillance were approved by the KEMRI and CDC ethics review boards. The 2012 KAIS survey was approved by the KEMRI Scientific and Ethics Review Unit and by the CDC Institutional Review Board (\#6189), and the Committee on Human Research of the University of California, San Francisco. No personally identifiable data were accessed or used for this analysis.

\section{Results}

In August 2015, we conducted an assessment of the consistency between RANC HIV prevalence and ANCSS for Kenya based on the aggregated annual RANC HIV prevalence from the former ANC sentinel sites, which found that with some exceptions, the RANC prevalence appeared to behave consistently with recent ANC trends, with some outliers (Figure 2 panel A). Based on this assessment, the team began including county-level pooled RANC prevalence from 2012-14 onwards in data visualizations used for choosing weights to disaggregate Spectrum estimates to counties. In addition, annual RANC data, both for former ANCSS sites as well as pooled for the Spectrum regions from 2013 onwards, were subjected to additional data cleaning (see text S1) and included in EPP starting in 2017, after EPP was updated to allow their use in model fitting. These data were also used to set weights for distributing estimates for the Nyanza region starting in 2017 by applying a small-area estimates model.

Figure 2 panel B shows the comparison of KEMRI HDSS, Gem sub-county and Siaya County RANC HIV prevalence estimates. Gem sub-county RANC estimates are lower than those seen for Siaya County as a whole in 2015 (14.9\% for the Gem HDSS area compared to $17.1 \%$ for Siaya County in 2015). The RANC prevalence for facilities within the Gem HDSS area is similar to the RANC prevalence in the 

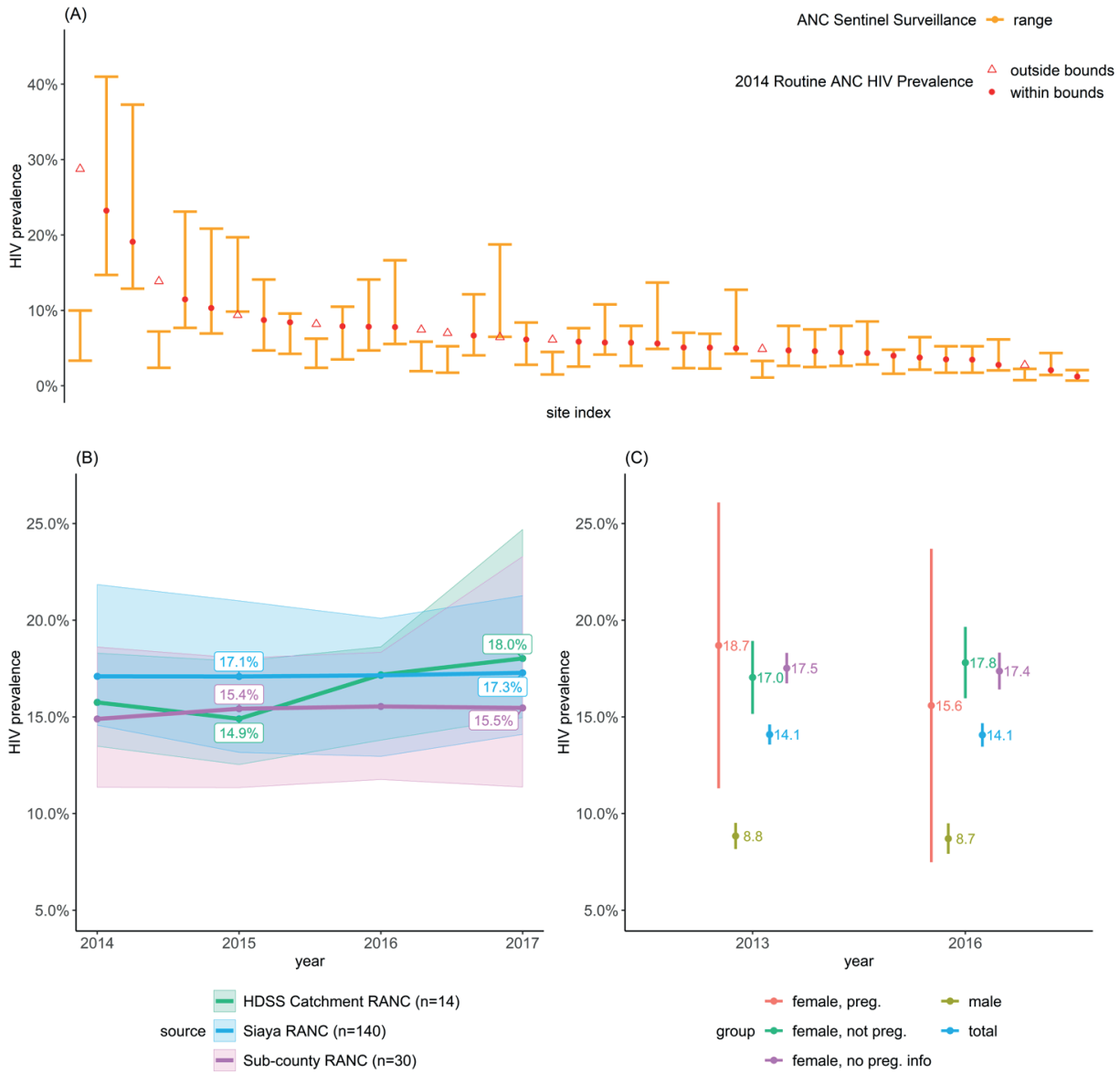

Figure 2. Routine antenatal care (RANC) HIV prevalence, and sero-surveillance HIV prevalence from the Gem area HDSS, Gem sub-county, and Siaya County, 2011-16

Notes: Panel A shows 2014 routine antenatal (RANC) HIV prevalence compared with ranges based on historical antenatal sentinel surveillance (ANC SS) observations, by site in decreasing order of prevalence. The ranges are computed as a minimum of 0.5 times the 2011 ANC SS value to either a maximum of 1.5 times the 2011 ANC SS value or the maximum ANC SS value ever observed, whichever is lower. Values outside the range are shown as hollow triangles. Panel B shows routine antenatal care (RANC) HIV prevalence estimates aggregated for the facilities within the HDSS catchment area, along with interquartile ranges across facilities, for all facilities in Gem sub-county, and Siaya County as a whole. HIV prevalence in pregnant women is broadly similar across these three overlapping areas. Panel C shows how HIV prevalence from the sero-surveillance activity among 15-49 year olds in Gem varies by pregnancy status from the longitudinal bio-behavioral survey. HIV prevalence in pregnant women is similar to nonpregnant women (and women without pregnancy data) and higher than the total prevalence in both 2013 and 2016 surveys. 
entire sub-county of Gem (14.9\% versus 15.4\%), though it increases in 2016 to approximately equivalent with Siaya County overall, while the sub-county RANC prevalence remains stable between 2015 and 2016.

Examining HDSS HIV prevalence from four survey rounds, 28,532 adults aged 1549 years participated in $2011,16,875$ participated in 2012, 21,197 participated in 2013 , and 15,627 participated in the 2016 round of the sero-surveillance activity. In 2016, 1,734 women had matched pregnancy status from the longitudinal biobehavioral surveillance; HIV prevalence was not significantly different between pregnant women (15.6\%) and non-pregnant women $\left(17.8 \%, \chi^{2}=0.120, \mathrm{df}=1\right.$, $\mathrm{p}=0.729)$ though both were higher than among men $(8.7 \%)$ in $2016\left(\chi^{2}=106.2\right.$, $\mathrm{df}=2, \mathrm{p}<0.0001)$. Routine ANC prevalence for Gem was similar to that seen in the surveillance activity among women in both 2013 and 2016 (Figure 2, panels B \& C). In sum, this provides evidence that RANC may be a reasonable estimate for HIV prevalence in adult women in this area, but an over-estimate for combined HIV prevalence in men and women.

Comparing the HIV prevalence in adults aged 15-64 years from the most recent national AIDS indicator survey for the Nyanza region, the HIV prevalence in adults aged 15-49 years in Nyanza was 15.7\% (95\% CI 12.0-19.5\%) in 2012 versus $15.4 \%$ (95\% UI 14.1-17.0\%) in 2012 based on the Spectrum projection.

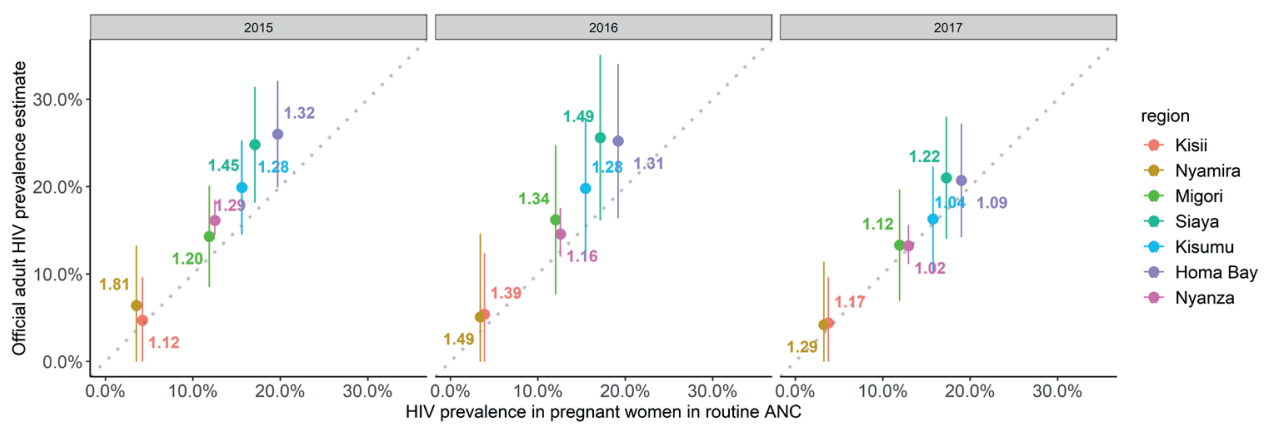

Figure 3. Comparison of HIV prevalence estimates for Nyanza region, Kenya, 2014-17

Notes: Official HIV prevalence estimates and HIV prevalence in pregnant women in routine ANC settings (RANC) are shown for the Nyanza region and counties for 2015-17. Uncertainty bounds are shown for official prevalence estimates. The center line represents equality between estimates, with points above/left of the line having greater estimates than RANC. Points are labeled with the ratio of estimates to RANC. 
The ratio between adult HIV prevalence in the HDSS to the RANC prevalence in the HDSS catchment area was 0.82 (14.1\% versus $17.2 \%)$ in 2016 . Noting that recent RANC HIV prevalence over-estimates adult HIV prevalence in Gem, we proceeded to compare official county estimates derived from Spectrum and Nyanza region Spectrum estimates to RANC for those areas. The evolution of official prevalence estimates and RANC estimates for Nyanza as a whole and the corresponding counties from 2015 to 2017 are shown in Figure 3. All of the ratios are greater than one and range from 1.12 to 1.81 in 2015 and 1.04 to 1.29 in 2017. If we restrict the analysis to pregnant women in Spectrum rather than all adults, the ratio is 1.32 for Nyanza in 2015 and 1.12 in 2017. Thus Spectrum estimates were consistently higher by $12-81 \%$ for the highest HIV-prevalence counties and the highest HIVprevalence region in Kenya in 2015, with the ratio reducing over time to $4-29 \%$ greater in 2017.

If we convert this analysis to look at absolute numbers of PLHIV instead of HIV prevalence, we see that Spectrum estimated there to be 537,000 PLHIV aged 15 years and above in Nyanza in 2015 (Figure 4). If we were to recalculate the burden of HIV using the RANC HIV prevalence instead of the Spectrum-based estimates, we would have a reduction of 108,000 PLHIV in this year in the region. The total reduction would be slightly larger after including children ( $<15$ years). In the estimates for 2016, the first year in which Spectrum estimates include RANC as an input, the over-estimate declines to 105,000, and in 2017 it further declined to 16,000. Such an analysis assumes RANC is an unbiased estimate for adult HIV prevalence, whereas true HIV prevalence may be lower than RANC based on the evidence from the HDSS, which would result in a greater reduction. 


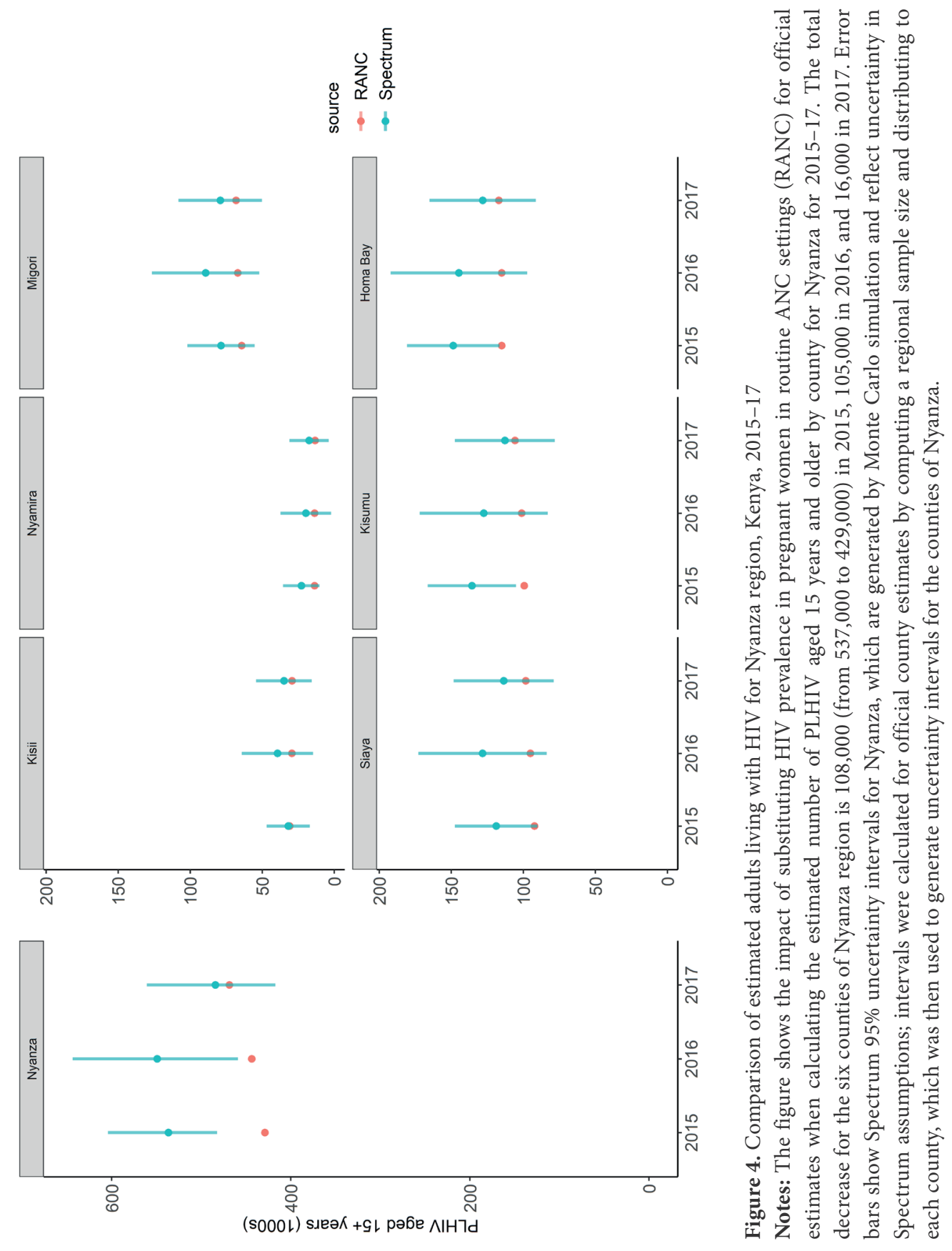


When assessing program targets against estimated PLHIV, we found that three out of six counties' targets for currently on treatment by Sep 30, 2018 were unachievable (i.e. > 100\%) based on 2017 estimates of PLHIV aged 15+ years (Figure 5).

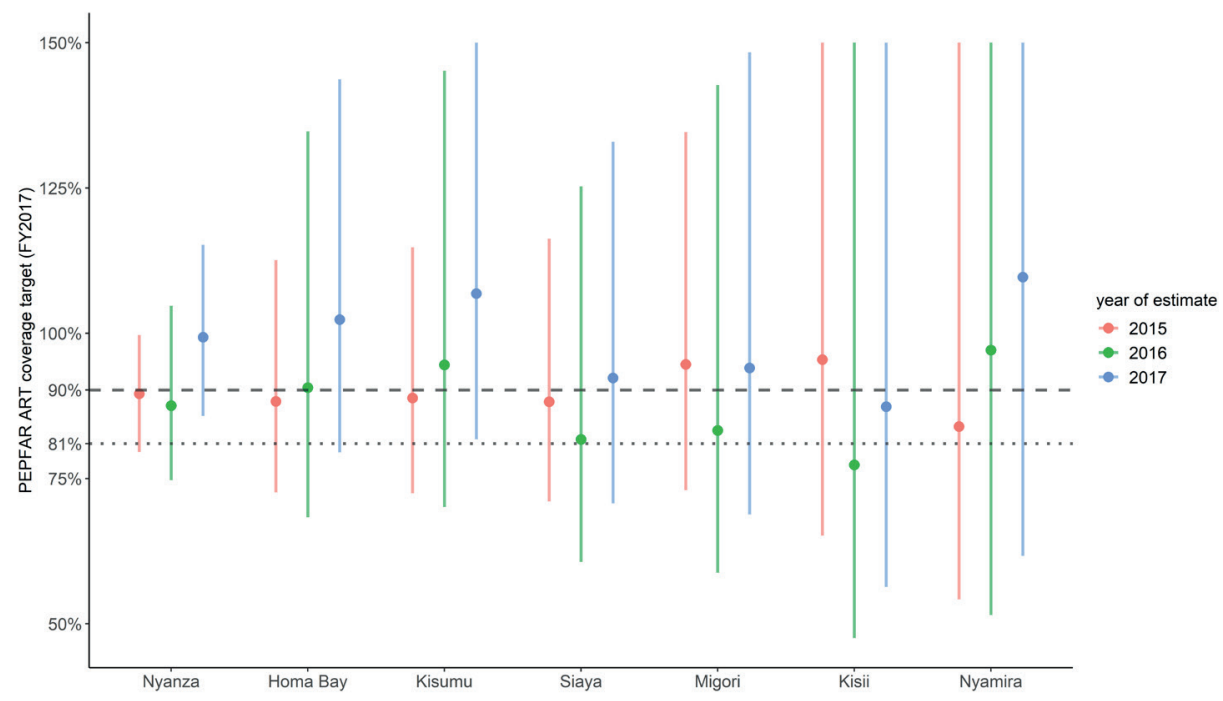

Figure 5. Coverage of PEPFAR antiretroviral treatment targets with estimated PLHIV aged 15+ years, 2015-17, Nyanza region

Coverage targets were computed by dividing PEPFAR fiscal year 2018 antiretroviral treatment (ART) targets by estimated PLHIV aged 15+ years for each County and Nyanza as a whole (confidence intervals are truncated at $150 \%$ coverage for display purposes). The UNAIDS Fast-Track targets for 2020 of $81 \%$ ART coverage, and for 2030 of $90 \%$ ART coverage of all PLHIV are shown for comparison purposes.

\section{Sensitivity analysis}

Our sensitivity analysis of the effects of data cleaning on estimated HIV prevalence in RANC showed that the cleaning steps had a modest impact on HIV prevalence, especially in more recent years (Table S1).

\section{Influence of model inputs and attributes on outputs}

To understand how and why the sub-national estimates evolved from the 2015 to 2017 versions, we incrementally removed model changes and assessed the incremental change in estimated adult PLHIV in Nyanza in 2015. Based on this analysis, matching the population to the Kenya National Bureau of Statistics projected population ( $12 \%$ reduction) and addition of RANC to the model ( $9 \%$ 
reduction) were the most influential changes to the model. The model was also sensitive to changing assumptions about the ratio of incidence between pregnant women and all adults (Text S2, Table S3).

\section{Discussion}

Inclusion of routine $\mathrm{HIV}$ testing in $\mathrm{ANC}$, HIV prevalence in the national and county estimation process, along with other model improvements introduced over time have led to reductions in estimated HIV prevalence and PLHIV in the highestburden region of Kenya. Compared with RANC, estimated PLHIV were 29\% greater overall for Nyanza, equivalent to 108,000 adults aged 15 or more years living with HIV. After the inclusion of RANC prevalence in the model-fitting procedure in Spectrum along with other updates to the model, 2017 official estimates were $2 \%$ greater than pooled RANC prevalence for Nyanza as a whole.

The Spectrum estimates in Nyanza for 2012 closely match the survey-based estimate, which is as expected given that EPP uses the survey estimates in the fitting process. Although population-based surveys are currently the gold standard for estimating population HIV prevalence in high-burden countries and areas, they suffer from limitations, including participation and response biases. As target-setting for HIV programs usually happens annually, survey-based estimates are often out of date before new estimates are available. Due to the expense and time required, survey estimates are often not available for all desired sub-national areas or sub-populations such as adolescents, needed for planning purposes. Thus reliance on model-based estimates is likely to continue as they provide a costeffective, scalable and more easily updated program planning input.

It is crucial to ensure models are optimized, include all available relevant data, and are calibrated against other useful sources of information where available. Although the uncertainty interval from Spectrum includes the RANC HIV prevalence in some areas and years, uncertainty intervals are unfortunately often ignored in practice when setting program targets, with the point estimates taken as a fixed parameter rather than an estimated quantity measured with uncertainty. In the future, methods for incorporating uncertainty into workbook-based disaggregation of Spectrum estimates, such as those presented here, should be adopted and extended, though it is not clear how uncertainty could be built into program target-setting. The consistently lower prevalence in RANC versus among pregnant women in Spectrum indicates that while the model may fit historical survey estimates reasonably well, and appears considerably improved by the introduction of RANC data, it may not 
yet be optimally fit to the current epidemic in the highest-burden region of Kenya, and that better data on fertility patterns among HIV-infected women may further improve estimates. In addition to supporting impact evaluation, longitudinal population surveillance data such as that provided by HDSS sites can be used to understand changes over time in the population's age and fertility structure, which can impact model assumptions.

Our analysis was subject to several limitations. The available data sources did not align perfectly by period, age group, or geographic area. We also chose to focus on the counties within the Nyanza region. Future analyses could extend this work to include other counties, though the Gem HDSS findings may not be generalizable to areas with different demographic structure or epidemiological patterns. Routine data from dhis 2 are less than $100 \%$ complete; however, a sensitivity analysis did not find significant biases due to the exclusion of incomplete records. Differences in test algorithms between settings could partially explain differences in resulting prevalence estimates. However, although national HIV testing algorithms evolved over the period, both RANC and HDSS estimates were based on the same national algorithms, thus the algorithm is unlikely to lead to significant differences between these data sources.

Unoptimized estimates could bias assessments of program coverage and performance and lead to suboptimal allocation of resources between interventions and geographic areas. We believe that our results highlight the value of data comparison and calibration for assessing model-based estimates of HIV in the real world. Inclusion of available local-level data, such as Kenya's RANC and HDSS data, when understood in the context of available population-based survey data, can serve a critical role to supplement the estimates from global models. Our observations in Nyanza help ground discussions of appropriate service-delivery targets for these highest-burden counties. 


\section{Competing interests}

The authors declare no conflicts of interest.

\section{Collaborators}

Kenya HIV estimates task team develops national HIV estimates and is convened by the National AIDS Control Council (NACC), chaired by NACC and the National HIV \& STI Control Programme (NASCOP), and is comprised of representatives nominated from stakeholder organizations including Kenya Ministry of Health, Kenya National Bureau of Statistics, National CDC, USAID, UNAIDS, UNICEF, National Empowerment Network of People Living with HIV and AIDS in Kenya (NEPHAK).

\section{Acknowledgments}

We are grateful to the Ministry of Health for leadership and support of the Kenya HIV estimates process, and to the UNAIDS reference group on estimates and projections for valuable technical assistance and support over the years, as well as the stakeholder organizations that have supported their staff to participate in the Kenya HIV estimates task team.

\section{Funding}

This work has been supported in part by the President's Emergency Plan for AIDS Relief (PEPFAR) through the U.S. Centers for Disease Control and Prevention (CDC). The funders had no role in drafting or submitting this manuscript.

\section{Authors' contributions}

PWY, EZG and KDC drafted the manuscript, PWY designed and conducted the primary data analysis and prepared figures and tables, JW and JG assisted with interpretation of results and manuscript revision, $\mathrm{KM}$ and $\mathrm{SM}$ developed the method for generating confidence intervals for sub-national estimates, DK advised on interpretation and use of the KEMRI Gem DSS data, DK and MWB assisted with data management for the KEMRI Gem HDSS data. All authors read and approved the final manuscript. 


\section{References}

1. AIDSinfo team. AIDSinfo. 2017 [cited 2017 May 5]. Available from: http://aidsinfoonline.org

2. National AIDS Control Council, National AIDS and STI Control Programme. Kenya HIV estimates report 2018. Nairobi; 2018.

3. Kimanga D0, Ogola S, Umuro M, Ng'ang'a A, Kimondo L, Murithi $P$, et al. Prevalence and Incidence of HIV Infection, Trends, and Risk Factors Among Persons Aged 15-64 Years in Kenya. JAIDS J Acquir Immune Defic Syndr. 2014 May;66:S13-26. doi: 10.1097/QAl.0000000000000124

4. National AIDS Control Council NA and SCP. Kenya HIV Estimates, 2015. Kenya; 2016 0ct.

5. Stover J, Andreev K, Slaymaker E, Gopalappa C, Sabin K, Velasquez C, et al. Updates to the Spectrum model to estimate key HIV indicators for adults and children. AIDS. 2014;28(4):S427-34. doi: 10.1097/QAD.0000000000000483

6. Mahy M, Brown T, Stover J, Walker N, Stanecki K, Kirungi W, et al. Producing HIV estimates: From global advocacy to country planning and impact measurement. Glob Health Action. 2017;10(1). doi: 10.1080/16549716.2017.1291169

7. UNAIDS. Fast-track: ending the AIDS epidemic by 2030. Geneva, Switzerland; 2014.

8. Marsh $K$, Mahy M, Salomon JA, Hogan DR. Assessing and adjusting for differences between HIV prevalence estimates derived from national population-based surveys and antenatal care surveillance, with applications for Spectrum 2013. AIDS. 2014 Nov;28(August):S497-505. doi: 10.1097/QAD.0000000000000453

9. Eaton JW, Rehle TM, Jooste $S$, Nkambule R, Kim AA, Mahy M, et al. Recent HIV prevalence trends among pregnant women and all women in sub-Saharan Africa: Implications for HIV estimates. AIDS. 2014;28(June):S507-14. doi: 10.1097/QAD.0000000000000412

10. Sirengo M, Rutherford GW, Otieno-Nyunya B, Kellogg TA, Kimanga D, Muraguri N, et al. Evaluation of Kenya's readiness to transition from sentinel surveillance to routine HIV testing for antenatal clinicbased HIV surveillance. BMC Infect Dis. 2016 Dec 5;16(1):113. doi: 10.1186/s12879-016-1434-1

11. Seguy N, Hladik W, Munyisia E, Bolu O, Marum LH, Diaz T. Can data from programs for the prevention of mother-to-child transmission of HIV be used for HIV surveillance in Kenya? Public Heal Rep. 2006;121(6):695-702. Available from: http://www.ncbi.nlm.nih.gov/pmc/articles/PMC1781911/

12. Kenya National Bureau of Statistics (KNBS). Kenya Demographic and Health Survey 2014. Nairobi; 2015. Available from: https://dhsprogram.com/pubs/pdf/fr308/fr308.pdf

13. Odhiambo FO, Laserson KF, Sewe M, Hamel MJ, Feikin DR, Adazu K, et al. Profile: The KEMRI/CDC Health and Demographic Surveillance System--Western Kenya. Int J Epidemiol. 2012;41(4):977-87. doi: $10.1093 /$ ije/dys 108

14. Borgdorff MW, Kwaro D, Obor D, Otieno G, Kamire V, Odongo F, et al. HIV incidence in western Kenya during scale-up of antiretroviral therapy and voluntary medical male circumcision: a populationbased cohort analysis. Lancet HIV. 2018 May;5(5):e241-9. doi: 10.1016/S2352-3018(18)30025-0

15. District Health Information System Version 2 (DHIS2). Open Health News. 2017. Available from: http://www.openhealthnews.com/resources/district-health-information-system-2-dhis2

16. Ministry of Health and Sanitation, Kenya. National Guidelines for HIV Testing and Counselling in Kenya. Nairobi, Kenya; 2008. 
17. Odhiambo JO, Kellogg TA, Kim AA, Ng'ang'a L, Mukui I, Umuro M, et al. Antiretroviral Treatment Scaleup Among Persons Living With HIV in Kenya: Results From a Nationally Representative Survey. J Acquir Immune Defic Syndr. 2014;66(Suppl 1):S116-22. doi: 10.1097/QAI.0000000000000122

18. Stover J, Johnson $P_{1}$ Hallett $T_{1}$ Marston M, Becquet $R_{1}$ Timaeus IM. The Spectrum projection package: improvements in estimating incidence by age and sex, mother-to-child transmission, HIV progression in children and double orphans. Sex Transm Infect. 2010;86 Suppl 2:ii16-ii21. doi: 10.1136/ sti.2010.044222

19. Brown $T$, Bao L, Eaton JW, Hogan DR, Mahy M, Marsh K, et al. Improvements in prevalence trend fitting and incidence estimation in EPP 2013. AIDS. 2014 Nov;28:S415-25. doi: 10.1097/ QAD.0000000000000454

20. Chen W-J, Walker N. Fertility of HIV-infected women: insights from Demographic and Health Surveys. Sex Transm Infect. 2010;86(Suppl 2):ii22-7. doi: 10.1136/sti.2010.043620

21. National AIDS Control Council (NACC), National AIDS and STI Control Programme (NASCOP). Kenya HIV Estimates, 2014. Kenya: NACC; 2014 Jun [cited 2016 Aug 20]. Available from: http://reliefweb. int/sites/reliefweb.int/files/resources/HIV estimates report Kenya 2014_print.pdf

22. Team RDC. R: A Language and Environment for Statistical Computing. Vienna, Austria; 2011. Available from: http://www.r-project.org/

23. Wickham H. ggplot2: elegant graphics for data analysis. New York, NY: Springer New York; 2009. doi: 10.1007/978-0-387-98141-3 


\section{Supplemental materials}

\section{Text S1. Data cleaning steps and sensitivity analysis for routine antenatal care (RANC) HIV testing}

Analysis of aggregate data requires careful data cleaning to ensure the validity of results. Routine ANC data were cleaned prior to analysis using the following rules, developed through trial and error, to identify and exclude invalid records or records that would bias prevalence estimates (justification for the exclusion are provided parenthetically):

a) records that reported more positive tests results than tests performed were excluded (lack of face validity)

b) records with only known positives but no tests performed (possible stock out)

c) records where $100 \%$ of tests had positive results and more than three women were tested (lack of face validity)

d) records from facilities with less than five tests performed per year (possible under-reporting)

e) records where the number tested was greater than 1.1 times the number of first ANC visits (lack of face validity - high-volume sites)

f) records where the number tested was greater than three more than the absolute number of ANC visits (lack of face validity - low-volume sites)

All rules except for (d) were applied at the level of individual monthly reports from a facility, thus if a given month was excluded the remaining months of available data were included. Rule (b) is important because test kit stockouts can significantly bias RANC results since previously-diagnosed women will continue to be reported in both the numerator and the denominator, but no women testing negative will be identified. Although technically the number of tests should always be less than or equal to the number of first ANC visits, some allowance was made for spillover of reporting of test results from one month to the next in rules (e) and (f).

The impact of the cleaning rules in terms of excluded records and HIV prevalence with and without exclusion of records is summarized for Siaya County, Gem Sub-County and the Gem HDSS catchment areas in Table S1. On average, the cleaning steps cause a slight reduction in HIV prevalence, with greater numbers of records excluded, and greater impact on HIV prevalence, in earlier compared with later years. 
Table S1. Summary of the impact of data cleaning on routine ANC HIV prevalence, Siaya County, Kenya 2013-16

\begin{tabular}{|c|c|c|c|c|c|c|c|}
\hline \multirow[b]{2}{*}{ region } & \multirow[b]{2}{*}{ Year } & \multicolumn{2}{|c|}{ Monthly reports } & \multicolumn{2}{|c|}{ Results } & \multicolumn{2}{|c|}{ Pooled prevalence of } \\
\hline & & evaluated & included & evaluated & included & $\begin{array}{c}\text { all } \\
\text { records }\end{array}$ & $\begin{array}{c}\text { included } \\
\text { records }\end{array}$ \\
\hline Kisii & 2013 & 1255 & 1255 & 26600 & 19980 & 5.635 & 5.265 \\
\hline Kisii & 2014 & 1535 & 1534 & 31144 & 27035 & 4.698 & 4.583 \\
\hline Kisii & 2015 & 1559 & 1559 & 32744 & 29182 & 4.230 & 4.212 \\
\hline Kisii & 2016 & 1541 & 1538 & 30728 & 27770 & 3.908 & 3.900 \\
\hline Kisii & 2017 & 1268 & 1271 & 27370 & 23616 & 3.877 & 3.773 \\
\hline Nyamira & 2013 & 1055 & 1042 & 14319 & 10633 & 5.552 & 4.966 \\
\hline Nyamira & 2014 & 1249 & 1247 & 17358 & 15366 & 3.566 & 3.599 \\
\hline Nyamira & 2015 & 1328 & 1327 & 18962 & 17625 & 3.423 & 3.535 \\
\hline Nyamira & 2016 & 1312 & 1315 & 16772 & 15194 & 3.404 & 3.436 \\
\hline Nyamira & 2017 & 1053 & 1048 & 14390 & 12532 & 3.509 & 3.264 \\
\hline Migori & 2013 & 1366 & 1363 & 33347 & 22992 & 13.872 & 14.074 \\
\hline Migori & 2014 & 1572 & 1579 & 36805 & 31511 & 13.004 & 13.281 \\
\hline Migori & 2015 & 1624 & 1623 & 39222 & 35190 & 11.833 & 11.930 \\
\hline Migori & 2016 & 1662 & 1663 & 39406 & 33254 & 11.404 & 12.110 \\
\hline Migori & 2017 & 1478 & 1475 & 33326 & 27813 & 11.820 & 11.922 \\
\hline Siaya & 2013 & 1523 & 1514 & 29088 & 21647 & 19.771 & 19.162 \\
\hline Siaya & 2014 & 1591 & 1582 & 27979 & 24479 & 17.320 & 17.109 \\
\hline Siaya & 2015 & 1602 & 1602 & 26626 & 23755 & 16.796 & 17.079 \\
\hline Siaya & 2016 & 1629 & 1629 & 26740 & 23515 & 17.498 & 17.147 \\
\hline Siaya & 2017 & 1427 & 1424 & 25564 & 21987 & 17.681 & 17.274 \\
\hline Gem & 2013 & 335 & 323 & 6068 & 4509 & 17.337 & 17.476 \\
\hline Gem & 2014 & 347 & 345 & 5716 & 4976 & 14.538 & 14.891 \\
\hline Gem & 2015 & 338 & 338 & 5058 & 4753 & 15.401 & 15.422 \\
\hline Gem & 2016 & 342 & 342 & 5093 & 4305 & 15.708 & 15.540 \\
\hline Gem & 2017 & 307 & 305 & 4712 & 4229 & 16.044 & 15.465 \\
\hline Gem-HDSS & 2013 & 154 & 142 & 2932 & 2136 & 18.486 & 16.292 \\
\hline Gem-HDSS & 2014 & 161 & 161 & 2850 & 2540 & 15.544 & 15.748 \\
\hline Gem-HDSS & 2015 & 165 & 165 & 2413 & 2242 & 14.961 & 14.897 \\
\hline Gem-HDSS & 2016 & 166 & 166 & 2387 & 2032 & 17.553 & 17.175 \\
\hline Gem-HDSS & 2017 & 141 & 141 & 2174 & 1970 & 18.905 & 18.020 \\
\hline Kisumu & 2013 & 1153 & 1152 & 36664 & 21586 & 17.979 & 17.308 \\
\hline Kisumu & 2014 & 1373 & 1369 & 33930 & 27997 & 16.469 & 16.409 \\
\hline Kisumu & 2015 & 1441 & 1440 & 33758 & 29336 & 15.570 & 15.592 \\
\hline Kisumu & 2016 & 1484 & 1481 & 33193 & 29757 & 15.684 & 15.452 \\
\hline
\end{tabular}




\begin{tabular}{|c|c|c|c|c|c|c|c|}
\hline & & \multicolumn{2}{|c|}{ Monthly reports } & \multicolumn{2}{|c|}{ Results } & \multicolumn{2}{|c|}{ Pooled prevalence of } \\
\hline region & Year & evaluated & included & evaluated & included & $\begin{array}{c}\text { all } \\
\text { records }\end{array}$ & $\begin{array}{c}\text { included } \\
\text { records }\end{array}$ \\
\hline Kisumu & 2017 & 1408 & 1405 & 34678 & 31839 & 15.658 & 15.732 \\
\hline Homa Bay & 2013 & 1619 & 1602 & 31446 & 20838 & 23.545 & 20.856 \\
\hline Homa Bay & 2014 & 1968 & 1963 & 31711 & 26492 & 18.902 & 18.915 \\
\hline Homa Bay & 2015 & 2147 & 2139 & 33496 & 30876 & 19.728 & 19.675 \\
\hline Homa Bay & 2016 & 2222 & 2216 & 34084 & 31336 & 19.115 & 19.147 \\
\hline Homa Bay & 2017 & 2207 & 2199 & 32811 & 30033 & 19.015 & 18.992 \\
\hline
\end{tabular}

Notes: HDSS = KEMRI Gem health and demographic surveillance site. 


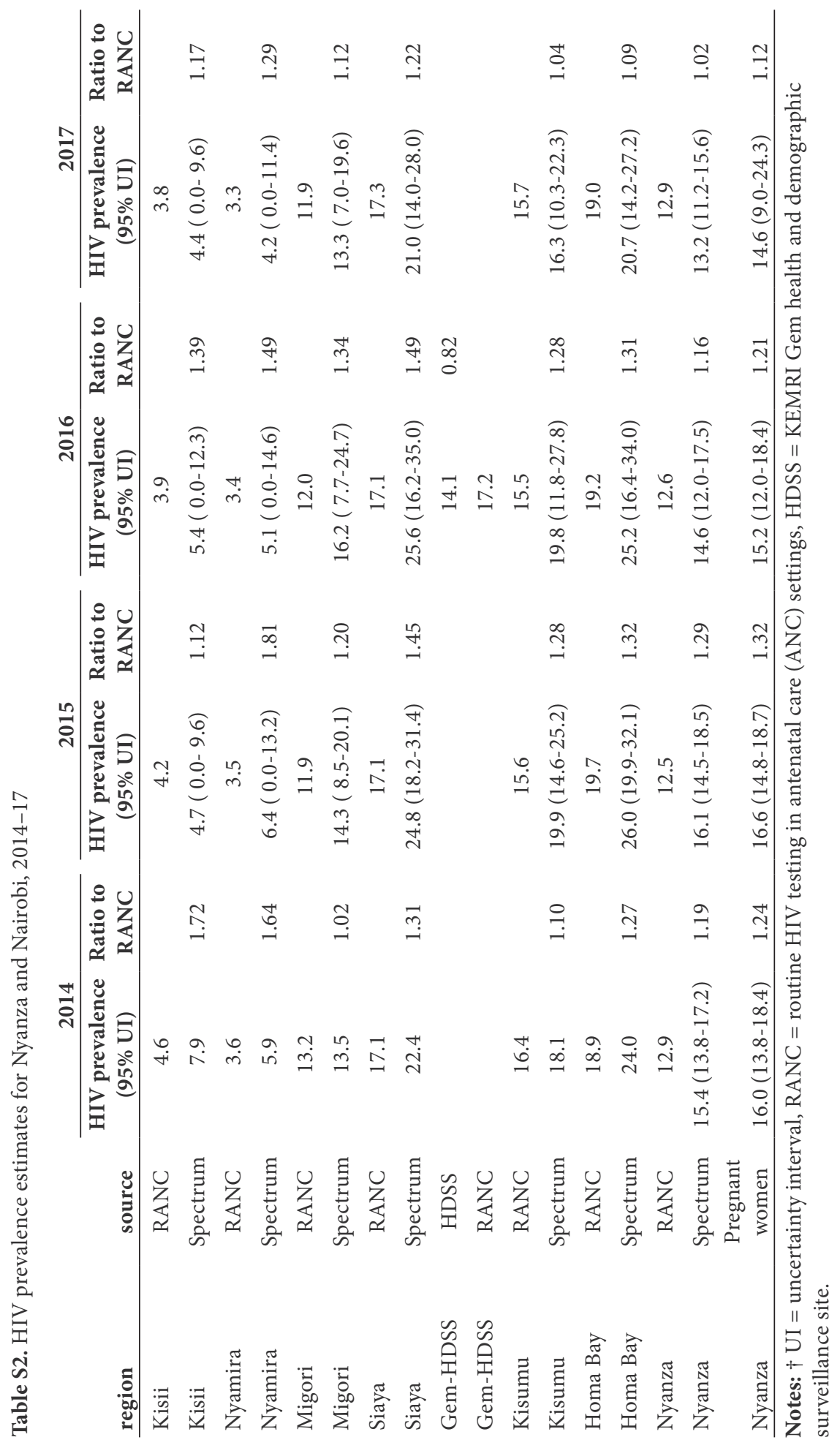




\section{Text S2. Assessment of influence of model inputs and attributes on outputs}

To assess the impact of different changes to the estimates models over time, we incrementally removed changes to the models until the 2015 estimates (conducted in 2016) were recovered, summarizing incremental and cumulative changes. The projections used were reflective of projections tested during the annual estimates review process by the Kenya HIV estimates task team, in consultation with UNAIDS. Changes made can be summarized into three categories, Spectrum version utilized, epidemiological assumptions, demographic, epidemiological and program data inputs. Changes in Spectrum version reflect updates to the software which can include changes to the fitting process/algorithm or changes in epidemiological assumptions based on new scientific evidence (for example, changes in the motherto-child transmission rate during breastfeeding) [1-4]. As we also changed some of these epidemiological assumptions independently of the Spectrum version, we also have included as a separate projection where they were found to have a notable impact on adult HIV prevalence. The particular change included here was the choice of pregnant women to adults incidence rate ratio (IRR) database. This database is updated every year and distributed with Spectrum and provides assumed IRRs between pregnant women and adults, by year, for a large number of countries and sub-national regions, including Nyanza region in Kenya. The third category includes changes to the demographic model of population growth for Nyanza to match the Kenya National Bureau of Statistics population projections [5], inclusion of or updates to HIV prevalence from routine antenatal care (RANC) data, and updated annual information on coverage of adult antiretroviral treatment, which affects mortality among people living with HIV as well as transmission risk.

This simple approach to summarizing the impact of model changes does have limitations. First, as we did not assess all possible permutations of model changes, we do not have a picture of interactions between changes, and it is possible if applied in a different order the incremental effects would vary. Furthermore, we did not evaluate the underlying causes of the changes but just summarized their impact on estimated adult PLHIV. Finally, we focused on one indicator relevant to the objectives of this analysis rather than looking at impact on other indicators (children living with HIV, incidence rates, mortality estimates, etc). However, this approach provides a simple assessment of the influence of model elements on the estimates and highlights the importance of carefully choosing model inputs. 


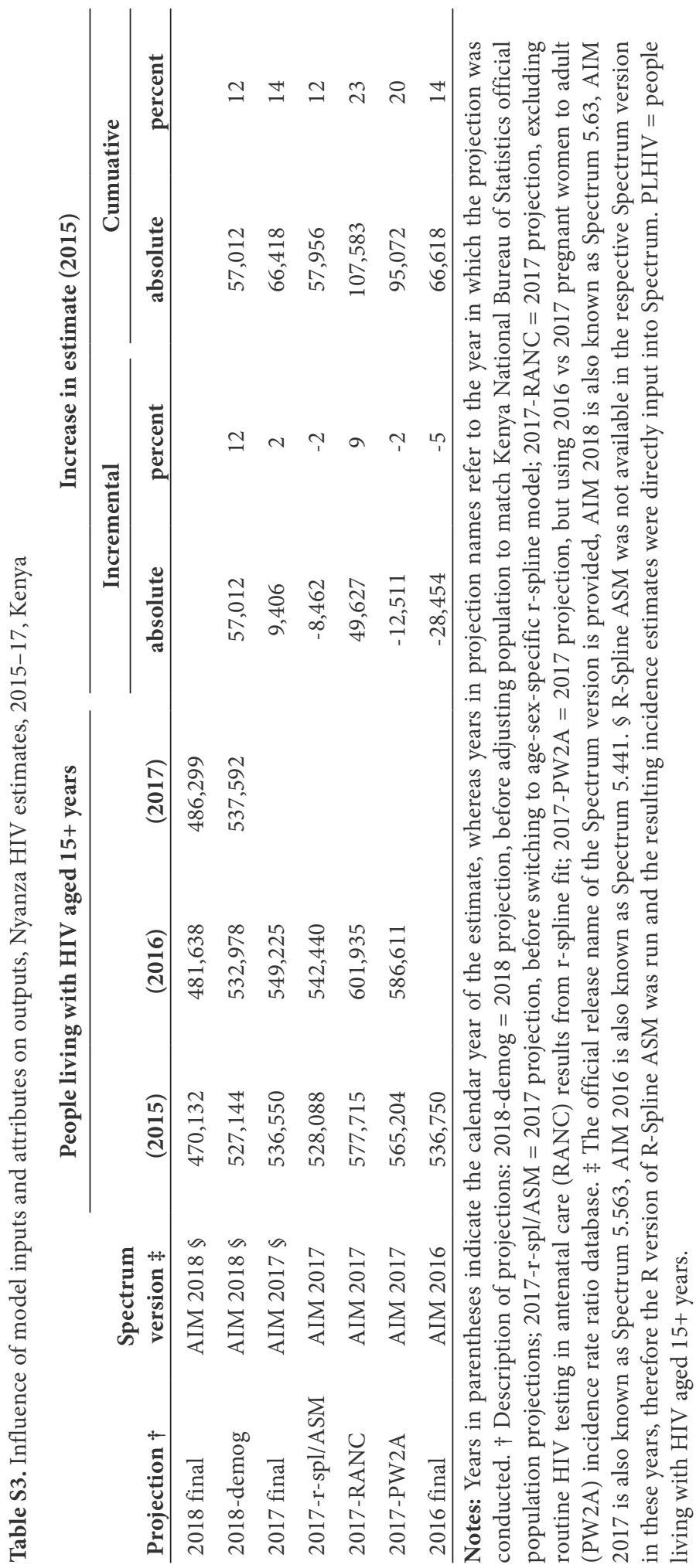




\section{References}

1. Rollins N, Mahy M, Becquet R, Kuhn L, Creek T, Mofenson L. Estimates of peripartum and postnatal mother-to-child transmission probabilities of HIV for use in Spectrum and other population-based models. Sex Transm Infect. 2012; 88(Supp 2):i44-51. doi: 10.1136/sextrans-2012-050709

2. Mahy M, Penazzato M, Ciaranello A, Mofenson L, Yianoutsos CT, Davies MA, et al. Improving estimates of children living with HIV from the Spectrum AIDS Impact Model. AIDS. 2017; 31:S13-22. doi: 10.1097/QAD.0000000000001306

3. Stover J, Brown $T$, Puckett $R$, Peerapatanapokin W. Updates to the Spectrum/Estimations and Projections Package model for estimating trends and current values for key HIV indicators. AIDS. 2017;31:S5-11. doi: 10.1097/QAD.0000000000001322

4. Brown $T$, Bao L, Eaton JW, Hogan DR, Mahy M, Marsh $K$, et al. Improvements in prevalence trend fitting and incidence estimation in EPP 2013. AIDS. 2014;28:\$415-25. doi: 10.1097/ QAD.0000000000000454

5. Kenya National Bureau of Statistics (KNBS). 2009 Kenya Population and Housing Census Analytical Report on Population Projections Volume XIV. Vol. XIV. Nairobi, Kenya; 2012. Available from: https://www.knbs.or.ke/download/analytical-report-on-population-projections-volume-xiv-pdf2/?wpdmdl=3763 


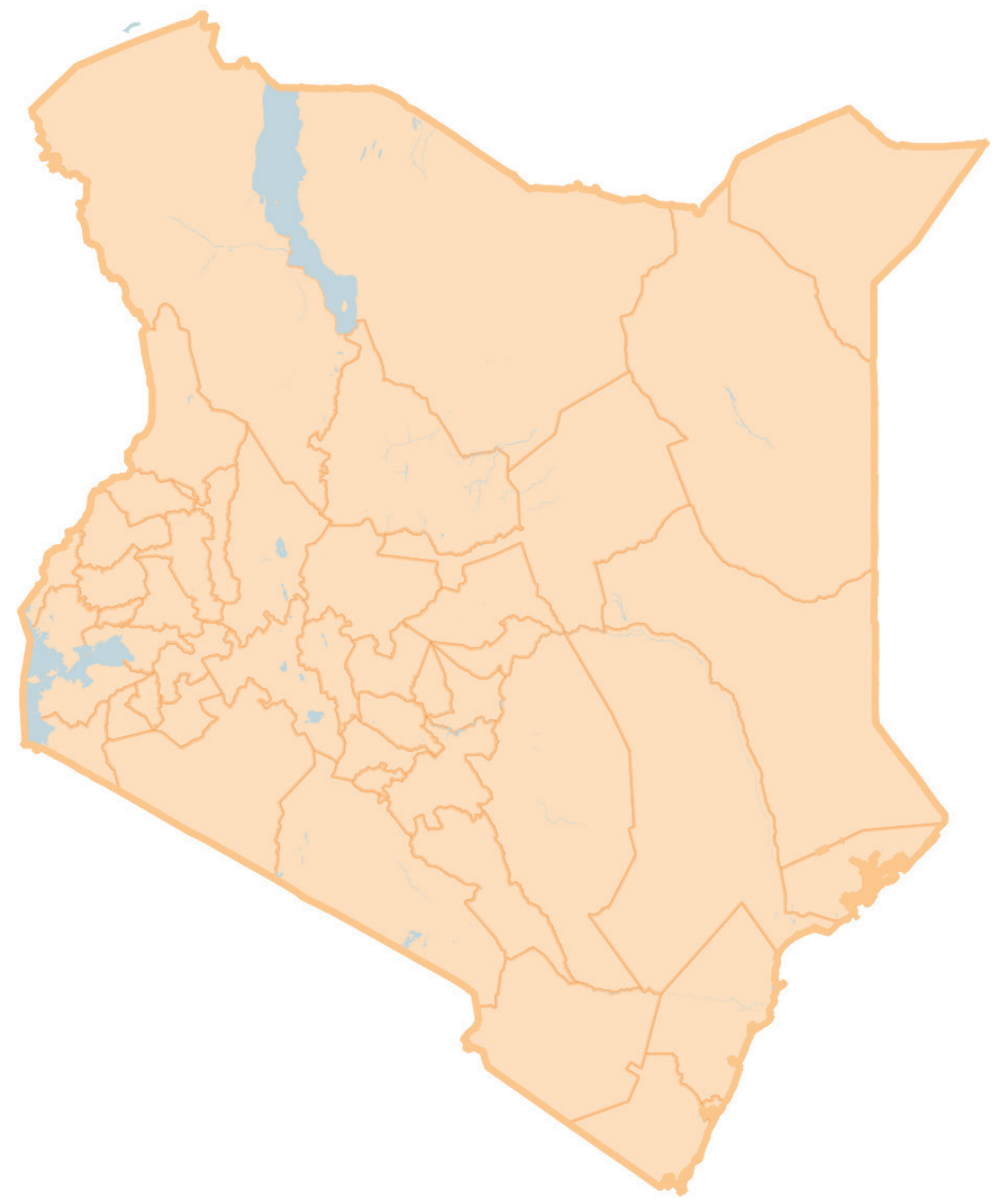




\section{Chapter 4}

Equity of antiretroviral treatment use in high HIV burden countries: Analyses of data from nationallyrepresentative surveys in Kenya and South Africa

Sizulu Moyo

Peter W Young 9

Eleanor Gouws

Inbarani Naidoo

Joyce Wamicwe

g authors contributed equally

PLoS ONE. 2018;13(8):1-17

https://doi.org/10.1371/journal.pone.0201899
Irene Mukui

Kimberly Marsh

Ehimario U Igumbor

Andrea A Kim

Thomas Rehle 


\section{Abstract}

Objective: To assess changes and equity in antiretroviral therapy (ART) use in Kenya and South Africa.

Methods: We analysed national population-based household surveys conducted in Kenya and South Africa between 2007 and 2012 for factors associated with lack of ART use among people living with HIV (PLHIV) aged 15-64 years. We considered ART use to be inequitable if significant differences in use were found between groups of PLHIV (e.g. by sex).

Findings: ART use among PLHIV increased from 29.3\% (95\% confidence interval [CI]: $22.8-35.8$ ) to $42.5 \%$ (95\%CI: 37.4-47.7) from 2007 to 2012 in Kenya and 17.4\% (95\%CI: 14.2-20.9) to 30.3\% (95\%CI: 27.2-33.6) from 2008 to 2012 in South Africa. In 2012, factors independently associated with lack of ART use among adult Kenyan PLHIV were rural residency (adjusted odds ratio [aOR] 1.98, 95\%CI: 1.233.18 ), younger age (15-24 years: aOR 4.25, 95\%CI: $1.7-10.63$, and $25-34$ years: aOR 5.16, 95\%CI: 2.73-9.74 versus 50-64 years), nondisclosure of HIV status to most recent sex partner (aOR 2.41, 95\%CI: 1.27-4.57) and recent recreational drug use (aOR 2.50, 95\%CI: 1.09-5.77). Among South African PLHIV in 2012, lack of ART use was significantly associated with younger age (15-24 years: aOR 4.23, 95\%CI: 2.56-6.70, and 25-34 years: aOR 2.84, 95\%CI: 1.73-4.67, versus 50-64 years), employment status (aOR 1.61, 95\%CI: 1.16-2.23 in students versus unemployed), and recent recreational drug use (aOR 4.56, 95\%CI: 1.79-11.57).

Conclusion: Although we found substantial increases in ART use in both countries over time, we identified areas needing improvement including among rural Kenyans, students in South Africa, and among young people and drug users in both countries. 


\section{Introduction}

Significant progress has been made in recent years in scaling up the provision of anti-retroviral therapy (ART) to people living with HIV (PLHIV) in sub-Saharan Africa. As of December 2015, over 17 million people globally were accessing ART, reaching the target of the Treatment 2015 agenda established in 2012 by the Joint United Nations Programme on HIV/AIDS (UNAIDS), the World Health Organization (WHO), and partners, ahead of schedule $[1,2]$.

Modelling suggests that high levels of ART coverage are required to control the HIV epidemic [3]. Despite progress in scaling up ART, only about half of all PLHIV in the East and Southern African region were receiving treatment by the end of 2015 [4]. This is partly due to global and country-specific recommended treatment guidelines that were in place in the past that recommended ART initiation until after onset of illness or immune suppression [5]). However, low ART coverage could also be explained by other structural factors such as health system deficiencies, individual factors such as lack of awareness of HIV status, healthcare seeking behaviours and risk behaviours, and socio-demographic factors [6]. Access to ART has been found to be greater in females than males, lower among young compared with older people [7-9], and among those living in poverty [10]. Stigma and discrimination $[11,12]$, as well as incorrect or incomplete information about HIV and treatment have also been associated with lower ART use [13].

Identifying and eliminating barriers to access will be important if countries are to achieve universal ART coverage. WHO recommends assessing treatment equity and addressing obstacles to equitable access in line with the 2015 "treatment for all” recommendations which makes identifying and addressing potential barriers to achieving universal treatment coverage even more urgent [14]. For this study, we defined inequitable ART use based on differences in the proportion of PLHIV on treatment between groups defined by socio-economic, demographic, and behavioural characteristics.

Both Kenya and South Africa have been severely affected by the HIV epidemic. In Kenya HIV prevalence was estimated at 5.6\% in 2012 with 1.4 million adult PLHIV and 898,000 people on ART by end of 2015 [15]. South Africa has the greatest number of PLHIV worldwide, estimated at 7 million in 2015, a $12.1 \%$ prevalence in the general population in 2012, and the largest ART programme in the world with approximately 3.4 million people on ART by end of 2015 [2]. 
Kenya and South Africa have undertaken nationally-representative populationbased surveys with financial and technical support from the U.S. Centers for Disease Control and Prevention (CDC) to track both the burden of the epidemic in the general population as well as the impact of prevention and treatment strategies over time. These surveys have included biomarkers to assess HIV prevalence, HIV incidence and ART usage. Biomarker measurement of ART use is particularly useful since it is conducted on all HIV-positive samples and is not subject to selfreporting biases. We used these surveys to investigate differences in ART use among groups to shed light on whether equitable distribution of treatment has been achieved and maintained over time.

\section{Methods}

\section{Survey design}

Two Kenya AIDS Indicator Surveys (KAIS), implemented in 2007 and 2012, were conducted to measure behaviours and biomarkers related to HIV infection, including HIV status, recency of HIV infection, CD4+ T-cell count, HIV-1 ribonucleic acid levels, and ART status among PLHIV aged 15-64 years in 2007 and 18 months-64 years in 2012. In South Africa, the Human Sciences Research Council (HSRC) has conducted four cross-sectional nationally-representative surveys to assess HIV prevalence, incidence and related behaviours in the general population since 2002. Data from the 2008 and 2012 surveys are presented here. The methods and results of all of the surveys have been described elsewhere $[16,17]$. In summary, the surveys were designed using multi-stage cluster sampling of households from a master sample to generate representative HIV prevalence estimates by sex, locality type, region, and national domains (and by age and race in South Africa). For Kenya, locality type is defined dichotomously as urban or rural, while for South Africa there are four defined locality types namely: urban formal, urban informal (informal settlements in urban areas characterized by shanty towns); rural formal (farming areas); and rural informal (informal settlements in rural areas also characterized by shanty towns). The 2007 Kenya survey included respondents aged 15-64 years, while the 2012 survey included respondents aged 18 months-64 years. The South African surveys both included respondents of all ages.

In both the Kenyan and South African surveys, written informed consent was sought from respondents prior to household and individual interviews and blood collection; assent was obtained from children aged less than 18 years in addition to consent from their caregiver or guardian. In the South African surveys, institutional review boards provided a waiver to allow use of verbal consent if a respondent 
was not able to provide written consent. Venous whole blood was collected from participants and used to prepare dried blood spot (DBS) specimens in Kenya. During KAIS 2012, participants were also offered home-based counselling and testing with point-of-care CD4 testing offered to those who tested HIV-positive. In South Africa, DBS specimens were collected directly from capillary blood using a finger prick. In the 2007 Kenya and 2012 South African surveys, results of central HIV testing were made available for participant collection at a nearby health facility. Data from the questionnaires and the blood test results were linked using unique identifiers, which were anonymised prior to HIV and ART testing.

\section{Laboratory methods}

Survey HIV prevalence was based on centralized testing of plasma (KAIS 2007) or DBS specimens (KAIS 2012; South Africa 2008 and 2012) tested with validated enzyme-linked immunosorbent assays based on national HIV testing algorithms, as previously described [16-18]. In Kenya, CD4+ T-cell counts were measured with BD FACSCalibur flow cytometer (Becton Dickinson BioSciences, San Jose, CA). Remaining plasma and DBS specimens were stored at $-80^{\circ} \mathrm{C}$ for future testing.

For all surveys, a qualitative antiretroviral (ARV) drug assay was applied to test for a panel of ARVs defined separately for each country by liquid chromatography-tandem mass spectrometry in all HIV-positive specimens [19]. Frozen stored DBS specimens from Kenya were tested in 2015 while DBS specimens for the South African surveys were tested within two months of specimen collection. Drug panels used for each country were designed to cover one or more drugs in all approved first- and secondline regimens in use at the time of each survey (also including salvage regimens in South Africa). Panels used were nevirapine (NVP), efavirenz (EFV), lamivudine (3TC), and lopinavir (LPV) in Kenya and azidothymidine (AZT), NVP, and EFV, LPV, atazanavir (ATV) and darunavir (DRV) in South Africa. The ARV drug assay's lower limit of detection was $0.02 \mu \mathrm{g} / \mathrm{mL}$. Samples that fell above the lower limit of detection for any of the ARVs tested were classified as ARV positive.

\section{Data analysis}

Data from each survey were analysed separately. Previously-developed survey weights were applied in order to provide estimates representative of the population from which each survey was drawn. Analysis was limited to individuals aged 15-64 years testing HIV-positive in centralized laboratory testing. North Eastern Province was excluded from the 2012 Kenya survey due to insecurity at the time of the survey and thus the province was also excluded from the 2007 survey analysis for consistency. In cells where the denominator is less than 25 the proportion and confidence intervals were replaced with an asterisk. 


\section{Measures}

The outcome measure of ART use was defined as having evidence of ART exposure in the survey blood specimen, i.e. a positive test for one or more ARVs among PLHIV. Note that treatment guidelines have evolved in both Kenya [20-22] and South Africa [23,24]. The guidelines in effect at the time of each survey are summarized in S1 Table.

A wealth index was created for each survey using measures related to household living standards including household characteristics (source of drinking water, access to electricity, main source of energy for cooking, type of toilet) and household ownership of assets (presence of a working refrigerator, radio, television, and in South Africa, mobile and landline phones) captured in the household questionnaire. The index was generated using factor analysis [25] and the resulting indices were grouped into quintiles from lowest (Quintile I) to highest (Quintile V) socioeconomic status (SES). As the indices were developed independently they are not directly comparable across countries.

Additional covariates were selected for inclusion in the analysis based on availability in the survey datasets and a structured literature review conducted prior to the survey that identified sex, age, disease stage, socio-economic status, employment, residency, cost, and decentralization of treatment as factors likely to predict ART use. Individual- and household-level factors identified in the review were included in the analysis.

For Kenya, employment status was defined as currently employed if the participant reported receiving payment or goods in exchange for work in the last seven days, otherwise they were unemployed. For South Africa, employment included selfemployed as well as employment in the formal and informal sectors on a full-time or part-time basis. Students comprised those attending schools, including tertiary institutions.

\section{Statistical methods}

Logistic regression analysis was performed to assess associations between lack of ART (no evidence of ART exposure in the blood specimen) and selected demographic, socioeconomic and behavioural variables separately for each survey. Significance of covariates for purposes of model building was assessed using Wald tests. Variables were selected for inclusion in initial models based on significance of association with ART use in bivariate analyses $(\mathrm{p}<0.1$, presented in S3 and S4 Tables) or selected a priori in the case of sex, locality type, and household wealth. Models were then refined iteratively. Final regression models included covariates 
that were significantly associated with the outcome in multiple regression analysis $(\mathrm{p}<0.05)$ or that presented evidence of confounding as demonstrated by a $20 \%$ or greater change in coefficients of other significant covariates. Statistical significance for differences in prevalence of ART use between surveys was assessed by comparing confidence intervals (CI). For Kenya, separate models were developed including only women in order to further explore associations between pregnancy status and ART non-use.

To handle missing values, multiple imputation using chained equations was conducted with the Stata mi command on ART status, CD4 count, and disclosure of HIV status to last sex partner variables for each survey prior to regression analysis, to account for missing data for the Kenya surveys. The multiple imputation model assumes that data are missing at random. In South Africa, data were rarely missing and where this occurred the few cases affected were dropped at that stage of the analysis. A summary of the imputation modelling procedure is provided in S1 Text.

Analyses were conducted in SAS version 9.2 and Stata version 13 using commands designed to handle the complex survey design, except where otherwise noted.

\section{Ethical approval}

The South African surveys were approved by the HSRC Research Ethics Committee and by the U.S. Centers for Disease Control and Prevention (CDC) in Atlanta, USA. A waiver of written consent was granted for situations where respondents were unable to provide written consent but were able to provide verbal consent with signature of an impartial witness. The Kenyan surveys were approved by the Ethical Review Committee of the Kenya Medical Research Institute and the Institutional Review Board of the CDC. The 2012 KAIS was also approved by the Committee on Human Research of the University of California, San Francisco.

\section{Results}

In Kenya, 17,104 persons aged 15-64 years participated in KAIS 2007, of whom 88.3\% provided a blood specimen and 1,097 tested HIV-positive in the survey (Fig 1). Of these, 575 (52.4\%) had ART testing results available for complete case analysis; a total of 1,092 cases were available after imputing missing values. In 2012, 13,720 persons aged 15-64 years participated in the study of which 11,626 (84.7\%) provided blood specimens and 648 tested positive in the survey. Of these, 559 (86.3\%) had an ARV test result available for analysis, while after imputing missing values a total of 635 cases were available. Additional information about the multiple 
imputation model is provided in S1 Text, including a table comparing the distribution of observed and completed values (S2 Table). In South Africa, 14,543 individuals participated in the 2008 survey, with $78.2 \%$ giving a blood specimen, and 1,284 testing HIV-positive (Fig 1). Corresponding figures for 2012 were 24,084 participants, $77.5 \%$ of whom gave a blood specimen, with 2,588 of these testing HIV-positive. Antiretroviral treatment results were available for almost all HIVpositive samples in South Africa (100\% in 2008 [n=1,284], and 99.9\% $[n=2,586]$ in 2012) (Fig 1).
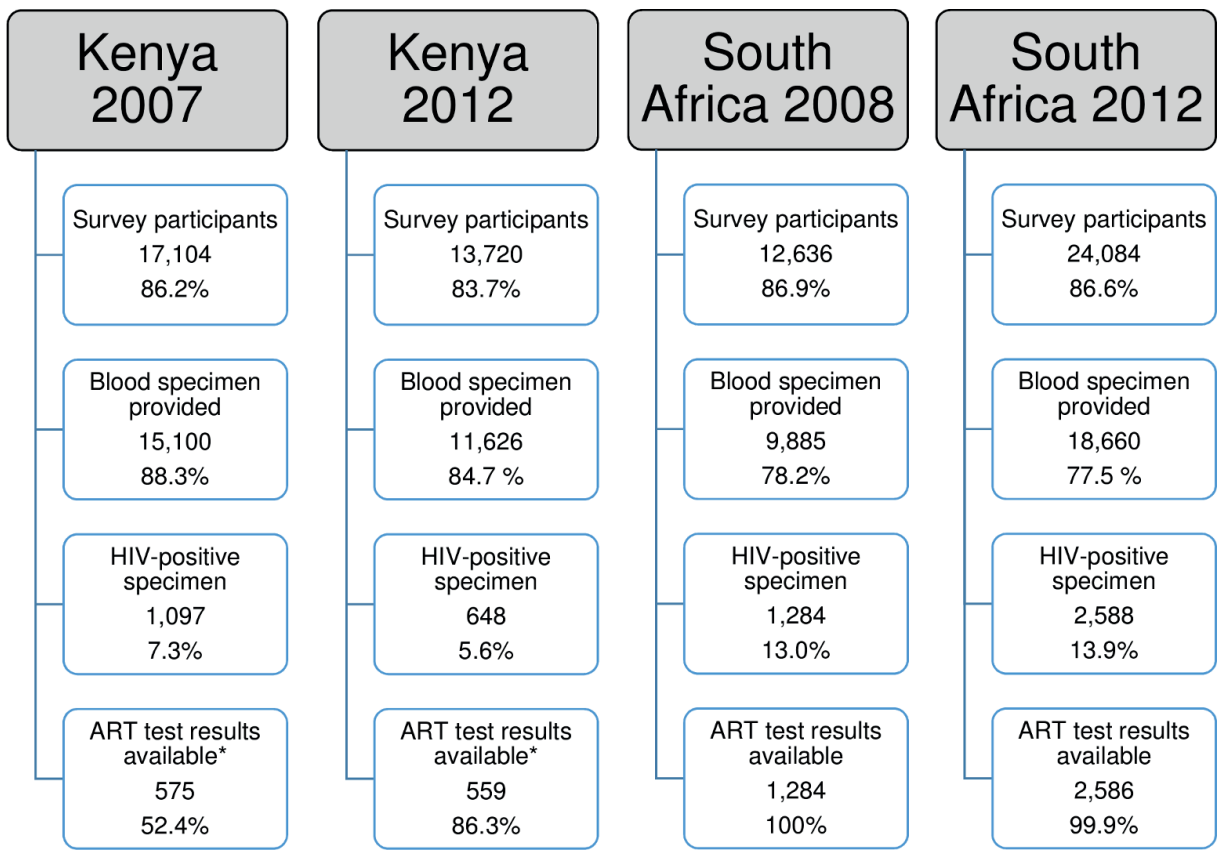

Fig 1. Study sample, HIV status and ART exposure testing, participants aged 15-64 years, Kenya and South Africa, 2007, 2008 and 2012

Notes: Data are unweighted. Percentages are calculated with respect to previous row, except interview response rates shown in first row which are calculated with respect to total eligible population (not shown). ${ }^{*}$ For Kenya, 1092 cases have ART results available in 2007 and 635 have results available in 2012 after multiple imputation. 


\section{Kenya}

The proportion of PLHIV on ART increased from 29.3\% (95\% confidence interval [CI]: $22.8-35.8$ ) in 2007 to $42.5 \%$ (95\% CI: 37.4-47.7) in 2012. For females, it increased from $31.2 \%$ (95\% CI: $23.0-39.4$ ) to $45.6 \%$ (95\% CI: $40.5-50.7$ ). The unadjusted proportion on treatment also increased significantly for the Rift Valley region, for those aged 35-49 years, for persons who were married or cohabitating, and for those who disclosed their status to their most recent sex partner.

The proportion of PLHIV on ART did not differ significantly by locality, province or sex, education or household wealth quintile in either Kenyan survey. However, the likelihood of being on ART differed by age and marital status in both surveys. ART coverage differed significantly by current CD4 count in 2007 ( $\mathrm{p}<0.001)$ but not in 2012. ART use varied by time since last HIV test in both surveys. In 2012, ART use varied by employment status $(\mathrm{p}=0.021)$, disclosure to most recent partner $(\mathrm{p}=0.046)$ and recreational drug use in the last 12 months $(\mathrm{p}<0.001)$. Women who were pregnant in the last three years were less likely to be on ART in both surveys (Table 1). 
Table 1. ARV exposure by selected characteristics of HIV-infected individuals aged 15-64 years old, Kenya 2007 and 2012

\begin{tabular}{|c|c|c|c|c|c|c|}
\hline \multirow[b]{3}{*}{ Variable } & \multicolumn{3}{|c|}{ Kenya, 2007} & \multicolumn{3}{|c|}{ Kenya, 2012} \\
\hline & \multicolumn{3}{|c|}{ On ART } & \multicolumn{3}{|c|}{ On ART } \\
\hline & $\mathbf{N}$ & $\begin{array}{c}\text { Weighted \% } \\
\text { (95\% CI) }\end{array}$ & p-value & $\mathbf{N}$ & $\begin{array}{l}\text { Weighted \% } \\
(95 \% \text { CI })\end{array}$ & p-value \\
\hline Locality type & & & 0.875 & & & 0.240 \\
\hline Rural & 389 & $29.7(22.3-37.1)$ & & 317 & $39.9(32.5-47.2)$ & \\
\hline Urban & 186 & $28.5(15.5-41.4)$ & & 242 & $45.9(38.9-52.9)$ & \\
\hline Province & & & 0.219 & & & 0.240 \\
\hline Nairobi & 79 & $36(14.3-57.7)$ & & 54 & $45.1(32.4-57.8)$ & \\
\hline Central & 41 & $40.2(25.3-55.2)$ & & 50 & $47.6(34.2-61.0)$ & \\
\hline Coast & 78 & $15.4(3.1-27.8)$ & & 55 & $41(23.7-58.3)$ & \\
\hline Eastern & 47 & $28.9(4.3-53.4)$ & & 66 & $59.3(41.3-77.2)$ & \\
\hline Nyanza & 197 & $35.6(22.2-49.0)$ & & 212 & $36.6(29.1-44.0)$ & \\
\hline Rift Valley & 77 & $17.6(8.9-26.3)$ & & 70 & $45.5(29.4-61.6)$ & \\
\hline Western & 56 & $28.9(10.5-47.3)$ & & 52 & $36.8(22.7-50.8)$ & \\
\hline Sex & & & 0.259 & & & 0.120 \\
\hline Male & 203 & $25.7(18.5-32.9)$ & & 175 & $37.8(28.6-46.9)$ & \\
\hline Female & 372 & $31.2(23.0-39.4)$ & & 384 & $45.6(40.5-50.7)$ & \\
\hline Age (years) & & & $<.001$ & & & $<.001$ \\
\hline $15-24$ & 100 & $18.2(8.3-28.1)$ & & 59 & $21.6(8.8-34.3)$ & \\
\hline $25-34$ & 212 & $23(15.0-31.0)$ & & 182 & $25.1(18.1-32.2)$ & \\
\hline $35-49$ & 208 & $38.3(29.6-47.1)$ & & 229 & $55(47.7-62.4)$ & \\
\hline $50-64$ & 55 & $38.2(24.2-52.3)$ & & 89 & $59.6(48.6-70.6)$ & \\
\hline Marital status & & & 0.002 & & & 0.002 \\
\hline Single/never married & 70 & $22.8(10.1-35.6)$ & & 73 & $24.5(12.8-36.2)$ & \\
\hline Married/cohabitating & 373 & $25.5(19.3-31.7)$ & & 337 & $42(35.4-48.7)$ & \\
\hline $\begin{array}{l}\text { Divorced/separated/ } \\
\text { widowed }\end{array}$ & 132 & $42(30.6-53.3)$ & & 149 & $53.1(44.7-61.5)$ & \\
\hline Education & & & 0.943 & & & 0.130 \\
\hline None & 292 & $30(20.7-39.3)$ & & 81 & $35.5(24.0-46.9)$ & \\
\hline Primary & 181 & $27.4(19.9-35.0)$ & & 298 & $39.5(32.4-46.6)$ & \\
\hline Secondary & 77 & $29.5(19.7-39.4)$ & & 28 & $45.7(25.7-65.8)$ & \\
\hline Higher & 25 & $32.7(9.8-55.6)$ & & 151 & $50.6(40.8-60.4)$ & \\
\hline Household wealth & & & 0.507 & & & 0.900 \\
\hline Quintile I (lowest) & 98 & $27.5(14.7-40.2)$ & & 87 & $41(28.0-54.1)$ & \\
\hline Quintile II & 102 & $20.7(8.5-32.9)$ & & 133 & $40.6(28.8-52.3)$ & \\
\hline Quintile III & 96 & $31.9(19.3-44.5)$ & & 122 & $41.2(30.9-51.4)$ & \\
\hline
\end{tabular}


Table 1. Continued

\begin{tabular}{|c|c|c|c|c|c|c|}
\hline \multirow[b]{3}{*}{ Variable } & \multicolumn{3}{|c|}{ Kenya, 2007} & \multicolumn{3}{|c|}{ Kenya, 2012} \\
\hline & \multicolumn{3}{|c|}{ On ART } & \multicolumn{3}{|c|}{ On ART } \\
\hline & $\mathbf{N}$ & $\begin{array}{l}\text { Weighted \% } \\
\text { (95\% CI) }\end{array}$ & p-value & $\mathbf{N}$ & $\begin{array}{l}\text { Weighted \% } \\
(95 \% \mathrm{CI})\end{array}$ & p-value \\
\hline Employment & & & 0.432 & & & 0.021 \\
\hline Unemployed & 90 & $33.7(19.4-48.1)$ & & 197 & $50(41.1-58.8)$ & \\
\hline Employed & 485 & $28.5(22.1-34.9)$ & & 361 & $39(33.5-44.5)$ & \\
\hline $\begin{array}{l}\mathrm{CD} 4 \text { category (cells/ } \\
\mathrm{mm}^{3} \text { ) }\end{array}$ & & & $<.001$ & & & 0.310 \\
\hline$<=250$ & 106 & $24.1(15.4-32.8)$ & & 44 & $51.5(37.0-65.9)$ & \\
\hline $250>-350$ & 60 & $53.4(38.1-68.8)$ & & 35 & $59.9(42.5-77.4)$ & \\
\hline $350>-500$ & 93 & $32.9(22.2-43.7)$ & & 37 & $47.6(27.9-67.4)$ & \\
\hline$>500$ & 276 & $23.9(15.6-32.2)$ & & 168 & $42.4(32.9-51.9)$ & \\
\hline Most recent HIV test $\dagger$ & & & $<.001$ & & & $<.001$ \\
\hline$<12$ months ago & 135 & $38.1(27.5-48.7)$ & & 264 & $49.9(42.1-57.6)$ & \\
\hline $1-2$ years ago & 69 & $47.1(32.8-61.5)$ & & 100 & $32.9(21.7-44.1)$ & \\
\hline$>2$ years ago & 84 & $41.3(25.4-57.2)$ & & 122 & $51.7(42.1-61.3)$ & \\
\hline $\begin{array}{l}\text { Disclosed results to } \\
\text { partner }\end{array}$ & & & 0.572 & & & 0.046 \\
\hline Yes & 193 & $35.3(25.8-44.8)$ & & 174 & $69(60.9-77.0)$ & \\
\hline No & 38 & $27.9(5.3-50.4)$ & & 90 & $55(43.1-66.9)$ & \\
\hline \multicolumn{7}{|l|}{$\begin{array}{l}\text { Pregnancy and HIV } \\
\text { testing } \$\end{array}$} \\
\hline Pregnant & 141 & $18.5(10.3-26.7)$ & $<.001$ & 98 & $35.2(24.6-45.8)$ & 0.031 \\
\hline Not pregnant & 231 & $38.1(28.5-47.8)$ & & 286 & $49.1(43.2-55.0)$ & \\
\hline $\begin{array}{l}\text { Antenatal care (ANC) } \\
\text { visit }\end{array}$ & 123 & $18.8(10.1-27.5)$ & 0.727 & 95 & $35.2(24.5-45.9)$ & 0.988 \\
\hline No ANC visit & 18 & * & & 3 & * & \\
\hline $\begin{array}{l}\text { Ever tested for HIV in } \\
\text { pregnancy }\end{array}$ & 76 & $22.3(11.7-32.9)$ & 0.172 & 88 & $33.3(22.0-44.6)$ & 0.288 \\
\hline $\begin{array}{l}\text { Never tested for HIV } \\
\text { in pregnancy }\end{array}$ & 47 & $13.4(2.9-23.9)$ & & 7 & * & \\
\hline Recreational drug use $₫$ & & & & & & $<.001$ \\
\hline Yes & - & & & 55 & $17.9(6.5-29.4)$ & \\
\hline No & & & & 504 & $45.3(40.2-50.5)$ & \\
\hline Total & 575 & $29.3(22.8-35.8)$ & & 559 & $42.5(37.4-47.7)$ & \\
\hline
\end{tabular}

Notes: All numbers are unweighted except where otherwise specified. ${ }^{\star}$ Suppressed due to denominator $<25$ observations. $\uparrow$ Applies to respondents who reported ever testing for HIV † Applies to respondents who self-reported HIV-positive, partner refers to most recent sex partner. $\$$ Applies to pregnancy during last 3 years among female respondents only. $\$ \$$ Drug use in last 12 months. ART = antiretroviral treatment, $\mathrm{CI}=$ confidence interval. 
Chapter 4. Equity of antiretroviral treatment use in high HIV burden countries

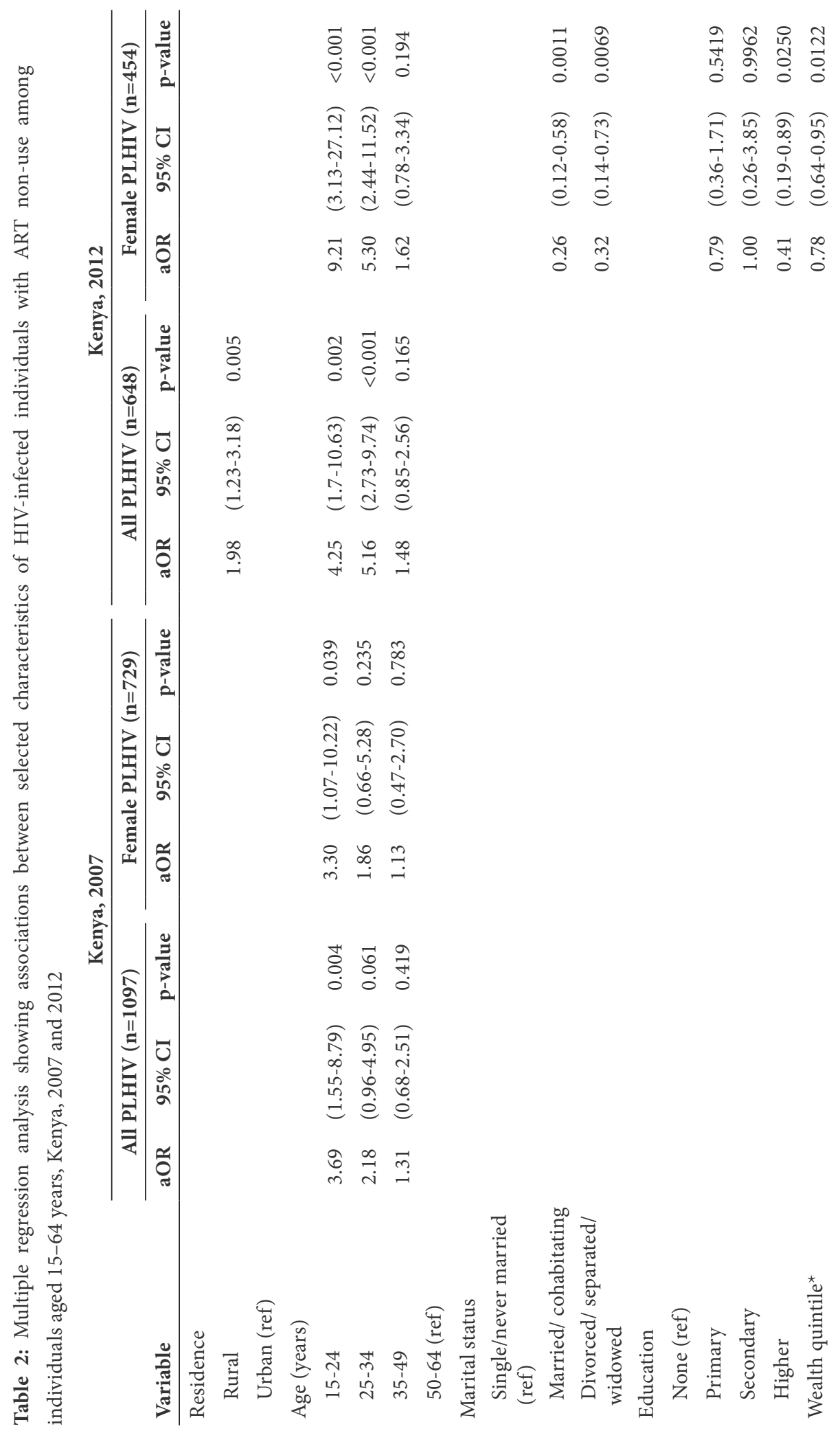




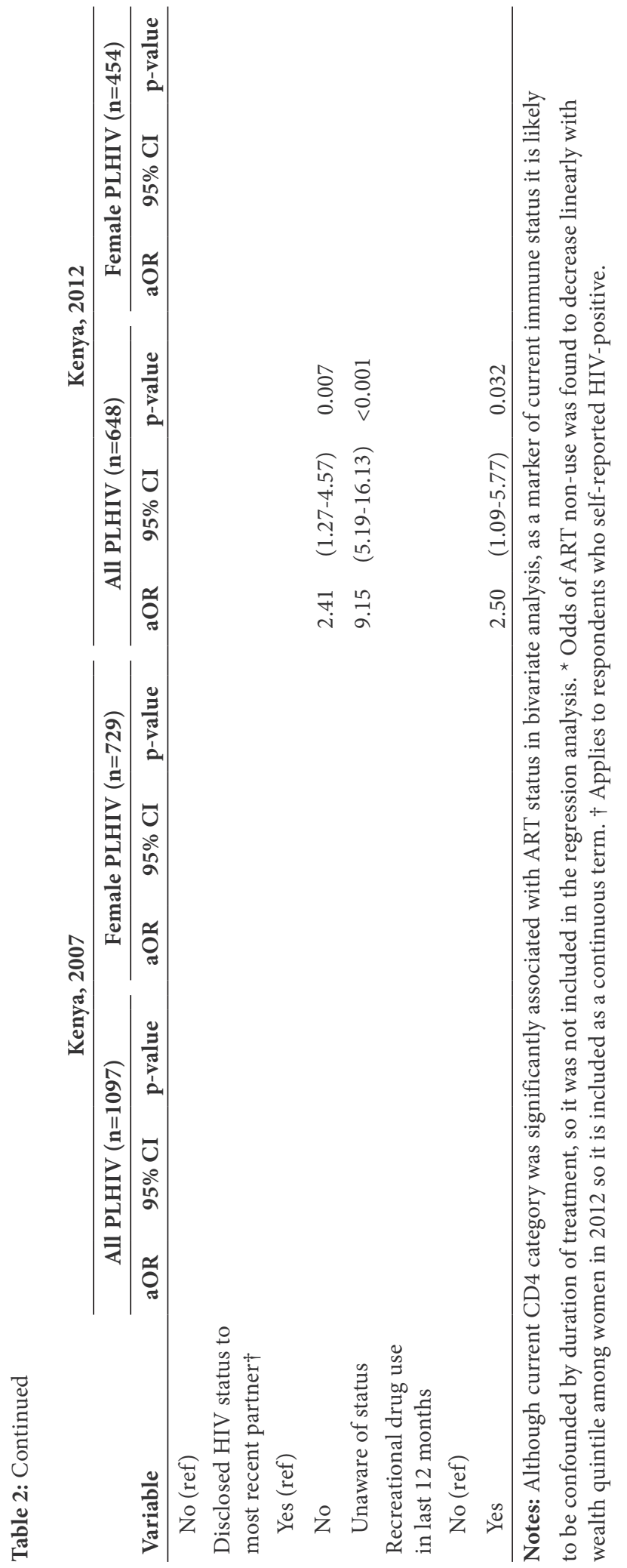


In bivariate analysis, in 2012, ART non-use was also greater among women aged 15-24 years $(\mathrm{OR}=5.6)$ and 25-44 years $(\mathrm{OR}=4.09)$ compared with those aged 50-64 years $(\mathrm{p}<0.001)$, and inversely with being married or cohabitating, or divorced, separated or widowed, compared to those who were single/never married $(\mathrm{p}<0.001)$, having last HIV test $1-2$ years ago versus $<1$ year ago, not disclosing HIV status to their most recent sex partner $(\mathrm{p}=0.011)$, pregnancy in the last three years among women $(\mathrm{p}=0.045)$ and reporting having used recreational drugs in the last 12 months $(\mathrm{p}=0.003)$ ( $\mathrm{S} 3$ Table).

In multiple regression, only younger age was associated with lack of ART use among PLHIV in 2007, with an adjusted odds ratio (aOR) of ART use of 3.69 (95\% CI: 1.558.79) for PLHIV aged 15-24 versus 50-64 years of age. In 2012, when controlling for residency, age group, disclosure, and recreational drug use, ART non-use was more likely in respondents living in rural compared with urban areas (aOR 1.98, CI 1.23-3.18), and in younger respondents (aged 15-24 years, aOR 4.25, CI 1.7010.63, aged 25-34, aOR 5.16, CI 2.73-9.74 compared with those aged 50-64 years). ART non-use was also more likely in those who reported they had not disclosed their status to their last sex partner (aOR 2.41, 95\% CI: 1.27-4.57) and those who reported a recreational drug use in last 12 months (aOR 2.50, 95\% CI: 1.09-5.77) (Table 2). In order to explore the association between recent pregnancy and ART non-use among women, separate multiple regression models were constructed for women in both 2007 and 2012. No significant association between lack of ART use among those recently pregnant was found in 2007 (aOR 1.30, 95\% CI: 0.76-2.21) or 2012 (aOR 0.97, 95\% CI: 0.54-1.74). However, the women-only model for $2012 \mathrm{did}$ reveal associations with marital status, education, and wealth quintile not seen in the combined male-female model. Lack of ART was significantly less likely among married women compared with single women (aOR 0.26, 95\% CI: 0.12-0.58), as among women who were divorced, separated or widowed (aOR 0.32, 95\% CI: 014-0.73). Wealth quintile also showed a $22 \%$ increase in odds of ART use for each increase in wealth quintile (aOR of non-use: $0.78,95 \% \mathrm{CI}: 0.64-0.95$ ). Unlike in the combined male-female model, disclosure of status and recreational drug use in last 12 months was not found to be associated with ART non-use in women (S5 Table).

\section{South Africa}

Overall the proportion of PLHIV on ART increased from 17.3\% (95\% CI: 14.2-20.9) in 2008 , to $30.3 \%$ (95\% CI: $27.2-33.6$ ) in 2012. ART use increased more than fourfold among those living in rural informal areas from $7.7 \%$ (95\% CI: 3.7-15.4) in 2008 to $34.3 \%$ (95\% CI: 30.8-38.9) in 2012 (S1 Fig), and more than doubled among females from $16.8 \%$ (95\% CI: $13.5-20.7$ ) in 2008 to $43.2 \%$ (95\% CI: 30.9-37.7) over the same period. Although ART use increased across all age groups, increases were 
much greater among the older age groups with 14.9\% (95\% CI: 8.9-23.7) of those aged 50-64 years on ART in 2008 compared with 43.3\% (95\% CI: 36.1-50.7) in 2012. The proportion of PLHIV on ART differed significantly by marital status in both survey years ( $p=0.031$ in 2008 and $p=0.002$ in 2012). In 2012 the proportion of PLHIV on ART also differed significantly by sex $(\mathrm{p}=0.001)$, by age $(\mathrm{p}<0.001)$, by employment status $(\mathrm{p}<0.001)$ and by recreational drug use $(\mathrm{p}<0.0001)$ (Table 3$)$. On bivariate analysis, ART non-use was significantly associated with province, marital status, highest level of education, employment status and household wealth in 2008. In 2012 there was significantly greater ART non-use among males $(\mathrm{p}=0.001)$, those aged 15-24 (OR 4.57, p<0.001) and 25-34 years (OR 2.75, p<0.001) versus those aged 50-64 years, those who were employed $(\mathrm{p}<0.001)$ or students $(\mathrm{p}<0.033)$ versus unemployed, and those with recent recreational drug use $(\mathrm{p}<0.001)$, while those who were divorced/separated/widowed had lower non-use of ART compared with those who were single/never married/no stable partnership $(\mathrm{p}<0.017)$. Recency of testing showed no significant association with ART non-use in either survey year (S4 Table).

On multiple regression analysis, marital status was significantly associated ART non-use: being divorced, separated or widowed was associated with a lower likelihood of ART non-use when compared to being single or never married (aOR 0.45, 95\% CI: 0.22-0.01, $\mathrm{p}=0.027)$. Significant associations were also observed by level of education ( $\mathrm{aOR} 0.14,95 \% \mathrm{CI}$ : $0.03-0.68, \mathrm{p}=0.014$ for tertiary (higher) level of education versus no education), employment status (aOR 2.16, 95\% CI: $1.26-$ 1.37, $\mathrm{p}=0.01$ for those who were employed versus the unemployed) and household wealth (aOR 0.43, 95\% CI: 0.20-0.90, p=0.03 for Quintile III versus Quintile I) in 2008. In 2012, younger age was significantly associated with ART non-use (aOR 4.23, 95\% CI: 2.56-6.70, p<0.001 and aOR 2.84, 95\% CI: $1.73-4.67, \mathrm{p}<0.001$ for age groups 15-24 years and 25-34 years, respectively, compared to age group 50-64 years). Students were significantly more likely not to use ART (aOR 1.61, 95\% CI: 1.16-2.23) compared to those who were unemployed. Recreational drug users were also more likely not to use ART (aOR 4.56, 95\% CI: 1.79-11.57, p=0.001) when compared to non-drug users (Table 4). 
Table 3: Antiretroviral exposure by selected characteristics of HIV-infected individuals aged 15-64 years old, South Africa, 2008 and 2012

\begin{tabular}{|c|c|c|c|c|c|c|}
\hline \multirow[b]{3}{*}{ Variable } & \multicolumn{3}{|c|}{ South Africa, 2008} & \multicolumn{3}{|c|}{ South Africa, 2012} \\
\hline & \multicolumn{3}{|c|}{ ART } & \multicolumn{3}{|c|}{ On ART } \\
\hline & $\mathbf{N}$ & $\begin{array}{c}\text { Weighted \% } \\
(95 \% \text { CI })\end{array}$ & p-value & $\mathbf{N}$ & $\begin{array}{c}\text { Weighted \% } \\
\text { (95\% CI) }\end{array}$ & p-value \\
\hline Locality type & & & 0.211 & & & 0.068 \\
\hline Urban formal & 481 & $15.9(11.3-22.0)$ & & 888 & $27.1(21.3-33.8)$ & \\
\hline Urban informal & 345 & $20.5(14.1-29.0)$ & & 525 & $27.2(22.7-32.3)$ & \\
\hline Rural formal & 117 & $19.4(13.9-26.2)$ & & 335 & $27.5(19.6-37.2)$ & \\
\hline Rural informal & 341 & $7.7(3.7-15.4)$ & & 840 & $34.7(30.8-38.9)$ & \\
\hline Province & & & 0.710 & & & 0.200 \\
\hline Western Cape & 83 & $28.3(16.1-44.7)$ & & 157 & $27.5(18.6-38.6)$ & \\
\hline Eastern Cape & 146 & $19.1(10.1-33.2)$ & & 324 & $31.2(25.1-38.2)$ & \\
\hline Northern Cape & 70 & $18.9(8.9-35.8)$ & & 131 & $13.6(5.6-29.6)$ & \\
\hline Free State & 125 & $13.5(8.1-21.6)$ & & 258 & $27.0(20.2-35.1)$ & \\
\hline KwaZulu Natal & 288 & $15.4(10.2-22.6)$ & & 726 & $32.8(28.2-37.7)$ & \\
\hline Northwest & 114 & $21.5(13.8-31.8)$ & & 211 & $39.6(30.0-50.2)$ & \\
\hline Gauteng & 211 & $18.6([10.7-30.4)$ & & 291 & $26.2(18.0-36.5)$ & \\
\hline Mpumalanga & 141 & $16.4([10.7-24.2)$ & & 291 & $35.9(27.9-44.7)$ & \\
\hline Limpopo & 106 & $13.8([7.3-24.7)$ & & 197 & $24.8(15.6-37.1)$ & \\
\hline Race & & & 0.864 & & & 0.102 \\
\hline Black African & 1205 & $17.3(14.2-21.0)$ & & 2365 & $30.0(26.8-33.4)$ & \\
\hline Other race & 79 & $16.2(7.6-31.5)$ & & 223 & $40.8(29.0-53.7)$ & \\
\hline Sex & & & 0.650 & & & 0.001 \\
\hline Male & 352 & $18.5(12.6-26.4)$ & & 801 & $24.1(19.5-29.5)$ & \\
\hline Female & 932 & $16.8(13.5-20.7)$ & & 1787 & $43.2(30.9-37.7)$ & \\
\hline Age (years) & & & 0.350 & & & $<0.001$ \\
\hline $15-24$ & 279 & $11.6(4.9-25.2)$ & & 399 & $14.3(10.0-20.0)$ & \\
\hline $25-34$ & 441 & $17.7(13.0-23.6)$ & & 926 & $21.7(17.9-26.1)$ & \\
\hline $35-49$ & 444 & $20.8(15.9-26.8)$ & & 912 & $41.0(35.5-46.7)$ & \\
\hline $50-64$ & 120 & $14.9(8.9-23.7)$ & & 349 & $43.3(36.1-50.7)$ & \\
\hline Education & & & 0.177 & & & 0.661 \\
\hline None & 73 & $6.5(2.2-17.5)$ & & - & - & \\
\hline Primary & 297 & $16.0(10.7-23.3)$ & & 568 & $32.8(27.4-38.8)$ & \\
\hline Secondary & 794 & $17.5(13.6-22.3)$ & & 1544 & $30.4(26.7-34.4)$ & \\
\hline Higher education & 43 & $31.1(12.5-58.7)$ & & 84 & $26.5(13.9-44.6)$ & \\
\hline Missing/unknown* & 77 & - & & 392 & - & \\
\hline
\end{tabular}


Table 3: Continued

\begin{tabular}{|c|c|c|c|c|c|c|}
\hline \multirow[b]{3}{*}{ Variable } & \multicolumn{3}{|c|}{ South Africa, 2008} & \multicolumn{3}{|c|}{ South Africa, 2012} \\
\hline & \multicolumn{3}{|c|}{ ART } & \multicolumn{3}{|c|}{ On ART } \\
\hline & $\mathbf{N}$ & $\begin{array}{c}\text { Weighted \% } \\
(95 \% \mathrm{CI})\end{array}$ & p-value & $\mathbf{N}$ & $\begin{array}{c}\text { Weighted \% } \\
(95 \% \mathrm{CI})\end{array}$ & p-value \\
\hline Marital status & & & 0.031 & & & 0.002 \\
\hline Single & 726 & $17.5(13.2-23.0)$ & & 530 & $33.3(26.0-41.6)$ & \\
\hline Married & 342 & $13.2(9.3-18.4)$ & & 1784 & $27.7(24.4-31.3)$ & \\
\hline $\begin{array}{l}\text { Divorced/ } \\
\text { separated/ } \\
\text { widowed }\end{array}$ & 143 & $28.8(19.3-40.5)$ & & 229 & $47.0(38.8-55.3)$ & \\
\hline Household wealth & & & 0.118 & & & 0.738 \\
\hline Quintile I & 375 & $15.1(10.6-21.2)$ & & 759 & $31.4(26.9-36.4)$ & \\
\hline Quintile II & 382 & $15.0(10.9-20.4)$ & & 683 & $29.1(24.1-34.6)$ & \\
\hline Quintile III & 243 & $24.5(16.7-34.4)$ & & 652 & $31.1(24.2-38.9)$ & \\
\hline Quintile IV & 197 & $13.1(7.7-21.5)$ & & 315 & $27.0(19.4-36.4)$ & \\
\hline Quintile V & 68 & $24.0(9.8-47.8)$ & & 148 & $37.8(24.2-53.6)$ & \\
\hline Employment & & & 0.186 & & & $<0.001$ \\
\hline Unemployed & 706 & $20.4(16.2-25.5)$ & & 1489 & $33.9(30.2-37.9)$ & \\
\hline Employed & 426 & $11.4(8.1-15.7)$ & & 101 & $9.7(4.2-20.9)$ & \\
\hline Student & 61 & $22.2(5.2-59.6)$ & & 933 & $27.8(23.2-32.8)$ & \\
\hline Most recent HIV test & & & 0.328 & & & 0.209 \\
\hline$<12$ months & 365 & $21.8(15.6-29.4)$ & & 1276 & $35.4(31.3-39.7)$ & \\
\hline $1-2$ years & 192 & $17.3(10.9-26.5)$ & & 266 & $33.4(25.8-42.0)$ & \\
\hline $2-3$ years & 91 & $23.4(13.2-37.9)$ & & 152 & $30.5(21.8-40.9)$ & \\
\hline $3+$ years & 98 & $31.3(19.5-46.0)$ & & 245 & $44.3(33.6-55.6)$ & \\
\hline $\begin{array}{l}\text { Alcohol intake in last } \\
12 \text { months }\end{array}$ & & & 0.491 & & & 0.066 \\
\hline $\begin{array}{l}\text { Non-high-risk } \\
\text { drinker }\end{array}$ & 1083 & $16.6(13.3-20.6)$ & & 2050 & $31.5(27.9-35.3)$ & \\
\hline High-risk drinker & 113 & $20.8(11.1-35.7)$ & & 249 & $21.2(13.4-31.8)$ & \\
\hline $\begin{array}{l}\text { Recreational drug } \\
\text { use } \dagger\end{array}$ & & & 0.871 & & & $<0.001$ \\
\hline Non-drug user & 10101 & $17.5(14.0-21.5)$ & & 2345 & $32.1(28.9-35.6)$ & \\
\hline Drug user & 45 & $15.8(4.1-45.1)$ & & 122 & $9.0(4.3-17.6)$ & \\
\hline Total & 1284 & $17.4(14.2-20.9)$ & & 2586 & $30.3(27.2-33.6)$ & \\
\hline
\end{tabular}

Notes: All numbers are unweighted except where otherwise specified. ${ }^{\star}$ Estimates not presented for missing/unknown categories. $\dagger$ Refers to last 3 months. 
Table 4: Multiple regression analysis showing associations between selected characteristics of HIV-infected individuals with ART non-use among individuals aged 15 to 64 years, South Africa, 2008 and 2012

\begin{tabular}{|c|c|c|c|c|}
\hline \multirow[b]{3}{*}{ Variable } & \multirow{2}{*}{\multicolumn{2}{|c|}{$\begin{array}{c}\text { South Africa, } 2008 \\
\text { Multiple Regression } \\
\text { Analysis n=1170 }\end{array}$}} & \multirow{2}{*}{\multicolumn{2}{|c|}{$\begin{array}{c}\text { South Africa, } 2012 \\
\text { Multiple Regression } \\
\text { Analysis n=2138 }\end{array}$}} \\
\hline & & & & \\
\hline & aOR $(95 \% \mathrm{CI})$ & p-value & aOR (95\% CI) & p-value \\
\hline \multicolumn{5}{|l|}{ Locality type } \\
\hline Urban formal (ref) & Ref & & ref & \\
\hline Urban informal & $0.49(0.24-0.98)$ & 0.04 & $1.20(0.75-1.92)$ & 0.441 \\
\hline Rural formal & $1.20(0.38-0.82)$ & 0.75 & $0.85(0.46-1.54)$ & 0.583 \\
\hline Rural informal & $0.52(0.25-1.09)$ & 0.084 & $0.78(0.50-1.20)$ & 0.259 \\
\hline \multicolumn{5}{|l|}{ Province } \\
\hline KwaZulu-Natal (ref) & ref & & & \\
\hline Western Cape & $0.40(0.13-1.20)$ & 0.104 & & \\
\hline Eastern Cape & $0.86(0.38-1.97)$ & 0.727 & & \\
\hline Northern Cape & $0.60(0.20-1.80)$ & 0.358 & & \\
\hline Free State & $1.49(0.63-3.54)$ & 0.365 & & \\
\hline Northwest & $0.71(0.30-1.68)$ & 0.431 & & \\
\hline Gauteng & $0.70(0.30-1.62)$ & 0.402 & & \\
\hline Mpumalanga & $0.84(0.38-1.83)$ & 0.656 & & \\
\hline Limpopo & $1.50(0.49-4.55)$ & 0.477 & & \\
\hline \multicolumn{5}{|l|}{ Sex } \\
\hline Male (ref) & & & ref & \\
\hline Female & & & $0.73(0.52-1.04)$ & 0.084 \\
\hline \multicolumn{5}{|l|}{ Age (years) } \\
\hline $15-24$ & $2.68(0.813-8.808)$ & 0.105 & $4.23(2.56-6.70)$ & $<0.001$ \\
\hline $25-34$ & $0.67(0.30-1.49)$ & 0.326 & $2.84(1.73-4.67)$ & $<0.001$ \\
\hline $35-49$ & $0.55(0.27-1.14)$ & 0.108 & $1.08(0.50-1.20)$ & 0.741 \\
\hline 50-64 (ref) & ref & & ref & \\
\hline \multicolumn{5}{|l|}{ Marital status } \\
\hline $\begin{array}{l}\text { Single/Never married/no } \\
\text { stable partnership (ref) }\end{array}$ & ref & & ref & \\
\hline Married/stable partnership & $1.52(0.85-2.72)$ & 0.159 & $1.25(0.86-1.82)$ & 0.241 \\
\hline Divorced/Separated/ Widowed & $0.45(0.22-0.91)$ & 0.027 & $0.99(0.59-1.67$ & 0.977 \\
\hline \multicolumn{5}{|l|}{ Education } \\
\hline None (ref) & ref & & & \\
\hline Primary & $0.34(0.97-1.22)$ & 0.099 & & \\
\hline Secondary & $0.29(0.09-0.99)$ & 0.048 & & \\
\hline Higher education & $0.14(0.03-0.66)$ & 0.014 & & \\
\hline
\end{tabular}


Table 4: Continued

\begin{tabular}{|c|c|c|c|c|}
\hline \multirow[b]{3}{*}{ Variable } & \multirow{2}{*}{\multicolumn{2}{|c|}{$\begin{array}{c}\text { South Africa, } 2008 \\
\text { Multiple Regression } \\
\text { Analysis } n=1170\end{array}$}} & \multirow{2}{*}{\multicolumn{2}{|c|}{$\begin{array}{c}\text { South Africa, } 2012 \\
\text { Multiple Regression } \\
\text { Analysisn=2138 }\end{array}$}} \\
\hline & & & & \\
\hline & aOR $(95 \% \mathrm{CI})$ & p-value & aOR $(95 \% \mathrm{CI})$ & p-value \\
\hline \multicolumn{5}{|l|}{ Employment } \\
\hline Unemployed (ref) & ref & & ref & \\
\hline Employed & $2.16(1.30-3.94)$ & 0.004 & $2.53(0.91-7.07)$ & 0.075 \\
\hline Student & $0.32(0.06-1.76)$ & 0.191 & $1.61(1.16-2.23)$ & 0.004 \\
\hline \multicolumn{5}{|l|}{ Household wealth quintile } \\
\hline Quintile I (ref) & ref & & & \\
\hline Quintile II & $0.89(0.47-1.69)$ & 0.724 & & \\
\hline Quintile III & $0.443(0.20-0.95)$ & 0.037 & & \\
\hline Quintile IV & $0.82(0.33-2.03)$ & 0.673 & & \\
\hline Quintile V & $0.40(0.13-1.26)$ & 0.116 & & \\
\hline \multicolumn{5}{|l|}{ Alcohol intake in past 12 months } \\
\hline Non high-risk drinker (ref) & & & ref & \\
\hline High-risk drinker & & & $1.36(0.72-2.55)$ & 0.344 \\
\hline \multicolumn{5}{|l|}{$\begin{array}{l}\text { Recreational drug use in past } 3 \\
\text { months }\end{array}$} \\
\hline No (ref) & & & ref & \\
\hline Yes & & & $4.56(1.79-11.57)$ & 0.001 \\
\hline
\end{tabular}

\section{Discussion}

Use of ART increased significantly in both countries, consistent with ART program scale-up and evolving treatment guidelines in both Kenya and South Africa during the study period. The proportion of PLHIV on ART was higher in Kenya than in South Africa both in 2007/2008 and 2012. However South Africa had a larger number of PLHIV compared to Kenya in both surveys, and the proportion of PLHIV on ART in South Africa nearly doubled over this period. While in South Africa it appears disparities in ART use may have decreased over the period of analysis, in Kenya household wealth among women and rural residency among men and women combined were both significantly associated with ART non-use in 2012 but not in 2007 . 
The analyses showed both similarities and differences in ART use in Kenya and South Africa. In both countries, after controlling for other covariates, there were no significant disparities in ART use by province and sex. In Kenya in 2012 lack of ART use was higher in rural areas while no differences were observed by locality type in South Africa in either survey year. Differences by household wealth were only seen in 2012 in Kenya, among women only, and in 2008 in South Africa, where they were limited to one quintile.

Older age was associated with greater likelihood of ART use in both countries in both survey periods when controlling for other factors. This may partially reflect natural disease progression and ART eligibility criteria at the time, with older people more likely to have been infected for a longer period of time compared to younger people, thus reaching the thresholds for ART treatment required by contemporary treatment guidelines. Nonetheless this finding of age differences in non-use of ART among PLHIV suggests need for strengthening efforts to ensure that younger people know their status, start ART, and adhere to care and treatment. In the 2012 KAIS $82 \%$ of HIV-infected youth aged $15-24$ years (50.6\%) were unaware of their HIV status, compared with $58.9 \%$ of those aged 25-34 [26], while the 2012 South Africa survey found a significantly lower proportion of youth aged 15-24 years had been tested for HIV compared with those aged 25-49 years (78.2\%) [18]. With the adoption of the test-and-treat policy in 2016 in both countries, decreasing disparities in ART use by age group are expected in the future. Nonetheless, high uptake of testing among young people combined with appropriate linkage to care will be a necessary precondition to achieving adequate ART coverage. Future studies may also find that reduced ART use among women with a recent pregnancy, as seen in both survey years in Kenya, may have since been mitigated by changed eligibility criteria which made all pregnant women eligible for life-long ART with the adoption of option B+ for PMTCT starting in 2014 regardless of CD4 count in Kenya [21]. In South Africa this policy was implemented in January 2015 [27].

Overall, household wealth and educational level were not associated with ART use in either country in 2012, which is perhaps a result of the large, governmentsponsored ART programs in both Kenya and South Africa offering ART to all regardless of ability to pay. However, in a sub-group analysis among women in Kenya, ART use was associated with increasing household wealth among women. In both countries, recent illicit/recreational drug use was associated with lower ART use, though drug users make up a small proportion of PLHIV. This finding could reflect low treatment access, adherence and/or retention in care in this population group. In a separate analysis of KAIS 2012, Mukui et al. found a significant association between both younger age and recreational drug use and poor 
adherence to treatment, and argue that increased identification and management of recreational drug use in this population is needed in order to mitigate its potential effects on adherence [28].

Kenya's epidemic is highly geographically heterogeneous, with highest prevalence in the Nyanza region and the greatest burden of PLHIV in Nyanza and Nairobi [15]. Point estimates for ART use increased across all regions except Nyanza, though only Rift Valley increased significantly. Given that over a third of PLHIV in Kenya live in Nyanza, additional efforts to achieve increases in ART use in this region are warranted. The appearance of reduced ART use in rural relative to urban areas in 2012, not seen in 2007, may reflect either reduced barriers to access in urban areas or challenges in accessing drugs in rural areas due to increased travel costs, fear of stigma, or other barriers, and is a cause for concern $[29,30]$.

In South Africa, HIV prevalence also varied across provinces and geographic locations, being highest in both urban and rural informal settlements in 2012. While ART use was lowest in rural informal settlements in 2008, it increased dramatically in 2012 reaching the same levels of use observed in other locality types, suggesting success in increasing geographical equity in ART access in South Africa over time. This suggestion is further corroborated by the absence of significant associations between ART non-use and province in both survey years and by locality type in 2012.

The lower levels of ART use among employed PLHIV versus unemployed in South Africa in 2008 might be due to a healthy worker effect, given that treatment initiation guidelines in South Africa historically recommended ART initiation based on CD4 count. Comparatively lower ART use among South African students in 2012, even when controlling for age, is an interesting finding, and could also be a reflection of the healthy worker effect as well as the natural disease progression as discussed above.

In Kenya, non-disclosure of HIV status to partners was significantly associated with higher adjusted odds of lack of ART use among PLHIV, suggesting that stigma may impact an individual's decision regarding use of ART. The most recent stigma index survey conducted in Kenya in 2009-2010 found high levels of social exclusion (40\%) and internalized stigma with $46 \%$ of PLHIV feeling guilty or ashamed for being HIV-positive [31]. In contrast, the stigma index survey conducted in South Africa in 2014 found low levels of social exclusion among PLHIV, however it 
revealed high levels of internalised stigma with $29 \%$ of participants in the survey reporting that they felt ashamed, while $28 \%$ had feelings of guilt [32]. This suggests need for continued stigma reduction strategies among PLHIV in both countries.

This analysis was subject to several limitations. Antiretroviral treatment access from 2007-2012 in both countries was highly dependent on treatment guidelines implemented at the time that individual patients engaged in care, and these guidelines have evolved over time. Our analysis did not attempt to establish eligibility for treatment, nor would it be entirely possible in a cross-sectional study to account for eligibility prior to ART initiation, but rather included all PLHIV regardless of eligibility. Since we measured presence of trace quantities of ART metabolites in blood we are not able to distinguish between PLHIV who have never been on ART, those who have stopped taking ART (i.e. disengagement from care) or those that have not taken their drugs for several days or weeks (i.e. nonadherent). Data regarding distance to the nearest facility offering ART, which may have provided further insights about ART accessibility, were not available. We also did not consider self-reported HIV status when assessing ART use. Finally, sample size was limited for some domains, especially in Kenya, which could have limited our power to detect differences in some cases and prevented more detailed sexspecific analyses.

In spite of these limitations, measurement of ART use in nationally-representative surveys in two countries with large HIV treatment programs allowed for an objective assessment of trends in ART use among PLHIV in the era of treatment expansion and identification of potential barriers to ART access and uptake. Both countries demonstrated substantial increases in ART use over time with broadly equitable access to ART across geographic and socioeconomic status with some exceptions. Our analyses did find evidence of increasing disparities in access to ART by household wealth in women in Kenya, and lingering inequities in use by age and among those who use recreational drugs, indicating some populations may require increased adherence support or access to HIV testing. To the degree that lower use in youth may be due to eligibility criteria, the adoption of test-and-treat provides a new opportunity to increase access to ART among youth. 


\section{Acknowledgements}

Authors would like to thank Yajna D. Moloo for her helpful literature review on socioeconomic factors affecting ART use in sub-Saharan Africa, the University of Cape Town Department of Clinical Pharmacology for conducting the ART biomarker testing, the study teams that conducted the studies in South Africa and Kenya and finally the survey participants.

\section{References}

1. UNAIDS. "15 by 15": a global target achieved [Internet]. Geneva, Switzerland: UNAIDS; Available: http://www.unaids.org/sites/default/files/media_asset/UNAIDS_15by15_en.pdf

2. UNAIDS. Global AIDS Update 2016. Geneva, Switzerland: UNAIDS; 2016.

3. Granich RM, Gilks CF, Dye C, De Cock KM, Williams BG. Universal voluntary HIV testing with immediate antiretroviral therapy as a strategy for elimination of HIV transmission: a mathematical model. Lancet Lond Engl. 2009;373: 48-57. doi:10.1016/S0140-6736(08)61697-9

4. UNAIDS. Eastern and Southern Africa HIV Epidemic Profile [Internet]. Geneva, Switzerland: UNAIDS; 2014. Available: http://www.unaidsrstesa.org/wp-content/uploads/2015/06/unaids_profile_ Regional.pdf

5. World Health Organization. Consolidated guidelines on the use of antiretroviral drugs for treating and preventing HIV infection. Recommendations for a public health approach. Geneva, Switzerland; 2013 Jun.

6. Posse M, Meheus $F$, van Asten $H$, van der Ven $A$, Baltussen R. Barriers to access to antiretroviral treatment in developing countries: a review. Trop Med Int Health TM IH. 2008;13: 904-913. doi:10.1111/j.1365-3156.2008.02091.x

7. Cleary S, Silal S, Birch S, Carrara H, Pillay-van Wyk V, Rehle T, et al. Equity in the use of antiretroviral treatment in the public health care system in urban South Africa. Health Policy. 99: 261-266. doi:10.1016/j.healthpol.2010.10.016

8. Tromp N, Michels C, Mikkelsen E, Hontelez J, Baltussen R. Equity in utilization of antiretroviral therapy for HIV-infected people in South Africa: a systematic review. Int J Equity Health. 2014;13: 60. doi:10.1186/s12939-014-0060-z

9. Loubiere S, Boyer S, Protopopescu C, Bonono CR, Abega SC, Spire B, et al. Decentralization of HIV care in Cameroon: Increased access to antiretroviral treatment and associated persistent barriers. Health Policy. 2009; doi:10.1016/j.healthpol.2009.03.006

10. Makwiza I, Nyirenda L, Bongololo G, Banda T, Chimzizi R, Theobald S. Who has access to counseling and testing and anti-retroviral therapy in Malawi - An equity analysis. Int J Equity Health. 2009; doi:10.1186/1475-9276-8-13

11. Nyamhanga TM, Muhondwa EPY, Shayo R. Masculine attitudes of superiority deter men from accessing antiretroviral therapy in Dar es Salaam, Tanzania. Glob Health Action. 2013; doi:10.3402/gha. v6i0.21812 
12. Phelps BR, Ahmed S, Amzel A, Diallo MO, Jacobs T, Kellerman SE, et al. Linkage, initiation and retention of children in the antiretroviral therapy cascade. AIDS. 2013; doi:10.1097/QAD.0000000000000095

13. Mooney AC, Gottert A, Khoza N, Rebombo D, Hove J, Suárez AJ, et al. Men s perceptions of treatment as prevention in South Africa: Implications for engagement in HIV care and treatment. AIDS Educ Prev. 2017; doi:10.1521/aeap.2017.29.3.274

14. World Health Organization. Guideline on when to start antiretroviral therapy and on pre-exposure prophylaxis for HIV [Internet]. Geneva, Switzerland: WHO; 2015 Sep. Available: http://apps.who.int/ iris/bitstream/10665/186275/1/9789241509565_eng.pdf

15. National AIDS Control Council (NACC), National AIDS and STI Control Programme (NASCOP). Kenya HIV Estimates, 2013 [Internet]. Kenya: NACC; 2014 Jun. Available: http://reliefweb.int/sites/ reliefweb.int/files/resources/HIV\%20estimates\%20report\%20Kenya\%202014_print.pdf

16. National AIDS and STI Control Programme (NASCOP). 2007 Kenya AIDS indicator survey: final report [Internet]. Nairobi, Kenya: NASCOP; 2009. Available: http://catalog.ihsn.org/index.php/catalog/3916

17. Waruiru W, Kim AA, Kimanga DO, Ng'ang'a J, Schwarcz S, Kimondo L, et al. The Kenya AIDS Indicator Survey 2012: rationale, methods, description of participants, and response rates. J Acquir Immune Defic Syndr 1999. 2014;66 Suppl 1: S3-12. doi:10.1097/QAl.0000000000000114

18. O Shisana, T Rehle, LC Simbayi, K Zuma, S Jooste, N Zungu, et al. South African National HIV Prevalence, Incidence and Behaviour Survey, 2012. Cape Town, South Africa; 2014.

19. Kim AA, Mukui I, Young PW, Mirjahangir J, Mwanyumba S, Wamicwe J, et al. Undisclosed HIV infection and art use in the kenya AIDS indicator survey 2012: relevance to targets for HIV diagnosis and treatment in kenya. AIDS. 2016; 1. doi:10.1097/QAD.0000000000001227

20. National AIDS Control Council (NACC), National AIDS and STI Control Programme (NASCOP). Guidelines for antiretroviral therapy in Kenya, 4th Edition 2011 [Internet]. Nairobi, Kenya: NASCOP; 2011. Available: http://www.emtct-iatt.org/wp-content/uploads/2013/04/Kenya_National-ARVGuidelines_2011.pdf

21. Ministry of Health; National AIDS Control Council (NACC), National AIDS and STI Control Programme (NASCOP). Guidelines on use of antiretroviral drugs for treating and preventing HIV infection: A rapid advice, 2014 [Internet]. Nairobi, Kenya: NASCOP; 2014. Available: http://healthservices.uonbi.ac.ke/ sites/default/files/centraladmin/healthservices/Rapid\%20Advice\%20Booklet $\% 202014 \% 2024 \% 20$ June\%2012\%20noon_0.pdf

22. Ministry of Health, National AIDS \& STI Control Programme. Guidelines on Use of Antiretroviral Drugs for Treating and Preventing HIV Infections in Kenya. 2016 Edition. [Internet]. NASCOP; 2016. Available: http://emtct-iatt.org/wp-content/uploads/2016/09/Guidelines-on-Use-of-AntiretroviralDrugs-for-Treating-and-Preventing-HI....pdf

23. Department of Health. HIV and AIDS Policy Guideline [Internet]. South Africa: Ministry of Health South Africa; 2004. Available: http://www.hst.org.za/uploads/files/sa_ART_Guidelines1.pdf

24. Department of Health. South African Antiretroviral Treatment Guidelines 2010 [Internet]. South Africa: Department of Health; 2010. Available: http://apps.who.int/medicinedocs/documents/ s19153en/s19153en.pdf

25. Greenacre M, Blasius J. Multiple Correspondence Analysis and Related Methods. Chapman \& Hall/CRC Statistics in the Social and Behavioral Sciences. CRC Press; 2006. 
26. Ng'ang'a A, Waruiru W, Ngare C, Ssempijja V, Gachuki T, Njoroge I, et al. The Status of HIV Testing and Counseling in Kenya: Results From a Nationally Representative Population-Based Survey. JAIDS I Acquir Immune Defic Syndr. 2014;66: S27-S36. doi:10.1097/QAI.0000000000000102

27. Department of Health. National consolidated guidelines for the prevention of mother-to-child transmission of HIV (PMTCT) and the management of HIV in children, adolescents and adults [Internet]. South Africa: Department of Health South Africa; 2014 Dec. Available: http://www. sahivsoc.org/Files/ART\%20Guidelines\%2015052015.pdf

28. Mukui IN, Ng'ang'a L, Williamson J, Wamicwe JN, Vakil S, Katana A, et al. Rates and Predictors of Non-Adherence to Antiretroviral Therapy among HIV-Positive Individuals in Kenya: Results from the Second Kenya AIDS Indicator Survey, 2012. PLOS ONE. 2016;11: e0167465. doi:10.1371/journal. pone. 0167465

29. Akullian AN, Mukose A, Levine GA, Babigumira JB. People living with HIV travel farther to access healthcare: a population-based geographic analysis from rural Uganda. J Int AIDS Soc. 2016;19. doi:10.7448/IAS.19.1.20171

30. Fox MP, Mazimba A, Seidenberg P, Crooks D, Sikateyo B, Rosen S. Barriers to initiation of antiretroviral treatment in rural and urban areas of Zambia: a cross-sectional study of cost, stigma, and perceptions about ART. J Int AIDS Soc. 2010;13: 8. doi:10.1186/1758-2652-13-8

31. NEPHAK, GNP+. PLHIV Stigma Index Kenyan Country Assessment [Internet]. Nairobi, Kenya: NEPHAK; 2011. Available: http://www.stigmaindex.org/sites/default/files/reports/Kenya\%20People\%20 Living\%20with\%20HIV\%20Stigma\%20Index\%20Report\%202009.pdf

32. South African National AIDS Council. The People Living With HIV Stigma Index: South Africa 2014 Summary-Booklet-on-Stigma-Index-Survey South Africa [Internet]. SANAC; 2015 May. Available: http://www.stigmaindex.org/sites/default/files/reports/Summary-Booklet-on-Stigma-IndexSurvey\%20South\%20Africa.pdf 


\section{Supporting Information}

S1 Table. Treatment guidelines by survey year in Kenya and South Africa

\begin{tabular}{lll} 
Survey & Kenya & South Africa \\
\hline $2007-2008$ & CD4 $<200$ cells $/ \mathrm{mm}^{3}$, or WHO stage & CD4 $<200$ cells $/ \mathrm{mm}^{3}$, WHO stage IV \\
& III or IV & \\
\hline 2012 & CD4 $<350$ cells $/ \mathrm{mm}^{3}$, or WHO stage III & CD $4<200$ cells $/ \mathrm{mm}^{3}$, or WHO stage IV, \\
& or IV, or co-infected with TB & or $4<350$ cells $/ \mathrm{mm}^{3}$ and pregnant or \\
& & co-infected with $\mathrm{TB}$ \\
\hline Present & Test-and-treat from mid-2016 & Test-and-treat from $1^{\text {st }}$ September \\
& & 2016 \\
\hline
\end{tabular}

\section{S1 Text. Statistical Methods for addressing missing data}

In order to address missing values for several key variables including ART use (the dependent variable) and CD4 count, we used multiple imputation. Potential targets for imputation were selected by first inspecting patterns of missing values using the Stata mi misstable command, resulting in the selection of ART use (the dependent variable), CD4 count, and disclosure of HIV status to sex partner as targets of imputation. We assumed that missing values were missing at random (MAR), in other words that the missingness can be completely explained by other observed covariates in the dataset. Given that missing ART status and CD4 count is generally due to laboratory transport or processing errors, or due to depletion of sample, all of which generally occur independently from factors likely to influence ART use, CD4 count or disclosure of HIV status, this assumption seemed plausible. We used multiple imputation with chained equations (MICE), implemented with the Stata mi command. This method was selected due to the ready availability of implementations in statistical software, as well as its flexibility and simplicity of specifying restrictions on imputed values (for example, allowing the exclusion of specific auxiliary variables in the model for specific imputation targets). Imputations were run separately on each survey. First, variables identified as likely to be associated with the outcome of interest were selected. Additional auxiliary variables were also selected. In the case of 2007, the following variables were selected as targets for multiple imputation based on the proportion of responses that were missing and their relevance to the primary analysis: CD4 category, ART status, and disclosure of HIV status to most recent sex partner. The following variables were selected as predictors of the response variables: cluster number, province, sex, wealth index quintile, employment status, educational level, age group, marital status, locality, history of HIV testing. Self-reported ART status was considered for inclusion but dropped due to colinearity with the dependent variable, as were household-level variables. The data were svyset before analysis 
using the normalized KAIS blood weights. The following equation was used to create 20 imputed datasets for the 2007 KAIS for HIV-positive respondents using chained equations to allow multiple outcomes to be imputed sequentially.

The imputation was restricted to HIV-positive respondents, as only these respondents are included in the analysis of ART use. CD4 category is an ordinal variable so was imputed using an ordered logistic model, ART status is a Boolean variable so was imputed using a logistic model, while disclosure status was a categorical variable with three unordered levels and was imputed using multinomial logistic regression. The MICE method assumes a joint normal distribution of imputed values.

After imputation, 517 of 522 missing ART status had been imputed, 81 of 84 missing CD4 category had been imputed, and 61 of 61 missing disclosure had been imputed. Not all cases were successfully imputed due to missingness of the predictors.

For the 2012 KAIS, CD4 count was not included as a target for imputation as the proportion of missing values was low. Cluster number was omitted from the predictors due to colinearity with ART status. Self-reported ART status was also included as a predictor of disclosure, but omitted from predicting the ART biomarker again due to colinearity. Several household-level variables were also found to be predictive of the response and were included in the final equation: sex of head of household, whether head of household was known to be HIV-infected, HIV test result of head of household, and the household hunger scale index.

After imputation, of 648 HIV-positive respondents, 89 missing ART status had been imputed, while 20 missing disclosure status had been imputed (there were no cases where imputation was unsuccessful).

To assess imputation errors such as misspecification of the imputation model or convergence issues, trace plots were used to look for patterns in the imputations to assess possible trends in imputed values or variances. The Stata mi xeq command was used to inspect and compare distributions of imputed values for individual imputations. Supplemental Table S2 compares the distribution of values for the observed and complete datasets. 


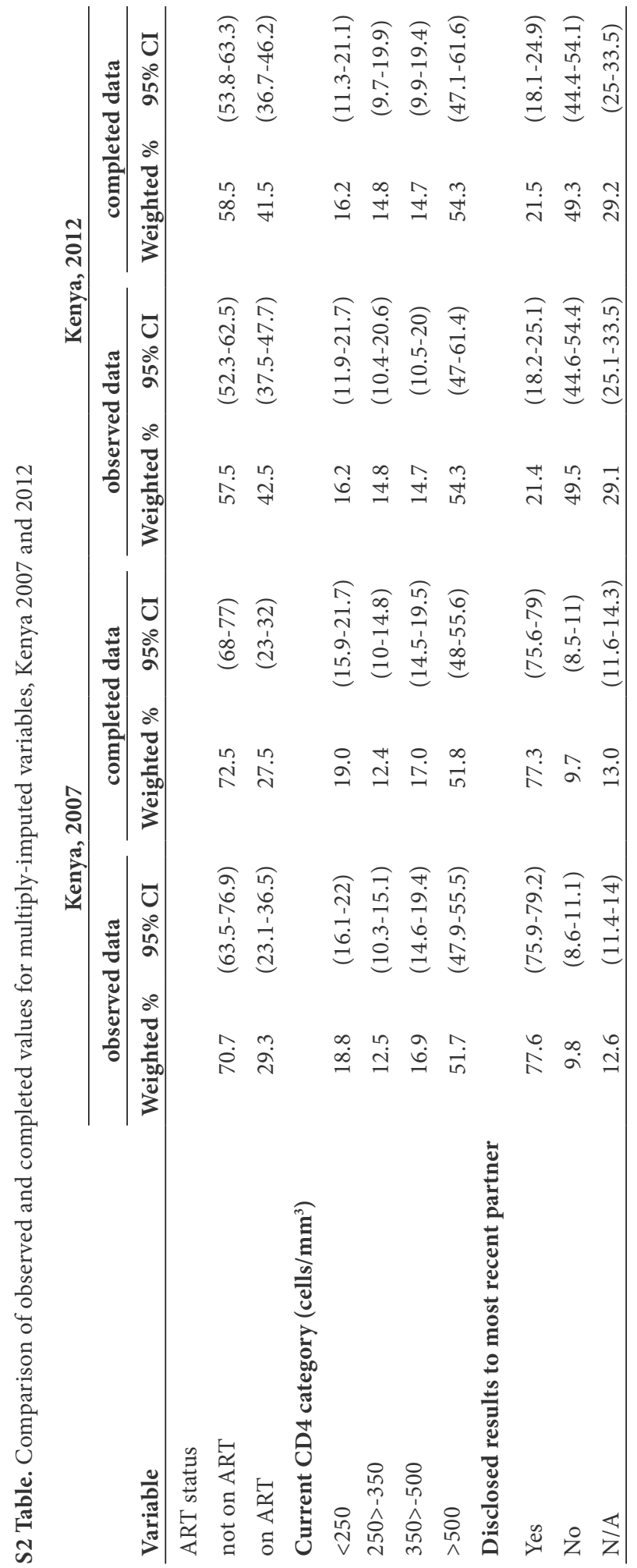


S3 Table. Bivariate regression analysis showing associations between selected characteristics of HIV-infected individuals with exposure to ART among individuals 15-64 years, Kenya 2007 and 2012

\begin{tabular}{|c|c|c|c|c|c|c|}
\hline \multirow[b]{2}{*}{ Variable } & \multicolumn{3}{|c|}{ Kenya, 2007} & \multicolumn{3}{|c|}{ Kenya, 2012} \\
\hline & OR & $(95 \% \mathrm{CI})$ & p-value & OR & $(95 \% \mathrm{CI})$ & p-value \\
\hline Residency type & & & & & & 0.232 \\
\hline Urban (ref) & ref & & & ref & & \\
\hline Rural & 0.81 & $(0.45-1.46)$ & 0.474 & 1.27 & $(0.86-1.89)$ & \\
\hline Province & & & 0.518 & & & 0.648 \\
\hline Central & 0.67 & $(0.27-1.67)$ & & 0.83 & $(0.4-1.7)$ & \\
\hline Coast & 1.71 & $(0.63-4.68)$ & & 1.10 & $(0.47-2.59)$ & \\
\hline Eastern & 1.02 & $(0.36-2.88)$ & & 0.63 & $(0.27-1.49)$ & \\
\hline Nairobi (ref) & ref & & & ref & & \\
\hline Nyanza & 0.80 & $(0.34-1.87)$ & & 1.18 & $(0.65-2.14)$ & \\
\hline Rift Valley & 1.26 & $(0.48-3.31)$ & & 0.94 & $(0.42-2.09)$ & \\
\hline Western & 0.84 & $(0.33-2.16)$ & & 1.31 & $(0.61-2.82)$ & \\
\hline Female sex & 0.92 & $(0.61-1.38)$ & 0.673 & 0.80 & $(0.54-1.2)$ & 0.288 \\
\hline Age (years) & & & 0.002 & & & $<0.001$ \\
\hline $15-24$ & 3.69 & $(1.55-8.79)$ & & 5.60 & $(2.45-12.78)$ & \\
\hline $25-34$ & 2.18 & $(0.96-4.95)$ & & 4.09 & $(2.4-6.96)$ & \\
\hline $35-49$ & 1.31 & $(0.68-2.51)$ & & 1.22 & $(0.72-2.05)$ & \\
\hline 50-64 (ref) & ref & & & ref & & \\
\hline Marital status & & & 0.069 & & & $<0.001$ \\
\hline single/never married (ref) & ref & & & ref & & \\
\hline married/cohabitating & 0.67 & $(0.33-1.38)$ & & 0.38 & $(0.21-0.71)$ & \\
\hline divorced/separated/widowed & 0.44 & $(0.2-1)$ & & 0.27 & $(0.14-0.53)$ & \\
\hline Education & & & 0.921 & & & 0.190 \\
\hline None (ref) & ref & & & ref & & \\
\hline Primary & 1.04 & $(0.62-1.75)$ & & 0.88 & $(0.5-1.56)$ & \\
\hline Secondary & 0.87 & $(0.45-1.69)$ & & 0.76 & $(0.29-1.97)$ & \\
\hline Higher & 0.80 & $(0.28-2.28)$ & & 0.57 & $(0.32-1.04)$ & \\
\hline Employment status & & & & & & 0.078 \\
\hline Employed & 1.04 & $(0.59-1.84)$ & 0.880 & 1.41 & $(0.96-2.07)$ & \\
\hline Unemployed (ref) & ref & & & ref & & \\
\hline Household wealth quintile & & & 0.736 & & & 0.934 \\
\hline Quintile I (ref) & ref & & & ref & & \\
\hline Quintile II & 1.07 & $(0.54-2.11)$ & & 0.95 & $(0.46-1.95)$ & \\
\hline Quintile II & 0.74 & $(0.36-1.52)$ & & 0.93 & $(0.46-1.86)$ & \\
\hline Quintile IV & 0.75 & $(0.35-1.58)$ & & 0.88 & $(0.45-1.73)$ & \\
\hline Quintile V & 0.76 & $(0.38-1.52)$ & & 0.75 & $(0.36-1.55)$ & \\
\hline
\end{tabular}


Table S3. Continued

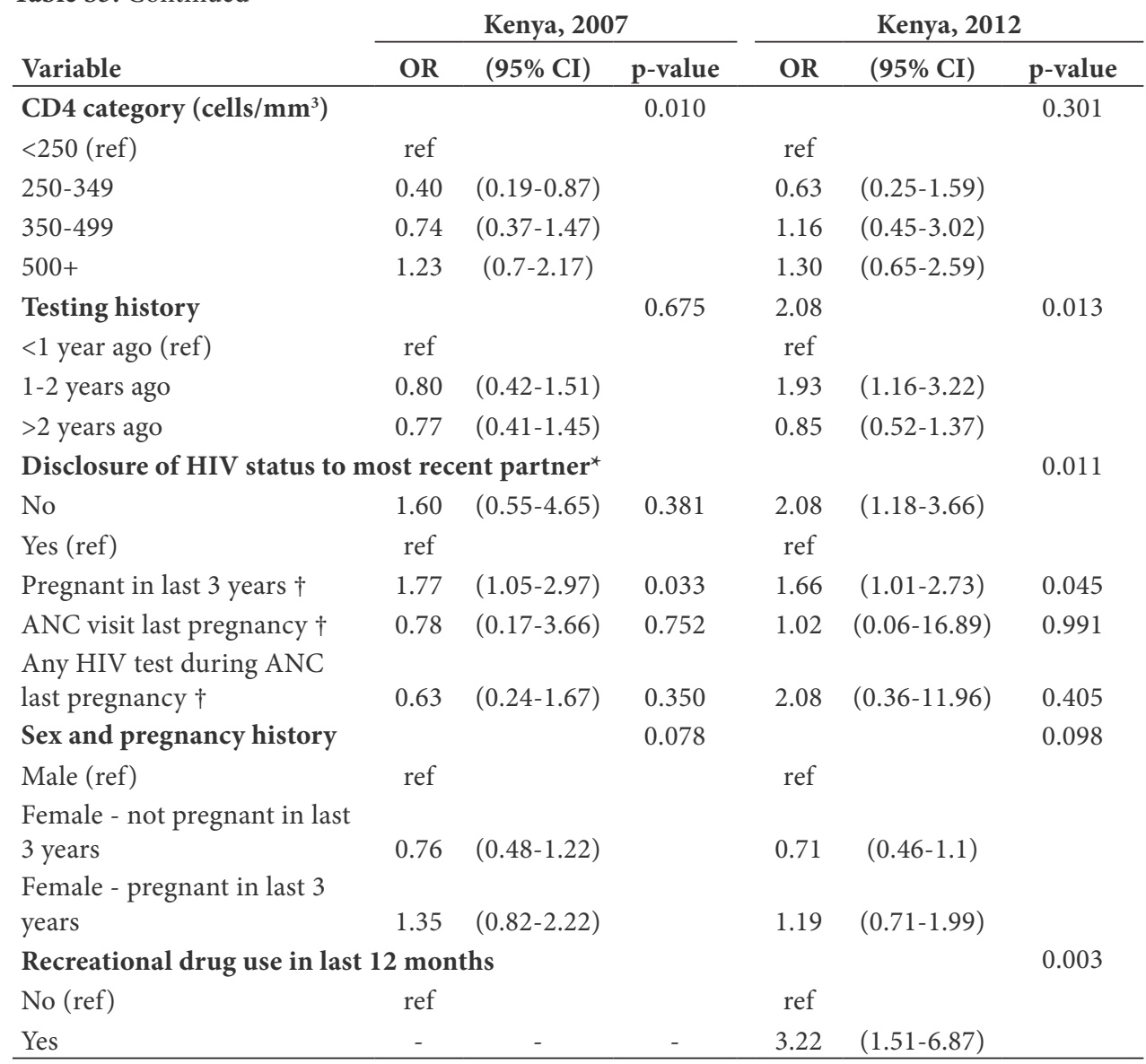

Notes: ${ }^{\star}$ Applies to respondents who self-reported HIV-positive. † Applies to women only.

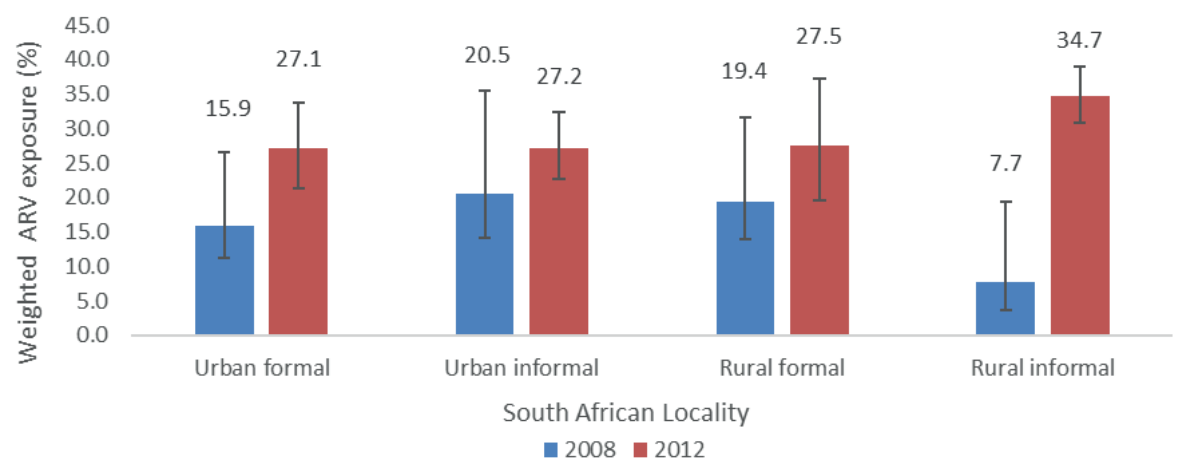

S1 Fig. Antiretroviral exposure by locality type among HIV-infected individuals aged 15-64 years old: South Africa, 2008 and 2012 
S4 Table. Bivariate regression analysis showing associations between selected characteristics of PLHIV with non-use ART among individuals 15-64 years: South Africa 2008 and 2012

\begin{tabular}{|c|c|c|c|c|}
\hline \multirow[b]{3}{*}{ Variable } & \multirow{2}{*}{\multicolumn{2}{|c|}{$\begin{array}{c}\text { South Africa, } 2008 \\
\text { Bivariate Analysis }\end{array}$}} & \multicolumn{2}{|c|}{ South Africa, 2012} \\
\hline & & & \multicolumn{2}{|c|}{ Bivariate Analysis } \\
\hline & OR (95\% CI) & p-value & OR $(95 \% \mathrm{CI})$ & p-value \\
\hline \multicolumn{5}{|l|}{ Locality type } \\
\hline Urban formal (ref) & ref & & ref & \\
\hline Urban informal & $0.73(0.40-1.34)$ & 0.313 & $0.99(0.67-1.48)$ & 972 \\
\hline Rural formal & $0.79(0.45-1.38)$ & 0.405 & $0.98(0.57-0.69)$ & 0.935 \\
\hline Rural informal & $2.25(0.94-5.42)$ & 0.069 & $0.70(0.49-1.00)$ & 0.053 \\
\hline \multicolumn{5}{|l|}{ Province } \\
\hline KwaZulu-Natal (ref) & ref & & ref & \\
\hline Western Cape & $2.16(0.91-5.12)$ & 0.079 & $1.29(0.74-2.23)$ & 0.372 \\
\hline Eastern Cape & $1.67(0.59-4.69)$ & 0.333 & $1.20(0.66-2.17)$ & 0.549 \\
\hline Northern Cape & $1.69(0.55-5.21)$ & 0.364 & $0.42(0.138-1.25)$ & 0.119 \\
\hline Free State & $2.53(1.01-6.35)$ & 0.048 & $0.98(0.52-1.84)$ & 0.938 \\
\hline Northwest & $1.44(0.59-3.52)$ & 0.423 & $1.73(0.89-3.36)$ & 0.105 \\
\hline Gauteng & $1.72(0.65-4.53)$ & 0.27 & $0.94(0.47-1.88)$ & 0.853 \\
\hline Mpumalanga & $2.01(0.84-4.80)$ & 0.115 & $1.48(0.79-2.76)$ & 0.223 \\
\hline Limpopo & $2.45(0.89-6.77)$ & 0.083 & $0.87(0.40-1.88)$ & 0.722 \\
\hline \multicolumn{5}{|l|}{ Race } \\
\hline Other race (ref) & ref & & ref & \\
\hline Black African & $0.93(0.38-2.26)$ & 0.864 & $1.61(0.91-2.85)$ & 0.102 \\
\hline \multicolumn{5}{|l|}{ Sex } \\
\hline Male (ref) & ref & & ref & \\
\hline Female & $1.13(0.67-1.88))$ & 0.65 & $0.61(0.46-0.81)$ & 0.001 \\
\hline \multicolumn{5}{|l|}{ Age (years) } \\
\hline $15-24$ & $1.33(0.44-4.02)$ & 0.612 & $4.57(2.70-7.22)$ & $<0.001$ \\
\hline $25-34$ & $0.81(0.41-1.62)$ & 0.556 & $2.75(1.85-4.08)$ & $<0.001$ \\
\hline $35-49$ & $0.67(0.34-1.29)$ & 0.228 & $1.10(0.75-1.60)$ & 0.63 \\
\hline $50-64$ (ref) & ref & & ref & \\
\hline \multicolumn{5}{|l|}{ Marital status } \\
\hline $\begin{array}{l}\text { Single/Never married/no stable } \\
\text { partnership (ref) }\end{array}$ & ref & & ref & \\
\hline Married/stable partnership & $1.39(0.83-2.34)$ & 0.208 & $1.30(0.90-1.89)$ & 0.161 \\
\hline Divorced/Separated/Widowed & $0.53(0.28-1.00)$ & 0.05 & $0.56(0.35-0.91)$ & 0.017 \\
\hline \multicolumn{5}{|l|}{ Education } \\
\hline None (ref - 2008) & ref & & $\mathrm{n} / \mathrm{a}$ & $\mathrm{n} / \mathrm{a}$ \\
\hline Primary (ref - 2012) & $0.36(0.11-1.23)$ & 0.103 & ref & \\
\hline
\end{tabular}


Table S4. Continued

\begin{tabular}{|c|c|c|c|c|}
\hline \multirow[b]{3}{*}{ Variable } & \multicolumn{2}{|c|}{ South Africa, 2008} & \multicolumn{2}{|c|}{ South Africa, 2012} \\
\hline & \multicolumn{2}{|c|}{ Bivariate Analysis } & \multicolumn{2}{|c|}{ Bivariate Analysis } \\
\hline & OR $(95 \% \mathrm{CI})$ & p-value & OR $(95 \% \mathrm{CI})$ & p-value \\
\hline Secondary & $0.33(0.10-1.04)$ & 0.059 & $1.12(0.84-1.48)$ & 0.441 \\
\hline Higher education & $0.15(0.03-0.76)$ & 0.021 & $1.36(0.57-3.25)$ & 0.493 \\
\hline \multicolumn{5}{|l|}{ Employment } \\
\hline Unemployed (ref) & ref & & ref & \\
\hline Employed & $2.00(1.26-3.18)$ & 0.003 & $4.79(1.93-11.88)$ & 0.001 \\
\hline Student & $0.90(0.17-4.75)$ & 0.901 & $1.33(1.02-1.74)$ & 0.033 \\
\hline \multicolumn{5}{|l|}{ Household wealth quintile } \\
\hline Quintile I (ref) & ref & & ref & \\
\hline Quintile II & $0.99(0.57-1.74)$ & 0.983 & $1.13(0.82-1.55)$ & 0.467 \\
\hline Quintile III & $0.52(0.27-0.98)$ & 0.042 & $1.02(0.68-1.53)$ & 0.932 \\
\hline Quintile IV & $1.23(0.59-2.56)$ & 0.555 & $1.26(0.79-2.02)$ & 0.334 \\
\hline Quintile V & $0.58(0.18-1.84)$ & & $0.76(0.38-1.50)$ & 0.426 \\
\hline \multicolumn{5}{|l|}{ Most recent HIV test } \\
\hline$<12$ months (ref) & ref & & ref & \\
\hline $1-2$ years & $1.32(0.68-2.58)$ & 0.406 & $0.09(0.71-1.67)$ & 0.69 \\
\hline $2-3$ years & $0.91(0.41-2.05)$ & 0.822 & $1.24(0.77-2.01)$ & 0.365 \\
\hline $3+$ years & $0.61(0.29-1.29)$ & 0.197 & $0.69(0.44-1.08)$ & 0.103 \\
\hline \multicolumn{5}{|l|}{$\begin{array}{l}\text { Alcohol intake in the last } 12 \\
\text { month }\end{array}$} \\
\hline Non high-risk drinker (ref) & ref & & ref & \\
\hline High-risk drinker & $0.75(0.34-1.68)$ & 0.492 & $1.71(0.96-3.04)$ & 0.069 \\
\hline \multicolumn{5}{|c|}{$\begin{array}{l}\text { Recreational drug use in the last } \\
3 \text { months }\end{array}$} \\
\hline No (ref) & ref & & ref & \\
\hline Yes & & & $4.80(2.20-10.47)$ & $<0.001$ \\
\hline
\end{tabular}


S5 Table. ARV exposure by selected characteristics of HIV-infected women aged 15-64 years old, Kenya 2007 and 2012

\begin{tabular}{|c|c|c|c|c|c|c|}
\hline \multirow[b]{3}{*}{ Variable } & \multicolumn{3}{|c|}{ Kenya, 2007} & \multicolumn{3}{|c|}{ Kenya, 2012} \\
\hline & \multicolumn{3}{|c|}{ On ART } & \multicolumn{3}{|c|}{ On ART } \\
\hline & $\mathbf{N}$ & $\begin{array}{c}\text { Weighted \% } \\
\text { (95\% CI) }\end{array}$ & p-value & $\mathbf{N}$ & $\begin{array}{c}\text { Weighted \% } \\
\text { (95\% CI) }\end{array}$ & p-value \\
\hline Locality type & & & 0.715 & & & 0.576 \\
\hline Rural & 255 & $30.1(21.0-39.3)$ & & 216 & $42.7(35.6-49.8)$ & \\
\hline Urban & 117 & $33.7(16.6-50.7)$ & & 168 & $49.3(42.0-56.6)$ & \\
\hline Province & & & 0.271 & & & 0.721 \\
\hline Nairobi & 46 & $40.2(10.0-70.5)$ & & 37 & $49.7(37.1-62.2)$ & \\
\hline Central & 23 & * & & 40 & $51.4(36.8-66.0)$ & \\
\hline Coast & 49 & $12.4(1.5-23.2)$ & & 40 & $38.6(20.8-56.3)$ & \\
\hline Eastern & 35 & $39.2(10.5-67.9)$ & & 53 & $69.2(50.3-88.0)$ & \\
\hline Nyanza & 135 & $35.5(20.6-50.4)$ & & 132 & $40.7(33.8-47.5)$ & \\
\hline Rift Valley & 48 & $18.3(7.4-29.2)$ & & 45 & $40.8(25.1-56.5)$ & \\
\hline Western & 36 & $37.1(13.0-61.2)$ & & 37 & $40.5(28.8-52.2)$ & \\
\hline Age (years) & & & $<.001$ & & & 0.007 \\
\hline $15-24$ & 83 & $18.2(6.9-29.5)$ & & 50 & $17.7(7.4-28.0)$ & \\
\hline $25-34$ & 136 & $24.3(14.0-34.6)$ & & 123 & $29.6(21.1-38.1)$ & \\
\hline $35-49$ & 126 & $43.5(32.2-54.9)$ & & 157 & $59.1(51.2-67.0)$ & \\
\hline $50-64$ & 27 & $38.9(21.5-56.3)$ & & 54 & $67(53.4-80.6)$ & \\
\hline Marital status & & & $<.001$ & & & 0.822 \\
\hline Single/never married & 42 & $25.8(9.0-42.6)$ & & 51 & $19.4(9.3-29.6)$ & \\
\hline Married/cohabitating & 220 & $23.7(16.3-31.1)$ & & 201 & $46(39.1-52.8)$ & \\
\hline Divorced/separated/widowed & 110 & $45.8(33.6-58.0)$ & & 132 & $54.6(45.7-63.6)$ & \\
\hline Education & & & 0.394 & & & 0.937 \\
\hline None & 212 & $34.3(23.1-45.5)$ & & 64 & $37.6(22.7-52.5)$ & \\
\hline Primary & 111 & $24.7(15.9-33.5)$ & & 187 & $40.1(33.3-47.0)$ & \\
\hline Secondary & 36 & $32.3(15.2-49.4)$ & & 18 & * & \\
\hline Higher & 13 & * & & 114 & $56.2(46.8-65.6)$ & \\
\hline Household wealth & & & 0.815 & & & 0.886 \\
\hline Quintile I (lowest) & 71 & $30.4(16.2-44.6)$ & & 61 & $37.9(23.5-52.2)$ & \\
\hline Quintile II & 72 & $24.4(11.5-37.3)$ & & 89 & $42.4(31.1-53.8)$ & \\
\hline Quintile III & 58 & $34.2(18.7-49.7)$ & & 86 & $44.5(32.2-56.8)$ & \\
\hline Quintile IV & 81 & $33.1(17.3-48.9)$ & & 92 & $49.8(38.5-61.1)$ & \\
\hline Quintile V (highest) & 90 & $34(21.9-46.1)$ & & 56 & $54(41.8-66.2)$ & \\
\hline
\end{tabular}


Table S5. Continued

\begin{tabular}{|c|c|c|c|c|c|c|}
\hline \multirow[b]{3}{*}{ Variable } & \multicolumn{3}{|c|}{ Kenya, 2007} & \multicolumn{3}{|c|}{ Kenya, 2012} \\
\hline & \multicolumn{3}{|c|}{ On ART } & \multicolumn{3}{|c|}{ On ART } \\
\hline & $\mathbf{N}$ & $\begin{array}{l}\text { Weighted \% } \\
(95 \% \text { CI })\end{array}$ & p-value & $\mathbf{N}$ & $\begin{array}{l}\text { Weighted \% } \\
\text { (95\% CI) }\end{array}$ & p-value \\
\hline Employment & & & 0.646 & & & 0.019 \\
\hline Unemployed & 81 & $33.8(18.7-49.0)$ & & 165 & $47.8(39.3-56.3)$ & \\
\hline Employed & 291 & $30.4(22.3-38.5)$ & & 218 & $44.2(37.7-50.7)$ & \\
\hline CD4 category $\left(\right.$ cells $\left./ \mathrm{mm}^{3}\right)$ & & & $<.001$ & & & 0.086 \\
\hline$<=250$ & 58 & $20.5(8.8-32.2)$ & & 29 & $46.7(29.0-64.3)$ & \\
\hline $250>-350$ & 45 & $58.5(42.5-74.5)$ & & 25 & $60.3(40.0-80.5)$ & \\
\hline $350>-500$ & 56 & $34.2(20.7-47.6)$ & & 24 & * & \\
\hline$>500$ & 184 & $27(17.1-36.9)$ & & 120 & $48(38.3-57.7)$ & \\
\hline Most recent HIV test $\dagger$ & & & 0.897 & & & 0.690 \\
\hline$<12$ months ago & 92 & $40.7(28.4-53.0)$ & & 188 & $51(42.5-59.6)$ & \\
\hline 1-2 years ago & 55 & $44.6(28.0-61.1)$ & & 70 & $29.4(18.3-40.5)$ & \\
\hline$>2$ years ago & 56 & $41.6(25.9-57.4)$ & & 89 & $55.9(45.7-66.0)$ & \\
\hline $\begin{array}{l}\text { Disclosed results to most } \\
\text { recent partner }\end{array}$ & & & 0.369 & & & $<0.001$ \\
\hline Yes & 135 & $31.2(21.1-41.3)$ & & 78 & $61.9(49.3-74.4)$ & \\
\hline No & 19 & * & & 126 & $65.4(56.9-73.9)$ & \\
\hline $\begin{array}{l}\text { Recreational drug use in } \\
\text { last } 12 \text { months }\end{array}$ & & & & & & 0.002 \\
\hline Yes & - & & & $7 / 19$ & * & \\
\hline No & & & & 365 & $46.2(40.9-51.4)$ & \\
\hline Total & 372 & $31.2(23.0-39.4)$ & & 384 & $45.6(40.5-50.7)$ & \\
\hline
\end{tabular}

Notes: All numbers are unweighted except where otherwise specified. ${ }^{*}$ Suppressed due to denominator $<25$ observations. $\dagger$ Applies to respondents who reported ever testing for HIV $\ddagger$ Applies to respondents who self-reported HIV-positive. ART = antiretroviral treatment, $\mathrm{CI}=$ confidence interval. 


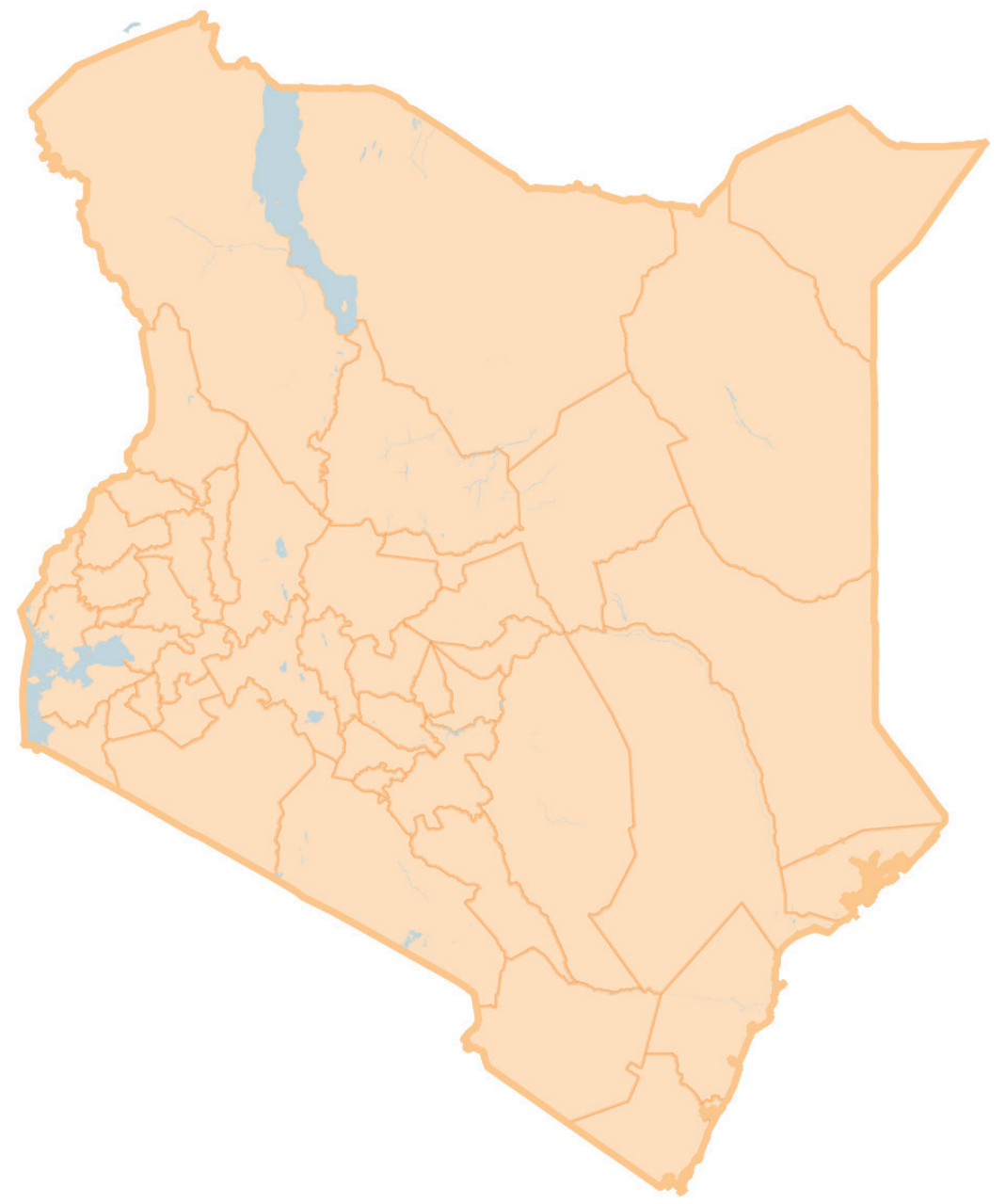




\section{Chapter 5}

\section{Use of viral load to improve survey estimates of known HIV-positive status and antiretroviral treatment coverage}

Peter W. Young

Emily Zielinski-Gutierrez

Joyce Wamicwe

Irene Mukui

Andrea A. Kim
Anthony Waruru

Clement Zeh

Mirjam E. Kretzschmar

Kevin M. De Cock

AIDS. 2020;34(4):631-6

https://doi.org/10.1097/QAD.0000000000002453 


\section{Abstract}

Objective: To compare alternative methods of adjusting self-reported knowledge of HIV-positive status and antiretroviral (ARV) therapy use based on undetectable viral load (UVL) and ARV detection in blood.

Design: Post hoc analysis of nationally-representative household survey to compare alternative biomarker-based adjustments to population HIV indicators.

Methods: We reclassified HIV-positive participants aged 15-64 years in the 2012 Kenya AIDS Indicator Survey (KAIS) that were unaware of their HIV-positive status by self-report as aware and on antiretroviral treatment if either ARVs were detected or viral load was undetectable $(<550$ copies $/ \mathrm{mL})$ on dried blood spots. We compared self-report to adjustments for ARVs measurement, UVL, or both.

Results: Treatment coverage among all HIV-positive respondents increased from $31.8 \%$ for self-report to $42.5 \%$ [95\% confidence interval (CI) 37.4-47.8] based on ARV detection alone, to $42.8 \%$ (95\% CI 37.9-47.8) when ARV-adjusted, $46.2 \%$ (95\% CI 41.3-51.1) when UVL-adjusted and 48.8\% (95\% CI 43.9-53.8) when adjusted for either ARV or UVL. Awareness of positive status increased from $46.9 \%$ for self-report to $56.2 \%$ (95\% CI 50.7-61.6) when ARV-adjusted, 57.5\% (95\% CI 51.9-63.0) when UVL-adjusted, and 59.8\% (95\% CI 54.2-65.1) when adjusted for either ARV or UVL.

Conclusions: Undetectable viral load, which is routinely measured in surveys, may be a useful adjunct or alternative to ARV detection for adjusting survey estimates of knowledge of HIV status and antiretroviral treatment coverage. 


\section{Introduction}

Since the 2007 Kenya AIDS Indicator Survey (KAIS), HIV seroprevalence surveys have often included questions on knowledge of HIV status and antiretroviral (ARV) use among HIV-infected respondents, as well as biomarkers such as viral load (VL) [1-3] and ARV testing. Self-reported knowledge of status and antiretroviral treatment (ART) status can be subject to either positive or negative social desirability bias in some respondents [4] due to the stigma associated with HIV $[5,6]$. Some respondents may also have inaccurate recall or understanding of detailed questions about their HIV testing and care histories [7].

Antiretroviral testing can be used to adjust self-reported HIV status by reclassifying respondents with ARVs detected in their blood as being previously diagnosed and on ART [8,9]. In the 2012 KAIS $46.9 \%$ of HIV-infected respondents self-reported that they were aware of their HIV-positive status, but ARVs were also detected in $21.0 \%$ of those not reporting prior HIV diagnosis and $19.3 \%$ of those reporting no previous HIV test. However, antiretroviral testing is relatively complex, expensive, and only available within a very limited number of specialized laboratories worldwide, necessitating international shipping, resulting in additional cost, administrative paperwork, and potential for delays.

Unlike ARV testing, which is added exclusively to correct self-reported HIV status and ART use, viral load testing is widely available and routinely included in surveys to estimate population viral suppression (defined as $\mathrm{VL}<1000$ copies/mL [10]). Undetectable viral load (UVL) is generally indicative of viral suppression due to treatment, hence it could serve as an alternative, indirect marker for treatment. Although the presence of elite controllers (EC) who have UVL in the absence of treatment could confound use of UVL as a proxy for ART use, in US and European cohorts EC are believed to represent only $0.15-1.5 \%$ of the HIV-infected population [11], while in East African settings similarly low prevalence of EC has been observed [12,13], limiting the potential impact of this confounding.

Given viral load testing is already conducted routinely in HIV surveys, we examined whether adjusting estimates of knowledge of HIV-positive status and ART coverage using a measure of viral load would achieve similar results to adjustments based on detection of ARVs in a national household survey conducted in Kenya in 2012. 


\section{Methods}

The 2012 KAIS included behavioral questions including self-reported HIV and ART status as well as collection of venous blood from which DBS were prepared by field teams and plasma separated and shipped for HIV testing at a national laboratory [2]. After participating in other survey procedures, participants were offered rapid HIV testing by trained HIV counselors in their homes with immediate return of results based on national HIV testing guidelines [14]. Participants testing positive for HIV at the central laboratory were subsequently tested for viral load using the Abbott M2000 platform on DBS subsequently stored at $-80^{\circ} \mathrm{C}$ for future testing. In 2015, DBS were shipped to the University of Cape Town for testing for presence of efavirenz, nevirapine, lopinavir or lamivudine by liquid chromatography tandem mass spectrometry (limit of detection $0.02 \mu \mathrm{g} / \mathrm{mL}$ ) [15]. These ARVs were selected to cover first- and second-line regimens in use in Kenya at the time of specimen collection [16-18].

We retrospectively re-analyzed survey data to compare self-reported and biomarker-adjusted versions of knowledge of status and ART use among HIVinfected respondents aged 15-64 years.

\section{Measures}

We defined UVL as having a viral load $<550$ copies/mL on dried blood spots, the limit of detection for the assay used in the study [19]. To calculate UVL-adjusted status, we updated the status for those respondents categorized as 'unaware' or 'aware, not on ART' with undetectable viral load to 'aware, on ART'. Similarly, ARVadjusted status was calculated by updating the status for respondents with ARVs detected in blood to 'aware, on ART'. For either case, the status for respondents with missing biomarker results was not updated.

We explored differences in self-reported, ARV-adjusted, and UVL-adjusted indicators by age, sex, marital status, educational attainment and mobility. Results were analyzed in $\mathrm{R}$ version 3.5.0 [20] using the survey package [21] to adjust and weight results to account for the complex survey design. Wald confidence intervals for survey indicators were calculated on the logarithmic scale and transformed to probability scale using the 'logit' method of the svyciprop function in R; confidence intervals previously reported by Kim et al. [16] were calculated on the probability scale. 


\section{Ethical considerations}

The 2012 KAIS was approved by the University of California, San Francisco, the U.S. Centers for Disease Control (CDC) in Atlanta, GA, USA and the Kenya Medical Research Institute. Prior to household and individual interviews and blood collection written consent was obtained; in the case of children aged less than 18 years assent was sought in addition to permission from their caregiver or guardian.

\section{Results}

Among $648 \mathrm{HIV}$-infected respondents, self-reported status was 'unaware' among 343 (53.1\%), 'aware, not on ART' among 100 (15.1\%), and 'aware, on ART' among 205 (31.8\%) (Supplemental Table S1). Of those with UVL and unaware of their HIV-positive status by self-report, 40 also had ARVs detected in blood (Supplemental Table S2). Antiretroviral treatment coverage among all HIV-infected increased from $31.8 \%$ (95\% CI 27.3-36.6) based on self-report to $42.8 \%$ (95\% CI 37.9-47.8) when combining self-report and ARV detection, to $46.2 \%$ (95\% CI 41.3-51.1) when combining self-report and UVL, and finally to $48.8 \%$ (95\% CI 43.9-53.8) with self-report, UVL or ARVs combined (Table 1). Changes in ART coverage were consistent across demographic characteristics, although the 15-24 year age group saw greater increases when adjusted compared to other age groups (Supplemental Figure S1).

Knowledge of status increased from 46.9\% (95\% CI 41.4-52.4) based on selfreport to $56.2 \%$ (95\% CI 50.7-61.6) when adjusting with ARVs, to 57.5\% (95\% CI 51.9-63.0) when adjusting for UVL, and to 59.8\% (95\% CI 54.2-65.1) when adjusting for either ARV or UVL (Table 2). Similar to population ART coverage, ART among those with known HIV-positive status also increased from self-report to adjustment, with similar increases between adjustment methods. The youngest age group also saw the biggest impact of adjustment versus self-report for these indicators in both relative and absolute terms.

We repeated the analysis excluding the respondents for whom either the ARV or UVL biomarkers were not available; findings were similar (Supplemental Table S3). 


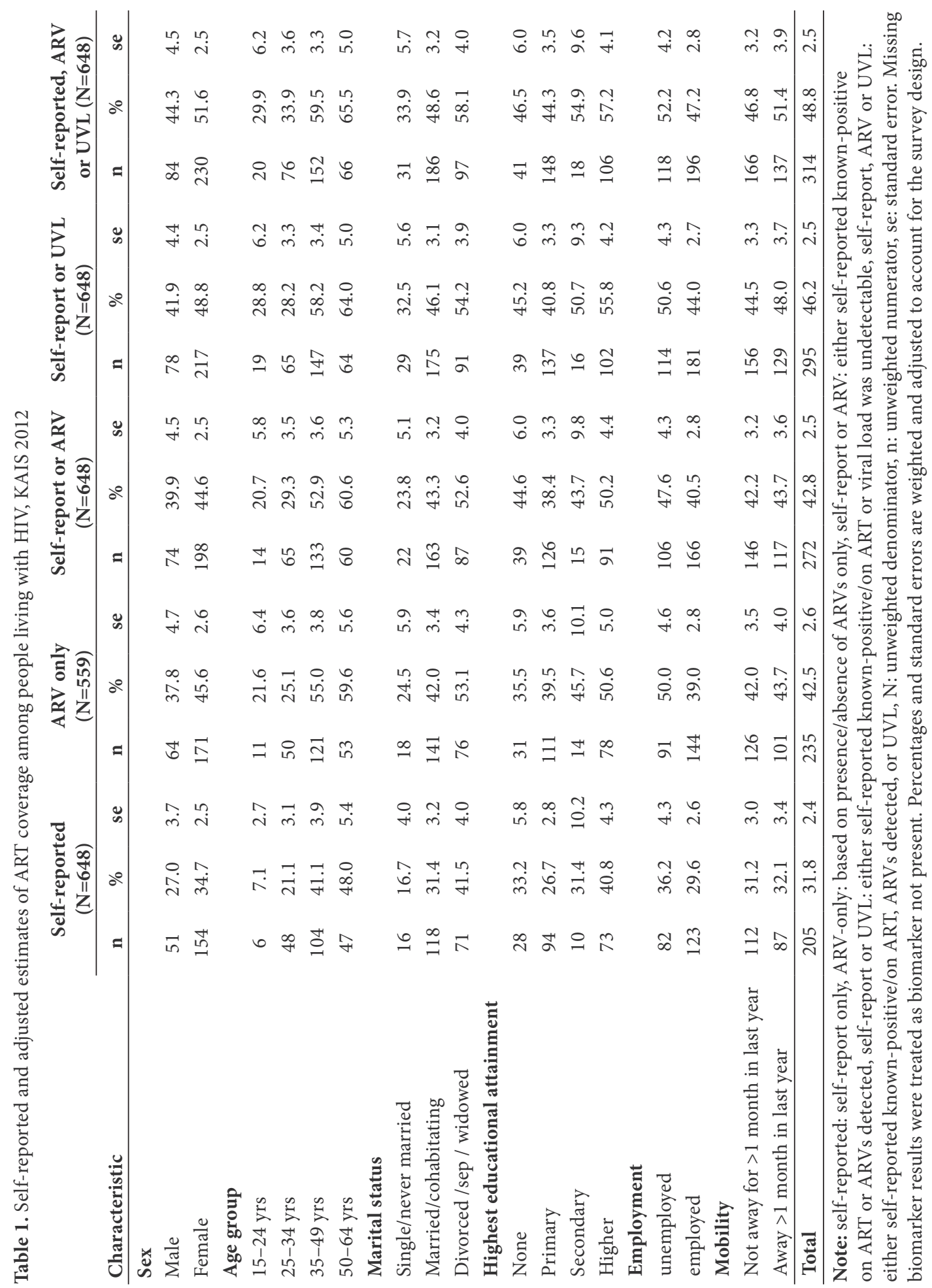




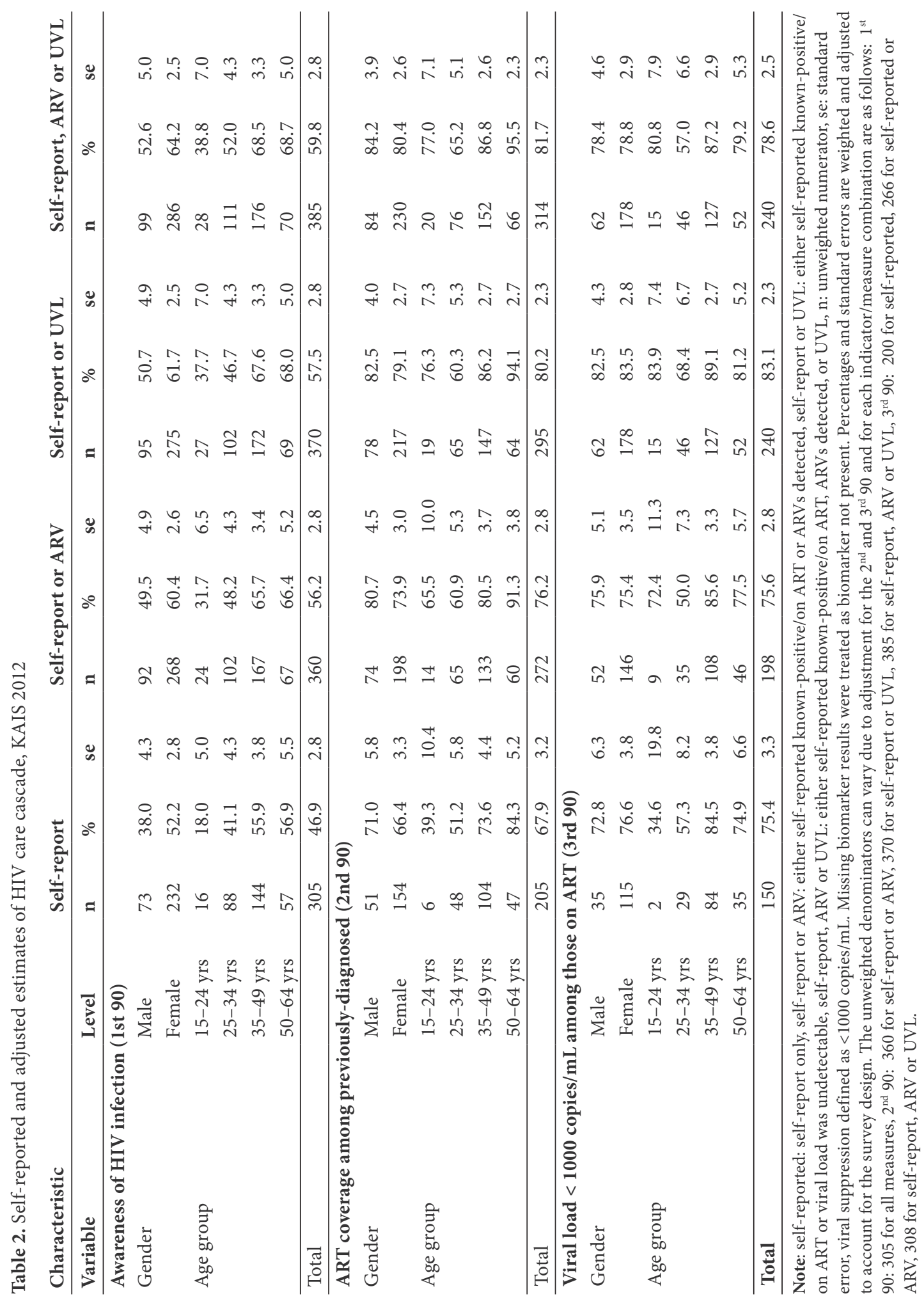




\section{Discussion}

In order to balance resources between finding undiagnosed HIV infections, linking patients to HIV treatment, and ensuring retention and adherence to care it is necessary to obtain the best possible estimates of knowledge of HIV-positive status and ART use. We set out to establish whether viral load, a routinely-available marker in HIV surveys, can be used to adjust self-reported estimates of knowledge of HIV-positive status and ART use. In KAIS 2012, UVL-adjusted point estimates were similar to, but slightly greater than ARV-adjusted estimates of knowledge of status and ART coverage, suggesting adjustment with UVL might have been sufficient. When measuring ART coverage, all of the adjusted estimates (ARV only, UVL only, and either ARV or UVL) had overlapping confidence intervals, but are notably higher than estimates based on self-report alone.

The change in estimates when adjusting by ARVs and UVL were similar across demographic groups, but 15-24 year olds did see a larger additional increase when adjusting by UVL. This may indicate poor recent adherence in this group leading to non-detection of the ARV biomarker but undetectable viral load $(<550$ copies $/ \mathrm{mL}$ in this study). Li et al found that $37 \%$ of patients still had a viral load $<200$ copies/ $\mathrm{mL}$ four weeks after interrupting ART [22]. Many ARVs reach undetectable levels in blood within several days of treatment interruption $[8,15,23]$, thus in populations with poor adherence or high rates of treatment interruption, adjusting based on UVL may result in higher estimated ART coverage than measures incorporating ARV detection.

The performance of UVL for adjusting ART use will depend on the prevalence of UVL in the population on HIV treatment. In populations with effective ART programs with high rates of viral suppression in the treated population, it may be a relatively sensitive marker for ART use; however, in populations with poor treatment outcomes a larger proportion of patients on treatment would not have UVL.

The prevalence of elite controllers has not been established in Kenya, hence it is not possible to quantify their influence on the UVL-adjusted estimates, but given the similarity between UVL-adjusted and ARV-adjusted estimates, their potential impact was limited. Simultaneously adjusting for either UVL or presence of ARVs may in fact be closest to true population prevalence of the indicators of interest. Without better data on prevalence of elite controllers in this population it is more conservative to use one or the other marker rather than both combined. In settings with ample evidence of low prevalence of elite control, or where population high 
ART coverage and immediate treatment initiation means even elite controllers are likely to be on treatment, using the combined indicator would likely represent the most sensitive approach to estimating population-based knowledge of status and ART coverage.

This analysis was subject to several limitations. While adjusting for biomarkers associated with ARV exposure from a single time-point can account for misreporting of status among those on ART, it cannot account for those who misreport their knowledge of HIV-positive status but are not currently on treatment, or those who may be on treatment but transiently non-adherent to medications. Other established methods for reducing bias in self-reported estimates, such as computer-assisted self-interview methods, may also be helpful [24]. This analysis was based on data from a single country with low ART coverage (43.5\%) and viral suppression among those on treatment $(73.9 \%)$ at the time of the survey compared with current program coverage; the UVL adjustment may perform differently in other populations. Simulation or replication of this analysis in a diverse set of populations, including the more recent population-based HIV impact assessments conducted in many countries, could help elucidate the performance of UVL adjustment in different settings. Finally, poor specimen quality could result in false-negative results for both biomarkers. In spite of these limitations, this analysis does strongly suggest that use of UVL to adjust self-reported HIV status and ART use should be considered, especially in surveys where the inclusion of the ARV biomarker may be cost-prohibitive or subject to delays.

\section{Conclusion}

Streamlining the estimation of key HIV program indicators should allow governments, donors and other stakeholders to assess program performance more quickly and affordably. Viral load, which is routinely measured in HIV surveys, may be a useful biomarker for adjusting self-reported indicators of HIV diagnosis and treatment in cross-sectional surveys in absence of, or in addition to, adjustment based on detected ARVs in blood. 


\section{Acknowledgements}

We would like to thank the University of Cape Town Department of Clinical Pharmacology for conducting the ART biomarker testing, the National HIV Reference Laboratory for conducting the KAIS 2012 viral load testing, the study teams that collected data in the field, and finally the survey participants.

\section{Competing interests}

All authors declare no competing interests.

\section{Authors' contributions}

PWY, EZG and KDC conceived the study. PWY conducted the analyses. All authors contributed to drafting and critical review of the manuscript. 


\section{References}

1 National AIDS/STI Control Programme (NASCOP). 2007 Kenya AIDS Indicator Survey: Final Report. Nairobi, Kenya: NASCOP; 2009. http://stacks.cdc.gov/view/cdc/12122/

2 Waruiru W, Kim AA, Kimanga DO, Ng'ang'a J, Schwarcz S, Kimondo L, et al. The Kenya AIDS Indicator Survey 2012: rationale, methods, description of participants, and response rates. J Acquir Immune Defic Syndr 2014; 66 Suppl 1:S3-12.

3 Brown K, Williams DB, Kinchen S, Saito S, Radin E, Patel H, et al. Status of HIV Epidemic Control Among Adolescent Girls and Young Women Aged 15-24 Years - Seven African Countries, 2015-2017. MMWR Morb Mortal Wkly RepMorb Mortal Wkly Rep Published Online First: 2018. doi:10.15585/mmwr.mm6701a6

4 Kelly CA, Hewett PC, Mensch BS, Rankin JC, Nsobya SL, Kalibala S, et al. Using biomarkers to assess the validity of sexual behavior reporting across interview modes among young women in Kampala, Uganda. Stud Fam Plann Published Online First: 2014. doi:10.1111/j.17284465.2014.00375.x

5 Bonnington O, Wamoyi J, Ddaaki W, Bukenya D, Ondenge K, Skovdal M, et al. Changing forms of HIV-related stigma along the HIV care and treatment continuum in sub-Saharan Africa: A temporal analysis. Sex Transm Infect 2017; 93:1-6.

6 Gurmu $E_{1}$ Etana D. HIVIAIDS knowledge and stigma among women of reproductive age in Ethiopia. African J AIDS Res 2015; 14:191-199.

7 Mooney AC, Campbell CK, Ratlhagana M-J, Grignon JS, Mazibuko S, Agnew E, et al. Beyond social desirability bias: investigating inconsistencies in self-reported HIV testing and treatment behaviors among HIV-positive adults in North West Province, South Africa. AIDS Behav 2018; 22:2368-2379.

8 Kim AA, Mukui I, Young PW, Mirjahangir J, Mwanyumba S, Wamicwe J, et al. Undisclosed HIV infection and ART use in the Kenya AIDS indicator survey 2012: relevance to targets for HIV diagnosis and treatment in Kenya. AIDS 2016; 30:2685-2695.

9 Huerga $H$, Shiferie $F$, Grebe $E$, Giuliani R, Farhat J Ben, Van-Cutsem $G$, et al. A comparison of selfreport and antiretroviral detection to inform estimates of antiretroviral therapy coverage, viral load suppression and HIV incidence in Kwazulu-Natal, South Africa. BMC Infect Dis 2017; 17:1-8.

10 Global AIDS Monitoring 2018: Indicators for monitoring the 2016 United Nations Political Declaration on Ending AIDS. Geneva, Switzerland: UNAIDS; 2017. https://www.unaids.org/sites/default/files/ media_asset/2017-Global-AIDS-Monitoring_en.pdf

11 Gonzalo-Gil E, Ikediobi U, Sutton RE. Mechanisms of virologic control and clinical characteristics of HIV+ elite/viremic controllers. Yale J Biol Med 2017; 90:245-259.

12 Kayongo A, Gonzalo-Gil E, Gümüșgöz E, Niwaha AJ, Semitala F, Kalyesubula R, et al. Identification of Elite and Viremic Controllers from a Large Urban HIV Ambulatory Center in Kampala, Uganda. J Acquir Immune Defic Syndr 2018; 79:394-398.

13 Kiros Y, Elinav H, Gebreyesus A, Gebremeskel H, Azar J, Chemtob D, et al. Identification and characterization of HIV positive Ethiopian elite controllers in both Africa and Israel. HIV Med $2018 ;: 1-5$. 
14 National Guidelines for HIV Testing and Counseling in Kenya. 2nd ed. Nairobi, Kenya: National AIDS and STI Control Programme (NASCOP); 2010.

15 Koal T, Burhenne H, Römling R, Svoboda M, Resch K, Kaever V. Quantification of antiretroviral drugs in dried blood spot samples by means of liquid chromatography/tandem mass spectrometry. Rapid Commun Mass Spectrom 2005; 19:2995-3001.

16 Kim AA, Mukui I, Young PW, Mirjahangir J, Mwanyumba S, Wamicwe J, et al. Undisclosed HIV infection and antiretroviral therapy use in the Kenya AIDS indicator survey 2012: Relevance to national targets for HIV diagnosis and treatment. AIDS 2016; 30. doi:10.1097/ QAD.0000000000001227

17 Guidelines for antiretroviral therapy in Kenya, 4th Edition 2011. Kenya: National AIDS and STI Control Programme (NASCOP); 2011. http://www.emtct-iatt.org/wp-content/uploads/2013/04/Kenya_ National-ARV-Guidelines_2011.pdf

18 Moyo S, Young PW, Gouws E, Naidoo I, Wamicwe J, Mukui I, et al. Equity of antiretroviral treatment use in high HIV burden countries: Analyses of data from nationally-representative surveys in Kenya and South Africa. PLOS ONE 2018; $13:$ :0201899.

19 Zeh $C_{1}$ Ndiege $K$, Inzaule $S$, Achieng R, Williamson J, Chang JCW, et al. Evaluation of the performance of Abbott m2000 and Roche COBAS Ampliprep/COBAS Taqman assays for HIV-1 viral load determination using dried blood spots and dried plasma spots in Kenya. PLOS ONE Published Online First: 2017. doi:10.1371/journal.pone.0179316

20 R Core Team. R: A Language and Environment for Statistical Computing. 2018.https://www.r-project. orgl

21 Lumley T. survey: analysis of complex survey samples. 2017.

22 Li JZ, Etemad B, Ahmed H, Aga E, Bosch RJ, Mellors JW, et al. The size of the expressed HIV reservoir predicts timing of viral rebound after treatment interruption. AIDS 2016; 30:343353.

23 Jackson A, Moyle G, Watson V, Tjia J, Ammara A, Back D, et al. Tenofovir, emtricitabine intracellular and plasma, and efavirenz plasma concentration decay following drug intake cessation: Implications for HIV treatment and prevention. J Acquir Immune Defic Syndr Published Online First: 2013. doi:10.1097/QAl.0b013e3182829bd0

24 Gnambs T, Kaspar K. Disclosure of sensitive behaviors across self-administered survey modes: a meta-analysis. Behav Res Methods 2014; 47:1237-1259. 


\section{Supplemental Material}

Table S1. Self-reported HIV status and antiretroviral treatment (ART) use, KAIS 2012

\begin{tabular}{|c|c|c|c|c|}
\hline Characteristic & $\begin{array}{c}\text { Unaware } \\
\text { n (\%) }\end{array}$ & $\begin{array}{c}\text { Aware, not on ART } \\
\text { n (\%) }\end{array}$ & $\begin{array}{c}\text { Aware, on ART } \\
\text { n (\%) }\end{array}$ & $\mathbf{N}$ \\
\hline \multicolumn{5}{|l|}{ Gender } \\
\hline Male & $120(62.0)$ & $22(11.0)$ & $51(27.0)$ & 193 \\
\hline Female & $223(47.8)$ & $78(17.5)$ & $154(34.7)$ & 455 \\
\hline \multicolumn{5}{|l|}{ Age } \\
\hline $15-24$ yrs & $59(82.0)$ & $10(10.9)$ & $6(7.1)$ & 75 \\
\hline $25-34$ yrs & $121(58.9)$ & $40(20.0)$ & $48(21.1)$ & 209 \\
\hline $35-49$ yrs & $120(44.1)$ & $40(14.8)$ & $104(41.1)$ & 264 \\
\hline $50-64$ yrs & $43(43.1)$ & $10(8.9)$ & $47(48.0)$ & 100 \\
\hline \multicolumn{5}{|l|}{ Marital status } \\
\hline Single/never married & $67(73.5)$ & $10(9.8)$ & $16(16.7)$ & 93 \\
\hline Married / cohabitating & $210(54.2)$ & $57(14.4)$ & $118(31.4)$ & 385 \\
\hline Divorced / sep / widowed & $66(38.9)$ & $33(19.7)$ & $71(41.5)$ & 170 \\
\hline \multicolumn{5}{|l|}{ Highest educational attainment } \\
\hline None & $49(53.9)$ & $12(12.9)$ & $28(33.2)$ & 89 \\
\hline Primary & $192(55.8)$ & $60(17.5)$ & $94(26.7)$ & 346 \\
\hline Secondary & $18(57.4)$ & $3(11.2)$ & $10(31.4)$ & 31 \\
\hline Higher & $83(47.4)$ & $25(11.9)$ & $73(40.8)$ & 181 \\
\hline \multicolumn{5}{|l|}{ Employment } \\
\hline Unemployed & $124(49.1)$ & $33(14.7)$ & $82(36.2)$ & 239 \\
\hline Employed & $218(55.1)$ & $67(15.3)$ & $123(29.6)$ & 408 \\
\hline \multicolumn{5}{|l|}{ Mobility } \\
\hline Not away for $>1$ month in last year & $196(54.6)$ & $52(14.2)$ & $112(31.2)$ & 360 \\
\hline Away $>1$ month in last year & $131(51.4)$ & $45(16.6)$ & $87(32.1)$ & 263 \\
\hline \multicolumn{5}{|l|}{ ARV biomarker } \\
\hline Present & $55(25.2)$ & $12(4.5)$ & $168(70.4)$ & 235 \\
\hline Absent & $233(72.3)$ & $73(22.3)$ & $18(5.4)$ & 324 \\
\hline \multicolumn{5}{|l|}{ UVL biomarker } \\
\hline Present & $65(28.7)$ & $25(9.9)$ & $145(61.3)$ & 235 \\
\hline Absent & $253(66.5)$ & $74(19.2)$ & $55(14.3)$ & 382 \\
\hline Total & $343(53.1)$ & $100(15.1)$ & $205(31.8)$ & 648 \\
\hline
\end{tabular}

Note: ARV biomarker: test for presence of antiretrovirals in blood, UVL biomarker: present if respondent had undetectable viral load $(<550$ copies $/ \mathrm{mL})$ in blood. Missing values: one respondent was missing education and employment status, respectively, while 89 respondents were missing the ARV biomarker and 31 were missing viral load measure. Percentages are weighted to account for survey design. 
Table S2. Comparison of antiretroviral (ARV) detection and undetectable viral load (UVL) by self-reported HIV status, KAIS 2012

UVL biomarker

\begin{tabular}{|c|c|c|c|c|c|}
\hline \multirow[b]{2}{*}{ Status } & \multirow[b]{2}{*}{$\begin{array}{c}\text { ARV } \\
\text { biomarker }\end{array}$} & \\
\hline & & Present & Absent & Missing & Total \\
\hline \multirow{4}{*}{$\begin{array}{l}\text { Unaware of HIV-positive } \\
\text { status }\end{array}$} & present & 40 & 15 & 0 & 55 \\
\hline & absent & 14 & 209 & 10 & 233 \\
\hline & missing & 11 & 29 & 15 & 55 \\
\hline & total & 65 & 253 & 25 & 343 \\
\hline \multirow{4}{*}{$\begin{array}{l}\text { Aware of HIV-positive } \\
\text { status, not on ART }\end{array}$} & present & 8 & 3 & 1 & 12 \\
\hline & absent & 12 & 61 & 0 & 73 \\
\hline & missing & 5 & 10 & 0 & 15 \\
\hline & total & 25 & 74 & 1 & 100 \\
\hline \multirow{4}{*}{$\begin{array}{l}\text { Aware of HIV-positive } \\
\text { status, on ART }\end{array}$} & present & 132 & 35 & 1 & 168 \\
\hline & absent & 3 & 15 & 0 & 18 \\
\hline & missing & 10 & 5 & 4 & 19 \\
\hline & total & 145 & 55 & 5 & 205 \\
\hline \multirow{4}{*}{$\begin{array}{l}\text { Self-reported adherent last } \\
30 \text { days }\end{array}$} & present & 116 & 3 & 9 & 128 \\
\hline & absent & 27 & 11 & 4 & 42 \\
\hline & missing & 1 & 0 & 14 & 15 \\
\hline & total & 144 & 14 & 27 & 185 \\
\hline \multirow{5}{*}{$\begin{array}{l}\text { Self-reported non-adherent } \\
\text { last } 30 \text { days }\end{array}$} & present & 16 & 0 & 1 & 17 \\
\hline & absent & 8 & 3 & 1 & 12 \\
\hline & missing & 0 & 0 & 5 & 5 \\
\hline & total & 24 & 3 & 7 & 34 \\
\hline & $\mathrm{N}$ & 235 & 382 & 31 & 648 \\
\hline
\end{tabular}

Note: ARV biomarker is present if ARVs detected in blood, UVL biomarker present if viral load undetectable ( $<550$ copies $/ \mathrm{mL}$ ). Self-reported adherence is based on response to question among those who self-reported aware of HIV-positive status and on ART: 'In the last 30 days, have you missed taking any of your ARV pills?' One respondent who reported 'don't know' to this question was excluded from the self-reported adherence analysis. 


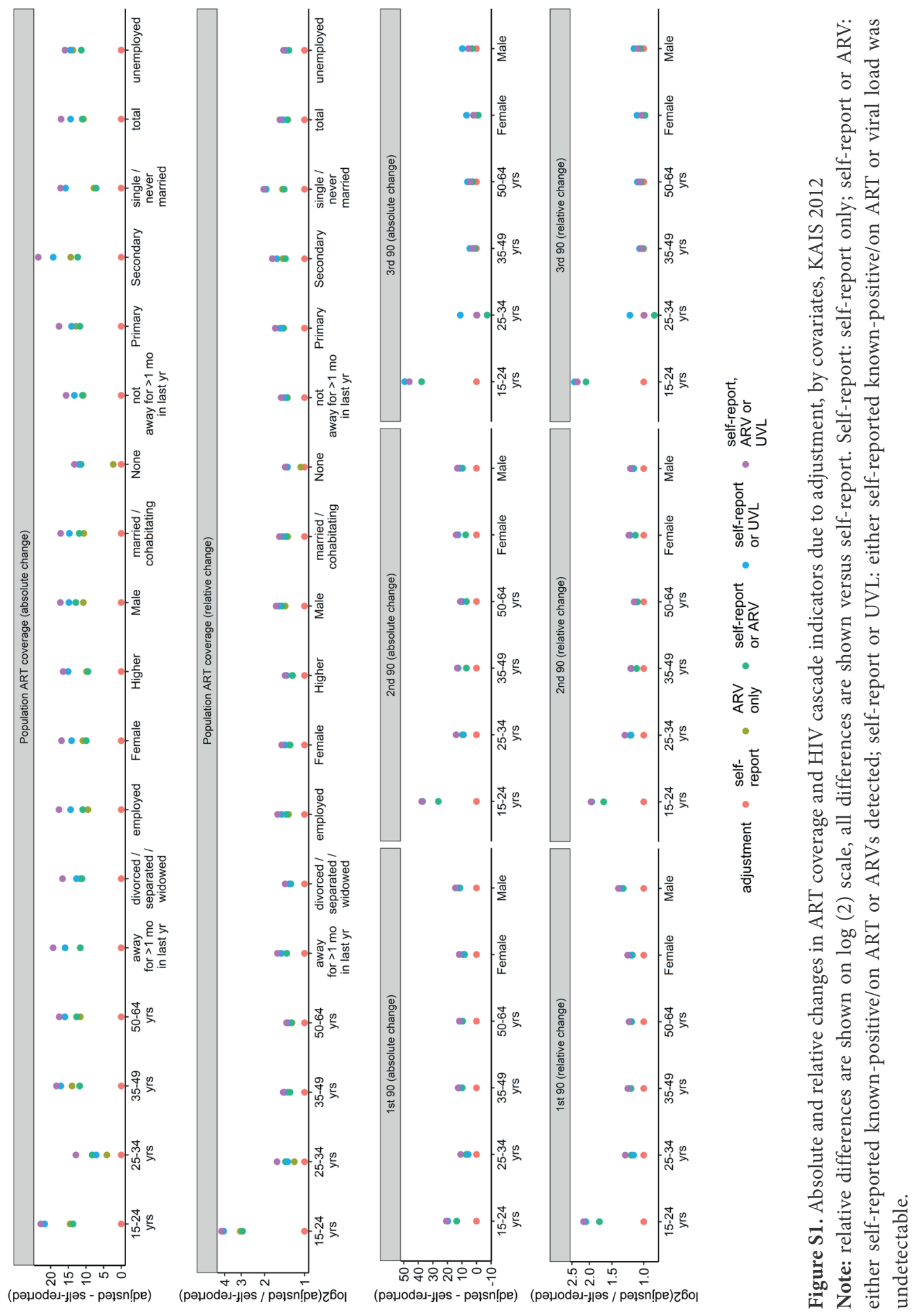




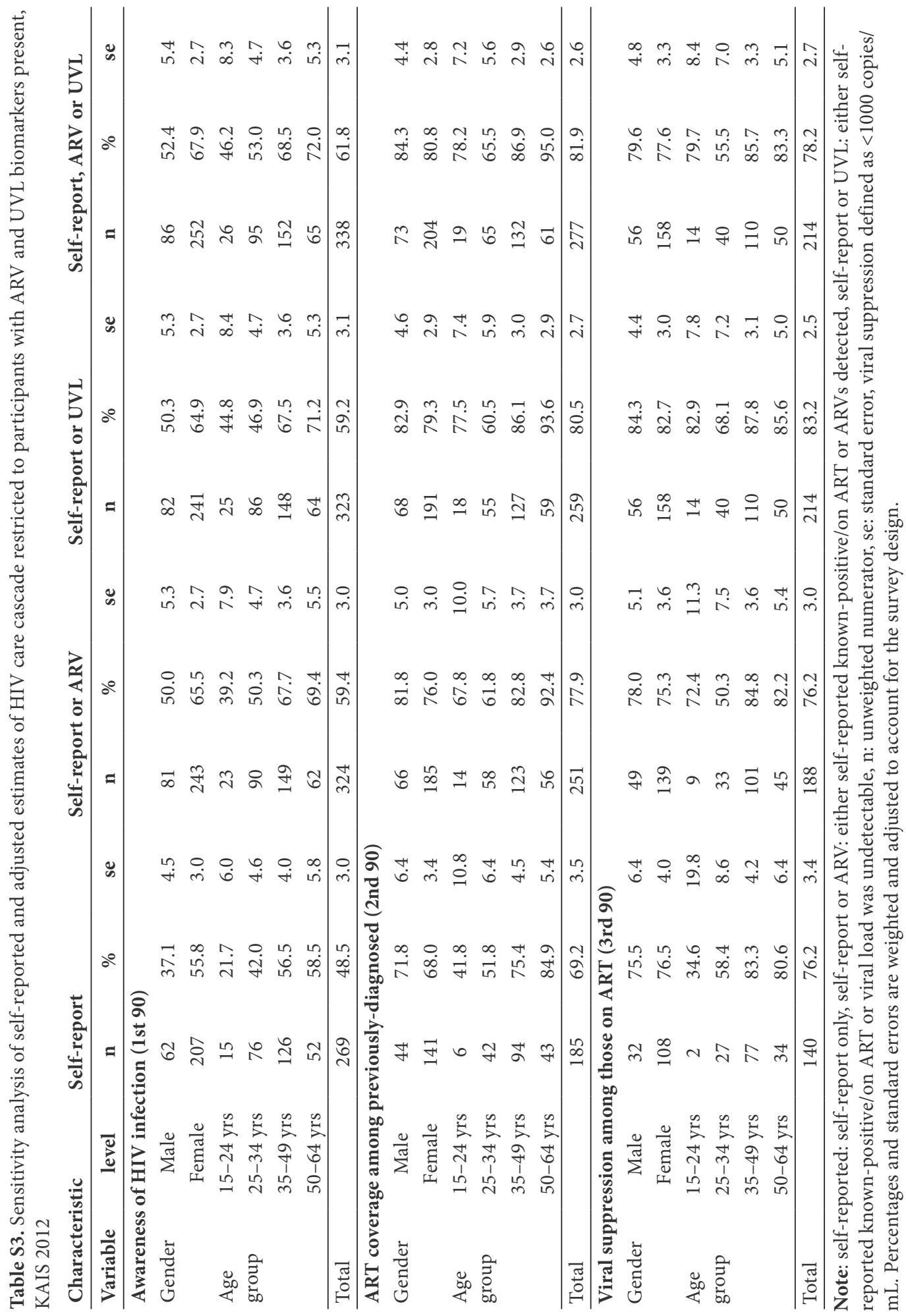




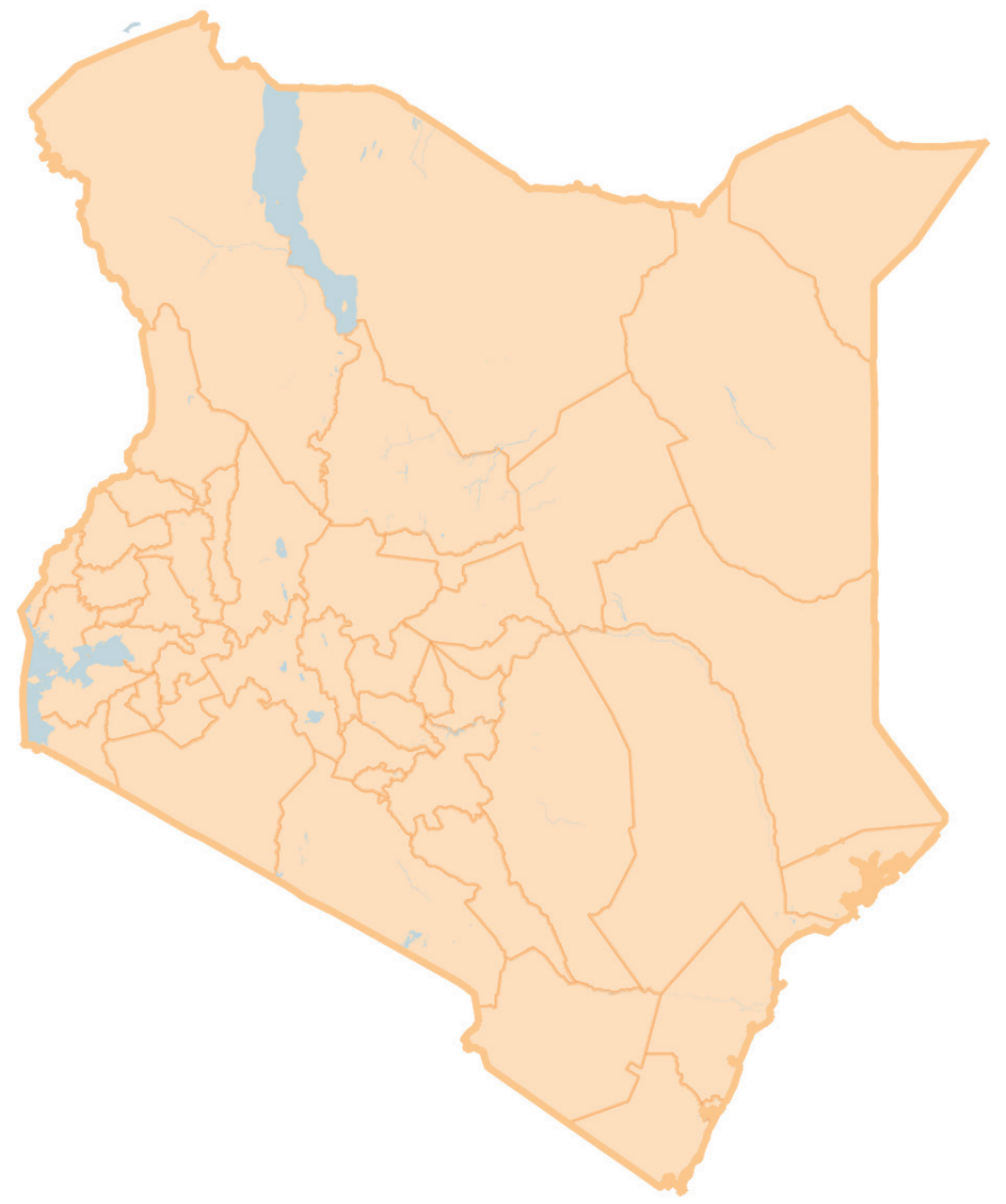




\section{Chapter 6}

\section{HIV-related deaths in Nairobi, Kenya: Results from a HIV mortuary surveillance study, 2015}

Lilly Nyagah

Peter W. Young

Andrea Kim

Joyce Wamicwe

Maureen Kimani

Wanjiru Waruiru

Emily Rogena
Johansen Oduor

Edwin Walong

Anthony Waruru

Julius Oyugi

Marie Downer

Kevin M. De Cock

Martin Sirengo

J Acquir Immune Defic Syndr 2019;81(1):18-23

https://doi.org/10.1097/QAI.0000000000001975 


\section{Abstract}

Background: Death is an important but often unmeasured endpoint in public health HIV surveillance. We sought to describe HIV among deaths using a novel mortuary-based approach in Nairobi, Kenya.

Methods: Cadavers aged $\geq 15$ years at death at Kenyatta National Hospital (KNH) and City Mortuaries were screened consecutively from January $29^{\text {th }}$ to March $3^{\text {rd }}$ 2015. Cause of death was abstracted from medical files and death notification forms. Cardiac blood was drawn and tested for HIV infection using the national HIV testing algorithm followed by viral load testing of HIV-positive samples.

Results: Of 807 eligible cadavers, 610 (75.6\%) had an HIV test result available. Cadavers from $\mathrm{KNH}$ had significantly higher HIV positivity at $23.2 \%$ (95\% CI 19.3-27.7) compared to City Mortuary at $12.6 \%$ (95\% CI 8.8-17.8), p<0.001. HIV prevalence was significantly higher among women than men at both City $(33.3 \%$ versus 9.2\%, $\mathrm{p}=0.008$ ) and $\mathrm{KNH}$ Mortuary (28.8\% versus $19.0 \%, \mathrm{p}=0.025)$. Half (53.3\%) of HIV infected cadavers had no diagnosis prior to death and an additional $22.2 \%$ were only diagnosed during hospitalization leading to death. Although not statistically significant, $61.9 \%$ of males had no prior diagnosis compared to $45.8 \%$ of females ( $\mathrm{p}=0.144)$. Half $(52.3 \%)$ of 44 cadavers at KNH with HIV diagnosis prior to death were on treatment, and one in five $(22.7 \%)$ with a prior diagnosis had achieved viral suppression.

Conclusions: HIV prevalence was high among deaths in Nairobi, especially among women, and prior diagnosis among cadavers was low. Establishing routine mortuary surveillance can contribute to monitoring HIV-associated deaths among cadavers sent to mortuaries. 


\section{Introduction}

Globally, the number of people living with HIV (PLHIV) in 2015 was estimated at 36.7 million persons (1). Between 2010 and 2015, antiretroviral therapy (ART) use for HIV-infected persons increased by $126 \%$ in parallel with a $26 \%$ reduction in HIV-related deaths, from 1.5 million deaths in 2010 to 1.1 million deaths in 2015 $(1,2)$. Sub-Saharan Africa bears the greatest burden of HIV. In 2015, there were 470,000 HIV-related deaths in East and Southern Africa representing 43\% of global deaths due to HIV (1-3).

Kenya is estimated to have the fourth-largest HIV epidemic in the world, with 1.5 million PLHIV (4). The country reported an estimated 30\% decline in HIVrelated deaths between 2010 and 2015, from 52,314 to 35,822 respectively (5). This is attributed to the rapid increase of number of ART sites and increased ART coverage (6). However, HIV remains a serious public health challenge despite these achievements. Nairobi, the national capital, has the highest burden of HIV in the country with 171,510 residents estimated to be living with HIV and 2,500 HIV-related deaths occurring per year (5). Antiretroviral therapy coverage among PLHIV in Nairobi was estimated at $72 \%$ in 2014, nine percentage points below the treatment coverage target of $81 \%$ set in UNAIDS 90-90-90 fast-track targets for epidemic control by $2020(6,7)$.

Although the impact of ART on mortality in African settings has been widely demonstrated (8-10) monitoring HIV-associated mortality is vital for tracking the success of the national ART program. Although standardized mathematical models based on indirect methods are used to estimate and project the number of people dying due to HIV (11), these models rely on assumptions that are subject to uncertainty, and can limit understanding of the true level of HIV-associated mortality. The national vital statistics system also tracks cause of death, but limited standardization of cause of death coding, lack of availability of HIV status at time of certification of cause of death, and the low estimated coverage of death reporting $(<50 \%)$ limit the generalizability of these statistics $(12,13)$. Early studies demonstrated the ability of enzyme-based assays to detect HIV in post mortem blood specimens (13-15). A mortuary-based surveillance system could help estimate the proportion of deaths that are HIV-associated, the proportion of deaths that are directly due to HIV, provide the actual age and sex distribution of HIV mortality, and relate HIV mortality to important factors such as viral suppression, ART use and HIV diagnosis, and hence to missed opportunities for epidemic control. We conducted a surveillance study in the two largest mortuaries in Nairobi. A prior publication from this study describes the fraction of deaths attributable to 
HIV in the Nairobi population by comparing the observed sero-prevalence among deaths with that expected based on demographic models (16). In this manuscript, we map HIV deaths to the steps in the cascade of care including HIV diagnosis, treatment, and achieving viral suppression. We describe the prevalence of HIV among cadavers by age, sex and other factors, and the proportion of HIV-infected cadavers whose underlying cause of death was classified as due to HIV and other causes. We also explore important behavioral and biological covariates such as HIV test history and viral suppression among HIV-associated deaths in order to better define the gaps that, if addressed, may help prevent excess HIV-related mortality.

\section{Materials and Methods}

This study was conducted in the two largest mortuaries in Nairobi - Kenyatta National Hospital (KNH) Mortuary and City Mortuary covering $51 \%$ of all reported deaths in Nairobi county (18). The KNH Mortuary is attached to Kenyatta National Hospital which is a national public referral and teaching hospital, while City Mortuary is managed by the Nairobi County Health Services and receives cadavers from other facilities as well as medico-legal cases brought by the police. All cadavers admitted to both mortuaries were screened consecutively between January $29^{\text {th }}$ and March $3^{\text {rd }} 2015$. Cadavers aged $\geq 15$ years at time of death were eligible for the study. We abstracted cause of death and demographic variables from death notifications and pathology reports. For eligible deaths that occurred at $\mathrm{KNH}$, additional variables regarding history of HIV diagnosis and ART were abstracted from patient files. Cadavers brought in by the police (which require autopsy to establish cause of death) are referred to as medico-legal cases and are generally taken to City Mortuary.

Cardiac blood samples were collected for this study using transthoracic aspiration; although cadavers were not excluded based on time from death to admission or collection, those from which HIV test results were not obtained were excluded from analysis. HIV testing was conducted using the national diagnostic algorithm (17): screening was done using Colloidal Gold assay (KHB Shangai Kehua BioEngineering Co, Ltd, Shanghai, China), confirmation of HIV-positive samples was done using First Response HIV 1-2-0 assay (PMC Medical India Pvt Ltd, Mumbai, India), and samples with discrepant results were tested using Unigold HIV assay (Trinity Biotech PLC, Bray, Ireland) as a tie breaker. HIV RNA testing was performed on HIV-positive samples using the Abbott m2000 real time RNA system (Abbott Molecular, Inc., Des Plaines, IL) to determine the HIV RNA concentration. Viral suppression was defined as HIV-1 RNA concentration $<1000$ copies/milliliter. 


\section{Measures}

Sex, age, and cause of death were abstracted from death certificates completed by the attending physician or, in case of autopsy, by the pathologist. Where age was not available from records it was estimated by mortuary technicians. Prior HIV diagnosis and ART use were ascertained from the clinical history documented in patient files for deaths occurring at KNH. HIV positivity was based on HIV serology performed during the study.

\section{Data analysis}

Data were analyzed in Stata 14 (StataCorp, Texas, USA). We conducted bivariate analysis to assess the relationship between HIV and select characteristics, and the chi-square test for independence and Fisher's exact test were used to assess statistical significance. The logit transformation was used to compute confidence interval limits. Multiple logistic regression was used to further explore associations between characteristics and outcome of HIV status. Predictive margins of HIV prevalence as a function of sex and age group were plotted to describe interaction between these variables when predicting HIV status of cadavers. In stratified analyses, the numerator, proportion and confidence intervals were replaced with an asterisk where the denominator was less than 20 .

\section{Ethics approvals}

This public health surveillance study was approved by the US Centers for Disease Control and Prevention Center for Global Health Associate Director for Science as research that did not involve human subjects (because subjects were deceased). Kenyatta National Hospital/University of Nairobi Ethical Review Board also approved the study. Nairobi County Health Services and the Kenyatta National Hospital Research Office gave administrative approval.

\section{Results}

A total of 807 cadavers received at the mortuaries were found to be eligible and enrolled into the study (Figure 1). Specimens were not available for 167 (20.7\%) cadavers due to various reasons including logistical/staffing $(n=91)$, extensive burns or putrefaction $(n=26)$, other/legal/discharge or transfer of cadaver $(n=31)$, and failed collection attempt $(\mathrm{n}=19)$. Of the $640(79.3 \%)$ with a blood specimen collected, 610 (95.3\%) had sufficient quality for HIV testing, and 119 (19.5\%) were HIV-positive. Of the 119 HIV-positive specimens, 90 (75.6\%) were from cadavers at $\mathrm{KNH}$ mortuary for which medical records were abstracted. Of the 90 HIV- 
positive specimens at KNH, 44 (48.9\%) had a prior HIV diagnosis, 23 of whom had a documented history of ART use, while of these, 12 had viral load testing results available in the study.

Cadavers were more likely to be males at City (86.0\%) versus KNH $(67.2 \%$, $\mathrm{p}<0.001)$. Cadavers also differed between mortuaries in terms of age: the median age was 33 years at City Mortuary (inter-quartile range [IQR] 28-42) and 44.5 years at KNH (IQR 33-59.5, p<0.001). Given the demographic differences between the deaths enrolled at City and $\mathrm{KNH}$ mortuaries, the remaining analyses are stratified by mortuary.

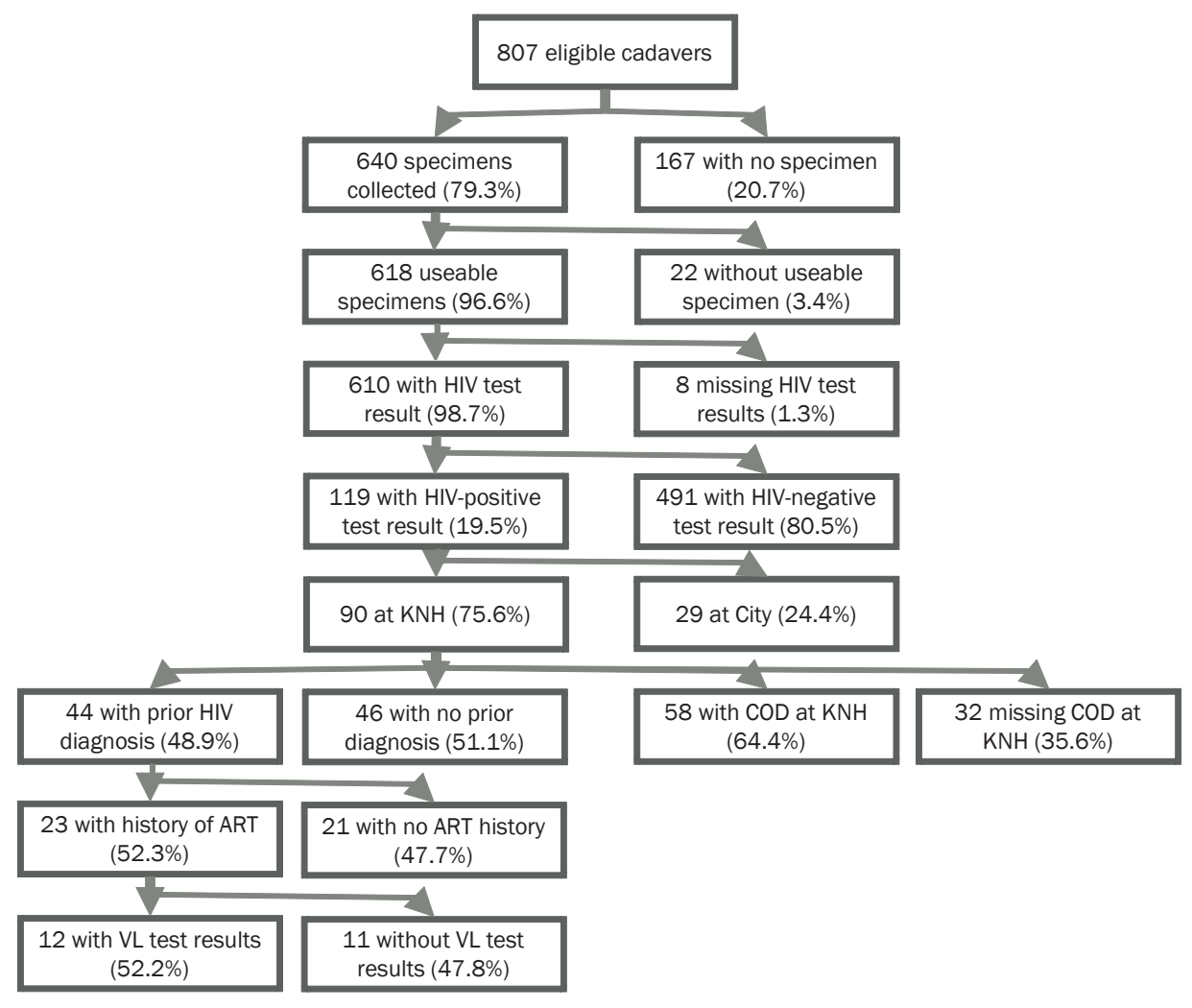

Figure 1: Data flow of eligible cadavers aged $\geq 15$ years, HIV mortuary survey.

Notes: $\mathbf{K N H}=$ Kenyatta National Hospital, ART = antiretroviral treatment, VL = viral load, COD = cause of death 
HIV prevalence differed by sex at both mortuaries: among 30 females at City Mortuary, HIV positivity was 33.2\%, while among 184 males it was $9.2 \%$ ( $\mathrm{p}=0.008$ ); at $\mathrm{KNH}$, HIV positivity was $28.8 \%$ among 170 females, compared with $19.0 \%$ among 226 males $(p=0.025)$. Specimen availability was not associated with age, sex or mortuary but specimens were less likely to be available for medico-legal cases at City Mortuary $(\mathrm{p}=0.004)$ (Table S1). At City Mortuary, the HIV positivity was significantly higher among cadavers admitted as non-medico-legal cases at $30 \%$ (95\% CI 18.9-44.1) compared to medico-legal cases at 7.3\% (95\% CI 4.2-12.5), $\mathrm{p}=0.001$.

As medical chart abstraction was performed for deaths at $\mathrm{KNH}$, additional HIV diagnosis and care information was available for HIV-infected deaths at this mortuary (Table 3). About one quarter (24.4\%) of HIV-infected deaths had a diagnosis prior to the hospitalization just prior to their death, while an additional $22.2 \%$ were diagnosed while hospitalized. The remaining half $(53.3 \%)$ did not have a diagnosis prior to death. Although $61.9 \%$ of males had no prior diagnosis compared to $45.8 \%$ of females, the difference was not significant $(\mathrm{p}=0.144)$. Two thirds $(66.7 \%)$ of HIV infected cadavers aged 45 years and above did not did not have a prior HIV diagnosis, while under half $(46.7 \%)$ of those aged between 15-44 years had no prior HIV diagnosis, again the difference was not significant $(\mathrm{p}=0.079)$. In contrast, the majority $(84.1 \%)$ of the deaths where HIV was assigned as the underlying cause had a prior HIV diagnosis, compared to only $35.7 \%$ being diagnosed among those for which the underlying cause assigned was not HIV $(\mathrm{p}=0.001)$.

In a multiple logistic regression model including mortuary, age and sex as independent predictors, the adjusted odds of HIV infection were twice as high at KNH Mortuary compared with City Mortuary (adjusted odds ratio [aOR] 1.80, 95\% CI 1.08-3.01), higher for women than men ( $\mathrm{aOR}=6.39,95 \%$ CI 1.47-27.68) among cadavers aged 15-24 years old, and significantly lower for cadavers aged 45+ years $(\mathrm{aOR}=0.18,95 \%$ CI 1.64-18.67) versus $15-24$ years among women (Table S2). There was a significant interaction between sex and age, consistent with higher prevalence among younger females and older males. When modeling finer-grained age groups, the peak risk of HIV infection for females was seen in the 35-44 years age group, while for males it was in the 45-54 years age group (Figure S1). No significant interaction was found between sex and mortuary.

Half (52.3\%) of the 44 cadavers with HIV diagnosis prior to death were on treatment, although treatment status was missing for 10 cadavers, so the true prevalence of treatment may have been higher. Among those with a prior HIV diagnosis, 10 had 
Table 1. Demographic characteristics of cadavers aged $\geq 15$ years by mortuary, HIV mortuary surveillance study, Nairobi, Kenya 2015 ( $\mathrm{n}=610)$

\begin{tabular}{|c|c|c|c|c|c|c|c|}
\hline \multirow[b]{2}{*}{$\begin{array}{l}\text { Selected } \\
\text { characteristics }\end{array}$} & \multicolumn{2}{|c|}{ City Mortuary } & \multicolumn{2}{|c|}{$\mathrm{KNH} \dagger$ Mortuary } & \multicolumn{2}{|r|}{ Total } & \multirow{2}{*}{$\begin{array}{c}\text { Significance }^{\star} \\
\chi^{2} \text { (degrees } \\
\text { of freedom), } \\
\text { p-value }\end{array}$} \\
\hline & $\mathbf{n}$ & $(\%)$ & $\mathrm{n}$ & $(\%)$ & $\mathbf{n}$ & (\%) & \\
\hline \multicolumn{8}{|l|}{ Sex } \\
\hline Male & 184 & $(86.0)$ & 226 & $(57.1)$ & 410 & $(67.2)$ & \multirow{3}{*}{$\begin{array}{c}\chi^{2}(1)=52.7 \\
\mathrm{p}<0.001\end{array}$} \\
\hline Female & 30 & $(14.0)$ & 170 & $(42.9)$ & 200 & $(32.8)$ & \\
\hline Total & 214 & & 396 & & 610 & & \\
\hline \multicolumn{8}{|l|}{ Age in years } \\
\hline $15-24$ & 36 & $(16.8)$ & 26 & $(6.6)$ & 62 & $(10.2)$ & \multirow{8}{*}{$\begin{array}{c}\chi^{2}(5)=64.3 \\
p<0.001\end{array}$} \\
\hline $25-34$ & 75 & $(35.0)$ & 79 & $(19.9)$ & 154 & $(25.2)$ & \\
\hline $35-44$ & 57 & $(26.6)$ & 93 & $(23.5)$ & 150 & $(24.6)$ & \\
\hline $45-54$ & 30 & $(14.0)$ & 72 & $(18.2)$ & 102 & $(16.7)$ & \\
\hline $55-74$ & 12 & $(5.6)$ & 89 & $(22.5)$ & 101 & $(16.6)$ & \\
\hline $75+$ & 4 & (1.9) & 37 & (9.3) & 41 & $(6.7)$ & \\
\hline Total & 214 & & 396 & & 610 & & \\
\hline Median (IQR) $\ddagger$ & 33.0 & $(28.0-42.0)$ & 44.5 & $(33.0-59.5)$ & 40.0 & $(33.0-53.0)$ & \\
\hline \multicolumn{8}{|c|}{ Medico-legal cases } \\
\hline Yes & 164 & $(76.6)$ & $\mathrm{n} / \mathrm{a}$ & $\mathrm{n} / \mathrm{a}$ & 164 & $(76.6)$ & \\
\hline No & 50 & $(23.4)$ & $\mathrm{n} / \mathrm{a}$ & $\mathrm{n} / \mathrm{a}$ & 50 & $(23.4)$ & $\mathrm{n} / \mathrm{a}$ \\
\hline Total & 214 & & $\mathrm{n} / \mathrm{a}$ & $\mathrm{n} / \mathrm{a}$ & 214 & & \\
\hline
\end{tabular}

Notes: ${ }^{\star}$ chi-square test for independence between mortuary and sex or age. $\dagger \mathrm{KNH}=$ Kenyatta National Hospital. $\neq \mathrm{IQR}=$ Inter-quartile range.

achieved viral suppression (Table 4). Only two of the 23 with evidence of treatment were not virally suppressed at time of death, though an additional 11 cadavers did not have viral load available. 
Table 2. HIV positivity rates among cadavers aged $\geq 15$ years at $\mathrm{KNH}$ and City Mortuaries, Nairobi, Kenya $2015(n=610)$

\begin{tabular}{|c|c|c|c|c|c|c|c|c|}
\hline \multirow[b]{2}{*}{$\begin{array}{l}\text { Selected } \\
\text { characteristics }\end{array}$} & \multicolumn{3}{|c|}{ City Mortuary } & \multirow{2}{*}{$\begin{array}{c}\text { Significance } \dagger \\
\text { F(df1,df2) } \\
\text { p-value }\end{array}$} & \multicolumn{3}{|c|}{ KNH Mortuary } & \multirow{2}{*}{$\begin{array}{c}\text { Significance } \dagger \\
\text { F(df1,df2), } \\
\text { p-value }\end{array}$} \\
\hline & $\mathbf{n}$ & $\%$ & $(95 \% \mathrm{CI})$ & & $\mathbf{n}$ & $\%$ & $(95 \% \mathrm{CI})$ & \\
\hline \multicolumn{9}{|l|}{ Sex } \\
\hline Male & 184 & 9.2 & $(5.8-14.4)$ & \multirow{2}{*}{$\begin{array}{c}\mathrm{F}(1,609)=7.15 \\
\mathrm{p}=0.008\end{array}$} & 226 & 19.0 & $(14.4-24.7)$ & \multirow{2}{*}{$\begin{array}{c}\mathrm{F}(1,609)=5.06 \\
\mathrm{p}=0.025 \neq\end{array}$} \\
\hline Female & 30 & 33.3 & $(18.9-51.8)$ & & 170 & 28.8 & $(22.5-36.1)$ & \\
\hline \multicolumn{9}{|l|}{ Male } \\
\hline $15-24$ & 30 & 6.7 & $(1.7-23.2)$ & \multirow{4}{*}{$\begin{array}{c}\mathrm{F}(2,609)=0.21 \\
\mathrm{p}=0.813 \S\end{array}$} & 17 & 11.8 & $(2.9-37.0)$ & \multirow{4}{*}{$\begin{array}{c}\mathrm{F}(2,609)=0.69 \\
\mathrm{p}=0.502 \S\end{array}$} \\
\hline $25-44$ & 119 & 10.1 & $(5.8-17.0)$ & & 96 & 21.9 & $(14.7-31.3)$ & \\
\hline $45+$ & 35 & 8.6 & $(2.8-23.5)$ & & 113 & 17.7 & $(11.7-25.9)$ & \\
\hline Total & 184 & 9.2 & $(5.8-14.4)$ & & 226 & 19.0 & $(14.4-24.7)$ & \\
\hline \multicolumn{9}{|l|}{ Female } \\
\hline $15-24$ & 6 & 50 & $(16.6-83.4)$ & \multirow{4}{*}{$\begin{array}{c}\mathrm{F}(2,609)=3.19 \\
\mathrm{p}=0.042 \S\end{array}$} & 9 & 33.3 & $(11.0-66.9)$ & \multirow{4}{*}{$\begin{array}{c}\mathrm{F}(2,609)= \\
11.98, \mathrm{p}<0.001 \S\end{array}$} \\
\hline $25-44$ & 13 & 46.2 & $(22.2-72.0)$ & & 76 & 46.1 & $(35.1-57.4)$ & \\
\hline $45+$ & 11 & 9.1 & $(1.2-44.3)$ & & 85 & 12.9 & $(7.3-22.0)$ & \\
\hline Total & 30 & 33.3 & $(18.9-51.8)$ & & 170 & 28.8 & $(22.5-36.1)$ & \\
\hline \multicolumn{9}{|l|}{ Age in years } \\
\hline $15-24$ & 36 & 13.9 & $(5.9-29.4)$ & \multirow{4}{*}{$\begin{array}{c}\mathrm{F}(2,609)=0.50 \\
\mathrm{p}=0.604 \|\end{array}$} & 26 & 19.2 & $(8.2-38.8)$ & \multirow{4}{*}{$\begin{array}{c}\mathrm{F}(2,609)=7.35, \\
\mathrm{p}<0.001 \|\end{array}$} \\
\hline $25-44$ & 132 & 13.6 & $(8.8-20.6)$ & & 172 & 32.6 & $(26.0-39.9)$ & \\
\hline $45+$ & 46 & 8.7 & $(3.3-21.0)$ & & 198 & 15.7 & $(11.2-21.4)$ & \\
\hline Total & 214 & 12.6 & $(8.8-17.8)$ & & 396 & 23.2 & $(19.3-27.7)$ & \\
\hline
\end{tabular}

Police case

\begin{tabular}{|c|c|c|c|c|c|c|c|c|}
\hline Yes & 164 & 7.3 & $(4.2-12.5)$ & \multirow{3}{*}{$\begin{array}{c}\mathrm{F}(1,213)=10.94 \\
\mathrm{p}=0.001\end{array}$} & & $\mathrm{n} / \mathrm{a}$ & & \multirow{3}{*}{$\begin{array}{c}\mathrm{F}(1,213)=10.94 \\
\mathrm{p}=0.001\end{array}$} \\
\hline No & 50 & 30.0 & $(18.9-44.1)$ & & & $\mathrm{n} / \mathrm{a}$ & & \\
\hline Total & 214 & 12.6 & $(8.8-17.8)$ & & & $\mathrm{n} / \mathrm{a}$ & & \\
\hline Total & 214 & 12.6 & $(8.8-17.8)$ & $\mathrm{n} / \mathrm{a}$ & 396 & 23.2 & $(19.3-27.7)$ & $\begin{array}{c}\mathrm{F}(1,609)=11.63 \\
\mathrm{p}<0.001 \pi\end{array}$ \\
\hline
\end{tabular}

Notes: ${ }^{\star} \mathrm{n}$ /percentages not shown are based on $<20$ cases. $\dagger$ F-tests for differences in HIV prevalence by group as follows: $\ddagger$ by mortuary, sex; $\S$ by mortuary and sex, age; $\|$ by mortuary, age; $\boldsymbol{g}$ by medico-legal status (at City mortuary only); $\pi$ overall between mortuaries. 


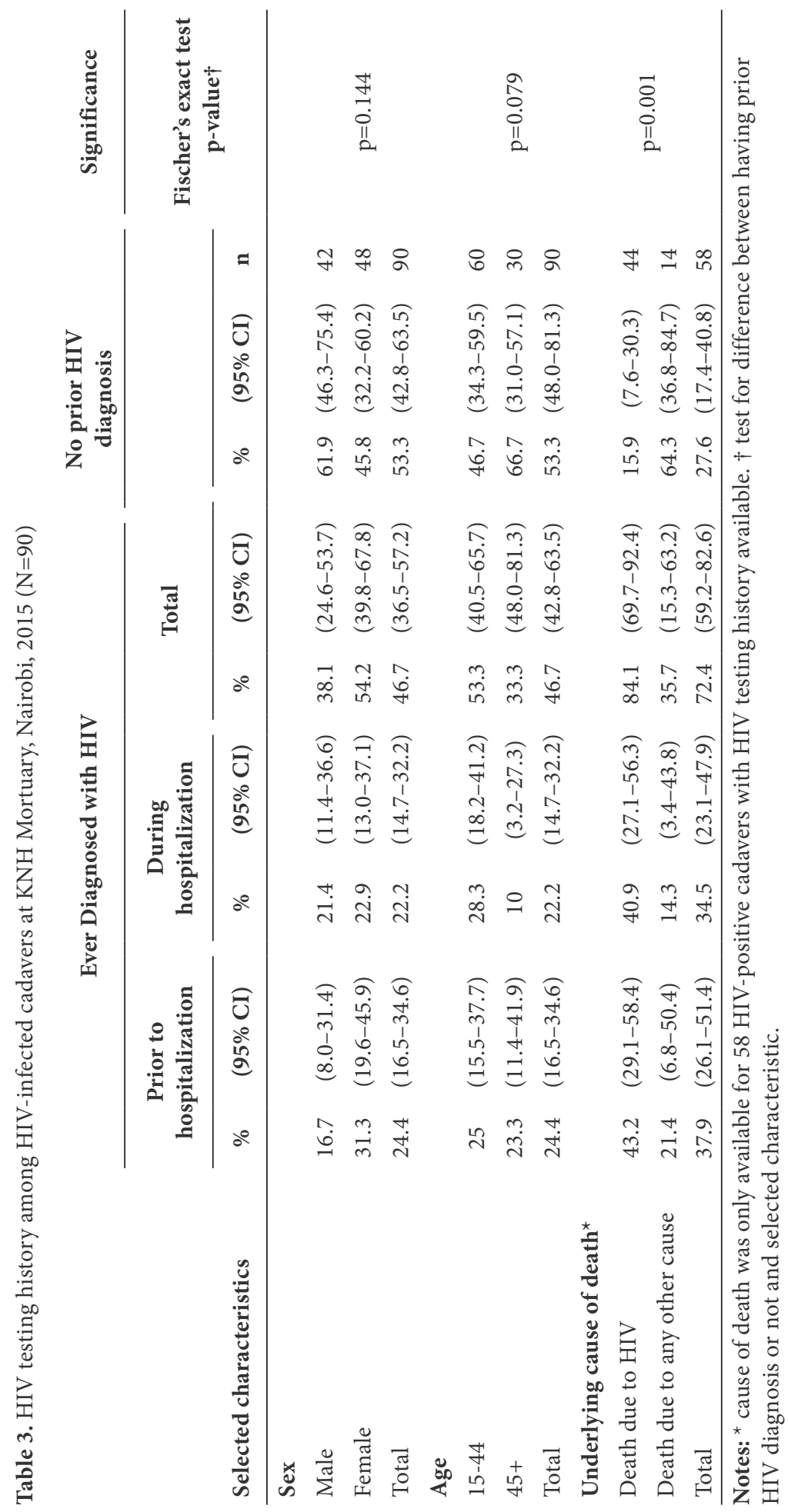


Table 4. HIV testing and ART history among cadavers diagnosed with HIV prior to death, KNH Mortuary, Nairobi, $2015(\mathrm{~N}=44)$

\begin{tabular}{lccc}
\hline Indicator & $\mathbf{n}$ & $\mathbf{\%}$ & $\mathbf{( 9 5 \% ~ C I )}$ \\
\hline Total treated for HIV & 23 & 52.3 & $(37.6-66.5)$ \\
Treated and virally suppressed & 10 & 22.7 & $(12.6-37.4)$ \\
Treated and not suppressed & 2 & 4.5 & $(1.1-16.6)$ \\
Treated and viral load unknown & 11 & 25.0 & $(14.4-39.9)$ \\
Not treated & 11 & 25.0 & $(14.4-39.9)$ \\
Treatment unknown & 10 & 22.7 & $(12.6-37.4)$ \\
\hline
\end{tabular}

Notes: Includes two cases excluded from previous table where timing of HIV diagnosis was not known

\section{Discussion}

In this study we estimated HIV positivity in cadavers at the two largest mortuaries in Nairobi, HIV diagnosis prior to death, subsequent use of ART and viral suppression for hospital-based deaths. Females continue to bear the greatest burden of HIV infection. The percentage of female cadavers that were HIV-infected was greater than that for males at both mortuaries. While greater HIV-associated mortality in women than men was not surprising earlier in the epidemic, given the high ART coverage, especially among women, further research is warranted to confirm and interpret this finding.

We found that one in eight cadavers at City Mortuary and one in four cadavers at $\mathrm{KNH}$ Mortuary were HIV infected. The higher HIV positivity among cadavers at KNH compared to City Mortuary may be due to KNH's status as a referral hospital, the majority of whose patients are hospitalized prior to death and who might have sought care for HIV complications, while conversely City Mortuary primarily receives medico-legal deaths, which are likely to be due to external causes.

The last national survey conducted in 2012 estimated HIV prevalence among adults at $4.9 \%$ and that only $57.5 \%$ of adults living with HIV in Kenya had been previously diagnosed (18). We found that more than eight in ten hospitalized patients for whom the underlying cause of death assigned was HIV had been diagnosed prior to death, however only about half of these were known to have been diagnosed prior to admission. The remaining $15.9 \%$ of deaths due to HIV did not have a documented HIV diagnosis at time of death. These scenarios represent missed opportunities for diagnosis prior to life-threatening illness and death. Among those with prior HIV diagnosis, the approximately half of deaths with no evidence of treatment represent 
additional missed opportunities to save lives. About one fifth of those with a prior HIV diagnosis were on treatment and virally suppressed at time of death. These deaths are difficult to explain in the absence of a detailed clinical history, including duration on treatment, and diagnosed comorbidities and opportunistic infections.

The study had important limitations. Medical history was only available for hospital-based deaths at $\mathrm{KNH}$ and in those cases, was limited to the inpatient records for their hospitalization just prior to death, representing only a third (199/610) of all deaths with HIV test results captured in this study, and 50\% (199/396) of those captured at KNH Mortuary. This limited our ability to establish whether a detectable viral load was due to treatment failure, poor adherence, or lack of treatment. Cause of death was also missing for 38.5\% (235/610) of sampled mortuary deaths. Our study relied on routinely recorded causes of death, and full autopsies were not performed specifically for this study, so the underlying cause of death may have been ascertained incorrectly. While we included the two largest mortuaries in Nairobi in the study, a demographic analysis reported elsewhere found coverage to be $51 \%$ of expected deaths in the city (16), hence our findings are not necessarily representative of all deaths in Nairobi. Although inclusion of City Mortuary may have led to over-representation of external causes among males, excluding City from the analysis did not have a significant impact on the association between sex and death due to HIV. Additionally, the fact that threequarters of the deaths at City Mortuary were medico-legal cases may also explain why no deaths were assigned HIV as a cause of death at this mortuary.

In spite of these limitations, the implementation of a novel mortuary-based surveillance study in Kenya provided an estimate of the proportion of HIV-related deaths at the two largest mortuaries in Nairobi, as well as important ancillary information on ART use, viral load, and diagnosis of HIV prior to death. Although studies have documented a reduction in HIV associated mortality attributable to ART, the prevalence of HIV among deaths in Nairobi is still higher than in the general population (19-22). In assessing impact of HIV treatment programs, measurement of mortality is rarely undertaken. As national ART programs continue to scale-up in an effort to save lives and achieve epidemic control, it is critical that appropriate surveillance systems are implemented that can monitor reductions in mortality as well as the patterns of specific causes of death among PLHIV, including those that are not being reached by care and treatment programs. Although measuring the level of HIV infection among deaths can help interpret declining trends in HIV prevalence in Nairobi, increasing the representativeness of the catchment of mortuary surveillance and developing methods for generalizing to the population of all deaths in the community is key. Although strengthened 
national vital statistics and HIV case-based surveillance would provide more robust and comprehensive data, establishment of routine mortality surveillance in sentinel sites could play an important role in monitoring outcomes among people living with HIV in Kenya. This study shows that routine testing of cadavers and linking results to clinical records is a feasible approach that can provide important insights into the levels of HIV-associated mortality in the era of widespread ART availability. The findings also highlight the need to determine why PLHIV continue to experience high mortality even as ART is believed to be widely accessible, so that appropriate actions can be taken.

\section{Acknowledgements}

The authors would like to acknowledge the contributions of the mortuary and laboratory staff for without whom this manuscript would not have been possible. We would also like to appreciate the thoughtful comments of reviewers and referees that improved the manuscript. 


\section{References}

1. UNAIDS. Global AIDS Update. 2016. Available from: http://www.unaids.org/sites/default/files/media_ asset/global-AIDS-update-2016_en.pdf

2. UNAIDS_FactSheet_en.pdf. [cited 2016 Oct 11]. Available from: http://www.unaids.org/sites/default/ files/media_asset/UNAIDS_FactSheet_en.pdf

3. UNAIDS. AIDS by the numbers, AIDS is not over, but it can be 2016 Available from: http://www.unaids. org/sites/default/files/media_asset/AIDS-by-the-numbers-2016_en.pdf

4. UNAIDS. AIDSinfo Online Database. 2017 [cited 2017 May 5]. Available from: aidsinfoonline.org

5. National AIDS Control Council (NACC) Kenya HIV Estimates, 2015. Kenya: NACC; 2016 0ct.

6. UNAIDS. 90-90-90: an ambitious treatment target to help end the AIDS epidemic. Geneva: UNAIDS; 2014 Oct [cited 2016 Aug 19]. Available from: http://www.unaids.org/sites/default/files/media_ asset/90-90-90_en_0.pdf

7. UNAIDS. Fast-Track: Ending the epidemic by 2030. Available from: http://www.unaids.org/sites/ default/files/media_asset/JC2686_WAD2014report_en.pdf

8. Floyd $S$, Marston M, Baisley $K$, et al. The effect of antiretroviral therapy provision on all-cause, AIDS and non-AIDS mortality at the population level - a comparative analysis of data from four settings in Southern and East Africa. Tropical Medicine and International Health. 2012; 17(8): E84-E93.

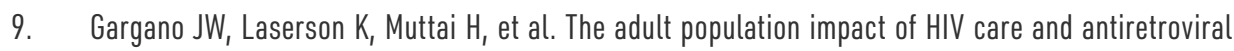
therapy in a resource poor setting, 2003-2008. AIDS. 2012, 26:1545-1554.

10. Reniers G, Slaymaker E, Nakiyingi-Miiro J, et al. Mortality trends in the era of antiretroviral therapy: evidence from the Network for Analysing Longitudinal Population based HIV/AIDS data on Africa (ALPHA). AIDS. 2014; 28 (Suppl 4):S533-S542.

11. Stover J, Andreev K, Slaymaker E, et al. Updates to the Spectrum model to estimate key HIV indicators for adults and children. AIDS. 2014;28(4):S427-S434. doi:10.1097/QAD.0000000000000483

12. Civil Registration Services (CRS). Kenya vital statistics report 2014. Nairobi, Kenya: Civil Registration Services, CRS; Statistics Division. Government of Kenya; 2015.

13. Karhunen PJ, Brummer-Korvenkontio H, Leinikki P, Nyberg M. Stability of human immunodeficiency virus (HIV) antibodies in postmortem samples. J Forensic Sci. 1994.

14. Klatt EC, Shibata D, Strigle SM. Postmortem enzyme immunoassay for human immunodeficiency virus. Arch Pathol Lab Med. 1989. doi:S0004-27302009000500011 [pii]

15. Leshchinskaia N, Smol'skaia T. [Postmortem detection of antibodies to human immunodeficiency virus]. Klin Lab Diagn. 1993;May-Jun(3):47-50.

16. Young PW, Kim AA, Wamicwe J, et al. HIV-associated mortality in the era of antiretroviral therapy scale-up - Nairobi, Kenya, 2015. PLoS One. 2017. doi:10.1371/journal.pone.0181837

17. Ministry of Health and Sanitation, Kenya. Circular No. MPHS/ADM/1/12. Nairobi, Kenya: NASCOP; 2013 Feb.

18. Kim AA, Mukui I, Young PW, et al. Undisclosed HIV infection and art use in the Kenya AIDS indicator survey 2012: relevance to targets for HIV diagnosis and treatment in Kenya. AIDS. 2016:1. doi:10.1097/QAD.0000000000001227 
19. Mberu B, Wamukoya M, Oti S, Kyobutungi $C$. Trends in causes of adult deaths among the urban poor: Evidence from Nairobi Urban Health and Demographic Surveillance System, 2003-2012. J Urban Heal. 2015. doi:10.1007/s11524-015-9943-6

20. Rubaihayo J, Tumwesigye NM, Konde-Lule J, et al. Trends and predictors of mortality among HIV positive patients in the era of highly active antiretroviral therapy in Uganda. Infect Dis Rep. 2015. doi:10.4081/idr.2015.5967

21. Salihu HM. Global reduction in HIV-related maternal mortality: ART as a key strategy. Int J MCH AIDS. 2015;4(2):8.

22. Rubaihayo J, Tumwesigye NM, Konde-Lule J, et al. Trends and predictors of mortality among HIV positive patients in the era of highly active antiretroviral therapy in Uganda. Infect Dis Rep. 2015. doi:10.4081/idr.2015.5967 


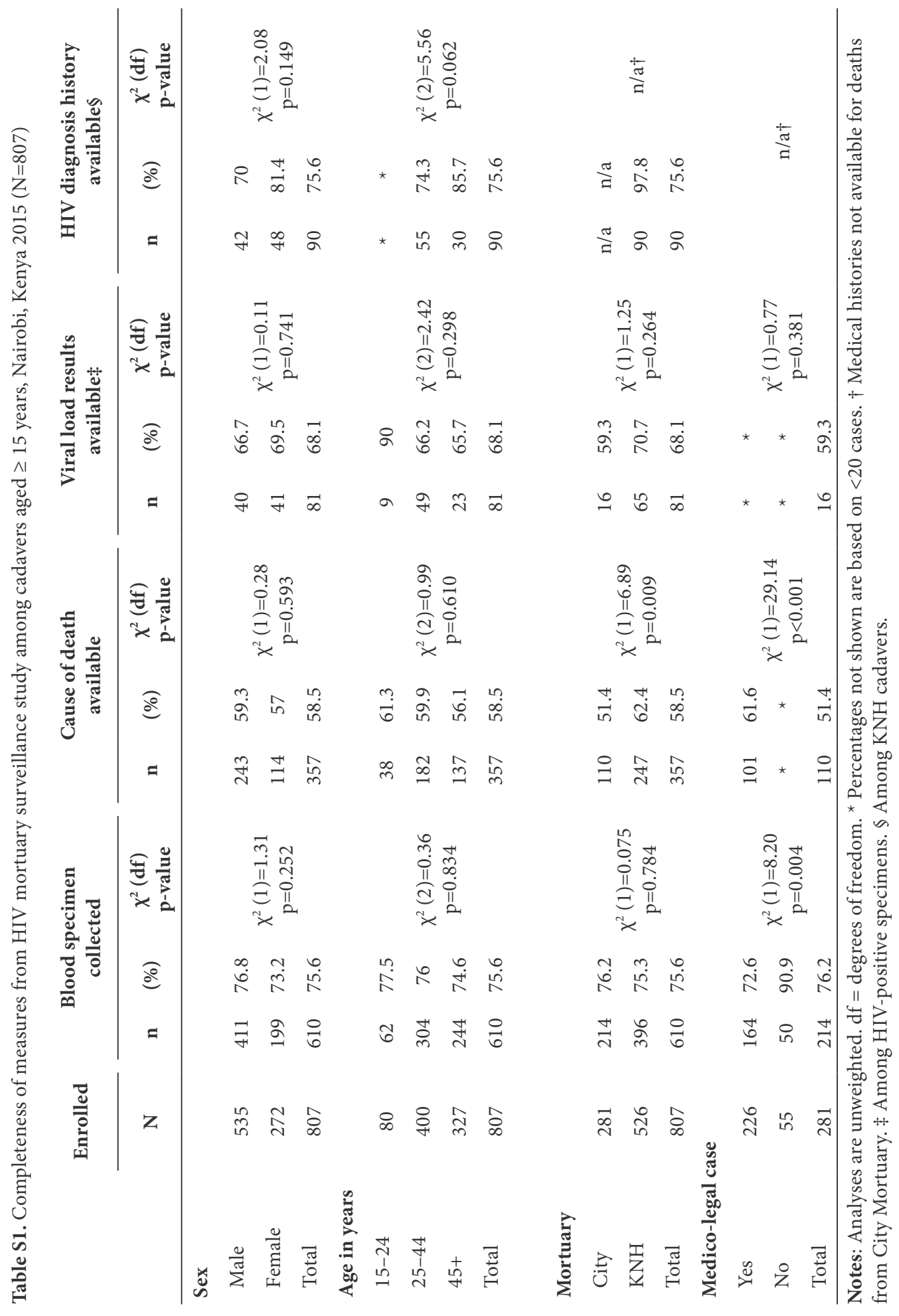


Table S2. Interaction between sex and age on risk of HIV infection among cadavers aged $\geq 15$ years, HIV mortuary surveillance study, Nairobi, Kenya 2015 (N=610)

\begin{tabular}{|c|c|c|c|c|}
\hline \multirow[b]{2}{*}{ Age group (years) } & \multicolumn{2}{|c|}{ Males } & \multicolumn{2}{|c|}{ Females } \\
\hline & $\begin{array}{c}\mathrm{N} \text { infected / } \\
\text { total }\end{array}$ & $\begin{array}{c}\text { Odds Ratio (OR) } \\
(95 \% \mathrm{CI})\end{array}$ & $\begin{array}{c}\mathrm{N} \text { infected / } \\
\text { total }\end{array}$ & OR $(95 \% \mathrm{CI})$ \\
\hline $15-24$ & $4 / 47$ & 1.0 & $6 / 15$ & $\begin{array}{c}6.39(1.47-27.69) \\
p=0.013\end{array}$ \\
\hline $25-44$ & $33 / 215$ & $\begin{array}{c}1.86(0.62-5.56) \\
p=0.265\end{array}$ & $41 / 89$ & $\begin{array}{c}7.09(2.29-21.9) \\
\mathrm{p}=0.001\end{array}$ \\
\hline $45+$ & $23 / 148$ & $\begin{array}{c}1.58(0.51-4.93) \\
p=0.428\end{array}$ & $12 / 96$ & $\begin{array}{c}1.15(0.34-3.89) \\
\mathrm{p}=0.818\end{array}$ \\
\hline \multicolumn{5}{|c|}{ Within-strata ORs $(95 \% \mathrm{CI})$ p-value } \\
\hline $25-44$ & & & & $\begin{array}{c}1.11(0.36-3.44) \\
\mathrm{p}=0.856\end{array}$ \\
\hline $45+$ & & & & $\begin{array}{c}0.18(0.05-0.61) \\
\mathrm{p}=0.006\end{array}$ \\
\hline \multicolumn{5}{|c|}{ Ratio of ratios of ORs ( $95 \% \mathrm{CI})$ p-value } \\
\hline $25-44$ & & & & $\begin{array}{c}0.60(0.12-2.87) \\
p=0.518\end{array}$ \\
\hline $45+$ & & & & $\begin{array}{c}0.11(0.02-0.59) \\
\mathrm{p}=0.010\end{array}$ \\
\hline
\end{tabular}

Notes: all odds ratios adjusted for mortuary. 
Figure S1. Predictive margins of HIV prevalence among cadavers for age when controlling for sex, HIV mortuary surveillance study, Nairobi, Kenya 201

A

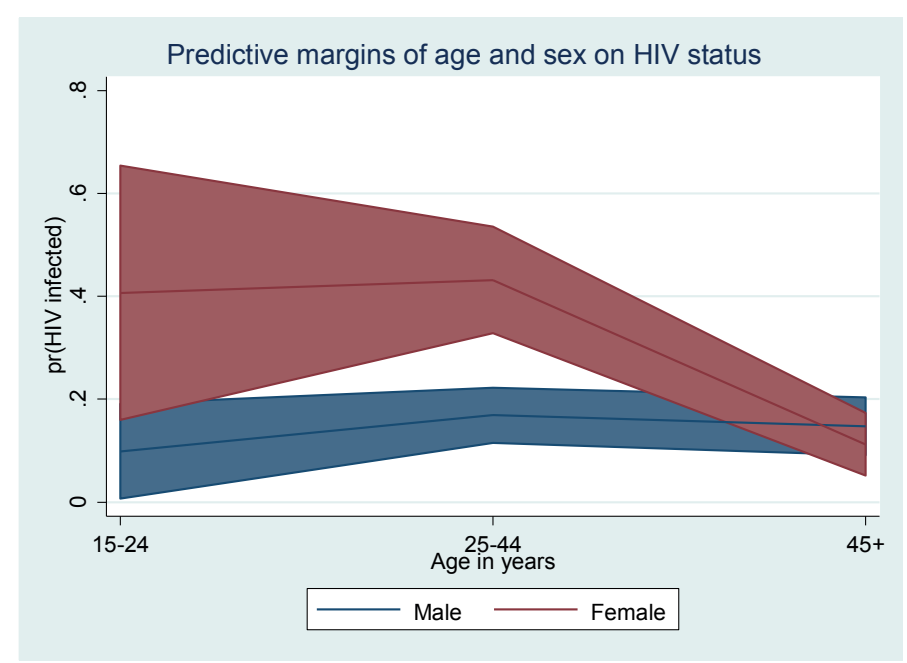

B

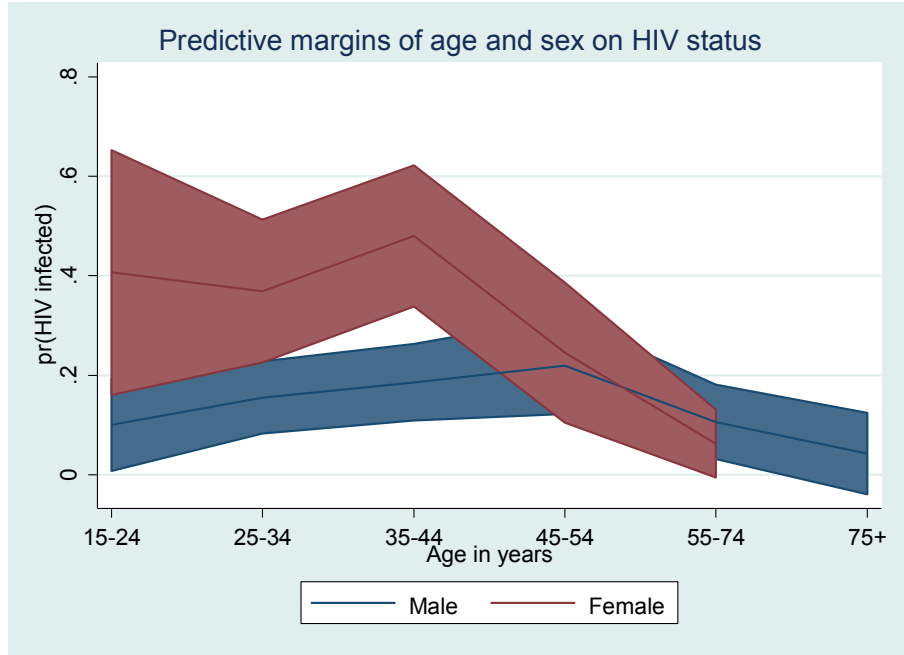

Panel A shows larger age grouping used throughout analysis. Panel B shows finer-grained age grouping with peak marginal probability of HIV infection by sex peaking at 35-44 years among females and 45-54 years among males. 


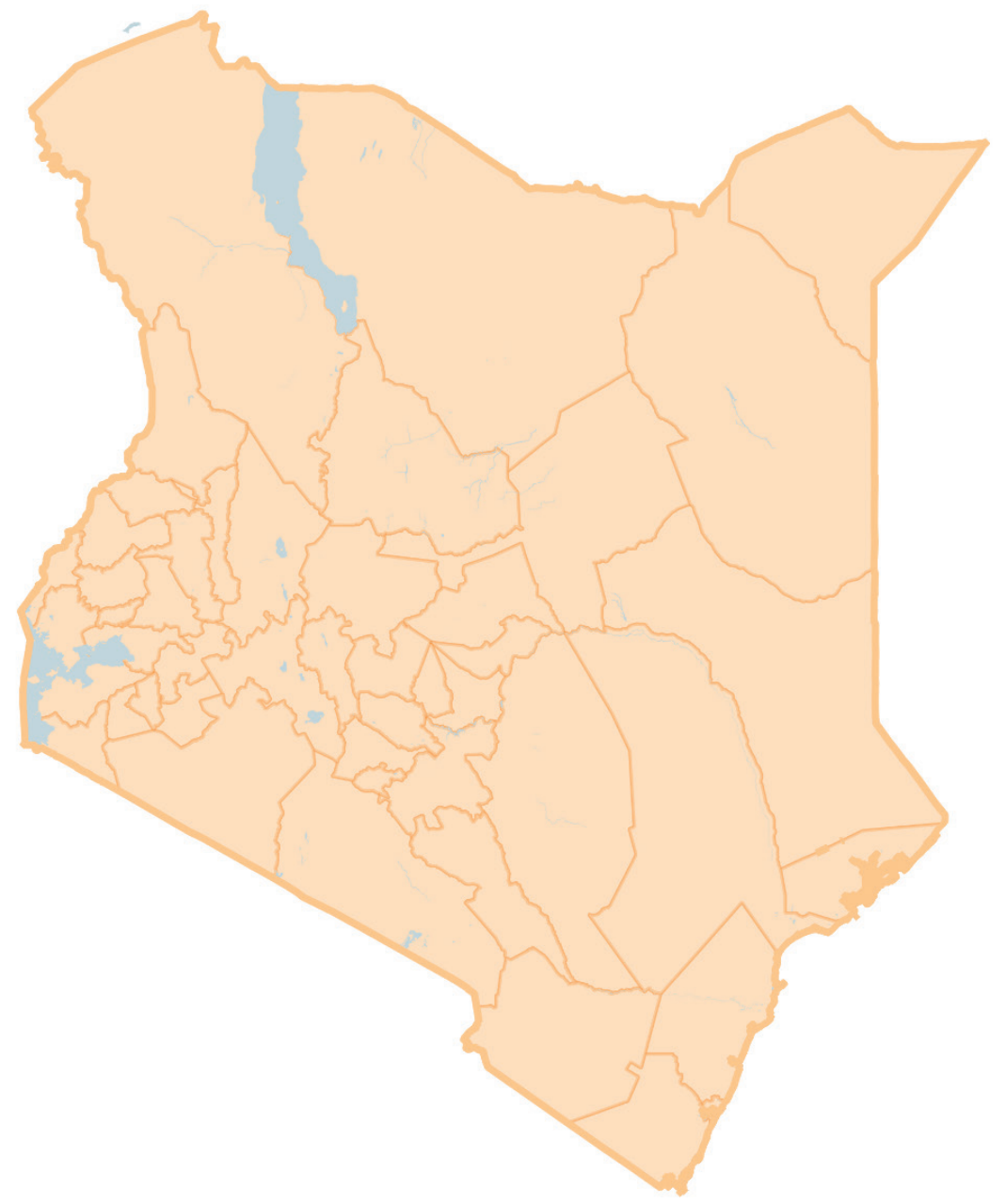




\section{Chapter 7}

\section{HIV-associated mortality in the era of antiretroviral therapy scale-up - Nairobi, Kenya, 2015}

Peter W. Young

Andrea A. Kim

Joyce Wamicwe

Lilly Nyagah

Catherine Kiama

John Stover

Johansen Oduor
Emily A. Rogena

Edwin Walong

Emily Zielinski-Gutierrez

Andrew Imbwaga

Martin Sirengo

Timothy A. Kellogg

Kevin M. De Cock

PLoS One. 2017 Aug 2;12(8):e0181837

https://doi.org/10.1371/journal.pone.0181837 


\section{Abstract}

Background: Declines in HIV prevalence and increases in antiretroviral treatment coverage have been documented in Kenya, but population-level mortality associated with HIV has not been directly measured. In urban areas where a majority of deaths pass through mortuaries, mortuary-based studies have the potential to contribute to our understanding of excess mortality among HIV-infected persons. We used results from a cross-sectional mortuary-based HIV surveillance study to estimate the association between HIV and mortality for Nairobi, the capital city of Kenya.

Methods and Findings: HIV seropositivity in cadavers measured at the two largest mortuaries in Nairobi was used to estimate HIV prevalence in adult deaths. Modelbased estimates of the HIV-infected and uninfected population for Nairobi were used to calculate a standardized mortality ratio and population-attributable fraction for mortality among the infected versus uninfected population. Monte Carlo simulation was used to assess sensitivity to epidemiological assumptions. When standardized to the age and sex distribution of expected deaths, the estimated HIV positivity among adult deaths aged 15 years and above in Nairobi was 20.9\% (95\% CI 17.7-24.6\%). The standardized mortality ratio of deaths among HIV-infected versus uninfected adults was 4.35 (95\% CI 3.67-5.15), while the risk difference was 0.016 (95\% CI 0.013-0.019). The HIV population attributable mortality fraction was 0.161 (95\% CI 0.131-0.190). Sensitivity analyses demonstrated robustness of results.

Conclusions: Although $73.6 \%$ of adult PLHIV receive antiretrovirals in Nairobi, their risk of death is four-fold greater than in the uninfected, while $16.1 \%$ of all adult deaths in the city can be attributed to HIV infection. In order to further reduce $\mathrm{HIV}$-associated mortality, high-burden countries may need to reach very high levels of diagnosis, treatment coverage, retention in care, and viral suppression. 


\section{Introduction}

Access to antiretroviral treatment (ART) has increased from 1 million to 17 million people living with HIV (PLHIV) globally from 2003 to 2015 [1, 2]. High HIV burden countries have accounted for the majority of this scale-up, with the number of PLHIV on ART increasing from 4 million to over 10 million in the last 5 years in Eastern and Southern Africa [3]. In both high- and low-income countries ART substantially increases life expectancy, especially for patients who start ART early $[4,5]$. Given the rapid increase in coverage of life-saving treatment, a commensurate decrease in mortality in HIV-infected populations in high-burden countries would be expected. While cohort studies have demonstrated reductions in mortality among patients accessing ART, high rates of loss to follow-up (LTFU) make it difficult to fully assess the impact of ART at the population level. Complementary surveillance systems that can systematically assess population impact of ART programs on all-cause mortality on an ongoing basis are needed.

Civil registration systems in developing countries are often incomplete and causes of death poorly characterized. While a large fraction of PLHIV may be enrolled in care, high levels of LTFU, undocumented transfers, and passive reporting of deaths mean that program data underestimate mortality in the population in care if not linked to vital statistics [6] or adjusted statistically with LTFU studies [7, 8]. Hospital-based surveillance can shed light on HIV mortality among hospitalized patients, when both testing and HIV surveillance are routinely conducted [9]. Disease case surveillance systems, which could link patient records across systems, are still in their infancy in these settings. Further, the population in care is likely to have reduced mortality compared with those not in care, due to having access to medical interventions.

In urban areas where a majority of cadavers pass through mortuaries, mortuarybased studies have the potential to contribute to our understanding of excess mortality among HIV-infected persons. Although the literature is sparse on use of HIV testing in mortuary settings for surveillance purposes, De Cock et al. conducted a mortuary-based study to estimate mortality rates due to HIV and AIDS in Abidjan, Cote D'Ivoire in the late 1980s, before effective treatment for HIV existed, demonstrating that HIV was the leading cause of death in the city at the time [10]. A similar study conducted in 2001 found that nearly half of adult deaths in Pointe-Noire, Republic of Congo could be attributed to HIV, while the City of New York has been routinely testing for HIV during autopsies since the early 1990's [11]. In Addis Ababa, Ethiopia, mortality surveillance at burial grounds demonstrated reductions in AIDS-related mortality following scale-up of ART [12]. 
Coverage of ART has rapidly expanded in Kenya, reaching 59\% of all PLHIV by the end of 2014 [3], and is likely to be highest in the capital city of Nairobi. The high estimated coverage of death registration in Nairobi at 78\% in 2014 [13], together with the fact that all registered deaths in Nairobi are notified by mortuaries, implies that mortuary-based surveillance could be representative of all deaths in the city. Relatively high ART coverage among PLHIV coupled with high levels of mortuarybased death registration and moderate HIV prevalence in adults, made Nairobi an attractive site for examining HIV-related adult mortality. We conducted a crosssectional mortuary-based serological study to measure HIV prevalence among deaths in Nairobi. We used results from this study to estimate the population-level association between HIV and mortality for the city of Nairobi in the era of scale-up of ART towards universal access.

\section{Materials and methods}

\section{Mortuary HIV surveillance}

The two largest mortuaries in Nairobi in terms of admissions volume were selected for HIV mortuary surveillance. Kenyatta National Hospital $(\mathrm{KNH})$ is a national teaching and referral hospital and its mortuary saw 9,272 admissions in 2014. In contrast, City Mortuary saw 5,253 admissions in 2014 and primarily receives cadavers brought by the police in addition to cases from smaller health facilities lacking a mortuary. All cadavers admitted to KNH and City Mortuary over a 33 day period from 29 January to 3 March 2015 were registered. Cadavers of persons aged 15 years and above at death were sampled using transthoracic aspiration of cardiac blood which was shipped within 6 hours to a central laboratory for processing. Plasma was tested using the national HIV diagnostic algorithm. Specimens were screened with Colloidal Gold assay (KHB Shanghai Kehua Bio-Engineering Co, LTD, Shanghai, China). Reactive results were confirmed using First Response HIV 1-2-0 assay (PMC Medical India Pvt Ltd, Mumbai, India). Specimens with discrepant results were tested with Uni-Gold $H I V$ assay as a tie breaker (Trinity Biotech PLC, Bray, Ireland) and the result of the tie-breaker was taken as the final result for the specimen. Every seventh specimen that was non-reactive on the screening assay was confirmed as an internal quality assurance step.

\section{Nairobi Civil Registration}

To determine the proportion of annual deaths reported during the study period for City Mortuary, $\mathrm{KNH}$, and city-wide, as well as the proportion of deaths reported by each mortuary and seasonal variation of reported deaths, we abstracted death notifications from the Vital Statistics office at Nairobi City Hall for adults aged 15 
and above at time of death for all deaths reported in Nairobi in 2014. We extracted summary data of total deaths by age, sex and year for Nairobi from the 2014 annual vital statistics report for purposes of estimating the age/sex distribution of deaths in Nairobi. These data were used to assess the coverage of death reporting in Nairobi as well as the coverage of City and $\mathrm{KNH}$ mortuaries among all reported deaths.

\section{Measures}

Age and sex of cadavers in the mortuary study were based on the reported age and sex from the death notification, the sex, date of birth and age recorded in the patient medical records if the death occurred at Kenyatta National Hospital and medical records were available for abstraction, or the autopsy report completed by the pathologist. Age and sex of deaths reported to vital statistics were based on the age and sex recorded on the death notification.

\section{Population Projections}

Spectrum version 5.52b3 (Avenir Health, Glastonbury, Connecticut) was used to estimate ART program coverage, HIV-related mortality, as well as the age- and sex-specific HIV prevalence for Nairobi in 2015, based on official demographic statistics, HIV surveillance and program data and population-based survey data for Nairobi [14-17]. The age and sex distribution of HIV prevalence from Spectrum was applied to the sub-national population projection for Nairobi from the Kenya National Bureau of Statistics [18] to estimate the number of people living with and without HIV in Nairobi in 2015. A life table derived from the Spectrum projection for Nairobi was used to estimate age-specific mortality rates. The projection is summarized in S1 Table.

\section{Analysis Methods}

Data were logged into an Epi Info version 7.0.4 database (U.S. Centers for Disease Control and Prevention [CDC], Atlanta). Data cleaning, tabulation and statistical analyses were performed in Stata version 13 (Stata Corp., College Station, Texas). Coverage and representativeness of surveillance system deaths were assessed by plotting reported versus expected deaths by year and by age group and sex. Inverse probability weights were developed and used to adjust the observed deaths from the surveillance system to account for missing HIV status by age and sex, and mortuary population weights were developed to adjust for differences in age- and sex-specific coverage and annualize deaths with respect to expected deaths based on the KNBS population projection and the Spectrum life table. Mortality rates were calculated by dividing the weighted annualized deaths from the surveillance system by the estimated population size in Nairobi from the population projection, by age, sex and HIV status, then multiplying by 1000 . 
The standardized risk difference subtracts the mortality rate in the HIV-uninfected population from the corresponding rate in the HIV-infected population, by age and sex. It is an additive measure which describes the additional mortality burden in the HIV-infected population. The standardized mortality ratio (SMR) is a relative measure which divides the mortality rate in the infected population by the mortality rate in the uninfected population after standardizing to the age and sex distribution of the infected population. Both measures were calculated using Stata's epitab package.

The population attributable fraction (PAF) estimates the proportion of all deaths that would have been avoided if HIV were no longer a risk factor for mortality in the HIV-infected. Odds ratios were fit using logit models with population frequency rates normalized to the total observed deaths, and these were then used to calculate attributable fractions with Stata's punaf command [19]. We also used logit models to test for interaction between age group and sex.

\section{Simulation Methods}

Monte Carlo simulations were conducted to assess the sensitivity of risk ratio and attributable fraction estimates to epidemiological assumptions; additional details are provided in S1 Text.

\section{Data Access}

Data are available from the National AIDS \& STI Control Programme (NASCOP), Ministry of Health, Kenya on request. Requests for access should be directed to head@nascop.or.ke.

\section{Ethics Approvals}

This public health surveillance activity was approved by the U.S. Centers for Disease Control Center for Global Health as research that did not involve human subjects (because subjects were deceased) and did not require institutional review board review for human experimentation [2014/062]. The Kenyatta National Hospital/University of Nairobi Ethical Review Committee also approved this study [P380/06/2014] and did not require consent from next of kin. All data on deceased subjects were de-identified prior to data analysis. 


\section{Results}

We found a pooled, unadjusted HIV positivity rate of 19.5\% (95\% CI 16.5-22.9\%) among deaths at $\mathrm{KNH}$ and City Mortuaries, the positivity differing significantly by sex $(14.6 \%$ among men, $29.5 \%$ among women, $\mathrm{p}<0.001)$. After weighting to account for missing test results and the coverage of the included mortuaries with respect to expected deaths by age and sex, the estimated HIV positivity among adult deaths in Nairobi was 20.9\% (95\% CI 17.7-24.6\%) (Table 1).

Table 1. Percent HIV positivity among cadavers at City and KNH mortuaries, Nairobi 2015

\begin{tabular}{lccccc} 
Sex & Age (years) & $\begin{array}{c}\text { Unadjusted } \\
\text { HIV-positivity } \\
(\mathbf{n = 6 1 0})\end{array}$ & $(\mathbf{9 5 \%} \mathbf{C I})$ & $\begin{array}{c}\text { Adjusted } \\
\text { HIV-positivity } \\
(\mathbf{n = 8 0 7})^{*}\end{array}$ & $(\mathbf{9 5 \%} \mathbf{C I})$ \\
\hline \multirow{3}{*}{ Male } & $15-24$ & 8.5 & $(3.2,20.6)$ & 8.9 & $(3.3,21.7)$ \\
& $25-44$ & 15.3 & $(11.1,20.8)$ & 15.3 & $(11.1,20.8)$ \\
& $\geq 45$ & 15.5 & $(10.5,22.3)$ & 15.8 & $(10.7,22.7)$ \\
& Total & 14.6 & $(11.5,18.4)$ & 14.8 & $(11.6,18.7)$ \\
\hline \multirow{3}{*}{ Female } & $15-24$ & 40.0 & $(19.1,65.4)$ & 40.8 & $(19.6,66.1)$ \\
& $25-44$ & 46.1 & $(36.0,56.5)$ & 46.1 & $(35.8,56.7)$ \\
& $\geq 45$ & 12.5 & $(7.2,20.8)$ & 12.4 & $(7.2,20.7)$ \\
& Total & 29.5 & $(23.5,36.2)$ & 30.2 & $(24.0,37.3)$ \\
\hline
\end{tabular}

Notes: ${ }^{\star}$ Adjusted for missing HIV test results and coverage of selected mortuaries by age and sex, assuming HIV status missing at random.

A total of 807 deaths of persons aged 15 years and above (range 15-105 years, median 40 years) were reported during the 33 day period of data collection at the two mortuaries. These corresponded to 8,320 deaths when annualized and seasonally-adjusted. Based on a demographic projection, there were 16,173 deaths of persons aged 15 years and above for Nairobi City in 2015, indicating that after annualizing, the coverage of the sampled mortuaries was $65.0 \%$ of reported deaths, and $51.4 \%$ of expected deaths. Coverage versus expected deaths varied substantially by age and sex from $22.2 \%$ for women aged $15-24$ years to $63.5 \%$ for men aged 25-44 years. Annualized deaths were then adjusted for this age- and sex-specific coverage to obtain the total adjusted deaths (Table 2).

An estimated 2.8 million adults aged 15 years and above were residents of Nairobi in 2015, corresponding to 160,386 HIV-infected and 2,649,060 HIV-uninfected adults based on an overall HIV prevalence of $5.6 \%$ for Nairobi (Table 3 ). Dividing the estimated deaths from the surveillance system by the total projected population, the 


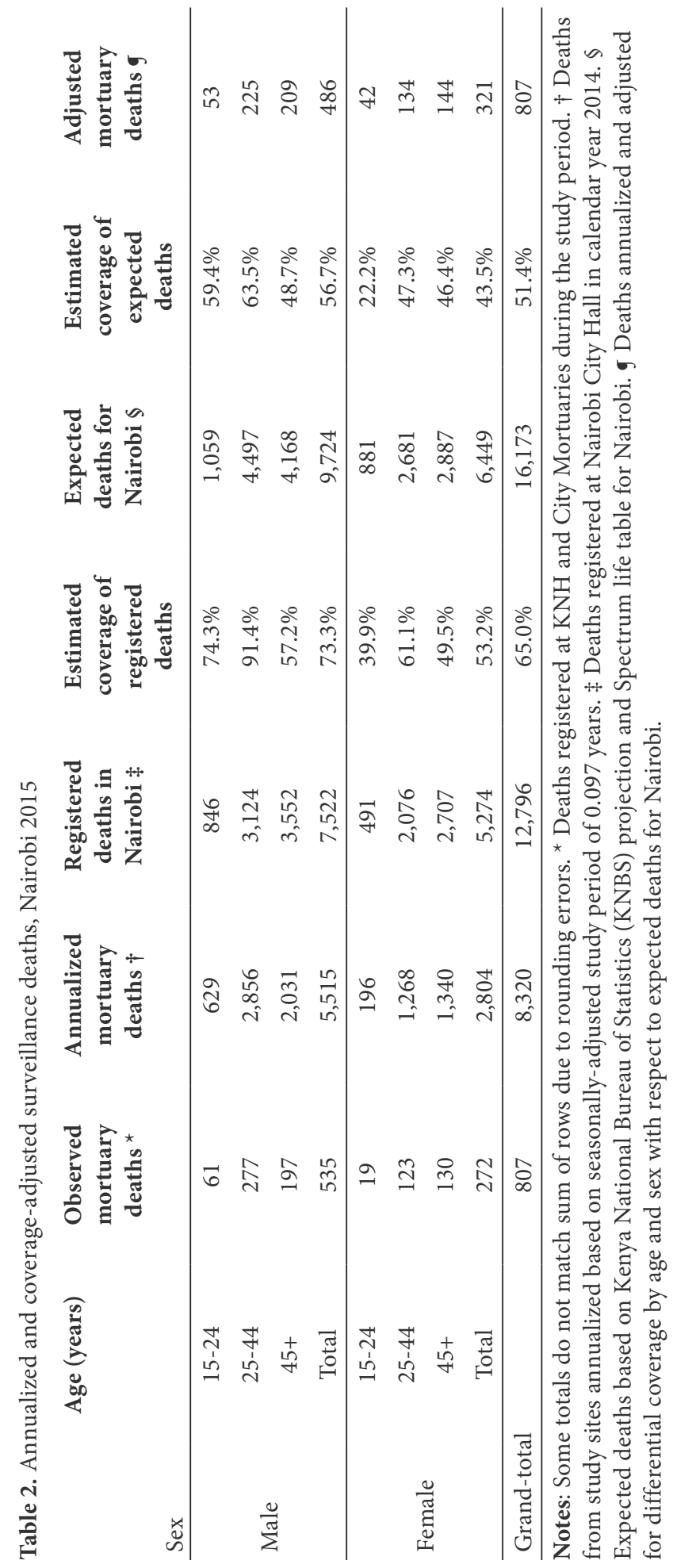


crude mortality rate in Nairobi among persons aged 15 years and older was 5.76 / 1,000 persons. In women, age-specific mortality estimates ranged from $1.92 / 1,000$ among those aged 15-24 to $16.70 / 1,000$ among women aged 45 and above. In men, mortality ranged from 3.16/1,000 among men aged 15-24 to 17.41 among men aged 45 and above. Overall, the mortality rate among HIV-infected persons was 21.12 / 1,000 compared with 4.83 / 1,000 among HIV-uninfected persons aged 15 years and older. Among HIV-infected women the mortality rate was 20.59 / 1,000 compared with 21.89 / 1,000 among HIV-infected men (Table 3). The standardized mortality ratio was 4.35 (95\% CI 3.67-5.15), indicating that risk of death was significantly higher among HIV-infected persons compared with HIV-uninfected persons, when controlling for age and sex. The standardized risk difference was 0.016 (95\% CI 0.013-0.019), corresponding to 16 additional deaths per 1,000 population among the HIV-infected after adjusting for age and sex (Table 4). The interaction between age and sex was significant, so all estimates were calculated using models stratified by sex and age group.

Table 3. Estimated age- and sex-specific deaths, population, and mortality rates per 1000 population, Nairobi 2015

\begin{tabular}{|c|c|c|c|c|}
\hline \multirow[b]{2}{*}{ Sex } & \multirow{2}{*}{$\begin{array}{c}\text { Age } \\
\text { (Years) }\end{array}$} & HIV-negative & HIV-positive & Total \\
\hline & & deaths / pop (rate) & deaths / pop (rate) & deaths / pop (rate) \\
\hline \multirow{4}{*}{ Male } & $15-24$ & $967 / 330,458(2.93)$ & $95 / 6,011(15.80)$ & $1,062 / 336,469(3.16)$ \\
\hline & $25-44$ & $3,818 / 767,352(4.98)$ & $691 / 46,156$ (14.97) & 4,509/813,508 (5.54) \\
\hline & $45+$ & $3,518 / 226,141(15.56)$ & $660 / 13,885(47.53)$ & $4,178 / 240,026(17.41)$ \\
\hline & Total & $8,303 / 1,323,951(6.27)$ & $1446 / 66,052(21.89)$ & $9,749 / 1,390,003(7.01)$ \\
\hline \multirow{4}{*}{ Female } & $15-24$ & 499/424,695 (1.17) & $344 / 13,607(25.28)$ & $843 / 438,302(1.92)$ \\
\hline & $25-44$ & $1,449 / 737,582(1.96)$ & $1238 / 70,315(17.61)$ & $2,687 / 807,897(3.33)$ \\
\hline & $45+$ & 2534/162,832 (15.56) & $360 / 10,412(34.58)$ & $2,894 / 173,244(16.70)$ \\
\hline & Total & $4,482 / 1,325,109(3.38)$ & $1,942 / 94,334$ (20.59) & $6,424 / 1,419,443(4.53)$ \\
\hline Overall & & $12,785 / 2,649,060(4.83)$ & $3,388 / 160,386$ (21.12) & $16,173 / 2,809,446(5.76)$ \\
\hline
\end{tabular}

Table 4. Risk difference (RD), standardized mortality rate (SMR) and population attributable fraction (PAF) due to HIV, Nairobi 2015

\begin{tabular}{|c|c|c|c|c|c|c|}
\hline \multirow[b]{2}{*}{ Statistic } & \multicolumn{2}{|c|}{ Male } & \multicolumn{2}{|c|}{ Female } & \multicolumn{2}{|c|}{ Total } \\
\hline & Estimate & $(95 \% \mathrm{CI})$ & Estimate & $(95 \% \mathrm{CI})$ & Estimate & $(95 \% \mathrm{CI})$ \\
\hline SMR & 3.12 & $(2.43-3.99)$ & 6.17 & $(4.86-7.83)$ & 4.35 & $(3.67-5.15)$ \\
\hline $\mathrm{RD}$ & 0.015 & $(0.010-0.020)$ & 0.017 & $(0.013-0.021)$ & 0.016 & $(0.013-0.019)$ \\
\hline PAF & 0.101 & $(0.067-0.133)$ & 0.254 & $(0.199-0.305)$ & 0.161 & $(0.131-0.190)$ \\
\hline
\end{tabular}


Combining the risk estimates with the prevalence of HIV in the population, the population attributable fraction (PAF) was 0.161 (95\% CI 0.131-0.190). The estimated PAF differed between men and women, with women having a higher PAF for HIV infection than men: the PAF for women was 0.254 and for men was 0.101 (Table 4).

There were 40,382 males and 77,640 females aged 15 years and above on ART in Nairobi by December 31, 2015 according to official HIV program statistics. The Spectrum ART coverage estimate for 2015 for all HIV-infected persons aged 15 or more years in Nairobi was $73.6 \%, 61.1 \%$ for males and $82.3 \%$ for females, and Spectrum predicted that $13.8 \%$ of male deaths and $8.3 \%$ of female deaths $(11.4 \%$ combined) would have been HIV-infected in 2015 (S1 Table).

Our sensitivity analysis looked at several key parameters that were estimated for this analysis as presented in S2 Table. The outcomes were most sensitive to HIV prevalence in the mortuaries and in the population, as well as the ratio of observed to unobserved prevalence in the mortuaries. The uncertainty interval for the SMR obtained through the uncertainty analysis was 3.04-7.19, while for the PAF the uncertainty interval was $0.118-0.221$ (S3 Table).

\section{Discussion}

We conducted an analysis to combine HIV prevalence in a sample of deaths in Nairobi with population estimates in order to assess the burden of mortality associated with HIV in adults. We believe this is the first African study of its kind in the era of ART scale-up and as such it provides important insights in to the association of mortality and HIV infection in a major urban center with generalized HIV prevalence and a public ART program that reaches the majority of adults living with HIV. People living with HIV are at risk from death from multiple competing causes, including HIV. By estimating measures such as the SMR, RD and PAF this study looks beyond disease prevalence and provides estimates of the continuing impact of HIV on the adult population of Nairobi. Despite 7 in $10 \mathrm{HIV}$ infected persons aged 15 years and above receiving ART, our study showed persons living with HIV had a four-fold increased risk of mortality compared with those not infected. The population attributable fraction of 0.161 shows that about one in six deaths would be avoided in Nairobi if the increased mortality associated with HIV infection were eliminated, and more deaths would potentially be avoided in women than in men. 
Antiretroviral treatment has been shown to dramatically reduce premature mortality. A prior study in Central Africa conducted at the height of the HIV epidemic when HIV prevalence was similar to Nairobi, but before ART was widely available, found nearly half of adult deaths were HIV-infected, while an East African cohort study in the late 1990's found a 20-fold increased mortality risk among the HIV-infected before widespread access to ART. A national study in South Africa found consistent declines in population all-cause mortality associated with early expansion of ART access from 2005-2009. In our study, conducted after over a decade of ART scale-up, we found about 1 in 5 deaths was HIV-infected, yet people living with HIV continue to be at significantly increased risk of death with a greater than four-fold increased risk of mortality. This is especially true for women in Nairobi who have reached $82.3 \%$ ART coverage in 2015 - surpassing the UNAIDS fast-track target of $81 \%$ of all PLHIV on treatment.

This study had several limitations. The mortality data were collected in early 2015, but the distribution of deaths available for abstraction at the time of the study was for 2014. The coverage of the two participating mortuaries was moderate, but may not have been representative of all deaths in the city. The calculation of mortality rates assumes that measured deaths were from the resident population, however deaths in Nairobi are not necessarily drawn from the resident population of the city. Some Nairobi residents die outside the city limits, and some non-Nairobi residents die within the city. The latter group is likely to be over-represented at $\mathrm{KNH}$ since it is a national referral hospital and routinely receives patients transferred from other counties.

Although these two facilities do not include all deaths in the city, they do include a significant fraction of deaths that occur in Nairobi. Although there may be some seasonal factors that affect mortality, Nairobi does not generally suffer from seasonal malaria epidemics or other infectious disease outbreaks that are likely to be over- or under-represented during the study period. After seasonal and annual adjustments for total deaths, our study covered $51.4 \%$ of expected deaths based on demographic estimates, but covered $65.0 \%$ of reported deaths, but coverage varied substantially by age and sex. Our sensitivity analysis found that outcome measures were sensitive to assumptions about HIV prevalence and representativeness of sampled mortuaries, however our uncertainty analysis showed that overall conclusions were robust in the face of this uncertainty, lending confidence in the robustness of the findings that the risk of dying is greater in the HIV-infected population than in the HIV-uninfected population, and that a considerable fraction of deaths at the population level can be attributed to HIV in Nairobi. 
Though a lower proportion of HIV-infected men access treatment, their lower HIV prevalence and competing causes of mortality result in HIV being a less frequent cause of death. A complete diagnosis, treatment and adherence history for all deaths could help elucidate to what extent undiagnosed infection, inadequate treatment access or late presentation, poor adherence, or treatment failure are responsible for the mortality differentials seen among PLHIV. Mathematical modeling has shown that the majority of deaths among PLHIV are likely to be among those not on treatment, even in high ART coverage settings, underscoring the need to reduce barriers to treatment initiation and improve retention on ART. Thus it was surprising to find a higher HIV-associated SMR among women than men, in spite of their greater access to ART. This may be due to over-representation of deaths due to external causes in our sample, which differentially affect men. If this is the case, our estimates of HIV mortality among men are conservative. Inclusion of additional mortuaries in future studies would help control this potential bias. Despite study limitations, it appears that mortality among PLHIV in Nairobi continues to be high in spite of high estimated ART treatment coverage. This high mortality among PLHIV may help explain why HIV prevalence has not increased in recent years in spite of continued new infections and a rapid expansion of public HIV care and treatment services [20].

\section{Conclusion}

Although sub-Saharan Africa has dramatically decreased mortality due to HIV through expansion of ART, in order to further reduce HIV-associated mortality, high-burden countries may need to reach very high levels of diagnosis, treatment coverage, retention in care, and viral suppression. Though hospitals are no longer overwhelmed with AIDS patients, Kenya has not yet achieved the goal of an AIDSfree generation.

\section{Acknowledgments}

We would like to acknowledge the study investigators and consultants for their participation in the development of the protocol and oversight of the study or development of specimen collection techniques, the study staff, laboratorians, data abstractors, mortuary staff that collected specimens from City Mortuary and $\mathrm{KNH}$ mortuary, those who assisted with $\mathrm{KNH}$ medical file reviews, and administrative support. 
The Nairobi mortuary HIV surveillance study was conducted by National AIDS and STI Control Programme (NASCOP), University of Nairobi Institute of Tropical and Infectious Diseases (UNITID), University of California, San Francisco (UCSF), and U.S. Centers for Disease Control and Prevention (CDC/Kenya, CDC/Atlanta). 


\section{References}

1. UNAIDS. The Cities Report. Geneva: UNAIDS.

2. UNAIDS. Global AIDS Update 2016. Geneva: UNAIDS.

3. AIDS Info Online database [Internet]. UNAIDS. 2015 [cited Apr 13, 2016]. Available from: http://www. aidsinfoonline.org/devinfo/libraries/aspx/dataview.aspx.

4. Antiretroviral Therapy Cohort Collaboration. Life expectancy of individuals on combination antiretroviral therapy in high-income countries: a collaborative analysis of 14 cohort studies. The Lancet. 2008;372(9635):293-9. doi: 10.1016/S0140-6736(08)61113-7. PubMed PMID: 18657708; PubMed Central PMCID: PMC3130543.

5. Nsanzimana S, Remera E, Kanters S, Chan K, Forrest JI, Ford N, et al. Life expectancy among HIVpositive patients in Rwanda: a retrospective observational cohort study. The Lancet Global health. 2015;3(3):e169-77. doi: 10.1016/S2214-109X(14)70364-X. PubMed PMID: 25701995.

6. Fox MP, Brennan A, Maskew M, MacPhail P, Sanne I. Using vital registration data to update mortality among patients lost to follow-up from ART programmes: evidence from the Themba Lethu Clinic, South Africa. Tropical medicine \& international health : TM \& IH. 2010;15(4):405-13. doi: 10.1111/j.13653156.2010.02473.x. PubMed PMID: 20180931; PubMed Central PMCID: PMC2951133.

7. An MW, Frangakis CE, Musick BS, Yiannoutsos CT. The need for double-sampling designs in survival studies: an application to monitor PEPFAR. Biometrics. 2009;65(1):301-6. doi: 10.1111/j.15410420.2008.01043.x. PubMed PMID: 18479488; PubMed Central PMCID: PMC4137787.

8. Geng EH, Bangsberg DR, Musinguzi N, Emenyonu N, Bwana MB, Yiannoutsos CT, et al. Understanding reasons for and outcomes of patients lost to follow-up in antiretroviral therapy programs in Africa through a sampling-based approach. Journal of acquired immune deficiency syndromes. 2010;53(3):405-11. doi: 10.1097/QAl.0b013e3181b843f0. PubMed PMID: 19745753; PubMed Central PMCID: PMC3606953.

9. Black AK, Janie; Mitchley, Michael; Williams, Brian G. The burden of HIV in a Public Hospital in Johannesburg, South Africa. arXiv. 2015;(1412):2788. Epub Dec 15, 2015.

10. De Cock KM, Barrere B, Diaby L, Lafontaine MF, Gnaore E, Porter A, et al. AIDS--the leading cause of adult death in the West African City of Abidjan, Ivory Coast. Science. 1990;249(4970):793-6. PubMed PMID: 2167515.

11. Ramaswamy C, Ellman TM, Myers J, Madsen A, Sepkowitz K, Shepard C. Human Immunodeficiency Virus Infection Newly Diagnosed at Autopsy in New York City, 2008-2012. Open forum infectious diseases. 2015;2(4):ofv146. doi: 10.1093/ofid/ofv146. PubMed PMID: 26566538; PubMed Central PMCID: PMC4630452.

12. Reniers G, Araya T, Davey G, Nagelkerke N, Berhane Y, Coutinho R, et al. Steep declines in populationlevel AIDS mortality following the introduction of antiretroviral therapy in Addis Ababa, Ethiopia. AIDS. 2009;23(4):511-8. doi: 10.1097/QAD.0b013e32832403d0. PubMed PMID: 19169138; PubMed Central PMCID: PMCPMC2666986.

13. Civil Registration Services (CRS). Kenya Vital Statistics Report 2014. Nairobi, Kenya: Civil Registration Services, CRS; Statistics Division. Government of Kenya.

14. Stover J. Projecting the demographic consequences of adult HIV prevalence trends: the Spectrum Projection Package. Sexually transmitted infections. 2004;80 Suppl 1:i14-8. doi: 10.1136/ sti.2004.010157. PubMed PMID: 15249694; PubMed Central PMCID: PMC1765840. 
15. Stover J, Andreev K, Slaymaker E, Gopalappa C, Sabin K, Velasquez C, et al. Updates to the spectrum model to estimate key HIV indicators for adults and children. AIDS. 2014;28 Suppl 4:S427-34. doi: 10.1097/QAD.0000000000000483. PubMed PMID: 25406748; PubMed Central PMCID: PMC4247263.

16. Stover J, Brown T, Marston M. Updates to the Spectrum/Estimation and Projection Package (EPP) model to estimate HIV trends for adults and children. Sexually transmitted infections. 2012;88 Suppl 2:i11-6. doi: 10.1136/sextrans-2012-050640. PubMed PMID: 23172341; PubMed Central PMCID: PMC3512426.

17. Stover J, Walker N, Grassly NC, Marston M. Projecting the demographic impact of AIDS and the number of people in need of treatment: updates to the Spectrum projection package. Sexually transmitted infections. 2006;82 Suppl 3:iii45-50. doi: 10.1136/sti.2006.020172. PubMed PMID: 16735293; PubMed Central PMCID: PMC2576732.

18. Kenya National Bureau of Statistics. 2009 Kenya Population and Housing Census Analytical Report on Population Projections, Volume XIV. Nairobi: KNBS, March, 2012.

19. Newson RB. Attributable and unattributable risks and fractions and other scenario comparisons. Stata Journal. 2013;13(4):672-98.

20. National AIDS /STI Control Program. Kenya AIDS Indicator Survey 2012: Final Report. Nairobi: NASCOP, June, 2014. 


\section{Supporting information}

\section{S1 Text. Simulation Methods}

Monte Carlo simulations were conducted to assess the sensitivity of risk ratio and attributable fraction estimates to epidemiological assumptions (HIV prevalence in the mortuaries, in the population, coverage of the sampled mortuaries with respect to all actual deaths, and the impact of seasonality of overall death notifications at sampled mortuaries, the male/female population prevalence ratio, and the ratio of observed to unobserved HIV prevalence in mortuaries in Nairobi). Input parameters are summarized in S2 Table. Each input parameter was independently sampled 10,000 times in Stata from a normal (log-normal in the case of ratio measures) random distribution. The mean was set to the "best" value and the standard deviation chosen to cover alternative plausible values for the parameter. Through trial and error 10,000 runs were selected to ensure the Monte Carlo standard error, a measure of the accuracy of the simulation itself, was less than $2.5 \%$ as reported by Stata's simsum command. R version 3.1.2 (R Development Core Team) was used to generate scatter plot matrices to visualize associations between input and output parameters. Non-parametric uncertainty bounds were generated for outcomes using the $2.5^{\text {th }}$ and $97.5^{\text {th }}$ centiles from the resulting distribution. Unlike traditional confidence intervals which describe uncertainty due to random sampling, the uncertainty bounds also reflect uncertainty about model assumptions. Results are summarized in S3 Table. 

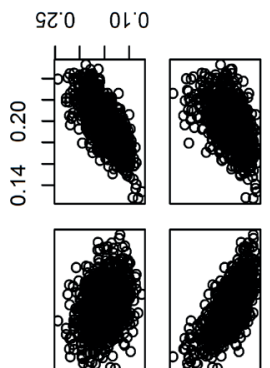

でเ 90
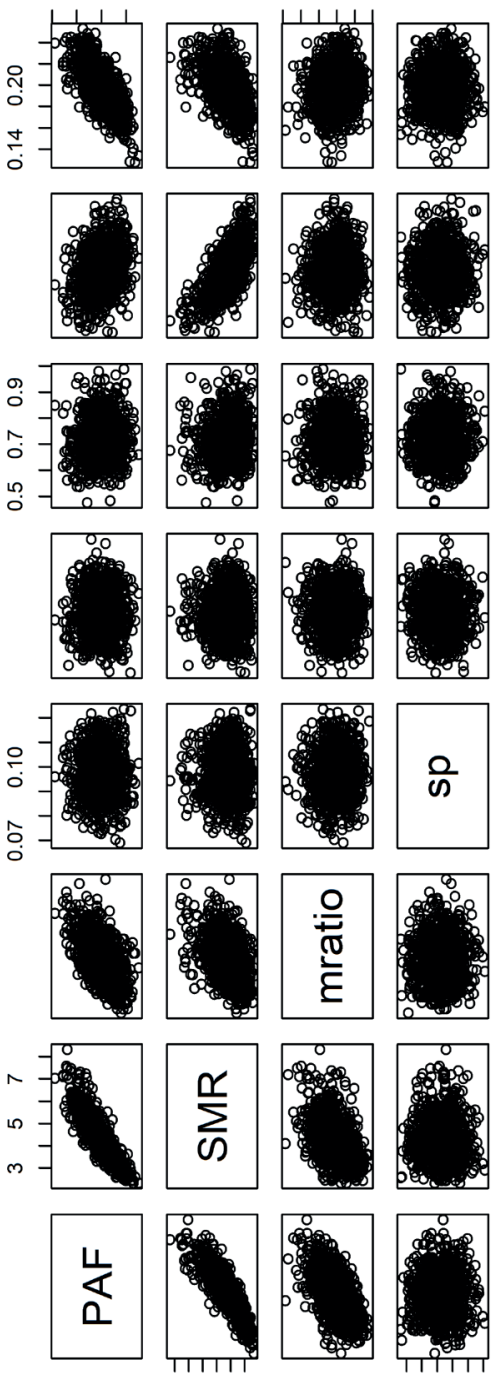

$9 \varepsilon$
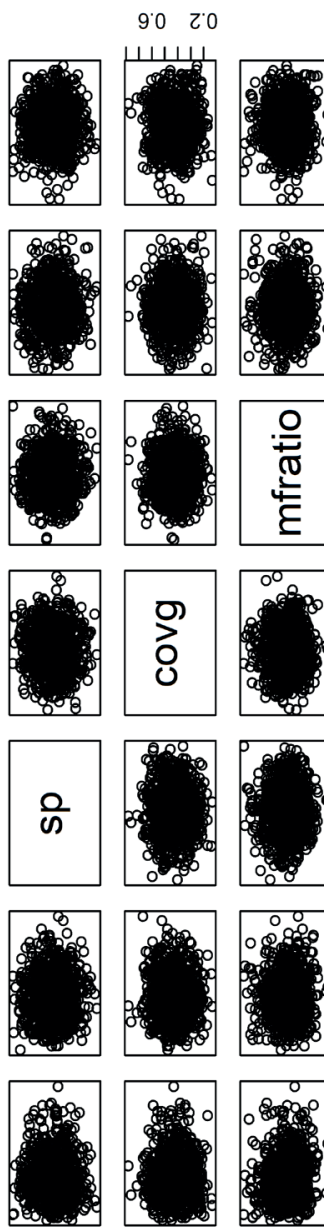

$80^{\circ} 0$ t0
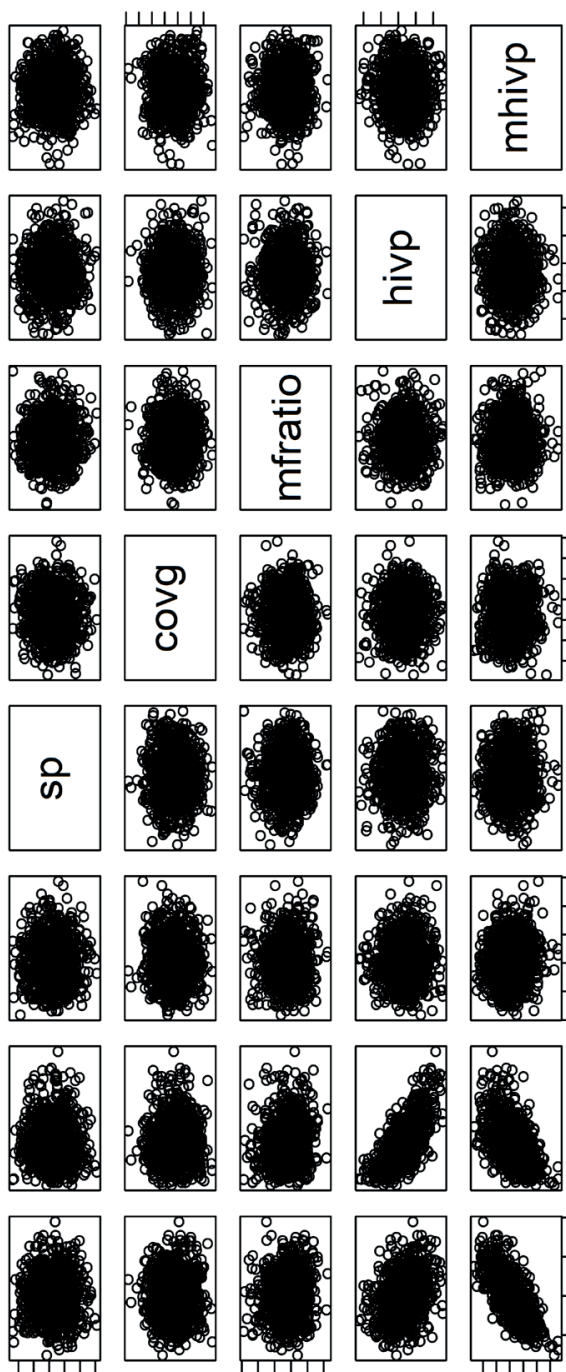

ILO $20^{\circ}$
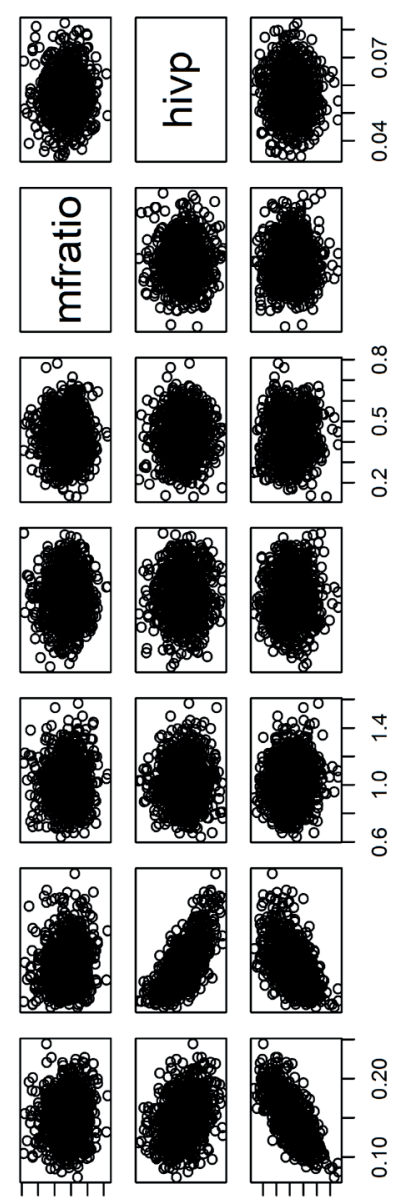

$80 \quad 50$

$\Delta Z 0$ tro

芯

की

$>$ क्षี

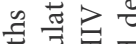

要五

ช 효

స : Е

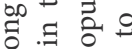

ำ 음

氙芯苛

责艺

त的

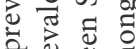

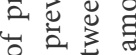

$0 \geq 0$

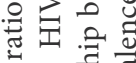

$11 \%$ 단

을

氜焉密

ㄹ 플

@ व

ت욜

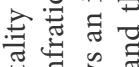

च द है

है की

ت्ञ

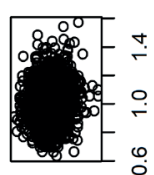

훙

है छ

芯可

॥苛苛吉

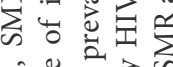

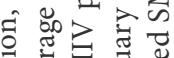

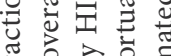

ॠ

॥ 11 己

용ㅎㅀ

可 崩

Е ठ

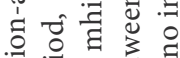

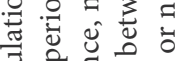

艾氜

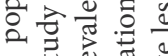

11 के

出 11 每

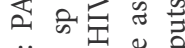

نे

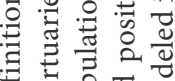

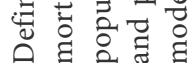


Table S1. Summary of demographic and epidemic projection, population age 15 years and above, Nairobi 2015

\begin{tabular}{lccc} 
Indicator & Total & Men & Women \\
\hline Population & $2,809,448$ & $1,390,003$ & $1,419,445$ \\
PLHIV $\dagger$ & 160,386 & 66,051 & 94,335 \\
Number on ART (coverage) $\neq$ & $118,022(73.6 \%)$ & $40,382(61.1 \%)$ & $77,640(82.3 \%)$ \\
All deaths $§$ & 16,173 & 9,724 & 6,449 \\
\% deaths HIV-infected & $11.4 \%$ & $13.8 \%$ & $8.3 \%$ \\
$\begin{array}{l}\text { Standardized mortality ratio (SMR) due } \\
\text { to HIV } \|\end{array}$ & 3.84 & 6.64 & 1.91 \\
$\begin{array}{l}\text { Population-attributable fraction (PAF) } \\
\text { due to HIV }\end{array}$ & 0.081 & 0.117 & 0.035 \\
\hline
\end{tabular}

Notes: * Total 2015 mid-year population and population age distribution from Kenya National Bureau of Statistics (KNBS) projections. $\dagger$ age-specific and total 2015 mid-year PLHIV from combining KNBS projected population with Spectrum age- and sex-specific HIV prevalence distribution. $\$$ Number on ART from official country program statistics as reflected in Spectrum (numbers on ART and ART coverage reported for December 31). $\$$ Deaths obtained by applying mortality rates from Spectrum life table for Nairobi to KNBS projected population for 2015. || Standardized mortality ratio calculated by indirectly standardizing mortality rate in the HIVnegative population as estimated by Spectrum by 5 -year age groups to the sex and age distribution among the HIV-infected, as estimated by Spectrum. Population-attributable fraction calculated by multiplying the proportion of deaths HIV-infected according to Spectrum by (SMR-1)/SMR.

Table S2. Parameters used for Monte Carlo simulation-based sensitivity and uncertainty analyses for standardized mortality ratio (SMR) and population attributable fraction (PAF), Nairobi 2015

\begin{tabular}{lcc} 
Parameter & Mean & Sd \\
\hline HIV prevalence & 0.563 & 0.008445 \\
Mortuary HIV prevalence & 0.2133659 & 0.018062 \\
Mortuary prevalence ratio & 1.0 & 0.15 \\
Male/female ratio & 0.71501239 & 0.107 \\
Sampling period & 0.097 & 0.0093 \\
Mortuary coverage & 0.512 & 0.1 \\
\hline
\end{tabular}


S3 Table. Simulation results for overall and sex-specific standardized mortality ratio (SMR) and population attributable fraction (PAF), Nairobi 2015

\begin{tabular}{lccc} 
Statistic & Median & 95\% UI & MCSE \\
\hline SMR & 4.58 & $(3.04-7.19)$ & $1.051 \%$ \\
SMR (male) & 3.52 & $(2.31-5.60)$ & $0.830 \%$ \\
SMR (female) & 6.53 & $(4.31-10.37)$ & $1.534 \%$ \\
PAF & 0.167 & $(0.118-0.221)$ & $0.019 \%$ \\
PAF (male) & 0.120 & $(0.075-0.160)$ & $0.016 \%$ \\
PAF (female) & 0.268 & $(0.205-0.337)$ & $0.024 \%$ \\
\hline
\end{tabular}

Notes: The Monte Carlo sampling error (MCSE) is a measure of the precision of the simulation and is a function of number of repetitions and variability in the simulated statistic. The number of repetitions was selected to ensure an MCSE less than 2.5\% for each statistic for each sub-group (male, female or combined). The $95 \%$ uncertainty interval $\left(2.5^{\text {th }}\right.$ to $97.5^{\text {th }}$ centiles) summarizes the variability in the estimate that is due to the uncertainty in the input parameters as provided in S1 Table. The SMR fell between 3.04-7.19, and the PAF fell within 0.0118-0.221 in $95 \%$ of simulations, lending support to the robustness of the finding of increased mortality among PLHIV aged 15 years and older in Nairobi. 


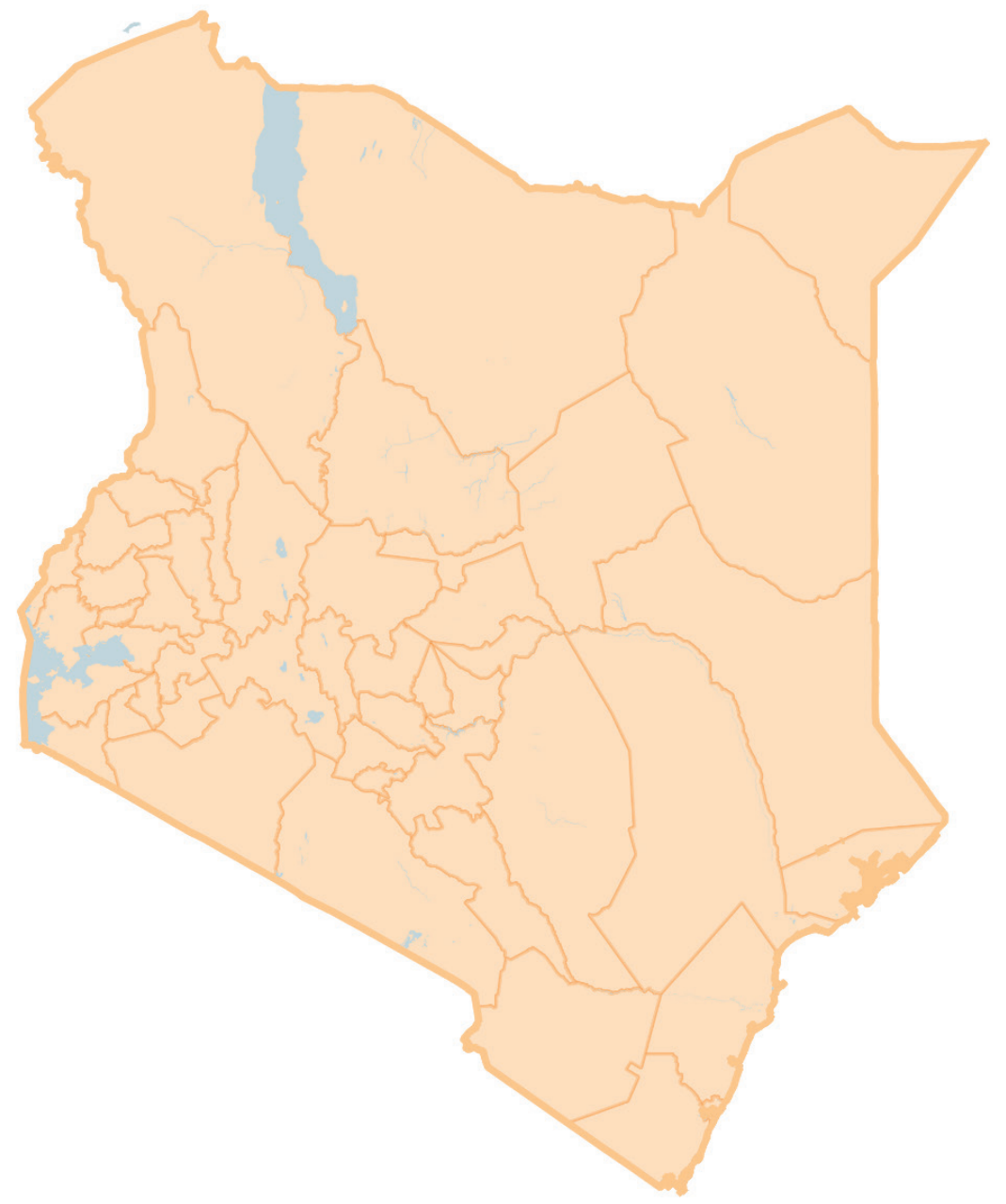




\section{Chapter 8}

\section{Leading causes of death and high mortality rates in a HIV-endemic setting, Kisumu County, Kenya, 2019}

Anthony Waruru

Dickens Onyango

Lilly Nyagah

Alex Sila

Wanjiru Waruiru

Solomon Sava

Elizabeth Oele

Emmanuel Nyakeriga
Sheru W. Muuo

Jacqueline Kiboye

Paul K. Musingila

Marianne A.B. van der Sande

Thaddeus Massawa

Emily A. Rogena

Kevin M. De Cock

Peter W. Young 


\section{Abstract}

Background: In resource-limited settings, underlying causes of death (UCOD) often are not ascertained systematically, leading to unreliable mortality statistics. We reviewed medical charts to establish UCOD for decedents at two high-volume mortuaries in Kisumu County, Kenya and compared ascertained UCOD to those notified to the civil registry.

Methods and Findings: Medical experts trained in COD certification examined medical charts and ascertained causes of death for 456 decedents who had been admitted to the mortuaries from April 16 through July 12, 2019. Decedents with unknown HIV status or who had tested HIV-negative $>90$ days before the date of death were tested for HIV. We calculated annualized all-cause and cause-specific mortality rates grouped according to the global burden of disease (GBD) categories and separately for deaths due to HIV/AIDS and expressed estimated deaths per 100,000 population. We compared notified to ascertained UCOD using Cohen's Kappa ( $\kappa$ ) and assessed for independence of proportions using Pearson's chisquared test.

The four leading UCOD were HIV/AIDS (102/442 [23.1\%]), hypertensive disease (41/442 [9.3\%]), other cardiovascular diseases (23/442 [5.2\%]), and cancer (20/442 [4.5\%]). The all-cause mortality rate was $1,086 / 100,000$ population. The highest cause-specific mortality was in GBD category II (noncommunicable diseases; 516/100,000), followed by GBD I (communicable, perinatal, maternal, and nutritional; 513/100,000), and III (injuries; 56/100,000). The HIV/AIDS mortality rate was $251 / 100,000$ population. The proportion of deaths due to GBD II causes was higher among females $(51.9 \%)$ than males $(42.1 \%$; $=0.039)$. Conversely, more males $(8.6 \%)$ than females $(2.1 \%)$ died of GBD III causes $(p=0.002)$. Most of the records with available recorded and ascertained UCOD ( $n=236), 167$ (70.8\%) had incorrectly recorded UCOD, and agreement between notified and ascertained UCOD was poor $(29.2 \% ; \kappa=0.26)$.

Conclusions: Mortality from infectious diseases, especially HIV/AIDS, is high in Kisumu County, but there is a shift toward higher mortality from noncommunicable diseases, possibly reflecting an epidemiologic transition and improving HIV outcomes. An increased focus on controlling noncommunicable conditions is needed despite the high communicable disease burden. The weak agreement between notified and ascertained UCOD could lead to substantial inaccuracies in mortality statistics, which wholly depend on death notifications. 


\section{Introduction}

The World Health Organization (WHO) classifies health problems into three broad categories: Group I includes communicable diseases (including HIV/ AIDS) as well as perinatal, maternal, and nutritional diseases; Group II includes noncommunicable diseases; and Group III includes injuries [1,2]. These classifications are used to calculate the global burden of disease (GBD) causes of death (COD) reports and to provide broad groupings of COD for comparing mortality rates between countries [3].

In Kenya, the overall crude mortality rate is currently estimated to be 550/100,000 population [4]. Estimated all-cause mortality rates increased from 850/100,000 population in 1990 to $902 / 100,000$ in 2006 but subsequently decreased to $519 / 100,000$ by 2016 [5]. Communicable diseases were the biggest contributor to mortality rates before the mid-2000s, driven largely by the impact of HIV. However, from 2006 to 2016, deaths due to communicable diseases, especially HIV/AIDS, have decreased; noncommunicable diseases and injuries account for an increasing fraction of deaths [5-7]. Among noncommunicable diseases, cancer is a major underlying cause of death (UCOD) even in rural settings [6], and approximately 100,000 Kenyans die of hypertension-related complications every year [8]. Hypertension further contributes to $50 \%$ of hospital admissions and over $40 \%$ of deaths in Kenya [9]. This epidemiological transition may be due to changes in population dynamics and other individual and environmental factors. The leading recertified UCOD in Kenya (estimated in 2016) were; HIV (11.0\%), lower respiratory infections $(9.1 \%)$, malaria (5.7\%), non-HIV related tuberculosis $(4.0 \%)$, diarrheal diseases (3.9\%), prematurity and low birth weight (3.7\%), digestive diseases (3.5\%) and anemia (3.3\%) [9]. Pneumonia, malaria, and cancer were leading COD in 2017 and were leading causes of morbidity. In 2017, deaths due to HIV/AIDS ranked fifth $(8,800)$ but declined by 55\% between 2010 and 2018 [10]. In 2017, of other communicable diseases, deaths due to tuberculosis ranked fourth; among deaths due to injuries, road traffic accidents were the ninth overall leading COD [11]. Deaths due to road traffic accidents are estimated to have increased by $8 \%$ from 2,907 in 2014 to 3,153 in 2018 [12].

In Kenya, mortality rates for children aged $<5$ years were 46.37 deaths per 1000 live births in 2018, a gradual decrease from 164.34 deaths per 1000 live births in 1969 [13]. However, 26/47 (55.3\%) counties have not met the World Summit for Children target to reduce mortality rates to 70 deaths per 1000 live births by the year 2000, and only nine counties were on course to meet the millennium development goal to reduce mortality rates in children aged $<5$ years by two-thirds between 1990 and 
2015 [13]. In 2009, the adult mortality rate (probability of dying between ages 15 and 60 years per 1000 population) was 348 among males and 313 among females [14].

Although summarizing mortality rates using GBD classes is useful, accurate and specific UCOD data are needed to guide and evaluate appropriate public health responses in preventive and curative services. Accuracy of mortality statistics can be improved by ascertaining the most probable COD and ensuring that death records include the correct UCOD. However, in resource-limited countries, UCODs recorded in civil registration and vital statistics (CRVS) systems are commonly determined by individual administrators or health providers, depending on the place of death, rather than on a systematic review of evidence in medical charts or autopsy. Often this is due to lack of medical attention at the time of death, a situation that could be remedied by the systematic assembly of health records, among other approaches [15]. Thus, to improve vital statistics, post-mortem examinations complemented by hospital-based reviews of clinical charts can help determine the UCOD. Methodologies for mortuary-based surveillance do not have to be invasive or logistically challenging. For example, minimally invasive autopsy techniques, such as oral swabs, have been used to improve vital statistics in outbreak investigations for diseases such as Ebola [16]. Such methods have utility in public health surveillance, and when combined with available medical history data, the most likely UCOD can be deduced. We ascertained UCOD, antecedent COD, and immediate COD for hospital-based deaths that occurred in two high-volume referral hospitals in Kisumu County, Kenya, compared them to those notified to the civil registry and estimated mortality rates.

\section{Methods}

\section{Setting}

Kisumu County had an estimated population of 1,155,574 in 2019 and has a high HIV burden [17]. The two largest mortuaries in the county are located at Jaramogi Oginga Odinga Teaching and Referral Hospital (JOOTRH) and Kisumu County Referral Hospital (KCRH), with the capacity to hold 99 and 46 bodies, respectively. There are three civil registries in the county (Kisumu East, Kisumu West, and Nyando). Kisumu East civil registry receives death notifications from Kisumu city and the surrounding areas. In 2019, notifications from the two mortuary facilities accounted for $42.0 \%$ of all reported deaths registered in the Kisumu East civil registry [18]. Deaths in Kisumu East civil registry over three years (2017-2019) 
contributed to a median of $74.8 \%$ of deaths registered in the entire county [19]. Cause of death data from the two hospitals were used to estimate the number of deaths at the county level with the estimated county population as a denominator.

\section{Study design and population}

This study was part of an overarching cross-sectional surveillance study designed to: understand HIV-associated mortality in Kisumu County through determining prior HIV diagnosis, HIV-positivity, and viral load among cadavers; assess the feasibility of using oral fluid obtained from cadavers for non-invasive rapid HIV antibody testing; and assess the quality of the UCOD certification, HIV status documentation, and efficiency of death notification in Kisumu County.

Three categories of decedents from the two mortuaries were included in the overarching study: hospital deaths (all deaths occurring in the hospital wards or outpatient department), dead on arrival (DOA; deaths occurring elsewhere, either outside of hospitals or in other hospitals with subsequent transfer), and police cases (DOA cases or hospital deaths that required a post-mortem examination for legal reasons). Data for this manuscript were drawn from the overarching study to establish the leading COD and included all hospital-based deaths admitted to the two morgues from April 16-July 12, 2019, irrespective of age. This analysis included decedents who died within the two hospitals whose medical records were available. Dead on arrival cases were excluded as they did not have medical history records at the hospitals.

\section{Sample size}

The sample size of 690 for the overarching study was powered to measure HIV prevalence of $5 \%$ among deaths of individuals aged $\geq 15$ years and was adjusted to account for the loss of specimens and ineligibility. All children aged $<15$ years who died and were admitted to one of the two mortuaries during the study period were included to cover all decedents admitted to the mortuaries during the study period.

\section{Ascertaining cause of death}

For our study, a panel of six medical officers and two health records information officers were trained by master certification and coding trainers on International Classification of Diseases and Health Conditions, version 10 (ICD10) certification and coding rules [20]. Afterward, the medical officers used a data entry form modified from the standard death notification form to abstract clinical information from the medical records for hospital-based deaths. The following details were abstracted: signs and symptoms of illnesses preceding death, clinical diagnoses, and results of investigations, including HIV status and HIV treatment status. 
Individual panel members used the abstracted information to assign immediate COD, antecedent COD, and UCOD and recorded them in a tool. Whenever UCOD was unclear, a panel discussion was held to determine and assign the most probable UCOD. The health records information officers then assigned the actual ICD10 code. These data were directly entered into an open data kit tool with logic checks for data accuracy and consistency and were submitted to a central database.

\section{Routinely notified versus panel-assigned cause of death}

We abstracted immediate COD, antecedent COD, and UCOD, as documented from notification forms for all deaths in the two hospitals. In Kenya, death notification forms are divided into two parts and are completed by trained medical officers in triplicate. The first part contains the burial permit, and the second part records the UCOD, antecedent COD, immediate COD, and other significant COD. The second part is submitted to the CRVS department for further analysis, reporting, and archiving in the permanent vital statistics within Kenya. In our study, a panel of trained medical experts revised the COD using the procedures described. As with the UCOD assigned by the medical expert panel, the deaths documented in the death notification forms were entered into the open data kit tool and were submitted to a central database. HIV status ascertained during the study, and UCOD assigned and coded by the medical experts' panel, were used for surveillance purposes and were not used to update CRVS information or decedents' medical records.

\section{Outcomes}

For decedents with unavailable HIV status, HIV status was ascertained using post-mortem testing in the overarching study, as described elsewhere [21]. HIVassociated mortality was defined as any death with a documented HIV-positive status, either in the medical files or post-mortem testing results. HIV/AIDS causespecific mortality was considered for all decedents who had HIV assigned as their UCOD (ICD-10 codes B20-B24), per ICD-10 guidelines. Other COD were as assigned based on ICD-10 coding rules.

Summary measures: Two parameters were used to calculate the summary rates. First, we considered the two mortuaries' contribution to deaths in Kisumu East civil registry (42.0\% in 2017) [18]. We then considered Kisumu East civil registry's contribution to deaths in the entire county for 2017-2019 (median, 74.8\%). Based on this coverage, we calculated the crude all-cause mortality rate for Kisumu County as the total number of deaths attributed to all causes reported during the study period ( $\mathrm{n}=938$ ), projected to $100 \%$ and annualized for 12 months. Rates were expressed per 100,000 of the mid-year population of Kisumu County [17], as shown in the formula: 


$$
C M R=\left(\frac{d}{p}\right) \times 100,000
$$

Where $\boldsymbol{d}$ is the annualized deaths in Kisumu County (i.e., deaths reported during the study period calculated for 12 months), and $\boldsymbol{p}$ is the mid-year population for Kisumu County.

To calculate the cause-specific mortality rate, we used the proportion of deaths attributable to specific causes as reported during the study period multiplied by the estimated deaths attributed to specific causes based on the annualized number of all deaths, projected to $100 \%$ for the entire county and finally expressed per 100,000 population as shown in the formula:

$$
\operatorname{CSMR}=c \times\left(\frac{d}{p}\right) \times 100,000
$$

Where $c$ is the proportion of deaths reported during the study period attributed to a specific cause; $\boldsymbol{d}$ is the annualized deaths in Kisumu County (i.e., deaths reported during the study period calculated for 12 months); and $\boldsymbol{p}$ is the mid-year population for Kisumu County.

We summarized age-specific mortality rates by sex per 100,000 population and plotted these log-transformed rates for graphical interpretation.

Stillbirths: Stillbirths were not subjected to UCOD ascertainment by the panel, but we documented and quantified the occurrence of stillbirths at the two hospitals during the study period. We used data from the Kenya health information system to determine the number of deliveries in the two facilities from April 1-July 31, 2019 and calculated the stillbirth rate per 1,000 deliveries.

\section{Statistical analysis}

COD were summarized using the free Microsoft Excel-based tool Analysing Mortality Levels and Causes-of-Death (ANACoD V2.0), developed by WHO in collaboration with the University of Queensland and Health Metrics Network (https://www.who.int/healthinfo/anacod/en/) [22]. This tool provides a stepwise approach to a comprehensive analysis of ICD-10-coded data. Using the tool, we reviewed coded mortality data for errors and tabulated and presented the UCOD by age and sex in tables and charts. The tool also classifies UCOD using the GBD categorization and compares findings with those from other countries. To measure the interrater agreement of notified compared to ascertained COD, we used Cohen's 
kappa ( $\kappa$ ) statistic. We used the Pearson chi-squared test to compare proportions, and when the $n$-values were $<5$, we used the Fisher exact test. P-values $<0.05$ were considered statistically significant.

\section{Ethical considerations}

No individual, personally identifiable information was included in the study database. Results of HIV tests conducted on decedents were not linked back to living individuals. This study was approved by the Kenya Medical Research Institute's Science and Ethical Review Unit; the JOOTRH ethics review committee; U.S. Centers for Disease Control and Prevention (CDC), Center for Global Health, Associate Director for Science, as research involving data and specimens from deceased persons; and University of California San Francisco Committee on Human Research.

\section{Results}

\section{Overview of included deaths}

Of the 938 deaths enrolled in the overarching study, 851 (90.7\%) cadavers were eligible, and 555/851 (65.2\%) died within the two hospitals. The rest (296/851; $35.8 \%)$ were either police cases or other DOA cadavers. We retrieved available medical charts and ascertained the probable UCOD for 456 decedents, representing $82.2 \%$ of the hospital-based deaths during the study period. The UCOD was not ascertained for $99 / 555$ (17.8\%) of the cadavers due to missing hospital records. Of the decedents with available records $(n=456), 442$ had UCOD that were classified, and 14/456 (3.1\%) deaths could not be classified due to ill-defined diseases (ICD10 codes R00-R99; Figure 1). Therefore, 52\% of decedents admitted to the mortuaries $(442 / 851)$ during the study period could be included in our secondary analysis.

Of the 442 decedents whose UCOD were ascertained and classified, 51 (11.6\%) were children aged $<1$ year, and $42(9.5 \%)$ were aged $>80$ years. Children aged $10-$ 14 years and young people aged 20-24 years accounted for the lowest proportions of decedents whose UCOD were ascertained and classified (2.7\% each). Overall, a similar number of females (234), and males (208), had their UCOD ascertained and classified (Table 1).

The prevalence of GBD group I causes was similar among males (49.0\%), and females $(45.7 \%$; $=0.486)$. Significantly more females $(52.1 \%)$ than males $(42.3 \%)$ died due to GBD group II causes $(\mathrm{p}=0.039)$, and significantly more males $(8.7 \%)$ than females $(2.1 \%)$ died due to GBD group III causes $(\mathrm{p}=0.002)$. 
The estimated age-specific number of deaths pyramid was inverted compared to the population pyramid from the 2019 census (Figure 2). The largest age-band for the population is $10-14$ years. Children aged $<5$ years and adults aged $\geq 70$ years had the highest numbers of deaths/100,000 population. Higher mortality rates were reported for male decedents aged $<1$ year, 15-19 years, and 55-59 years, whereas female decedents aged $30-34$ years, $45-49$ years, and $\geq 80$ years had higher mortality rates.

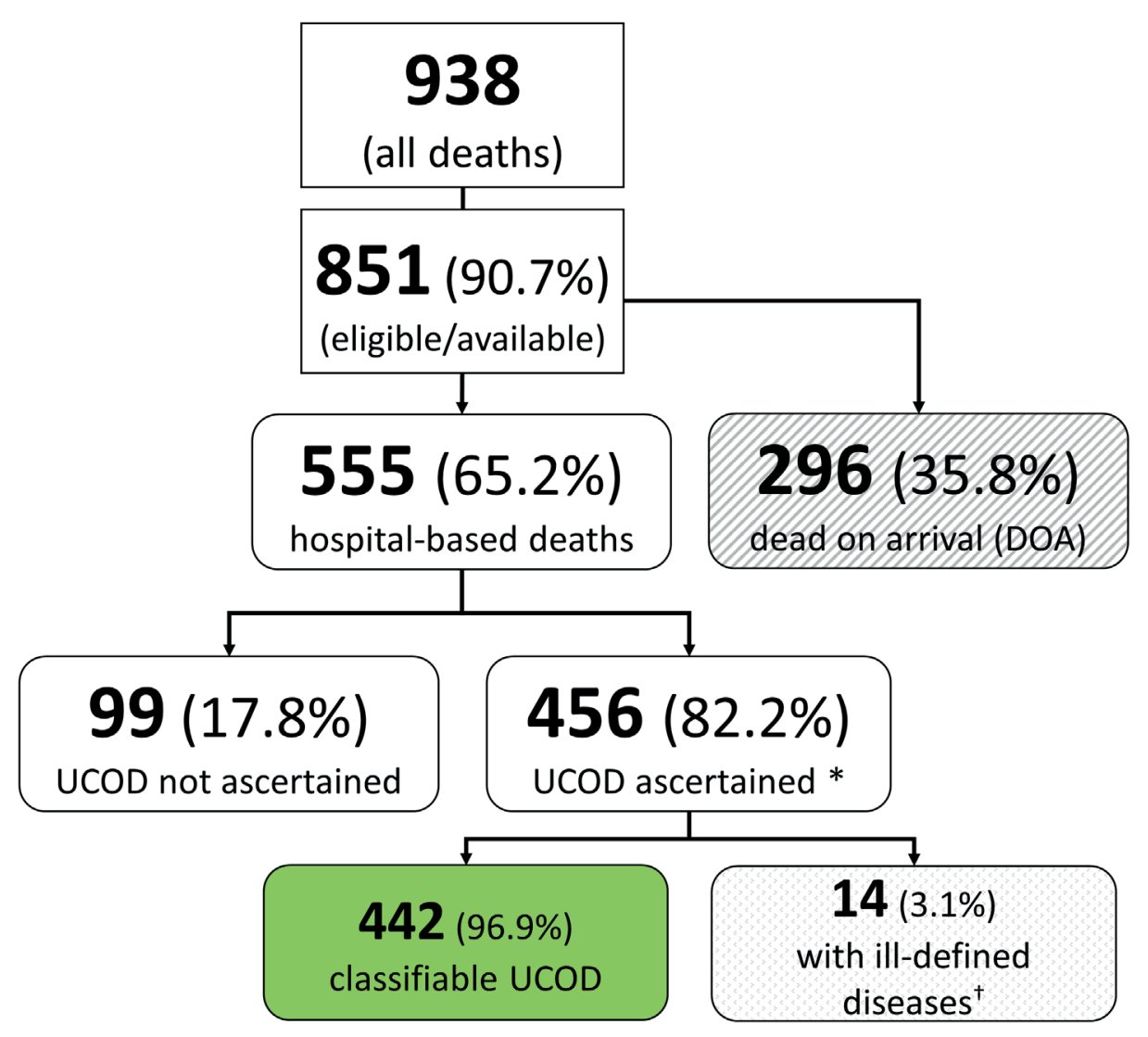

Figure 1. Deaths of hospitalized patients at two referral hospitals, Kisumu 2019

* Hospital records were available. $†$ Ill-defined diseases refer to UCOD with ICD10 codes R00-R99. 
Table 1. Distribution of ascertained causes of death by age and sex, and the global burden of disease category from admissions at two large hospitals, Kisumu 2019.

Caption: The table presents deaths by 5 -year age-bands among 208 males, and 234 females.

\begin{tabular}{|c|c|c|c|c|c|c|c|}
\hline \multirow{3}{*}{$\begin{array}{l}\text { Age } \\
\text { (years) }\end{array}$} & \multirow[b]{3}{*}{$\mathbf{N}\left(\%^{*}\right)$} & \multicolumn{2}{|c|}{ Group $\mathbf{I}^{\dagger}$} & \multicolumn{2}{|c|}{ Group II $^{\ddagger}$} & \multicolumn{2}{|c|}{ Group III } \\
\hline & & Males & Females & Males & Females & Males & Females \\
\hline & & n (\%) & n (\%) & n (\%) & n (\%) & n (\%) & n (\%) \\
\hline 0 & $51(11.5)$ & $26(25.5)$ & $19(17.8)$ & $3(3.4)$ & $3(2.5)$ & $0(0)$ & $0(0)$ \\
\hline $1-4$ & $16(3.6)$ & $8(7.8)$ & $5(4.7)$ & $1(1.1)$ & $2(1.6)$ & $0(0)$ & $0(0)$ \\
\hline $5-9$ & $20(4.5)$ & $5(4.9)$ & $5(4.7)$ & $4(4.5)$ & $6(4.9)$ & $0(0)$ & $0(0)$ \\
\hline $10-14$ & $12(2.7)$ & $3(2.9)$ & $4(3.7)$ & $2(2.3)$ & $3(2.5)$ & $0(0)$ & $0(0)$ \\
\hline $15-19$ & $19(4.3)$ & $5(4.9)$ & $2(1.9)$ & $6(6.8)$ & $4(3.3)$ & $2(11.1)$ & $0(0)$ \\
\hline $20-24$ & $12(2.7)$ & $3(2.9)$ & $3(2.8)$ & $2(2.3)$ & $3(2.5)$ & $1(5.6)$ & $0(0)$ \\
\hline $25-29$ & $37(8.4)$ & $2(2)$ & $13(12.1)$ & $10(11.4)$ & $5(4.1)$ & $6(33.3)$ & $1(20)$ \\
\hline $30-34$ & $41(9.3)$ & $10(9.8)$ & 17 (15.9) & $6(6.8)$ & $8(6.6)$ & $0(0)$ & $0(0)$ \\
\hline $35-39$ & $26(5.9)$ & $9(8.8)$ & $11(10.3)$ & $0(0)$ & $3(2.5)$ & $3(16.7)$ & $0(0)$ \\
\hline $40-44$ & $24(5.4)$ & $6(5.9)$ & $7(6.5)$ & $7(8)$ & $3(2.5)$ & $1(5.6)$ & $0(0)$ \\
\hline $45-49$ & $23(5.2)$ & $3(2.9)$ & $6(5.6)$ & $5(5.7)$ & $8(6.6)$ & $1(5.6)$ & $0(0)$ \\
\hline $50-54$ & $18(4.1)$ & $3(2.9)$ & $2(1.9)$ & $3(3.4)$ & $8(6.6)$ & $2(11.1)$ & $0(0)$ \\
\hline $55-59$ & $18(4.1)$ & $4(3.9)$ & $2(1.9)$ & $6(6.8)$ & $6(4.9)$ & $0(0)$ & $0(0)$ \\
\hline $60-64$ & $21(4.8)$ & $5(4.9)$ & $4(3.7)$ & $4(4.5)$ & $6(4.9)$ & $1(5.6)$ & $1(20)$ \\
\hline $65-69$ & $14(3.2)$ & $1(1)$ & $1(0.9)$ & $5(5.7)$ & $7(5.7)$ & $0(0)$ & $0(0)$ \\
\hline $70-74$ & $29(6.6)$ & $1(1)$ & $3(2.8)$ & $11(12.5)$ & $13(10.7)$ & $1(5.6)$ & $0(0)$ \\
\hline $75-79$ & $19(4.3)$ & $4(3.9)$ & $1(0.9)$ & $4(4.5)$ & $9(7.4)$ & $0(0)$ & $1(20)$ \\
\hline $80+$ & $42(9.5)$ & $4(3.9)$ & $2(1.9)$ & $9(10.2)$ & $25(20.5)$ & $0(0)$ & $2(40)$ \\
\hline Total & 442 & 102 & 107 & 88 & 122 & 18 & 5 \\
\hline p-values & - & \multicolumn{2}{|c|}{0.486} & \multicolumn{2}{|c|}{0.039} & \multicolumn{2}{|c|}{0.002} \\
\hline
\end{tabular}

* Column percentage; $\dagger$ Group I - Communicable, perinatal, maternal, and nutritional including HIV; $\ddagger$ Group II - Noncommunicable diseases; § Group III - Injuries; 9 P-values calculated using a chi-squared test show the significance of differences in proportions for each GBD category by sex. 
[A] Population pyramid (2019 census)

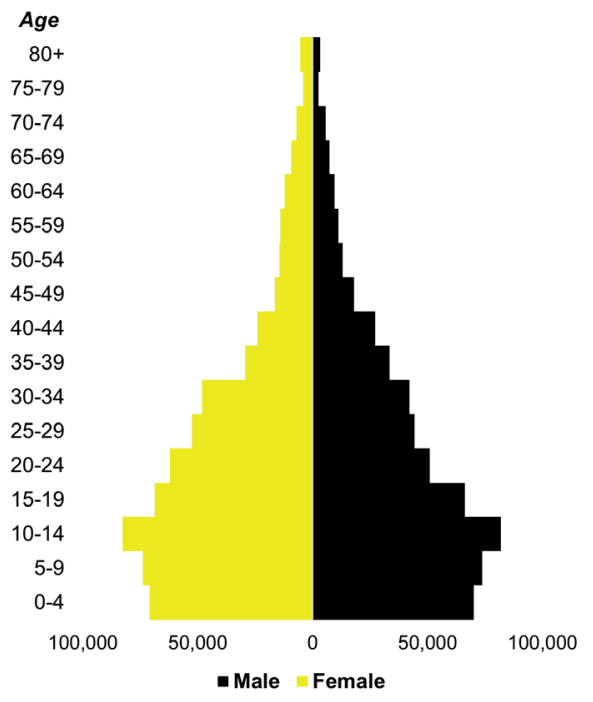

[B] Age-specific mortality rates $/ 100,000$

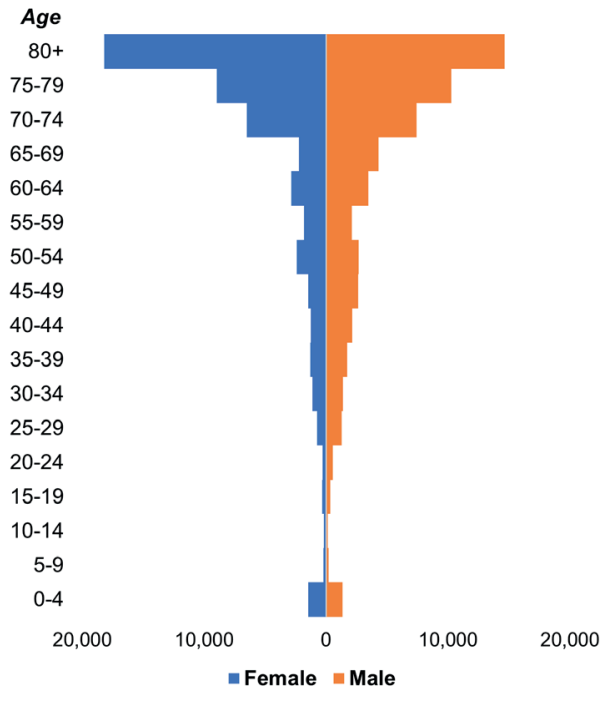

[C] Log of age-specific mortality rates $/ 100,000$

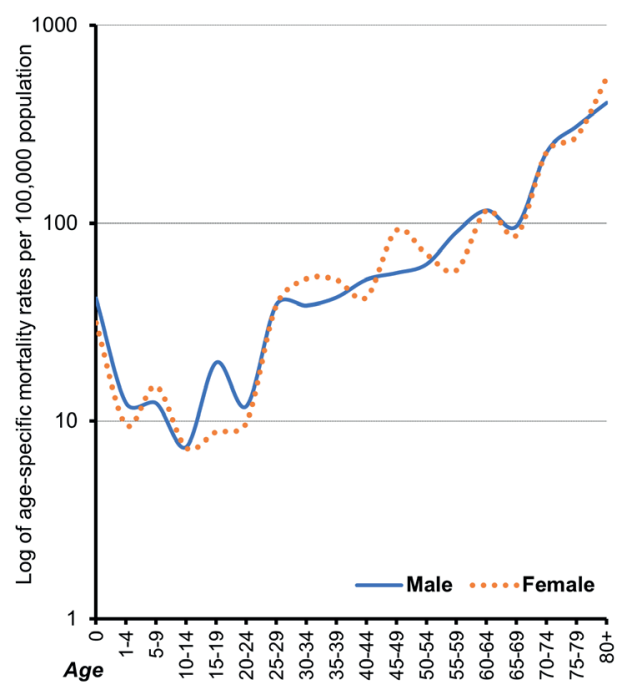

Figure 2. Kisumu County population pyramid and estimated deaths per 100,000 by sex and age, 2019.

Caption: A) Source of population data is 2019 census, B) Estimated deaths/100,000 calculated using the population denominator, C) Log-transformed age-specific mortality rates $/ 100,000$ population. 
Table 2. Ascertained leading causes of death at two large hospitals and among all persons and by sex, Kisumu, 2019

\begin{tabular}{|c|c|c|c|c|}
\hline \multirow[b]{2}{*}{ Causes of death } & \multirow{2}{*}{$\begin{array}{c}\text { Total }(\mathrm{n}=442) \\
\text { Rank, n (\%) }\end{array}$} & \multicolumn{2}{|c|}{ UCOD by sex, rank, n (\%) } & \multirow[b]{2}{*}{ p-value ${ }^{\dagger}$} \\
\hline & & Males & Females & \\
\hline Leading causes & $n=341(77.1)$ & $\mathrm{n}=149(71.6)$ & $\mathrm{n}=192(82.1)$ & - \\
\hline HIV/AIDS & $\mathbf{1}, 102(23.1)$ & $1,43(20.7)$ & $\mathbf{1}, 59(25.2)$ & 0.258 \\
\hline Hypertensive disease & $2,41(9.3)$ & $2,11(5.3)$ & $2,30(12.8)$ & 0.006 \\
\hline Other cardiovascular diseases & $3,23(5.2)$ & $4,10(4.8)$ & $4,13(5.6)$ & 0.724 \\
\hline Cancer $^{*}$ & $4,20(4.5)$ & $11,4(1.9)$ & $3,16(6.8)$ & 0.013 \\
\hline Endocrine disorders & $5,18(4.1)$ & $5,9(4.3)$ & $5,9(3.8)$ & 0.799 \\
\hline Lower respiratory infections & $6,16(3.6)$ & $2,11(5.3)$ & $12,5(2.1)$ & 0.077 \\
\hline Perinatal conditions & $7,16(3.6)$ & $6,8(3.8)$ & $6,8(3.4)$ & 0.810 \\
\hline Other digestive diseases & $8,13(2.9)$ & $9,6(2.9)$ & $8,7(3)$ & 0.947 \\
\hline Malaria & $9,12(2.7)$ & $8,7(3.4)$ & $11,5(2.1)$ & 0.428 \\
\hline Cerebrovascular disease & $10,12(2.7)$ & $11,5(2.4)$ & $7,7(3)$ & 0.704 \\
\hline Prematurity \& low birth weight & $11,11(2.5)$ & $9,6(2.9)$ & $13,5(2.1)$ & 0.614 \\
\hline Road traffic accidents & $12,11(2.5)$ & 6, $8(3.8)$ & $-8,3$ & 0.125 \\
\hline Diabetes mellitus & $13,10(2.3)$ & $\mathbf{1 6}, 4(1.9)$ & $10,6(2.6)$ & 0.755 \\
\hline Diarrheal diseases & $14,9(2)$ & $11,5(2.4)$ & $\mathbf{1 5}, 4(1.7)$ & 0.740 \\
\hline Infectious diseases (other) & $15,9(2)$ & $20,3(1.4)$ & $9,6(2.6)$ & 0.510 \\
\hline Birth asphyxia and birth trauma & $16,6(1.4)$ & $11,5(2.4)$ & $-s^{\S}, 1$ & 0.104 \\
\hline Protein-energy malnutrition & $17,6(1.4)$ & $-8,3$ & $18,3(1.3)$ & 1.000 \\
\hline Skin diseases & $18,6(1.4)$ & $-\$, 1$ & $14,5(2.1)$ & 0.220 \\
\hline All other causes &,$- 101(22.9)$ &,$- 59(28.4)$ &,$- 42(17.9)$ & - \\
\hline Total $(\mathrm{N})$ & 442 & 208 & 234 & \\
\hline
\end{tabular}

${ }^{\star}$ UCOD: underlying causes of death. Causes of death exclude Ill-defined diseases (ICD10 R00-R99). Three percent of underlying causes of death were/remained ill-defined. Results within columns presented as rank, N (\%). Rank is boldfaced.; $\uparrow p$-values show significance of differences in proportions for each UCOD by sex; $¥$ Cancers include UCOD defined as: "Esophageal cancer", "Cervix uteri cancer" and "Trachea, bronchus and lung cancers", "Other neoplasms", "Other malignant neoplasms", - hence combined cancers reduce the number of leading causes to 18 ; $\$$ Not among 20 overall leading UCOD within the sex category, hence percentages and ranking not included; $\boldsymbol{g}$ Includes all other mutually exclusive causes of death, percentages are out of the total number of deaths

\section{Twenty leading causes of death}

The 20 leading COD accounted for over three-quarters $(77.1 \%, 341 / 442)$ of the ascertained deaths (Table 2). The four leading UCOD were HIV/AIDS (102/442 [23.1\%]), hypertensive disease (41/442 [9.3\%]), other cardiovascular diseases $(23 / 442[5.2 \%])$, and cancer $(20 / 442$ [4.5\%]). Lower respiratory infections were 
important UCOD among male decedents (5.3\% of deaths) but were ranked twelfth among female decedents $(2.1 \%$ of deaths). More males had UCOD due to road traffic accidents, ranking sixth, but only three traffic accident-related deaths were reported among females. Significantly more females $(12.8 \%)$ than males $(5.3 \%)$ died of hypertensive disease $(\mathrm{p}=0.006)$ and cancer (females, 6.8\%; males, $1.9 \%$; $\mathrm{p}=0.013)$.

Among children aged $<5$ years, conditions arising during the perinatal period $(n=12[18.8 \%])$, followed by prematurity and low birth weight $(n=11[17.2 \%])$, were the first and second leading COD among 64 children. HIV/AIDS was the third leading COD among children aged $<5$ years (Table 3 ).

Table 3. Ascertained leading causes of death at two large hospitals and among children aged 0-4 years in Kisumu, 2019

Caption: Leading underlying causes of death among children aged 0-4 years ranked by frequency.

\begin{tabular}{llc} 
& Causes of death $^{*}$ & $\mathbf{n}(\%)^{\dagger}$ \\
\cline { 2 - 3 } Rank & Leading causes & $\mathbf{n}=\mathbf{6 4}$ \\
\hline 1 & Other conditions arising during the perinatal period & $12(18.8)$ \\
2 & Prematurity and low birth weight & $11(17.2)$ \\
3 & HIV/AIDS & $6(9.4)$ \\
3 & Birth asphyxia and birth trauma & $6(9.4)$ \\
4 & Diarrhoeal diseases & $5(7.8)$ \\
4 & Protein-energy malnutrition & $5(7.8)$ \\
5 & Lower respiratory infections & $4(6.3)$ \\
6 & Malaria & $3(4.7)$ \\
7 & Lymphomas and multiple myeloma & $2(3.1)$ \\
7 & Endocrine disorders & $2(3.1)$ \\
8 & Meningitis & $1(1.6)$ \\
8 & Other infectious diseases & $1(1.6)$ \\
8 & Other nutritional disorders & $1(1.6)$ \\
8 & Other malignant neoplasms & $1(1.6)$ \\
8 & Other digestive diseases & $1(1.6)$ \\
8 & Abdominal wall defect & $1(1.6)$ \\
8 & Other Congenital anomalies & $1(1.6)$ \\
- & All other causes & 4 \\
\hline & Total & $\mathrm{N}=67$ \\
\hline
\end{tabular}

${ }^{\star}$ Data for children overlap with data presented in Table 2; † Column percentages; $\ddagger$ Not ranked or included in the percentage. 


\section{Stillbirths}

In both hospitals, there were 66 documented stillbirths during the study period. From health services program data reported through the Kenya health information system, there were 3,360 total deliveries in the two facilities from April 1-July 31, 2019, and 81 (2.4\%) stillbirths over 121 days [19]. Using this denominator, we calculated approximately 2,416 deliveries in the 87 days of the study period and a stillbirth rate of $2.7 \%(66 / 2,416)$ or $27 / 1,000$ deliveries.

\section{Comparison of notified versus ascertained underlying causes of death}

We abstracted data from available death notification forms for 236 records matched with UCOD records ascertained by the expert panel. Overall, over two-thirds (167/236 [70.8\%]) of the decedents had incorrectly assigned UCOD in the death notification form (Table 4). The errors were attributed to either wrong sequencing, i.e., the chain of events leading to death was incorrectly ordered 10/167 [6.0\%]), or wrong assignment (157/167 [94.0\%]) of UCOD among decedents. The proportion of incorrectly assigned UCOD was not significantly different by sex $(p=0.174)$. Where underlying UCOD was HIV/AIDS, the concordance between panel-ascertained and notified deaths was higher (27/60 [45.0\%]) compared to other UCOD (42/176 [23.9\%]; $\mathrm{p}=0.002])$. The agreement between notified and ascertained UCOD was $29.2 \%(\kappa=0.259)$. The discrepancy was higher for immediate COD $(176 / 236$ [74.6\%]) than for UCOD (167/236 [70.8\%]).

Table 4. Comparison of notified versus ascertained cause of death (COD), Kisumu 2019

Caption: Comparison of notified versus ascertained COD and by selected variables.

Type of errors, $\mathbf{n}(\%)$

\begin{tabular}{lcccc}
\cline { 2 - 4 } & $\mathbf{N}(\%)$ & Correct COD & Erroneous COD & p-value \\
\hline COD type & & & & \\
Underlying & $236(100)$ & $69(29.2)^{*}$ & $167(70.8)^{\dagger}$ & \\
Immediate & $236(100)$ & $60(25.4)^{\ddagger}$ & $176(74.6)$ & \\
Sex & & & & $0.174^{\S}$ \\
Males & $124(52.5)$ & $41(33.1)$ & $83(66.9)$ & \\
Females & $112(47.5)$ & $28(25.0)$ & $84(75.0)$ & \\
Underlying COD & & & & $0.002^{\S}$ \\
HIV/AIDS & $60(25.4)$ & $27(45.0)$ & $33(55.0)$ & \\
Other & $176(74.6)$ & $42(23.9)$ & $134(76.1)$ & \\
\hline
\end{tabular}

${ }^{*}$ Poor interrater agreement $(29.2 \% ; \kappa=0.26)$; $\uparrow$ Wrong assignment of $\operatorname{COD}(n=157$ [94.0\%]) and wrong sequence $(\mathrm{n}=10[6.0 \%])$; $¥$ Poor interrater agreement $(25.4 \% ; \kappa=0.24) ; \S \mathrm{p}$-values show significance of differences in proportions for erroneously assigned COD. 


\section{Summary mortality rates}

The all-cause mortality rate among all decedents was 1,086/100,000 population. Noncommunicable diseases contributed to the highest cause-specific mortality (516/100,000 population), followed by GBD I (513/100,000 population) and III $(56 / 100,000$ population). Males $(81,154 / 100,000$ population) had a higher crude all-cause mortality rate compared to females (1,021/100,000 population). Among decedents aged $<15$ years at death, the crude all-cause mortality rate was $524 / 100,000$ population, and most deaths were attributed to communicable diseases (397/100,000 population compared to noncommunicable diseases [127/100,000 population]). Among decedents aged $\geq 15$ years at death, males had the highest rate (1,594/100,000 population; females, $1,315 / 100,000$ population), and GBD category II diseases were the leading COD (785/100,000 population compared to GBD I [566/100,000 population] and GBD III [97/100,000 population]). The HIVassociated mortality rate was $312 / 100,000$ population among all decedents. Females of any age (274/100,000 population) had a $20 \%$ higher mortality rate than males (224/100,000 population), and deaths that were directly attributed to HIV/AIDS were nearly $40 \%$ higher among females (413/100,000 population) than among males (298/100,000 population). The death rate due to HIV/AIDS was greater among persons aged $\geq 15$ years compared to younger individuals (Table 5).

Table 5. Estimated all-cause and cause-specific mortality rates by GBD and HIV disease classifications in Kisumu County, Kenya (2019)

Caption: The table shows mortality rates calculated for all causes of death and due to specific disease conditions per 100,000 population using the estimated mid-year population in Kisumu County, Kenya.

\begin{tabular}{|c|c|c|c|c|c|c|c|c|c|}
\hline \multirow{3}{*}{ Cause of death } & \multicolumn{9}{|c|}{ Mortality rate per 100,000 population } \\
\hline & \multicolumn{3}{|c|}{ All } & \multicolumn{3}{|c|}{$<15$ years old } & \multicolumn{3}{|c|}{$15+$ years old } \\
\hline & $\mathbf{M} / \mathbf{F}^{*}$ & M & F & $\mathrm{M} / \mathrm{F}^{*}$ & M & $\mathbf{F}$ & $\mathbf{M} / \mathbf{F}^{\star}$ & M & F \\
\hline All-cause & 1,086 & 1,154 & 1,021 & 524 & 552 & 495 & 1,448 & 1,594 & 1,315 \\
\hline Group $\mathrm{I}^{\dagger}$ & 513 & 566 & 467 & 397 & 446 & 348 & 566 & 613 & 521 \\
\hline Group $\mathrm{II}^{*}$ & 516 & 488 & 532 & 127 & 106 & 148 & 785 & 797 & 760 \\
\hline Group III ${ }^{\S}$ & 56 & 100 & 22 & 0 & 0 & 0 & 97 & 184 & 35 \\
\hline \multicolumn{10}{|l|}{ HIV } \\
\hline HIV-associated & 312 & 224 & 274 & 53 & 40 & 67 & 388 & 362 & 410 \\
\hline Due to HIV/AIDS* & 251 & 298 & 413 & 85 & 81 & 89 & 549 & 455 & 627 \\
\hline
\end{tabular}

${ }^{\star}$ Male or female; $\uparrow$ Group I - Communicable, perinatal, maternal and nutritional conditions including HIV; $末$ Group II - Noncommunicable diseases; ${ }^{\varsigma}$ Group III - Injuries; 9 HIV was listed as a significant cause of death; \# UCOD was ascertained as HIV/AIDS. 


\section{Discussion}

\section{Leading causes of death}

In Kisumu County, we found that the HIV/AIDS-related mortality rate is nearly $25 \%$, which is similar to that observed in Abidjan by De Cock et al during the late 1980's [23] and double the rate found in a Nairobi mortality study (12.6\%) [24]. In our study, the proportion of deaths attributed to HIV/AIDS was twice the proportion that is regularly reported through CRVS. However, the proportion is likely overestimated in our study because we did not include the DOA group. Prevalence of HIV infection was $23.7 \%$ among DOA compared to $31.0 \%$ among the hospital-based deaths. Among the 47 counties in Kenya, Kisumu County reported the greatest number of HIV/AIDS-related deaths (14.4\% of all HIV/AIDS deaths nationally in 2017) [9], compared to only $2.4 \%$ of the current national population [17]. Kisumu County is ranked second in adult HIV prevalence at $17.5 \%$ [25], and our finding of high HIV-related mortality rates is consistent with the national HIV prevalence. Though our finding of a high proportion of HIV/AIDS-related deaths likely reflects the complexity of cases in the two referral hospitals, our sample did have wide geographic coverage, including decedents from all over the county. However, the difference in our findings compared to CRVS data could be explained by the extra step of ascertaining UCOD in our study; thus, we had higher sensitivity in identifying HIV/AIDS-attributable mortality. We also tested the cadavers for HIV, and availability of these test results helped us distinguish HIV-related from non-HIV-related deaths with similar clinical presentation.

The proportion of deaths with hypertension as an underlying cause was $(9.3 \%)$ and greatest among persons aged $\geq 40$ years $(36 / 41 ; 87.8 \%)$ for both sexes, which is below the proportions previously reported of $12.3 \%$, [26], and $22.8 \%$, [27], in urban informal settlements in Kenya. Cancer was the fourth leading COD and accounted for a greater proportion of deaths among both sexes. Our findings are consistent with the reports that showed cancer as the third leading COD in Kenya, after infectious diseases and cardiovascular diseases [28], and the second leading COD globally, causing an estimated 9.6 million deaths in 2018 [29]. Additionally, our findings point to an epidemiologic transition underway in Kenyan adults in rural settings, highlighting the increasing importance of preventing non-communicable diseases to decrease adult mortality rates [6,7]. Nonetheless, infectious diseases still contribute to significant mortality in this population and, not surprisingly, most of the deaths among younger decedents were due to communicable diseases [30]. 
More than a fifth of certified deaths were among infants and among adults aged $\geq 80$ years. Mortality rates among the geriatric population were similar to those previously reported in Kenya $(\sim 10 \%)$, with similar mortality rates for both males and females [9]. Although high mortality rates are expected among the geriatric population, the high proportion of deaths among infants reflects the persistent high infant mortality rates in the Nyanza region, estimated to be 72 deaths/1,000 live births [31]. Possible contributors to this high infant mortality rate are malaria and child and maternal nutrition risk factors [5]. We also observed a higher proportion of deaths attributed to non-communicable diseases among females compared to males.

Although exclusion of police cases and DOA likely disproportionately affected our estimates of violence-related deaths (relatively low overall even for males) and injury-related deaths, deaths due to injuries were still four times higher among males than among females, probably due to greater exposure to poor road safety precautions and/or occupational hazards. The cause-specific mortality rate for deaths caused by injuries (mostly road traffic related) was higher for males than for females. Deaths due to road traffic-related injuries could be decreased, especially among younger men, by training of passengers, drivers, and other road users on safety precautions.

Surprisingly, we did not find injury-related deaths among children. This is in contrast to studies for other resource-limited countries, which have reported high rates of injury-related deaths among children and younger persons [32,33]. Injuries are often reported as UCOD for DOA cadavers. Since we did not capture UCOD for DOA cadavers, it is possible that we missed injury-related childhood deaths. However, in our study, hospital-based deaths had proportionately higher number of decedents aged $<5$ years at time of death compared to those DOA (Supplemental Figure), whereas more decedents aged $<70$ years at time of death were DOA than hospital-based deaths. Thus, age distribution for DOA compared to hospitalbased deaths was similar for most of the decedents aged 5-69 years (Supplemental Figure). In our study, the proportions of deaths due to communicable compared to non-communicable diseases were approaching 1:1, and similar to those previously reported through CRVS for Kisumu County [18]. However, this ratio is different compared to other similar resource-limited settings in which for every two deaths attributed to communicable diseases, there are three attributed to noncommunicable diseases [34], indicating that HIV still contributes substantially to the burden of communicable diseases in Kisumu. Other infectious diseases contributed to more deaths among children than among adults. 


\section{Stillbirths}

We reported a high rate of stillbirths as well as deaths due to perinatal conditions. The high incidence in this setting may be due in part to these referral hospitals attending to complicated pregnancies. These deaths may be related to lack of access to emergency care, during pregnancy, late presentation at health care facilities, and complications during childbirth. In Kenya, only about $18 \%$ of pregnant women have at least four ANC visits, and women with one visit within the first 3 months of pregnancy have better pregnancy outcomes than those with only one antenatal clinic visit [35]. Teaching expectant and postpartum women the danger signs of complications during pregnancy and the peripartum period could trigger timely health seeking behavior among women [43] and reduce maternal mortality and perinatal deaths [42]. Though our study lasted for only a few months, our estimated stillbirth rate (2.7\%) is higher than the national average (1.3\%) among women reporting a pregnancy in the 5 years before the 2014 demographic and health survey [34] but is similar to the 2015 estimate for sub-Saharan Africa (2.9\% or 29/1000 live births) [44].

\section{Annualized mortality rates}

We found an all-cause mortality rate of 1,086/100,000 in Kisumu that was about twice the national crude death rate average of 551.8/100,000 population for 20152020 [4]. Mortality rates have been higher in western Kenya including Kisumu County [5], which is mostly attributed to communicable diseases, especially HIV/ AIDS. The rate we found was lower than that reported in a similar setting in neighboring Siaya County (1,446/100,000 population) [40] and is also lower than the 2009 population census estimates of 1,370 deaths/100,000 population [14].

\section{Notified versus ascertained underlying causes of death}

Almost three-quarters of notified deaths at JOOTRH and KCRH had an incorrect UCOD in the death notification forms, which were submitted to the CRVS system. The errors were due to either wrong sequencing or wrong assignment, as noted in previous Ministry of Health reports [9]. Incorrect assignment was higher among male decedents compared to female decedents. Better assignment of underlying UCOD was observed for deaths due to HIV/AIDS, and the proportion with errors was higher for immediate compared to underlying COD. We could not determine whether the higher error rate for immediate COD was due to symptomatic presentation, availability of HIV diagnosis, or treatment records in patient charts. Among persons who died of HIV/AIDS, approximately $50 \%$ had one or more noncommunicable disease documented along the causal pathway as an immediate or intermediate COD. Assignment of the wrong UCOD could be due to various factors. First, the clinician who certified the death may not have seen the patient during 
hospitalization and thus may not be familiar with the patient's clinical history. Second, medical records may be unavailable or not reviewed by the certifier due to time constraints imposed by the urgency of completing administrative procedures related to the death.

The very low agreement of ascertained UCOD compared to notified UCOD in our study indicates that mortality statistics that depend wholly on death notifications may be grossly inaccurate. Certification of deaths by personnel who are not trained for that purpose may further compromise the quality of mortality data, which is also compounded by poor documentation. This was reflected in a previous study that found a low vital statistics performance index in Kenya [41]. This index is a composite metric that ranges from 0 to 1 for assessing the quality of data on mortality and COD containing six dimensions: quality of COD reporting, quality of reporting of age and sex of decedents, internal consistency, completeness, level of cause-specific detail, and data availability or timeliness [42]. In 2015, Kenya scored 0 in each of these elements [41]. Completeness, correctness, and order of COD statements among decedents have been noted to be poor in Kenya, with incomplete information and citing mechanisms of death as the most frequent errors [43].

Data contained in death notification forms in Kenya have been found to be of poor quality, with $18.4 \%$ containing ill-defined causes (such as those with incomplete descriptions of the cause or with vague descriptions), which is above the acceptable maximum threshold of $10 \%$ for all ages, and about a third of death notification forms were either incomplete or submitted without any COD listed [9]. Certification of deaths by clinicians trained on ICD procedures, availability of HIV status at time of certification in settings where HIV is a significant COD, and a thorough scrutiny of medical records before death certification could substantially improve the quality of UCOD information reported to CRVS.

\section{Limitations and assumptions}

Our study had several limitations. We used available medical records and postmortem HIV testing to assign COD; no diagnostic autopsies were performed specifically for this study. Group I communicable diseases include perinatal, maternal and nutrition diseases. However, without post-mortem, there may be no proper differentiation of deaths related to maternal and child health versus communicable diseases for younger decedents. For mortality rate estimates, we assumed that both mortality rates and reporting rates were similar in all calendar months. The study was conducted in public health facilities, and we assumed that the cadavers admitted in JOOTRH and KCRH would be representative of Kisumu County population. Data abstracted from the Kisumu East Civil Registry indicate 
that over $75 \%$ of deaths occur within health facilities, and about $42 \%$ of facilitybased deaths are admitted to these two mortuaries. Thus, though facility-based COD statistics may not accurately represent the COD throughout the community, the benefits of an estimation of COD based on facility-based reported deaths outweigh this bias. To mitigate this limitation, we confirmed that the decedents in our study came from all geographical areas of Kisumu County. Since we did not have medical charts for the DOA (one-third of all decedents during our study period), we assumed the distribution of UCOD for those who were DOA was similar to those who died in the hospitals for purposes of calculating mortality rates. These decedents were not selectively admitted to the morgues as a result of death from any specific GBD category. Regardless, homicides and other violent deaths are underrepresented as COD in our study since we did not include the DOA group in our analysis. This bias may be around 3\% of total mortality, since the estimated contribution of deaths caused by GBD III category in Kenya is about $8 \%$ [46], compared to the $3.8 \%$ we found in our analysis.

\section{Conclusions}

Kisumu County had similar communicable and non-communicable disease related mortality rates, with HIV contributing to the highest proportion of communicable disease-related deaths. Males have higher rates of injury-related deaths than females, whereas females have higher rates of non-communicable disease-related deaths. Although most deaths are preventable, our findings suggest that a holistic approach rather than focusing on one GBD category could help prevent deaths in Kisumu County. HIV prevention, improved viral load suppression among HIV-positive persons, and improved uptake of vaccines could help decrease communicable and non-communicable disease-related deaths, and prevention and treatment of hypertension and increased screening and community awareness, including advocating for behavior changes such as cessation of smoking, could help decrease non-communicable disease-related deaths.

Vital statistics reporting for hospital-based deaths could be improved by training medical officers on correct death certification, including proper sequencing using ICD10 rules. For deaths that occur within the community, training the chiefs and sub-chiefs who are responsible for collecting verbal autopsy data could help improve mortality surveillance, as recently reported in Uganda [45]. Routine review of patient charts and data quality reviews by trained medical experts before notification of death could improve the quality of COD reported to CRVS and 
enhance the utility of such reports for planning. Regular mortality case review meetings may offer a forum to share experiences and ensure that UCOD are documented appropriately.

Our study demonstrates the feasibility of determining probable COD and providing more precise cause-specific mortality rates without using expensive postmortem procedures. Our approach can be used in other limited-resource settings, particularly regions with high HIV burden, to help evaluate the impact of HIV care and treatment programs and to distinguish deaths caused by HIV/AIDS from other disparate causes and identify epidemiologic transitions.

\section{Acknowledgments}

We thank the study staff working at the mortuaries and hospitals and the data entry and management staff.

\section{Author contributions}

AW was a co-investigator, developed the protocol, conducted study training and field supervision, reviewed the literature, conceived of the paper, analyzed and interpreted the data, and drafted the manuscript. DO was the principal investigator, both he and LN (a co-investigator) developed the protocol, provided field supervision, monitored the study, and helped with interpreting the results. AS and PKM provided data management and analysis support. WW, SS, EO, EN, SWM, JK, and TM collaborated in the study and provided supervision. KDC and PWY helped to conceptualize the Nairobi HIV-associated mortality surveillance study that provided the backbone on which the Kisumu study was designed. EAR and PWY were coinvestigators and provided additional technical input during the writing of the manuscript. MABS and KDC edited the manuscript. All authors reviewed and commented on successive drafts and approved the final version of the manuscript. 


\section{References}

1 Murray CJL, Lopez AD, editors. The Global Burden of Disease: Summary. World Health Organization; 1996.

2 Mathers CD, Stein C, Fat DM, Rao C, Inoue M, Tomijima N, Bernard C, Lopez AD, Murray CJL. Global burden of disease 2000: version 2 methods and results. 2002.

3 Mathers $C D$, Fat DM, Inoue $M$, Rao $C_{1}$ Lopez AD. Counting the dead and what they died from: an assessment of the global status of cause of death data. Bull World Health Organ 2005;015784.

4 United Nations Department of Economic and Social Affairs. World Population Prospects 2019.

5 Achoki T, Miller-Petrie MK, Glenn SD, Kalra N, Lesego A, Gathecha GK, Alam U, Kiarie HW, Maina IW, Adetifa IMO, Barsosio HC, Degfie TT, Keiyoro PN, Kiirithio DN, Kinfu Y, et al. Health disparities across the counties of Kenya and implications for policy makers, 1990-2016: a systematic analysis for the Global Burden of Disease Study 2016. Lancet Glob Heal 2019;7:e81-95. doi:10.1016/S2214109X(18)30472-8.

6 Phillips-Howard PA, Laserson KF, Amek N, Beynon CM, Angell SY, Khagayi S, Byass P, Hamel MJ, Van Eijk AM, Zielinski-Gutierrez E, Slutsker L, De Cock KM, Vulule J, Odhiambo FO. Deaths ascribed to noncommunicable diseases among rural kenyan adults are proportionately increasing: Evidence from a health and demographic surveillance system, 2003-2010. PLoS One 2014;9:1-29. doi:10.1371/ journal.pone.0114010.

7 Sifuna P, Otieno L, Ogwang S, Ogutu B, Andagalu B, Owuoth J, Singoei V, Cowden J, Otieno W. Causespecific mortality in the Kombewa health and demographic surveillance systems site, rural Western Kenya from 2011-2015. Glob Health Action 2018;11. doi:10.1080/16549716.2018.1442959.

8 World Health Organization. World health statistics overview 2019: monitoring health for the SDGs, sustainable development goals. vol. 1. Geneva, Switzerland: 2019. doi:10.1017/ CB09781107415324.004.

9 Ministry of Health Kenya. Mortality Trends in Kenya 2012-2016: Cause of death, trends, and data quality. 2018.

10 United Nations Joint Programme on HIV/AIDS (UNAIDS). HIV in Kenya, 20182019.

11 Kenya National Bureau of Statistiscs. Kenya Economic Survey 2018. 2018.

12 Kenya National Bureau of Statistics. Kenya Economic Survey 2019. 2019.

13 Macharia PM, Giorgi E, Thuranira PN, Joseph NK, Sartorius B, Snow RW, Okiro EA. Sub national variation and inequalities in under-five mortality in Kenya since 1965. BMC Public Health 2019;19:112. doi:10.1186/s12889-019-6474-1.

14 Kenya National Bureau of Statistics. 2009 Kenya Population and Housing Census Analytical Report on Mortality. vol. VI. 2012.

15 Jha P. Reliable direct measurement of causes of death in low- and middle-income countries. BMC Med 2014;12. doi:10.1186/1741-7015-12-19.

16 De Cock KM, Zielinski-Gutiérrez E, Lucas SB. Learning from the Dead. N Engl J Med 2020:1-3.

17 Kenya National Bureau of Statistics (KNBS). 2019 Kenya Population and Housing Census: Population by County and Sub-County. vol. I. 2019.

18 Department of Vital Statistics. Kenya Vital Statistics Report (KVSR). 2017. 
19 Ministry of Health. Kenya Health Information System (KHIS) for Aggregate reporting 2019.

20 World Health Organization. International statistical classification of diseases and related health problems: 10th revision. vol. 2. 5th ed. Geneva, Switzerland: World Health Organization; 2016.

21 National AIDS and STI Control Programs (NASCOP). Mortuary and Hospital-Based Surveillance of HIVAssociated Mortality in Kisumu County. 2020.

22 World Health Organization. Analysing mortality levels and causes-of-death (ANACoD) 2014.

23 De Cock KM, Barrere B, Diaby L, Lafontaine MF, Gnaore E, Porter A, Pantobe D, Lafontant GC, DagoAkribi A, Ette M. AIDS--the leading cause of adult death in the West African City of Abidjan, Ivory Coast. Science 1990;249:793-6.

24 National AIDS and STI Control Programme (NASCOP). HIV Mortuary Surveillance in Nairobi. 2016.

25 National AIDS and STI Control Programme (NASCOP). Preliminary KENPHIA 2018 Report. 2020.

26 Van De Vijver SJM, Oti SO, Agyemang C, Gomez GB, Kyobutungi C. Prevalence, awareness, treatment and control of hypertension among slum dwellers in Nairobi, Kenya. J Hypertens 2013;31:1018-24. doi:10.1097/HJH.0b013e32835e3a56.

27 Joshi MD, Ayah R, Njau EK, Wanjiru R, Kayima JK, Njeru EK, Mutai KK. Prevalence of hypertension and associated cardiovascular risk factors in an urban slum in Nairobi, Kenya: A population-based survey. BMC Public Health 2014;14:1-10. doi:10.1186/1471-2458-14-1177.

28 Wambalaba FW, Son B, Wambalaba AE, Nyong'o D, Nyong'o A. Prevalence and capacity of cancer diagnostics and treatment: a demand and supply survey of health-care facilities in Kenya. Cancer Control 2019;26:107327481988693. doi:10.1177/1073274819886930.

29 World Health Organization, International Agency for Research on Cancer. World Health Organisation: All cancers excl. non-melanoma skin cancer. Globocan Database 2018;876:2018-9.

30 Osano BO, Were F, Mathews S. Mortality among 5-17 year old children in Kenya. Pan Afr Med J 2017:27:1-7. doi:10.11604/pamj.2017.27.121.10727.

31 Kenya National Bureau of Statistics (KNBS). Kenya Demographic and Health Survey 2014. Nairobi: 2015.

32 Lopez AD, Mathers CD, Ezzati M, Jamison DT, Murray CJL. Global Burden of Disease and Risk Factors. 2006.

33 Mokdad AH, Forouzanfar MH, Daoud F, Mokdad AA, El Bcheraoui C, Moradi-Lakeh M, Kyu HH, Barber RM, Wagner J, Cercy K, Kravitz H, Coggeshall M, Chew A, O'Rourke KF, Steiner $C$, et al. Global burden of diseases, injuries, and risk factors for young people's health during 1990-2013: a systematic analysis for the Global Burden of Disease Study 2013. Lancet 2016;387:2383-401. doi:10.1016/ S0140-6736(16)00648-6.

34 World Health Organization (WHO), University of Queensland and Health Metrics Network. ANACoD V2.0 2014.

35 Mbugua S, MacQuarrie KLD. Maternal Health Indicators in High-Priority Counties of Kenya: Levels and Inequities. Rockville, Maryland, USA: 2018.

36 Mwilike B, Nalwadda G, Kagawa M, Malima K, Mselle L, Horiuchi S. Knowledge of danger signs during pregnancy and subsequent healthcare seeking actions among women in urban Tanzania: a crosssectional study. BMC Pregnancy Childbirth 2018;18:4. doi:10.1186/s12884-017-1628-6. 
37 Ministry of Public Health and Sanitation, Ministry of Medical Services. National guideline for quality obstetrics and perinatal care 2010:1-410.

38 Kenya National Bureau of Statistics. Demographic and Health Survey. Nairobi, Kenya: 2014.

39 Lawn JE, Blencowe H, Waiswa P, Amouzou A, Mathers C, Hogan D, Flenady V, Frøen JF, Qureshi ZU, Calderwood C, Shiekh S, Jassir FB, You D, McClure EM, Mathai M, et al. Stillbirths: Rates, risk factors, and acceleration towards 2030. Lancet 2016;387:587 603. doi:10.1016/S0140-6736(15)00837-5.

40 Emukule G0, Spreeuwenberg $P$, Chaves SS, Mott JA, Tempia S, Bigogo G, Nyawanda B, Nyaguara A, Widdowson MA, Van Der Velden $K$, Paget JW. Estimating influenza and respiratory syncytial virusassociated mortality in Western Kenya using health and demographic surveillance system data, 2007-2013. PLoS One 2017;12:2007-13. doi:10.1371/journal.pone.0180890.

41 Mikkelsen L, Phillips DE, Abouzahr C, Setel PW, De Savigny D, Lozano R, Lopez AD. A global assessment of civil registration and vital statistics systems: Monitoring data quality and progress. Lancet 2015;386:1395-406. doi:10.1016/S0140-6736(15)60171-4.

42 Phillips DE, Lozano R, Naghavi M, Atkinson C, Gonzalez-Medina D, Mikkelsen L, Murray CJL, Lopez AD. A composite metric for assessing data on mortality and causes of death: The vital statistics performance index. Popul Health Metr 2014;12:1-16. doi:10.1186/1478-7954-12-14.

43 Rogena EA, Waruru A, Young PW, Abade P, Nyagah LM, Walong EO. A review of completeness, correctness, and order of cause of death statements among decedents with documented causes of death and HIV status at two major mortuaries in Kenya, 2015. J Forensic Leg Med 2020;73:101993. doi:10.1016/j.jflm.2020.101993.

44 World Health Organization. World Health Statistics 2012. vol. 2018.

45 Nabukalu D, Ntaro M, Seviiri M, Reyes R, Wiens M, Sundararajan R, Mulogo E, Boyce RM. Community health workers trained to conduct verbal autopsies provide better mortality measures than existing surveillance: Results from a cross-sectional study in rural western Uganda. PLoS One 2019;14:1-13. doi:10.1371/journal.pone.0211482. 


\section{Supplemental figure}

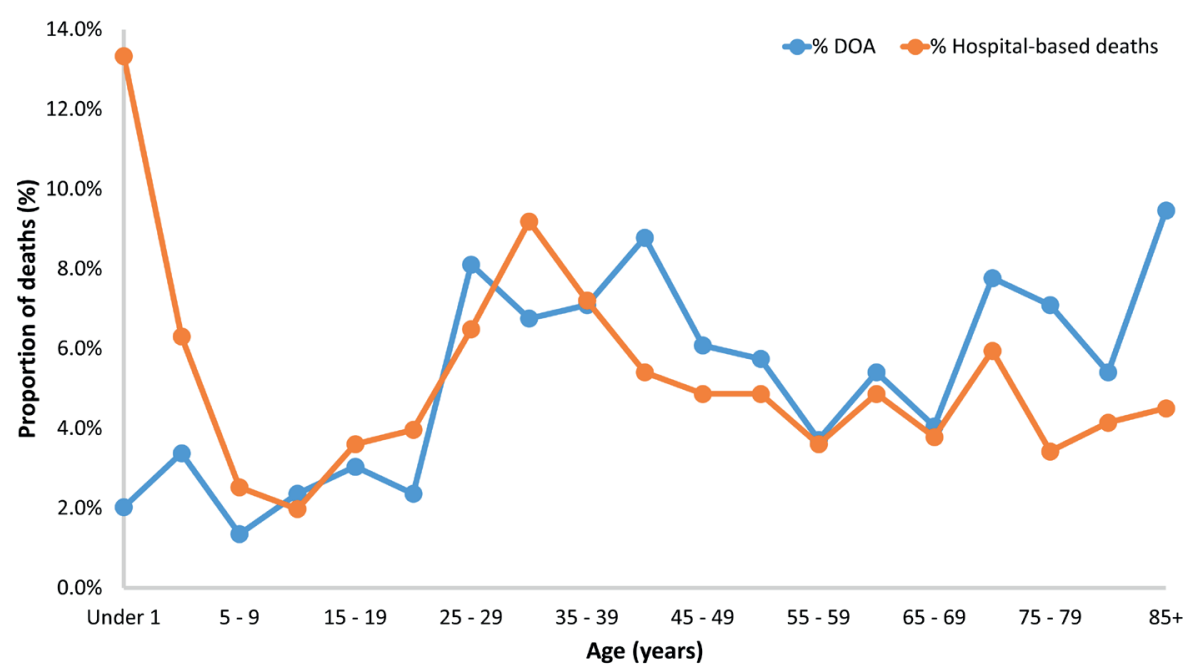

Supplemental figure. Age distribution of deaths by type of cadavers admitted to the two morgues at two referral hospitals in Kisumu County, 2019

Caption: The hospital-based deaths had a higher proportion of children aged $<5$ years than dead on arrival (DOA) cadavers. Age distribution was similar for the rest of the cadavers, except for the DOA group, which had proportionately more cadavers aged $\geq 70$ years than the hospitalbased group. 


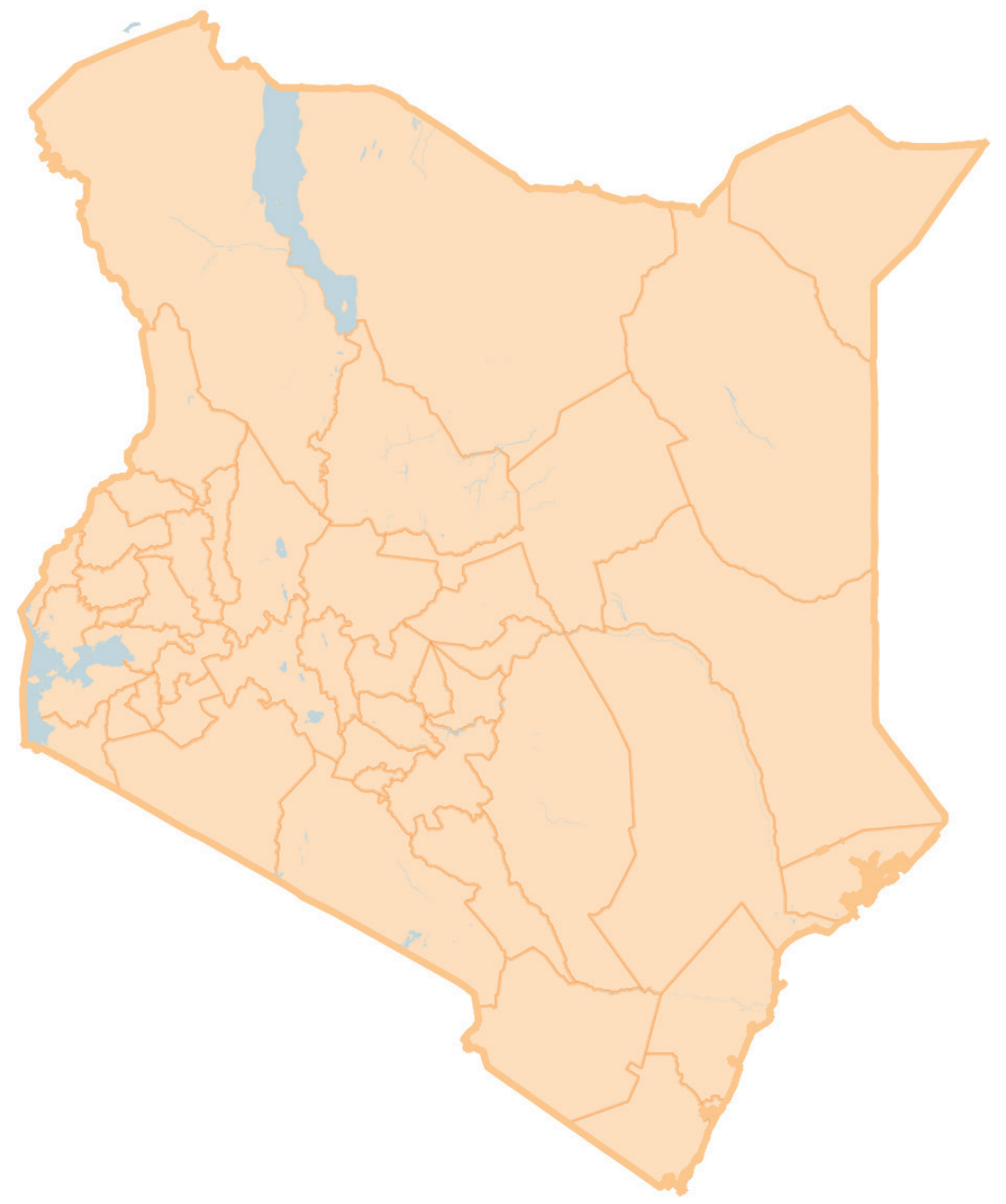




\section{Chapter 9}

\section{General discussion}




\section{General discussion}

This thesis presents an overview of the changing epidemiology of human immunodeficiency virus (HIV) in Kenya, with a focus on issues with measurement and modeling of epidemic and program outcomes. HIV presents various challenges to effective measurement and control, which help explain its persistence as a public health threat 39 years after the discovery of what would later be referred to as acquired immune deficiency syndrome (AIDS). These include the frequently asymptomatic or nonspecific nature of initial HIV infection, slow disease progression that can take years before clinical manifestation, and chronic, life-long infection, as well as the stigma associated with an incurable sexually-transmitted infection. After providing background on HIV epidemiology and surveillance in the introduction, this thesis describes the epidemiology of HIV in Kenya through a series of studies that together span the cascade of HIV care from infection to death.

In this final chapter, I discuss what was already known alongside what these studies add to the knowledge of HIV disease surveillance and control. Finally, I discuss implications on future research and control efforts for HIV in Kenya, East Africa and globally.

\section{Chapter 2. HIV incidence in western Kenya during scale- up of antiretroviral therapy and voluntary medical male circumcision: a population-based cohort analysis}

\section{What was known}

Based on HIV Prevention Trials Network (HPTN) 052, the clinical trial which found a minimum 96\% reduction in transmission of HIV infection in serodiscordant couples due to antiretroviral treatment (ART) use (1), the scale-up of early ART was expected to lead to reduced HIV incidence by suppressing viral load in patients on treatment and reducing the risk of onward transmission. Furthermore, prior studies had demonstrated that voluntary medical male circumcision (VMMC) could reduce the risk of HIV acquisition in males by approximately $60 \%(2-4)$. Models of these two interventions' scale-up led to predictions that their widespread implementation in sub-Saharan Africa would lead to significant reductions in population-level incidence $(5,6)$.

From 2007 onwards, VMMC had been scaled up in traditionally non-circumcising ethnic groups throughout sub-Saharan Africa, including in Kenya. In Kenya, over 1.4 million circumcisions were conducted from 2009-16 (7), and estimates of coverage reached $100 \%$ in some age bands in priority counties in western Kenya (8). 
Antiretroviral treatment coverage had also been widely scaled up, reaching 424,000 patients in the six counties of the former Nyanza province in western Kenya by the end of 2017 (9). While national surveys indicated there might have been a modest decrease in HIV incidence among adults at the national level from 2007 to 2012, these studies could not provide reliable sub-national incidence estimates (10).

\section{What this thesis adds}

The health demographic and surveillance system located in Gem sub-county, Siaya County, western Kenya, provides a platform for assessing trends in HIV incidence and coverage of HIV interventions. Although the system does not include HIV testing or behavioral questions as part of the underlying demographic census, a nested home-based counseling and testing program linked to the demographic platform at the individual level allows for longitudinally constructing participant profiles including change in HIV serostatus over time, which in turn allows for estimation of HIV incidence within the population.

This study found that HIV incidence had fallen significantly from 2010 to 2016. It also found that prevalence among 15-24 year olds had fallen, consistent with a reduction in incidence. Nonetheless, the incidence at the end of the period was still well above elimination targets, indicating that very high levels of both VMMC and ART may be required to reach incidence targets in the absence of other major changes in HIV prevention behaviors. The study demonstrated the value of direct HIV incidence estimation in high burden populations that are disproportionately affected by HIV and will thus have a disproportionate influence on the control of the epidemic at the national level. Such studies can also help relate changes in incidence with scale-up of prevention interventions that may not be apparent in national incidence surveillance.

\section{Chapter 3. Evolution of sub-national HIV estimates for a high- HIV-burden region in Kenya}

\section{What was known}

Global health initiatives are increasingly evaluated based on modeled estimates of disease burden $(11,12)$. HIV program targets have been refined to greater and greater levels of specificity over the years. The President's Emergency Plan for AIDS Relief (PEPFAR) country operations plan guidance for fiscal year 2019 (13) required dividing targets into five-year age groups by sex, resulting in 24 age-sex bands and setting targets for each of these bands per health facility. In Kenya, PEPFAR reported supporting 2,865 health facilities with patients currently receiving ART in September 2019, suggesting at least 68,760 targets were set just 
for this indicator in this year in Kenya alone. In 2020, PEPFAR's guidance relaxed this targeting requirement to require just setting the 24 age-sex band targets at the sub-national level, resulting in up to 960 separate targets for patients receiving ART across the 40 Kenyan counties that PEPFAR will support in 2021, but the age/sex/ site reporting requirement remains.

While modeling approaches are continuously refined, the primary data used to develop the models that inform these increasingly precise targets are relatively stable over time, consisting of national seroprevalence surveys every five years, data on numbers of beneficiaries, and prevalence in defined populations such as pregnant women attending antenatal care (ANC). Hence, in addition to identifying new sources of information to refine estimates, continually improving the models themselves and reconciling them with other information sources is of utmost importance.

According to official HIV estimates for Kenya based on the Spectrum model, an estimated 1.5 million people were living with HIV in 2017 (9). The Nyanza region in western Kenya, which borders Lake Victoria, accounted for $38 \%$ of prevalent HIV infections and a similar proportion of national unmet need for treatment in 2015. However, other program data were consistent with much higher treatment coverage. For example, the yield of new positives in HIV testing programs in the region was relatively low (about 1\%), whereas adult HIV prevalence was estimated at $16-21 \%$ throughout the region (14). This gap between testing yield and HIV prevalence suggests that most HIV-infected persons may have already been identified.

\section{What this thesis adds}

The Spectrum suite of mathematical models is updated regularly to respond to changing requirements and knowledge about HIV transmission dynamics (15). This study summarizes the model's application to Kenya with a focus on subnational estimation and how these estimates evolved through three cycles of models from 2015-17. The paper shows that improving the fit of the model to available demographic data in Nyanza, where out-migration of working-age adults is high, and inclusion of routine ANC seroprevalence data in the model led to more plausible fits. The paper also compared the trends in routine ANC to a small-area population-based cohort within the region of interest.

The paper highlights the sensitivity of model-based estimates to how the models are applied and adjusted, and thus the importance of triangulating their output to local data sources, where available. It also showed that rather than having moderate to low 
performance against the treatment cascade compared to the rest of the country, the performance was likely to be above average over the period of study. The 2018 Kenya Population-based HIV Impact Assessment (KENPHIA), released after this study, found ART coverage estimates in this region that validated these findings (16).

\section{Chapter 4. Equity of antiretroviral treatment use in high HIV burden countries: Analyses of data from nationally- representative surveys in Kenya and South Africa}

\section{What was known}

The Fast-Track 90-90-90 targets, announced by the Joint United Nations Programme on HIV/AIDS (UNAIDS) on World AIDS Day 2014, refocused global efforts on rapidly achieving a level of program coverage that could lead to epidemic control, reducing new infections while also preventing deaths among people living with HIV (17). UNAIDS projected that annual HIV infections and AIDS-related deaths would fall by $90 \%$ by 2030 , and 21 million AIDS-related deaths and 28 million new infections would be averted by 2030 through rapid scale-up of treatment versus maintaining 2013 coverage levels of $38 \%$ among adults and $24 \%$ among children. However, there were large disparities in ART access within and across regions, and it was not known how easily disadvantaged populations could be reached with treatment. While global initiatives held promise to remove supply-side barriers to antiretrovirals, questions remained about supply-side issues that could block efforts to expand ART rapidly to reach high coverage levels. Surveys in Kenya and South Africa had included questions on ART status and testing for antiretroviral (ARV) exposure, which allowed for estimation of ART coverage by demographic and other factors in these countries and exploration of equity in ART access and the evolving picture of ARV access in two higher-burden countries in sub-Saharan Africa.

\section{What this thesis adds}

The study estimated both changes in ART use over five years of national program expansion and looked at patterns of ART use by sociodemographic factors to assess equity of access. The study found significant increases in ART use from 2007-12 and 2008-12 in Kenya and South Africa, respectively. In Kenya, ART coverage among all HIV-infected persons increased from $29.3 \%$ to $42.5 \%$ from 2007 to 2012, while in South Africa, it increased from 17.3\% to 30.3\% from 2008 to 2012. Although in South Africa it seemed disparities in ART access had decreased over the period, there was evidence of increasing disparities by residency and household wealth in Kenya. Younger age was strongly associated with ART non-use in both countries, as was illicit drug use, reaffirming the need to ensure young people and key populations have access to testing and treatment. 


\section{Chapter 5. Use of viral load to improve survey estimates of known HIV-positive status and antiretroviral treatment coverage}

\section{What was known}

Estimating program coverage in terms of the proportion of people living with HIV who are infected and accessing treatment relies on population-based survey estimates in high HIV-burden countries due to the feasibility of obtaining nationally-representative population samples and the lack of robust case reporting systems in these countries. However, like other self-reported information on sensitive health topics, self-reported indicators of HIV status are likely subject to social desirability and recall biases (18). Blood-based tests for the presence of antiretroviral drugs are highly specific and sensitive for recent ARV drug exposure (19), thus testing blood for the presence of ARVs during surveys can improve estimates, though it imposes increased costs, complexity and time from collection to results.

While those on ART should generally have suppressed viral loads, it is not clear to what degree undetectable viral load (UVL) could be used as a proxy for ART use to adjust estimates of ART coverage and knowledge of status. Furthermore, as countries approach the 90-90-90 and 95-95-95 targets, quickly obtaining precise estimates becomes critical; hence leveraging additional biomarkers to increase precision, reduce cost or turnaround time is worth exploration.

\section{What this thesis adds}

This study used data collected in the 2012 Kenya AIDS Indicator Survey to analyze the impact of adjustments to self-reported HIV status using biomarkers for ARV exposure and viral load suppression separately and in combination. The study showed that upward adjustments of approximately 10 percentage points with ARV or 15 percentage points with UVL (17 points with both) versus self-report alone were seen in this survey. The UVL adjustments were generally higher than ARV adjustments. Adjustments were similar across demographic bands except for young people who saw greater adjustments for both ARV and UVL versus self-report.

The use of UVL is subject to limitations. Elite controllers would also have suppressed viral load in the absence of treatment and thus would result in biased estimates when UVL is used to adjust HIV status; however, the practical importance of this is limited by the rarity of elite control. Undetectable viral load may also capture some individuals who are 'on ART' from a program perspective but did not have detectable ARV exposure, for example, if they are on a less common regimen 
not tested for in the survey ARV panel, or if their poor adherence leads to drug levels falling below the level of detection. Thus, a combined method using both biomarkers may be the most promising approach, where the inclusion of ARV testing is feasible.

\section{Chapters 6-8. HIV-associated mortality}

\section{What was known}

Before the advent of effective treatment, HIV was responsible for significant mortality in countries with a high prevalence of HIV infection, leading to observable demographic changes and readily apparent increases in hospitalization and death due to AIDS. The widespread availability of ARVs has changed that, but most people living with HIV are neither followed through prospective surveillance nor covered by population registries, which would ensure their cause of death is linked to their HIV status. Improved vital registration, unique identification, and individual case-based HIV surveillance systems should eventually allow for a more comprehensive assessment of death among people living with HIV. In the meantime, mortuary-based HIV surveillance can provide useful information about avoidable causes of death among people living with HIV. Also, HIV prevalence among deaths can help improve model-based epidemic estimates. Studies in Botswana, Côte d'Ivoire, Mozambique and the United States have all assessed HIV in mortuaries, though focusing on different research questions, populations and utilizing different methods (20-23).

\section{What this thesis adds}

Given the relatively high estimated adult ART coverage at the time of the Nairobi survey (74\% in 2015), the Spectrum mathematical model predicted that $11.4 \%$ of deaths among adults aged 15+ would be HIV-positive. The adjusted HIV positivity for adult deaths in Nairobi from the study was 20.9\% (Chapter 6). The HIV prevalence differed significantly between the two study mortuaries; $12.6 \%$ at the city mortuary, which serves smaller health facilities and receives the majority of 'police cases,' and 23.2\% at Kenyatta National Hospital, which is a national referral hospital seeing many complex medical cases. Documentation of HIV status was poor among the HIV-infected deceased, with over half lacking evidence of diagnosis, and half of those with a known HIV-positive status being diagnosed during the hospitalization preceding death. Evidence of ART use was also limited-of those with known HIV status at time of death, approximately one in four had unknown treatment status, and one in four were not on treatment. This likely reflects both the increased risk of mortality among those who are not accessing HIV diagnosis and treatment services as well as the challenges of integrating demographic and health information across a 
fragmented health system. Despite ART restoring near-normal life expectancy, and the relatively high ART coverage, the standardized mortality ratio (SMR) among the HIV infected versus the HIV uninfected was about four, with a population attributable fraction of 0.16 , suggesting significant avoidable adult mortality in Nairobi (Chapter 7).

The Kisumu study, conducted in a higher-HIV-prevalence setting, extended the Nairobi study in several important ways: 1) all ages were included rather than just adults and adolescents aged 15 years and older, 2) oral fluid testing was piloted, and 3) where available, existing HIV status information was utilized. The study found that nearly a quarter $(23.1 \%)$ of deaths of all ages were due to HIV/AIDS. The HIV mortality rate was 251 per 100,000 population. The study also found high overall rates of mortality due to non-communicable disease (516 per 100,000) and communicable, perinatal, maternal and nutritional causes (513 per 100,000 population), providing evidence that western Kenya may be experiencing a 'stalled' epidemiological transition from infectious to non-infectious causes of death. There were significant discrepancies between the underlying cause of death notified by the health system and that established using study procedures (Chapter 8).

\section{Implications of this thesis for measurement and control of HIV}

Modeling studies (24) followed by clinical trials which showed a large and significant impact of biomedical prevention $(1,25)$ resulted in a large push to expand treatment and VMMC in high HIV-prevalence countries. Subsequent large community trials have shown that it is possible to obtain high levels of HIV diagnosis and ART coverage with concomitant reductions in the HIV incidence of between $20-30 \%$ over three years (26). In Kenya, the 2018 KENPHIA found $72 \%$ adult population viral suppression, indistinguishable from the UNAIDS target of $73 \%$, yet adult HIV incidence was $0.14 \%$, more than an order of magnitude greater than the elimination target of 1 per 10,000. While the further expansion of diagnosis and treatment of people living with HIV should further reduce HIV transmission, other complementary approaches to prevention are still required. Treating HIV as a traditional sexually transmitted infection, with case reporting and contact tracing are also necessary but have only recently begun to be scaled up (27). Applying research methods such as testing for recent HIV infection and phylogenetic analysis to identify clusters of transmission for disease control may also be beneficial $(28,29)$ and need to be evaluated in different epidemic settings. Population mobility and traceability are other challenges in many high-prevalence settings, including in Kenya. Fragmented health and development programs in 
the absence of unique identifiers that have difficulty linking interventions to individuals across space and time pose severe challenges to measuring outcomes and providing comprehensive services (30).

Population-based surveys will continue to be essential tools for HIV surveillance for the foreseeable future. Better use of available biomarkers should increase the precision of estimates of knowledge of HIV status and ART use. Interpretation of viral load-adjusted estimates would benefit from better characterization of the prevalence of elite control in countries with generalized epidemics and with different mixes of circulating HIV subtypes. While the validity of survey laboratory measures has been an ongoing topic of research (31-33), less attention has been paid to ensuring the validity of self-reported questionnaire data, for example, by following guidelines on question development (34). AIDS indicator survey questions are often derived from expert opinion, historical use or international norms rather than behavioral research into their validity. There is ample evidence that researchers' and respondents' understanding of questions often differs, to the detriment of the interpretation of results (35). Additional effort to ensure the validity of key self-reported measures such as knowledge of HIV-positive status and time since diagnosis is needed. Despite the large investments in populationbased surveys to measure knowledge of HIV status among people living with HIV, UNAIDS relies on the indirect estimation of this indicator (36), a tacit acknowledgment of this reality.

While population-based surveys continue to be critical for monitoring progress in HIV control, in countries such as Kenya with decreasing HIV prevalence and incidence recorded over time, it will be increasingly difficult to obtain precise measures of HIV cascade indicators with national population surveys, more so for subnational or subgroup estimates needed to target interventions. Furthermore, surveys are based on probabilistic sampling; hence they do not identify a significant number of individuals in need of intervention due to recent infection, unknown HIV status, ART non-use or unsuppressed viral load. Strengthening unique identifiers and integrated health information systems that can support longitudinal HIV case surveillance (30), on which recent infection surveillance and other approaches can be layered, will be increasingly important.

In order to know whether ART programs are working as designed, more routine measurement of mortality among people living with HIV is needed. Progress on this front must proceed along two complementary avenues, a) ensuring the HIV status and cause of all deaths is determined and reported, and b) ensuring the ability to detect and report death among all people living with HIV. Furthermore, 
surveillance studies can and should be used to assess the burden of HIV mortality and gaps in diagnosis and treatment among deaths admitted to mortuaries. Novel minimally-invasive approaches, such as oral fluid sampling for HIV testing of decedents, may have a role to play as well.

\section{Recommendations}

While universal test and treat (UTT) trials demonstrated that universal testing and treatment of those diagnosed are both possible in high-HIV-burden settings, the relatively modest decreases in 3-year HIV incidence suggest that a UTT strategy will not be enough to rapidly achieve fewer new infections per year than deaths among those who are HIV-infected. Moreover, concerns about the cost of universal testing have limited its use in practice. Thus, novel (and traditional) prevention strategies beyond UTT tailored to the population are still needed.

The rapid scaling of traditional public health approaches such as contact tracing and partner notification shows promise, with the proportion of contacts that are newly positive in these programs generally greater than that seen with other testing modalities (37). These approaches should be expanded for HIV control, and their effectiveness should be evaluated comprehensively to see if their introduction results in more timely diagnosis of infection and prevention of onward transmission. In addition to the scale-up of case identification techniques, testing for recent infection and phylogenetic analysis of viral specimens from those newly diagnosed may also be useful tools for identifying clusters and controlling onward transmission.

Knowledge of status is ascertained in population-based surveys through self-report. More work can be done to ensure the validity of this measure. In addition, viral load is now routinely measured in population-based HIV surveys. This marker can improve estimates of knowledge of status and ART use by adjusting for those who do not report their known HIV status but are likely to know their status due to their suppressed viral load.

To monitor the true impact of treatment on mortality, mortality should be added to HIV surveillance systems. In addition to standardized reporting of mortality among patient cohorts, novel, minimally invasive methods such as oral fluid testing should be further assessed and potentially introduced in HIV mortality surveillance systems to help determine HIV status among decedents of unknown HIV status at the time of death. 
Population-based surveys are useful tools but will never replace case surveillance in terms of timeliness, precision, and direct applicability to programs. Surveillance systems must be developed to identify and control HIV transmission and manage the quality of the cascade of care in the future. For these systems to work well, we must continue to develop and strengthen unique identifiers and methods for coping with the lack of robust universal national identifiers. 


\section{References}

1. Cohen MS, Chen YQ, McCauley M, Gamble T, Hosseinipour MC, Kumarasamy N, et al. Prevention of HIV-1 infection with early antiretroviral therapy. N Engl J Med. 2011 Aug 11;365(6):493-505. doi: 10.1056/NEJMoa1105243

2. Auvert B, Taljaard D, Lagarde E, Sobngwi-Tambekou J, Sitta R, Puren A. Randomized, controlled intervention trial of male circumcision for reduction of HIV infection risk: The ANRS 1265 trial. PLoS Med. 2005;2(11):1112-22. doi: 10.1371/journal.pmed.0020298

3. Gray RH, Kigozi G, Serwadda D, Makumbi F, Watya S, Nalugoda F, et al. Male circumcision for HIV prevention in men in Rakai, Uganda: a randomised trial. Lancet. 2007;369(9562):657-66. doi: 10.1016/S0140-6736(07)60313-4

4. Bailey RC, Moses S, Parker CB, Agot K, Maclean I, Krieger JN, et al. Male circumcision for HIV prevention in young men in Kisumu, Kenya: a randomised controlled trial. Lancet. 2007;369(9562):643-56. doi: 10.1016/S0140-6736(07)60312-2

5. Eaton JW, Johnson LF, Salomon JA, Bärnighausen T, Bendavid E, Bershteyn A, et al. HIV treatment as prevention: Systematic comparison of mathematical models of the potential impact of antiretroviral therapy on HIV incidence in South Africa. Bartlett J, editor. PLoS Med. 2012 Jul 10;9(7):e1001245. doi: 10.1371/journal.pmed.1001245

6. Njeuhmeli $E_{1}$ Forsythe $S$, Reed J, Opuni M, Bollinger L, Heard N, et al. Voluntary medical male circumcision: Modeling the impact and cost of expanding male circumcision for HIV prevention in eastern and southern Africa. PLoS Med. 2011;8(11). doi: 10.1371/journal.pmed.1001132

7. PEPFAR. Annual VMMC results by operating unit. Panorama Spotlight. 2020 [cited 2020 Jul 25]. Available from: https://data.pepfar.gov/dashboards

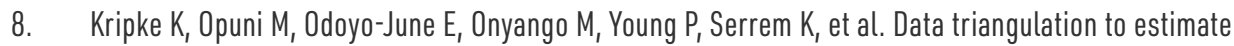
age-specific coverage of voluntary medical male circumcision for HIV prevention in four Kenyan counties. PLoS One. 2018;13(12). doi: 10.1371/journal.pone.0209385

9. National AIDS Control Council, National AIDS and STI Control Programme. Kenya HIV estimates report 2018. Nairobi; 2018.

10. National AIDS and STI Control Programme (NASCOP). Kenya AIDS indicator survey 2012: final report. Nairobi, Kenya: NASCOP; 2014. Available from: http://nacc.or.ke/wp-content/uploads/2015/10/ KAIS-2012.pdf

11. Boerma T, Victora $C_{\text {, Abouzahr }}$ C. Monitoring country progress and achievements by making global predictions: is the tail wagging the dog? Lancet. 2018 Apr 13;392(10147):607-9. doi: 10.1016/ s0140-6736(18)30586-5

12. Sharp A, O'Hagan R, Honermann B, Millett G. Setting targets for HIV. J Acquir Immune Defic Syndr. 2017 Dec;76(4):348-55. doi: 10.1097/QAl.0000000000001529

13. PEPFAR. PEPFAR 2019 country operational plan guidance for all PEPFAR countries. 2018. Available from: https://www.state.gov/wp-content/uploads/2019/08/PEPFAR-Fiscal-Year-2019-CountryOperational-Plan-Guidance.pdf

14. Muttai $H_{1}$ Guyah B, Musingila $P_{1}$ Achia $T_{1}$ Miruka F, Wanjohi S, et al. Development and validation of a sociodemographic and behavioral characteristics-based risk-score algorithm for targeting HIV testing among adults in Kenya. AIDS Behav. 2020; doi: 10.1007/s10461-020-02962-7 
15. Stover J, Glaubius R, Mofenson L, Dugdale CM, Davies M-A, Patten G, et al. Updates to the Spectrum/ AIM model for estimating key HIV indicators at national and subnational levels. AIDS. 2019 Dec;33:S227-34. doi: 10.1097/QAD.0000000000002357

16. National AIDS and STI Control Programme. KENPHIA 2018 preliminary report. Nairobi, Kenya; 2019. Available from: https://phia.icap.columbia.edu/wp-content/uploads/2020/02/KENPHIA-2018_ Preliminary-Report_final-web.pdf

17. UNAIDS. Fast-track: ending the AIDS epidemic by 2030. Geneva, Switzerland; 2014.

18. Johnson LF, Rehle TM, Jooste S, Bekker L-G. Rates of HIV testing and diagnosis in South Africa. AIDS. 2015; doi: 10.1097/QAD.0000000000000721

19. Koal T, Burhenne H, Römling R, Svoboda M, Resch K, Kaever V. Quantification of antiretroviral drugs in dried blood spot samples by means of liquid chromatography/tandem mass spectrometry. Rapid Commun Mass Spectrom. 2005 Nov 15;19(21):2995 3001. doi: 10.1002/rcm.2158

20. Ansari NA, Kombe AH, Kenyon TA, Hone NM, Tappero JW, Nyirenda ST, et al. Pathology and causes of death in a group of 128 predominantly HIV-positive patients in Botswana, 1997-1998. Int J Tuberc Lung Dis. 2002;6(1):55-63.

21. De Cock KM, Barrere B, Diaby L, Lafontaine MF, Gnaore E, Porter A, et al. AlDS--the leading cause of adult death in the West African City of Abidjan, Ivory Coast. Science. 1990;249(4970):793-6. doi: $10.1126 /$ science. 2167515

22. Menéndez $C$, Romagosa $C$, Ismail MR, Carrilho $C_{\text {, Saute }}$, 0 sman N, et al. An autopsy study of maternal mortality in Mozambique: The contribution of infectious diseases. PLoS Med. 2008;5(2):0220 6. doi: 10.1371/journal.pmed.0050044

23. Ramaswamy C, Ellman TM, Myers J, Madsen A, Sepkowitz K, Shepard C. Human immunodeficiency virus infection newly diagnosed at autopsy in New York City, 2008-2012. Open Forum Infect Dis. 2015 Dec;2(4):ofv146. doi: 10.1093/ofid/ofv146

24. Granich RM, Gilks CF, Dye C, De Cock KM, Williams BG. Universal voluntary HIV testing with immediate antiretroviral therapy as a strategy for elimination of HIV transmission: a mathematical model. Lancet (London, England). 2009;373(9657):48-57. doi: 10.1016/S0140-6736(08)61697-9

25. Cohen MS, Chen YQ, McCauley M, Gamble T, Hosseinipour MC, Kumarasamy N, et al. Antiretroviral therapy for the prevention of HIV-1 transmission. N Engl J Med. 2016;375(9):830-9. doi: 10.1056/ NEJMoa1600693

26. Lockman S, Holme MP, Makhema J, Bachanas P, Moore J, Wirth KE, et al. Implementation of universal HIV testing and treatment to reduce HIV incidence in Botswana: the Ya Tsie study. Curr HIVIAIDS Rep. 2020; doi: 10.1007/s11904-020-00523-0

27. Frieden TR, Foti KE, Mermin J. Applying public health principles to the HIV epidemic-how are we doing? N Engl J Med. 2015;373(23):2281-7. doi: 10.1056/NEJMms1513641

28. Rice BD, de Wit M, Welty S, Risher K, Cowan FM, Murphy G, et al. Can HIV recent infection surveillance help us better understand where primary prevention efforts should be targeted? Results of three pilots integrating a recent infection testing algorithm into routine programme activities in Kenya and Zimbabwe. J Int AIDS Soc. 2020;23(S3):9-17. doi: 10.1002/jia2.25513 
29. Hassan AS, Pybus OG, Sanders EJ, Albert J, Esbjörnsson J. Defining HIV-1 transmission clusters based on sequence data. AIDS. 2017;31(9):1211 22. doi: 10.1097/QAD.0000000000001470

30. Waruru A, Natukunda A, Nyagah LM, Kellogg TA, Zielinski-Gutierrez E, Waruiru W, et al. Where no universal health care identifier exists: comparison and determination of the utility of score-based persons matching algorithms using demographic data. JMIR Public Heal Surveill. 2018;4(4):e10436. doi: $10.2196 / 10436$

31. Mishra V, Barrere $B$, Hong $R$, Khan S. Evaluation of bias in HIV seroprevalence estimates from national household surveys. Sex Transm Infect. 2008;84 Suppl 1:i63-i70. doi: 10.1136/sti.2008.030411

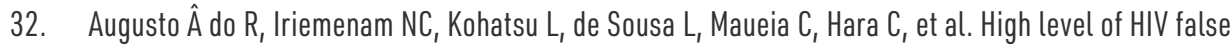
positives using ElA-based algorithm in survey: Importance of confirmatory testing. Kumar $S$, editor. PLoS One. 2020 Oct 22;15(10):e0239782. doi: 10.1371/journal.pone.0239782

33. Bärnighausen T, Bor J, Wandira-Kazibwe S, Canning D. Correcting HIV prevalence estimates for survey nonparticipation using Heckman-type selection models. Epidemiology. 2011;22(1):27 35. doi: 10.1097/EDE.0b013e3181ffa201

34. Citro CF. Principles and practices for a federal statistical agency: Sixth edition. National Academies Press; 2017. 1-198 p. doi: 10.17226/24810

35. Mooney AC, Campbell CK, Ratlhagana M-J, Grignon JS, Mazibuko S, Agnew E, et al. Beyond social desirability bias: investigating inconsistencies in self-reported HIV testing and treatment behaviors among HIV-positive adults in North West Province, South Africa. AIDS Behav. 2018;22(7):2368-79. doi: 10.1007/s10461-018-2155-9

36. Maheu-Giroux M, Marsh K, Doyle CM, Godin A, Lanièce Delaunay C, Johnson LF, et al. National HIV testing and diagnosis coverage in sub-Saharan Africa: A new modeling tool for estimating the 'first 90' from program and survey data. AIDS. 2019;33(January 2019):S255-69. doi: 10.1097/ QAD.0000000000002386

37. World Health Organization. Guidelines on HIV self-testing and partner notification. Supplement to consolidated Guidelines on HIV testing services. 2016. Available from: https://www.who.int/hiv/pub/ self-testing/hiv-self-testing-guidelines/en/ 


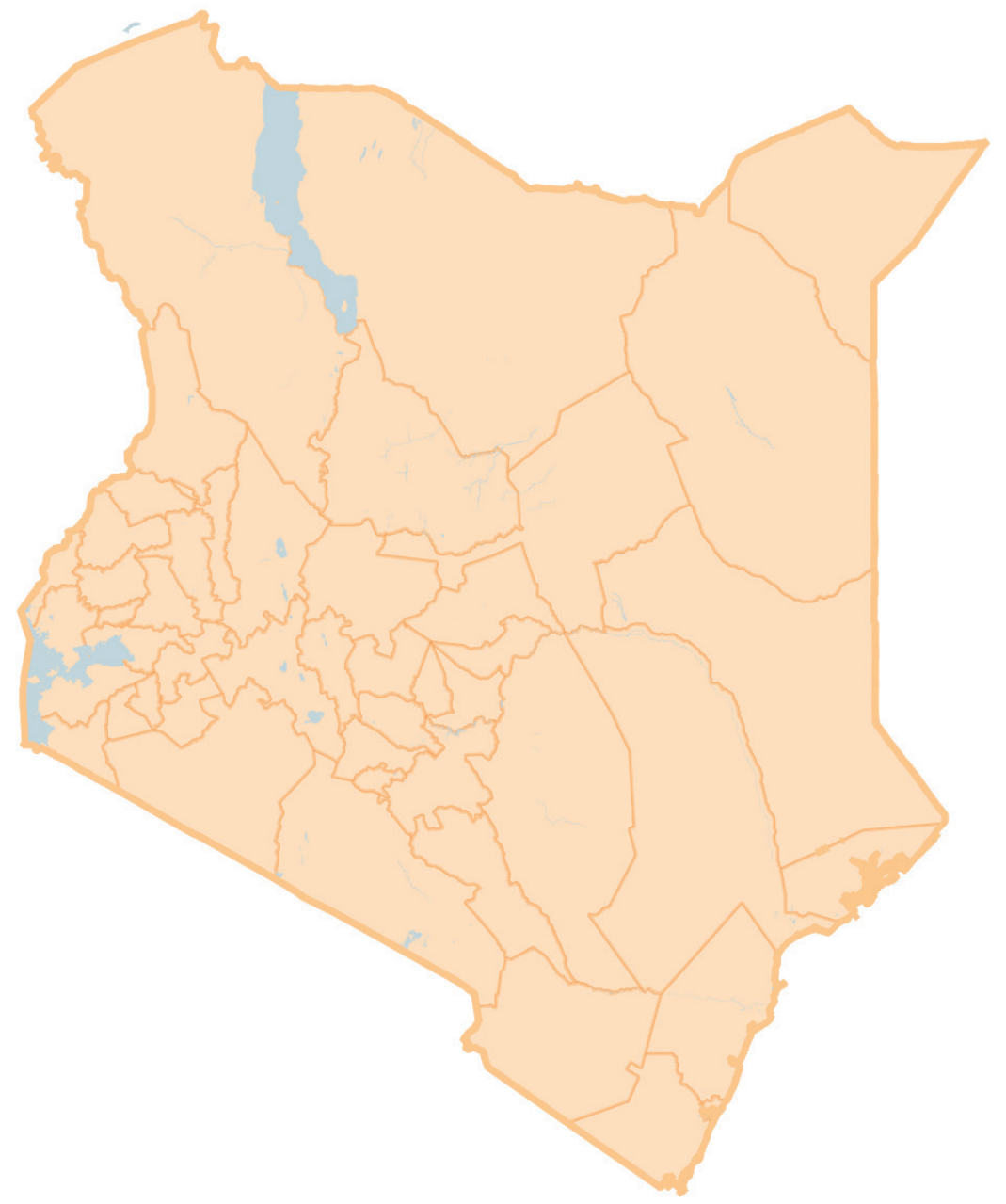


Appendices 


\section{Summary}

Human immunodeficiency virus (HIV) presents various challenges to effective measurement and control, which help explain its persistence as a public health threat nearly 40 years after the discovery of what would later be referred to as acquired immune deficiency syndrome (AIDS). These include the frequently asymptomatic or nonspecific nature of initial HIV infection, slow disease progression that can take years before clinical manifestation, and chronic, life-long infection, as well as the stigma associated with an incurable sexually transmitted infection. CD4+ T-cell counts have been used to stage HIV disease progression; later, viral load testing based on the polymerase chain reaction became the preferred way to monitor treatment failure. This thesis presents an overview of the epidemiology of HIV in Kenya, with a focus on issues with measurement and modeling of incidence, mortality and indicators of program achievement.

Chapter 1 provides an overview of virological, clinical and surveillance aspects of HIV as well as a historical summary of global attempts to monitor and control the epidemic. A lentivirus of the retroviridiae family, HIV has expanded worldwide over nearly 40 years since its discovery, with 38 million people infected in 2019. New HIV infections peaked globally in 1998 at 2.8 million per year; In 2019, 38 million people were living with HIV, with over half of those infected residing in East and southern Africa. In the same year, there were an estimated 690 thousand deaths due to HIV. In 2014, the Joint United Nations Programme on HIV/AIDS (UNAIDS) launched the Fast-Track approach to ensure $90 \%$ of those who are HIV infected know their status, $90 \%$ of those who know their HIV-positive status are on antiretroviral treatment, and $90 \%$ of those on treatment are virally suppressed by 2020 , increasing to $95-95-95$ by 2030 as part of the Sustainable Development Goal to end HIV as a public health threat by 2030 .

HIV can be monitored through a testing and treatment cascade that starts with diagnosis, followed by antiretroviral treatment (ART) initiation, and finally, viral suppression. These three stages are embodied in the UNAIDS 90-90-90 targets. Cohort analyses can monitor the proportion of patients that make it to subsequent stages, hence providing an indicator of program success. However, these indicators can also be monitored cross-sectionally, which provides a more rapid assessment subject to limitations. Longer-term measures of program impact, and hence epidemic control, include HIV incidence and mortality, both of which present unique challenges. In addition to the traditional cohort-based approaches to 
measuring incidence, various modeling approaches and biomarker approaches have been developed. Estimating HIV mortality requires either following HIV-infected persons until death or ascertaining HIV status at the time of death, combined with determining the underlying cause of death. All of these tasks present challenges such as loss to follow-up of patients on treatment and lack of training of clinicians on death certification, and lack of standardization of cause of death data. Ultimately one hopes to achieve a state of epidemic control, which has been defined multiply in terms of reductions in incidence and mortality or reductions in the ratio of new infections to deaths or new infections to prevalent infections.

Tracking the AIDS epidemic has evolved from disease-focused AIDS case reporting to sentinel antenatal clinic (ANC) HIV surveillance, followed by population-based behavioral and serological surveys, to HIV case surveillance. These surveys have evolved from identifying incident disease and prevalent infection to measuring the cascade of care among the HIV-infected population, as treatment has become a greater focus for preventing mortality and onward transmission.

Chapter 2 presented trends in HIV incidence in western Kenya, a high HIV prevalence region, during a period of rapid expansion of HIV treatment and voluntary medical male circumcision, the two most effective biomedical forms of HIV prevention. The study demonstrated the value of estimating HIV incidence in high-burden populations that are both disproportionately affected by HIV and will thus have a disproportionate influence on the control of the epidemic at the national level. Chapter 3 summarized the Spectrum HIV epidemic model's application to Kenya, with a focus on sub-national estimation using ancillary tools, and how these estimates evolved through three cycles of models from 2015-17. The paper showed that improving the fit of the model to available demographic data in Nyanza, where out-migration of working-age adults is high, and the inclusion of routine ANC seroprevalence data in the model, led to more plausible fits. The paper also compared the trends in routine ANC to a small-area population-based cohort within the region of interest. Chapter 4 investigated trends in ART use in Kenya and South Africa between 2007 and 2012. The study found significant increases in ART use from 2007-12 and 2008-12 in Kenya and South Africa, respectively. While in South Africa it seemed disparities in ART access had decreased over the period, in Kenya there was evidence of increasing disparities by residency and household wealth. Younger age was strongly associated with ART non-use in both countries, as was drug use, reaffirming the need to ensure young people and key populations have access to testing and treatment. Chapter 5 used data collected in the 2012 Kenya AIDS Indicator Survey to analyze the impact of 
adjustments to self-reported HIV status using biomarkers for ARV exposure and viral load suppression, separately and in combination. The study showed that in this survey, adjustments of approximately 10 percentage points with antiretrovirals or 15 percentage points with undetectable viral load (17 points with both) versus self-report alone were seen. The undetectable viral load adjustments were generally higher than antiretroviral adjustments. The study described in Chapters 6 and 7 was conducted in mortuaries in Nairobi, Kenya, in early 2015. The adjusted HIV positivity for adult deaths in Nairobi from the study was $20.9 \%$, higher than predicted from models. Documentation of HIV status was poor among the HIVinfected deceased, with over half lacking evidence of diagnosis. Half of those with known HIV-positive status were diagnosed during hospitalization preceding death. Evidence of ART use was also limited-among those diagnosed prior to death, approximately one in four had unknown treatment status, and one in four were not on treatment. In the higher HIV-prevalence region of Kisumu, 23.1\% of deaths of all ages were due to HIV/AIDS, with an HIV mortality rate of 251 per 100,000 population. There were significant discrepancies between the underlying cause of death notified by the health system and the underlying cause established using study procedures. 


\section{Key recommendations for HIV epidemic monitoring and control}

1. Given that universal test and treat will not be enough to rapidly suppress incidence to a point where epidemic control is reached, a new focus on a diversity of prevention strategies is needed to more rapidly reduce the number of new infections below the number of deaths to people living with HIV

2. Traditional public health approaches such as contact tracing and partner notification should be expanded for HIV control, and their effectiveness should be evaluated

3. The usefulness of recency testing and phylogenetic analysis for routine surveillance programs to quickly identify and control clusters of new infection should be assessed

4. More research into the accurate ascertainment of self-reported knowledge of HIV-positive status is needed given its importance as the first step in the testing and treatment cascade

5. Viral load measures should be used as an adjunct biomarker to improve (or simplify) survey estimates of ART coverage

6. Routine mortality surveillance should be implemented in order to monitor the real impact of treatment on morbidity and mortality

7. Novel, minimally invasive methods such as oral fluid testing should be further assessed and potentially introduced in HIV mortality surveillance systems

8. Surveys will never replace the need for HIV case surveillance. Surveillance systems should be developed to identify and control HIV transmission and manage the quality of care along the cascade.

9. Continued development and strengthening of unique identifiers and methods for coping with the lack of robust unique identifiers to support case surveillance are required 


\section{Dutch summary}

\section{Het meten van hiv-incidentie, mortaliteit en de cascade van hiv-zorg in Kenia}

Het humaan immunodeficiëntievirus (HIV) zorgt voor verschillende uitdagingen ten opzichte van een effectieve meting en beheersing; dit verklaart de hardnekkigheid de bedreiging die het na bijna 40 jaar sinds de ontdekking voor de volksgezondheid is en wat later als het Acquired Immune Deficiency Syndrome (AIDS) bekend zou worden. Dit zijn onder meer de regelmatig a-symptomatische of niet-specifieke aard van de eerst HIV-infectie, de langzame voortgang van de ziekte die jaren kan duren voordat er zich een klinische manifestatie voordoet, en chronische levenslange infectie en ook het stigma geassocieerd met een ongeneeslijk seksueel overdraagbare infectie. Er werden tellingen van CD4+ T-cel gebruikt om de voortgang van de HIV-ziekte te ensceneren; later kreeg het testen van de virale belasting gebaseerd op de polymerase-kettingreactie de voorkeur om het mislukken van behandelingen te monitoren. Deze thesis bevat een overzicht van de epidemiologie van HIV in Kenia, gefocust op de problemen met meten en het modelleren van incidentie, mortaliteit en indicatoren van de prestaties van het programma.

Hoofdstuk 1 bevat een overzicht van de virologische, klinische en surveillance aspecten van HIV en ook een historische samenvatting van wereldwijde pogingen om de epidemie te monitoren en te beheersen. Als lentivirus van de retroviridae-familie, heeft HIV zich de afgelopen 40 jaar sinds haar ontdekking wereldwijd verspreidt, en heeft het 38 miljoen mensen geïnfecteerd in 2019. Nieuw HIV-infecties bereikte wereldwijd een piek in 1998 met 2,8 miljoen per jaar; in 2019 waren er 38 miljoen mensen met HIV, waarvan meer dan de helft van de geïnfecteerden in Oost- en Zuidelijk Afrika leven. In dat jaar zijn er naar schatting 690 duizend mensen overleden aan HIV. In 2014 lanceerde de Joint United Nations Programme on HIV/AIDS (UNAIDS) de Fast-Track benadering om ervoor te zorgen dat $90 \%$ van hen die met HIV zijn geïnfecteerd hun status te weten zouden komen, en dat 90\% van hen die weten van hun HIV-positieve status een antiretrovirale behandeling krijgen, en dat 90\% van hen die deze behandeling krijgen viraal onderdrukt zijn tegen 2020, toenemend tot 95-95-95 tegen 2030 als onderdeel van het Sustainable Development Goal om HIV tegen 2030 als bedreiging voor de volksgezondheid te elimineren. 
HIV kan worden gemonitord door middel van een cascade van testen en behandelingen die begint met een diagnose gevolgd door een antiretrovirale behandeling (ART), en uiteindelijk, virale onderdrukking. Deze drie fasen worden belichaamd in de UNAIDS 90-90-90 doelen. Analyse in cohort kan het aandeel patiënten die de volgende fases halen monitoren, en derhalve een indicatie geven van het succes van het programma. Deze indicatoren kunnen echter ook in meerdere secties worden gemonitord waardoor er een snellere schatting onderhevig aan beperkingen wordt gegenereerd. Metingen op de langere termijn van de impact van het programma, en dus de beheersing van de epidemie zijn inclusief HIV-incidentie en mortaliteit, waarvan beide unieke uitdagingen bieden. Naast de traditionele op groepsonderzoeken gebaseerde benaderingen om incidenties te meten, zijn er verschillende benaderingen qua modellering en benaderingen qua biomarkers ontwikkeld. Voor het schatten van de HIV-mortaliteit is het volgen van met HIV geïnfecteerde personen tot overlijden of het vaststellen van de HIV-status bij het overlijden nodig, gecombineerd met het vaststellen van de onderliggende doodsoorzaak. Al deze taken brengen hun eigen moeilijkheden met zich mee zoals het verlies van follow-up patiënten die een behandeling ondergaan en een gebrek aan training van artsen op het gebied van het maken van overlijdensverklaringen, en een gebrekkig standaardisatie van de data van de doodsoorzaak. Uiteindelijk hoopt men een toestand te bereiken waarin de epidemie onder controle is gebracht en welke in meerdere reducties in incidentie en mortaliteit is gedefinieerd of in reducties in de ratio van nieuwe infecties ten opzichte van overlijdens of nieuwe infecties ten opzichte van heersende infecties.

Het volgen van de AIDS-epidemie heeft zich ontwikkeld van op ziekte gefocuste AIDS casusmeldingen tot volledige antenatale zorg (ANC) HIV-surveillance, gevolgd door op de bevolking gebaseerd gedrag en serologische onderzoeken tot HIV-casus-surveillance. Deze onderzoeken hebben zich ontwikkeld van het identificeren van incidentziekte en heersende infectie tot het meten van de cascade aan zorg onder de door HIV geïnfecteerde bevolking, aangezien er meer gefocust wordt op behandeling ter voorkoming van mortaliteit en verdere transmissie.

In hoofdstuk 2 worden trends in HIV-incidentie in westelijk Kenia, een regio waar HIV erg heerst, beschreven gedurende een periode van snelle uitbreiding van de HIV-behandeling en vrijwillige medische besnijden van mannen, de twee meest effectieve biomedische vormen voor het voorkomen van HIV. Het onderzoek toonde de waarde van het schatten van HIV-incidentie in zwaar getroffen bevolkingen aan die buitenproportioneel getroffen zijn door HIV en dus een buitenproportionele invloed hebben op het onder controle brengen van de epidemie op nationaal niveau. 
Hoofdstuk 3 bevat een samenvatting van het toepassen van het model van de Spectrum HIV-epidemie in Kenia, en is daarbij gefocust op subnationale schatting met behulp van aanvullende middelen en hoe deze schattingen zich ontwikkelden door de drie modelcycli in de periode van 2015-17. Het onderzoek toonde aan dat het verbeteren van de aansluiting van het model op de beschikbare demografische data in Nyanza, waar de emigratie van volwassenen in de werkzame leeftijd hoog is, en het meenemen van routine ANC seroprevalentie data in het model, tot geloofwaardigere aansluitingen leidden. Het onderzoek vergeleek ook trends in routine ANC met bevolkingsonderzoek in een klein gebied binnen de regio die werd onderzocht. In hoofdstuk 4 worden trends in het gebruik van ART in Kenia en Zuid-Afrika tussen 2007 en 2012 onderzocht. Het onderzoek ontdekte significante toenames in het gebruik van ART tussen 2007-12 en 2008-12 in respectievelijk Kenia en Zuid-Afrika. Hoewel het erop leek dat de discrepanties in het gebruik van ART gedurende de periode in Zuid-Afrika was afgenomen, was er bewijs van een toenemende discrepantie per residentie en huishoudelijke welvaart in Kenia. In beide landen werd de jongere leeftijd sterk geassocieerd met ART niet-gebruik, net als het gebruik van drugs, waardoor de noodzaak werd bevestigd om jonge mensen en belangrijke bevolkingsgroepen toegang te laten hebben tot testen en behandeling. In hoofdstuk 5 staat data die werd verzameld tijdens de Kenya AIDS Indicator Survey uit 2012 om de impact van aanpassingen bij zelfgerapporteerde HIV-status te analyseren met behulp van biomarkers voor blootstelling aan ARV en onderdrukking van virale belasting, zowel apart als in combinatie. Het onderzoek toonde aan dat in dit onderzoek aanpassingen van ongeveer 10 procentpunten met antiretroviralen of 15 procentpunten met niet vast te stellen virale belasting (17 punten bij beide) versus zelfrapportage werden waargenomen. De aanpassingen van de niet vast te stellen virale belastingen waren in het algemeen hoger dan de antiretrovirale aanpassingen. Het onderzoek dat wordt beschreven in hoofdstukken 6 en 7 werd begin 2015 uitgevoerd in mortuaria in Nairobi, Kenia. Uit het onderzoek bleek dat de aangepaste HIV-positiviteit voor overleden volwassenen in Nairobi $20,9 \%$ hoger was dan werd voorspeld uit de modellen. Documentatie over de HIVstatus was gebrekkig onder de met HIV geïnfecteerde overledenen, waarbij bij meer dan de helft bewijs ontbrak van een diagnose. Bij de helft van hen waarvan men wist dat ze HIV-positief waren werd de diagnose vastgesteld tijdens het verblijf in het ziekenhuis voor het overlijden. Bewijs van het gebruik van ART was eveneens beperkt - bij ongeveer 1 op 4 was de status van de behandeling onbekend, en 1 op 4 onderging geen behandeling. In de regio Kisumu met een hogere HIV-gehalte, was 23,1\% van alle overledenen van alle leeftijden het gevolg van HIV/AIDS, met een HIV-mortaliteitverhouding van 251 per 100.000 inwoners. Er waren significante discrepanties tussen de onderliggende doodsoorzaak gemeld door het zorgsysteem en de onderliggende oorzaak vastgesteld door onderzoeksprocedures. 


\section{Belangrijke aanbevelingen voor het monitoren en beheersen van een HIV-epidemie.}

1. Gezien het feit dat universeel testen en behandelen niet voldoende zullen zijn om incidentie snel te onderdrukken tot een punt waar beheersing van de epidemie wordt bereikt, is een nieuwe focus op verschillende preventiestrategieën nodig om sneller het aantal nieuwe infecties onder het aantal overlijdens ten opzichte van mensen die met HIV leven te reduceren.

2. Traditionele benaderingen met betrekking tot de volksgezondheid zoals het volgen van contacten en het inlichten van de partner dienen eveneens controle over HIV te omvatten en hun effectiviteit dient te worden geëvalueerd.

3. Het nut van recent testen en fylogenetische analyse voor routine surveillanceprograma's om snel clusters van nieuwe infecties te identificeren en beheersen dienen te worden geëvalueerd.

4. Meer onderzoek naar het accuraat vaststellen van zelfgerapporteerde kennis van HIV-positieve status is nodig gezien het belang ervan als de eerste stap in de cascade van het testen en behandelen.

5. Metingen van virale belasting dienen te worden gebruik als adjunct biomarkering om de schattingen van onderzoeken naar de dekking van ART te verbeteren (of te vereenvoudigen).

6. Surveillance met betrekking tot de routine mortaliteit dient te worden geïmplementeerd om de daadwerkelijke impact van de behandeling op morbiditeit en mortaliteit te monitoren.

7. Nieuwe minimaal invasieve methoden zoals het oraal testen van vloeistof dienen verder te wordne geëvalueerd en mogelijk te worden geïntroduceerd in HIV-mortaliteit surveillancesystemen.

8. Onderzoeken zullen nooit de noodzaak voor HIV-casus-surveillance vervangen. Er dienen surveillancesystemen te worden ontwikkelt om HIVtransmissie te identificeren en te beheersen, en om de kwaliteit van zorg langs de cascade te beheren.

9. Doorgaande ontwikkeling en het versterken van unieke identificatiemiddelen en -methoden om the kunnen omgaan met het gebrek aan robuuste unieke identificatiemiddelen ter ondersteuning van casus-surveillance zijn vereist. 


\section{Acknowledgments}

First to my supervisor and co-promoter Kevin De Cock, who encouraged me to head down this path in spite of my advancing years and considerable workload, thank you for your unflagging confidence in my abilities and at times relentless encouragement to never stop moving forward, if you were ever frustrated by delays and setbacks (I am sure you were) you never showed it. Thank you to Martien Borgdorff for advising me on how to go about a doctorate in the Netherlands, while based in Kenya, and for leading me to Mirjam Kretzschmar who agreed to become my promoter at Utrecht University. Thank you Mirjam for accepting to supervise me, a somewhat unorthodox candidate, 'sight unseen.' I have greatly appreciated your patient, methodical advice that helped me when I was not sure which direction to take.

I also must acknowledge the contributions of my many colleagues at the US Centers for Disease Control and Prevention in Nairobi who supported me in so many ways. Emily Zielinski-Gutierrez, who taught me how to laugh at some of the more absurd challenges we faced, Anthony Waruru for leading by example and finishing his doctorate before me, Prof Thomas Achia for your passion for teaching and for learning, Samuel Mwalili, and Jacques Muthusi, Clara Mutungu, Andrea Kim, Rachael Joseph, Marc Bulterys for the many ways you supported my efforts. Thank you to Daniel Kwaro, Joshua Gitonga, Kennedy Muttai and Lilly Nyagah for the close collaboration, and to Mary Mahy, John Stover and Jeff Eaton-my participation in the UNAIDS reference group under your leadership was always an intellectual stimulation and reminder that what one chooses to do, especially if done well and at the right time, can make a difference.

Finally, I would like to dedicate this thesis to Inocencia, thank you for supporting my pursuit of this dream; and to Nala, may this journey be a small inspiration to someday pursue your dreams, wherever they lead. 


\section{Curriculum Vitae}

Peter Young was born on July 20, 1973, in Rochester, New York, United States. After completing his secondary education at Newton South High School in Massachusetts in 1991, he studied computer science and Spanish language at Hampshire College in Amherst, Massachusetts, from 1991-96, including six months teaching computer science courses at the National Autonomous University of Nicaragua (UNAN), in Managua. After graduation, he worked from 1996-98 at the Massachusetts Institute of Technology's Whitehead Institute, where he supported the Human Genome Project as a bioinformatician. In the Fall of 1998, Peter rode a bicycle 1600 kilometers along the Atlantic coast from Boston to eastern North Carolina, then spent a year working in Mexico City for several different non-governmental organizations. He returned to the Whitehead Institute, staying for two more years before moving to New York City in 2000 to join a startup company developing software to secure genetic information collected in clinical trials. In 2004, Peter enrolled in the Master of Public Health program at Columbia University, where he developed an interest in international public health. This led him to Mozambique, where he was accepted to a two-year fellowship at the U.S. Centers for Disease Control and Prevention (CDC) in 2006. This was followed by full-time employment at CDC in Maputo, and from 2014, in Nairobi, Kenya, where he worked as epidemiology team lead, then chief of the surveillance and epidemiology branch for the HIV program. While in Nairobi, he started a thesis focusing on HIV incidence, mortality, and the cascade of HIV care in Kenya with Prof Mirjam Kretzschmar as promotor and Dr Kevin De Cock as co-promotor, and he enrolled as an external Ph.D. candidate at Utrecht University in late 2017. In mid-2020, Peter returned to Maputo and CDC-Mozambique as the Associate Director for Science. 


\section{List of publications}

Semá Baltazar C, Boothe M, Chitsondzo Langa D, Sathane I, Horth R, Young P, Schaad N, Raymond HF. Recognizing the hidden: strengthening the HIV surveillance system among key and priority populations in Mozambique. BMC Public Health. 2021;21(1):91. doi: 10.1186/s12889-020-10110-y

Fellows IE, Shiraishi RW, Cherutich P, Achia T, Young PW, Kim AA. A new method for estimating HIV incidence from a single cross-sectional survey. Ferrand RA, editor. PLoS One. 2020 Aug 12;15(8):e0237221. doi: 10.1371/journal.pone.0237221

Nyagah LM, Kirui E, Young PW, Gikunju J, Githuku J, Lowther S, Kim AA. Knowledge of HIV status among mothers accompanying their infants for immunization in Machakos, Kenya, 2014. East African J Appl Heal Monit Eval. 2020;(4). Available from: http://eajahme.com/wp-content/uploads/2020/04/Lilly_ Final_PDF.pdf

Rogena EA, Waruru A, Young PW, Abade P, Nyagah LM, Walong EO. A review of completeness, correctness, and order of cause of death statements among decedents with documented causes of death and HIV status at two major mortuaries in Kenya, 2015. J Forensic Leg Med. 2020 Jul;73:101993. doi: 10.1016/j.jflm.2020.101993

Young PW, Zielinski-Gutierrez E, Wamicwe J, Mukui I, Kim AA, Waruru A, Zeh C, Kretzschmar ME, De Cock KM. Use of viral load to improve survey estimates of known HIV-positive status and antiretroviral treatment coverage. AIDS. 2020 Mar;34(4):631-6. doi: 10.1097/QAD.0000000000002453

Muthusi J, Mwalili S, Young P. \%svy_logistic_regression: A generic SAS macro for simple and multiple logistic regression and creating quality publication-ready tables using survey or non-survey data. Denaxas S, editor. PLoS One. 2019 Sep 3;14(9):e0214262. doi: 10.1371/journal.pone.0214262

Nyagah LM, Young PW, Kim AA, Wamicwe J, Kimani M, Waruiru W, Rogena E, Oduor J, Walong E, Waruru A, Oyugi J, Downer M, et al. HIV-Related Deaths in Nairobi, Kenya: Results from a HIV mortuary surveillance study, 2015. J Acquir Immune Defic Syndr. 2019 May;81(1):18-23. doi: 10.1097/QAI.0000000000001975 
Semá Baltazar C, Horth R, Boothe M, Sathane I, Young P, Chitsondzo Langa D, Condula M, Ricardo H, Dengo Baloi L, Cummings B, Schaad N, Gouveia L, et al. High prevalence of HIV, HBsAg and anti-HCV positivity among people who injected drugs: Results of the first bio-behavioral survey using respondent-driven sampling in two urban areas in Mozambique. BMC Infect Dis. 2019;19(1):1-13. doi: 10.1186/s12879-019-4655-2

Ali H, Kiama C, Muthoni L, Waruru A, Young PW, Zielinski-Gutierrez E, Waruiru W, Harklerode R, Kim AA, Swaminathan M, De Cock KM, Wamicwe J. Evaluation of an HIV-Related Mortuary Surveillance System - Nairobi, Kenya, Two Sites, 2015. MMWR Surveill Summ. 2018;67(14). doi: 10.15585/MMWR.SS6714A1

Borgdorff MW, Kwaro D, Obor D, Otieno G, Kamire V, Odongo F, Owuor P, Muthusi J, Mills LA, Joseph R, Schmitz ME, Young PW, et al. HIV incidence in western Kenya during scale-up of antiretroviral therapy and voluntary medical male circumcision: a population-based cohort analysis. Lancet HIV. 2018 May;5(5):e241-9. doi: 10.1016/S2352-3018(18)30025-0

Cummings B, Horth R, McFarland W, Lane T, Young PW, Nalá R, Rutherford G, Raymond HF. Bisexual and Bidirectional: Assessing the Potential for HIV Bridging in Mozambique. AIDS Behav. 2018;22(7). doi: 10.1007/s10461-017-1994-0

Kripke K, Opuni M, Odoyo-June E, Onyango M, Young P, Serrem K, Ojiambo V, Schnure M, Stegman P, Njeuhmeli E. Data triangulation to estimate age-specific coverage of voluntary medical male circumcision for HIV prevention in four Kenyan counties. PLoS One. 2018;13(12). doi: 10.1371/journal.pone.0209385

Moyo S, Young PW, Gouws E, Naidoo I, Wamicwe J, Mukui I, Marsh K, Igumbor EU, Kim AA, Rehle T. Equity of antiretroviral treatment use in high HIV burden countries: Analyses of data from nationally-representative surveys in Kenya and South Africa. Ciccozzi M, editor. PLoS One. 2018 Aug 10;13(8):e0201899. doi: 10.1371/journal.pone.0201899

Waruru A, Achia T, Muttai H, Ng'ang'a L, Zielinski-Gutierrez E, Ochanda B, Katana A, Young PW, Tobias JL, Juma P, De Cock KM, Tylleskär T. Spatial-temporal trend for mother-to-child transmission of HIV up to infancy and during pre-Option B+ in western Kenya, 2007-13. PeerJ. 2018 Mar 13;6(3):e4427. doi: 10.7717/peerj.4427 
Waruru A, Natukunda A, Nyagah LM, Kellogg TA, Zielinski-Gutierrez E, Waruiru W, Masamaro K, Harklerode R, Odhiambo J, Manders E-J, Young PW. Where no universal health care identifier exists: comparison and determination of the utility of score-based persons matching algorithms using demographic data. JMIR Public Heal Surveill. 2018;4(4):e10436. doi: 10.2196/10436

Young PW, Kim AA, Wamicwe J, Nyagah L, Kiama C, Stover J, Oduor J, Rogena EA, Walong E, Zielinski-Gutierrez E, Imbwaga A, Sirengo M, et al. HIV-associated mortality in the era of antiretroviral therapy scale-up - Nairobi, Kenya, 2015. Wilkinson KA, editor. PLoS One. 2017 Aug 2;12(8):e0181837. doi: 10.1371/journal. pone. 0181837

Augusto ÂR, Young PW, Horth RZ, Inguane C, Sathane I, Ngale K, Benedetti M, Cummings B, Botão CFS, Baltazar CAS, Frank H, Fagan J, et al. High Burden of HIV Infection and Risk Behaviors Among Female Sex Workers in Three Main Urban Areas of Mozambique. AIDS Behav. 2016;20(4). doi: 10.1007/s10461-0151140-9

Botão C, Horth RZ, Frank H, Cummings B, Inguane C, Sathane I, McFarland W, Fisher Raymond H, Young PW. Prevalence of HIV and Associated Risk Factors Among Long Distance Truck Drivers in Inchope, Mozambique, 2012. AIDS Behav. 2016;20(4). doi: 10.1007/s10461-015-1194-8

Kim AA, Mukui I, Young PW, Mirjahangir J, Mwanyumba S, Wamicwe J, Bowen N, Wiesner L, Ng'ang'a L, De Cock KM. Undisclosed HIV infection and antiretroviral therapy use in the Kenya AIDS indicator survey 2012. AIDS. 2016 Nov;30(17):268595. doi: 10.1097/QAD.0000000000001227

Sathane I, Horth R, Young P, Inguane C, Nalá R, Miranda AE, Lane T, Raymond HF, Cummings B, McFarland W. Risk Factors Associated with HIV Among Men Who Have Sex Only with Men and Men Who Have Sex with Both Men and Women in Three Urban Areas in Mozambique. AIDS Behav. 2016 Oct 8;20(10):2296-308. doi: 10.1007/s10461-016-1390-1

Baltazar CS, Horth R, Inguane C, Sathane I, César F, Ricardo H, Botão C, Augusto $\hat{A}$, Cooley L, Cummings B, Raymond HF, Young PW. HIV Prevalence and Risk Behaviors Among Mozambicans Working in South African Mines. AIDS Behav. 2015;19(S1):59-67. doi: 10.1007/s10461-014-0941-6 
Horth RZ, Cummings B, Young PW, Mirjahangir J, Sathane I, Nalá R, Lane T, Raymond HF. Correlates of HIV Testing Among Men Who have Sex with Men in Three Urban Areas of Mozambique: Missed Opportunities for Prevention. AIDS Behav. 2015 Nov 19;19(11):1978-89. doi: 10.1007/s10461-015-1044-8

Inguane C, Horth RZ, Miranda AE, Young PW, Sathane I, Cummings BE, Augusto $\hat{A}$, Raymond HF, Mcfarland W. Socio-demographic, Behavioral and Health Characteristics of Underage Female Sex Workers in Mozambique: The Need to Protect a Generation from HIV Risk. AIDS Behav. 2015 Dec 1;19(12):2184-93. doi: $10.1007 / \mathrm{s} 10461-015-1068-0$

Nalá R, Cummings B, Horth R, Inguane C, Benedetti M, Chissano M, Sathane I, Young P, da Silva D, Mirjahangir J, Grasso M, Fisher Raymond H, et al. Men Who Have Sex with Men in Mozambique: Identifying a Hidden Population at High-risk for HIV. AIDS Behav. 2015 Feb 19;19(2):393-404. doi: 10.1007/s10461-014-0895-8

Sathane I, Horth R, Boothe M, Baltazar CS, Young P, Fisher H, Teodoro E, Gouveia ML, Lane T, Mcfarland W. Estimating the number of people who inject drugs in two urban areas in Mozambique using four different methods, 2014. J Int AIDS Soc. 2015;

Dokubo EK, Shiraishi RW, Young PW, Neal JJ, Aberle-Grasse J, Honwana N, Mbofana F. Awareness of HIV status, prevention knowledge and condom use among people living with HIV in Mozambique. PLoS One. 2014;9(9):e106760. doi: 10.1371/journal.pone.0106760

Bila DCA, Young P, Merks H, Vubil AS, Mahomed M, Augusto A, Abreu CM, Mabunda NJ, Brooks JI, Tanuri A, Jani IV. Evolution of Primary HIV Drug Resistance in a Subtype C Dominated Epidemic in Mozambique. PLoS One. 2013;8(7). doi: 10.1371/journal.pone.0068213

Young PW, Mahomed M, Horth RZ, Shiraishi RW, Jani I V. Routine data from prevention of mother-to-child transmission (PMTCT) HIV testing not yet ready for HIV surveillance in Mozambique: a retrospective analysis of matched test results. BMC Infect Dis. 2013 Dec 22;13(1):96. doi: 10.1186/1471-2334-13-96

Young P, Elul B, Maulsby C, Winchell D, Mavie B, Fernandes R. Medical record completeness and accuracy at an HIV clinic in Mozambique, 2005-2006. J Health Inform Dev Ctries. 2010;4(2):1-10. Available from: http://www.jhidc.org/index. $\mathrm{php/jhidc/article/download/45/85}$ 
Wang D, Fan J, Siao C, Berno A, Young P, Sapolsky R, Ghandour G, Perkins N, Winchester E, Spencer J, Kruglyak L, Stein L, et al. Large-Scale Identification, Mapping, and Genotyping of Single-Nucleotide Polymorphisms in the Human Genome. Science. 1998 May 15;280(5366):1077-82. doi: 10.1126/ science.280.5366.1077 


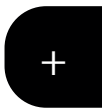

233 